ASIAN POLITICS IN DEVELOPMENT 


\title{
Of Related Interest
}

\author{
THE WORKERS' STATE MEETS THE MARKET \\ Labour in China's Transition \\ edited by Sarah Cook and Margaret Maurer-Fazio \\ ECONOMIC MOBILITY AND POVERTY DYNAMICS \\ IN DEVELOPING COUNTRIES \\ edited by Bob Baulch and John Hoddinott \\ GLOBALISATION AND TRADE \\ Implications for Exports from Marginalised Economies \\ edited by Oliver Morrissey and Igor Filatotchev \\ GLOBALISATION, COMPETITIVENESS AND \\ HUMAN SECURITY \\ edited by Cristóbal Kay \\ DEVELOPMENT AND THE RURAL-URBAN DIVIDE \\ edited by Ashutosh Varshney
}


ASIAN POLITICS IN

DEVELOPMENT

Essays in Honour of Gordon White

\author{
Editors \\ Robert Benewick \\ Marc Blecher \\ Sarah Cook
}

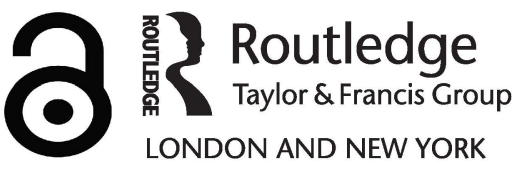


First published 2003 by Frank Cass Publishers

Published 2017 by Routledge

2 Park Square, Milton Park, Abingdon, Oxon OX14 4RN

711 Third Avenue, New York, NY 10017, USA

Routledge is an imprint of the Taylor \& Francis Group, an informa business

Copyright (C) 2003 Taylor \& Francis

The Open Access version of this book, available at www.tandfebooks.com, has been made available under a Creative Commons Attribution-Non Commercial-No Derivatives 4.0 license.

British Library Cataloguing in Publication Data

Asian politics in development : essays in honour of Gordon

White

1. Asia - Politics and government

I. Benewick, Robert II. Blecher, Marc, 1948 - III. Cook, Sarah

IV. White, Gordon

$320.9^{\prime} 5$

ISBN 978-0-7146-5333-4 (cloth)

ISBN 978-0-7146-8324-9 (pbk)

Library of Congress Cataloging in Publication Data

Gordon White Memorial Conference (1999 : Institute of Development Studies)

Asian politics in development : essays in honour of Gordon White/ editors, Robert Benewick, Marc Blecher, Sarah Cook.

p. cm.

Papers presented at the Gordon White Memorial Conference held at the Institute of Development Studies, University of Sussex, Apr. 30 and May 1,1999

Includes bibliographical references and index.

ISBN 0-7146-5333-0 (cloth) - ISBN 0-7146-8324-8 (pbk.)

1. Political planning-Asia-Congresses. 2. Asia-Politics and government-1945-Congresses. 3. Asia-Economic policy-Congresses. 4. Asia-Social policy-Congresses. I. White, Gordon, 1942- II.

Benewick, Robert. III. Blecher, Marc J. IV. Cook, Sarah. V. Title. JQ24.G67 1999

$320^{\prime} .6^{\prime} 095-\mathrm{dc} 21$ 
For Gordon White,

professor of politics, scholar of China,

democratic socialist, teacher and mentor,

musician, showman and wit, courageous lover of life

who will live on in minds made better by his presence. 



\section{Contents}

GORDON WHITE'S INTELLECTUAL LEGACY

Introduction

Robert Benewick, Marc Blecher

and Sarah Cook 3

Social Politics, the State, Policy, Comparison:

Gordon White's Contribution to China Studies Marc Blecher

Gordon White and Development Studies:

An Appreciation

Mark Robinson 20

POLITICS AND THE STATE

Reform and the Role of the State in China

Tony Saich 33

Managing Central-Local Relations During Socialist

Marketisation: A Changing Role for the Chinese

Communist Party

Akio Takahara 50

Treasuring the Word: Mao, Depoliticisation and Robert Benewick

the Material Present and Stephanie Hemelryk Donald 65

State Enterprise Reform and Gender: One Step

Backwards for Women?

Jude Howell

83

CIVIL SOCIETY

Corporatist Capitalism: The Politics of Accumulation in South India

Bias and Capture: Corruption, Poverty and the Limitations of Civil Society in India

Between Cant and Corporatism: Creating an

Enabling Political Environment for the Poor
Elisabetta Basile and Barbara Harriss-White 109

Rob Jenkins and Anne Marie Goetz 123

Mick Moore and Anuradha Joshi 150 
WELFARE

State Entrepreneurship and Community

Welfare Services in Urban China

Gordon White and

Xiaoyuan Shang 173

Creating Wealth and Welfare: Entrepreneurship and the Developmental State in Rural China

Sarah Cook 195

Can Welfare Systems be Evaluated Outside Their

Cultural and Historical Context? A Case Study

of Children's Homes in Contemporary Japan

Roger Goodman 214

The East Asian Welfare States in Transition:

Challenges and Opportunities

Huck-ju Kwon 230

GLOBALISATION

Is Globalisation All It is Cracked Up to Be? Raphael Kaplinsky 255

Globalisation, Privatisation and China's

Paul Bowles and

Industrial Labour Systems

Xiao-Yuan Dong 273

Bibliography of Gordon White's Works

Notes on Contributors

299

Index

303 
GORDON WHITE'S INTELLECTUAL LEGACY 



\section{Introduction}

\section{ROBERT BENEWICK, MARC BLECHER and SARAH COOK}

Asian Politics in Development arises from the Gordon White Memorial Conference held at the Institute of Development Studies on 30 April and 1 May 1999. The impact of Gordon and his work on his friends and colleagues in the Institute, and the academic community in general, was profound, and the conference was only one of a number of celebrations and commemorations of his life. (Others included a scholarship fund, an annual memorial prize by the China Quarterly, and the purchase of a keyboard for the IDS common room.) The conference was special for it brought together many of those who worked with Gordon and who were influenced by him, including co-authors, researchers and graduate students.

What was striking about Gordon, and represented among those present, was the multi-dimensionality of his work and diversity of his interests, which ranged across a number of disciplines and between theoretical constructs and substantive research. Authors and discussants included political scientists, economists, sociologists, anthropologists, and economic historians, all of whom had worked closely with Gordon. He was a talented and prolific writer, an expert on many things, but not a specialist, in the sense that he did not limit himself to a narrow field but ranged widely, finding interest and importance in many issues. Even within his primary area of expertise - China - his intellectual restlessness and curiosity led him to cover a multiplicity of topics.

Despite the multi-dimensionality, for Gordon politics was central - in several senses. Normatively, it was a worthy human activity in which both professional politicians and ordinary citizens ought to engage in the pursuit of a better world. Substantively, it was an activity in which not just leaders but also citizens could and did engage more frequently and effectually than was commonly thought - a thesis that Gordon demonstrated again and again for a multitude of social classes and groups working in a wide range of historical and political contexts, some quite unlikely. Analytically, politics was a key determinant of developmental outcomes, and therefore ought to be a central factor in development programs. This last point constitutes one meaning of our theme of Asian 'politics in development'. 
The other is that for Gordon politics was always changing - it was 'in development'. This development was not linear or teleological - Gordon was a modernist but surely no modernisation theorist. He showed how political change could take unexpected and, for progressives like him, unwelcome turns. The participatory populism and egalitarian developmentalism that Maoist radical socialism seemed to offer transmogrified into what he aptly dubbed market Stalinism. Even civil society could produce undemocratic politics, Gordon discovered. But the twists and turns were not random, and better politics - that is, more democratic and more effective in promoting development with some level of economic justice - could be nurtured by wise, responsible leaders and citizens operating under specific conditions that were both knowable and, Gordon hoped and urged, achievable.

\section{THE PAPERS}

The conference papers were as diverse as Gordon's substantive interests, but as befits him they could be grouped into four broad substantive areas in which he had significant interests: politics in the state, civil society, welfare and globalisation. In addition, two papers dealt specifically with Gordon's intellectual legacy. Most important, all the papers were unified by their links to one or both meanings of 'politics in development'.

\section{Gordon White's Intellectual Legacy}

Marc Blecher discusses Gordon's contributions to China studies, emphasising his abiding concern with the political engagement of society with the state as well as his interests in policy and comparative analysis. Following upon Gordon's commitment to comparative study and his developmental approach to China, Mark Robinson treats Gordon's contributions to development studies, focusing on political and policy-relevant concepts such as civil society, social capital, synergy and institutional design.

\section{Politics and the State}

Focusing on the relationships among development, institutions and policy that were so central to Gordon, Tony Saich assesses the effects of economic reform on the state's penchant and capacity for industrial, public health, and financial policy. In a similar vein, Akio Takahara looks at the changing role of the Chinese Communist Party and central-local relations in response to marketisation. Robert Benewick and Stephanie Donald take up the iconography associated with the persona of Mao Zedong, linking them to the seismic shifts in Chinese politics, economy and society since 1949. Jude Howell concludes with a discussion of the gendered effects of economic reform on industrial 
labour and the political resistance engendered thereby, addressing themes of the social effects of labour markets that deeply concerned Gordon.

\section{Civil Society}

Elisabetta Basile and Barbara Harriss-White hone in on the ways in which development in an Indian town is grounded fundamentally in local networks of caste power, using their study as a case of the ways in which development is determined, as Gordon always emphasised, by social, ideological and micro-political rather than just economic factors. They also attend to the second meaning of 'politics in development' by showing that caste politics is adapting to the needs of accumulation, that development fuels the proliferation of associations, and that caste-based hegemony prevents social movements. Rob Jenkins and Anne Marie Goetz, in their study of Indian social movements for transparency and accountability, build directly upon Gordon's work on understanding the conditions under which civil society is and too often is not a building block of democratic politics that can promote just development. Mick Moore and Anuradha Joshi take up this theme as well, by examining the institutional conditions most conducive to the political mobilisation of the poor.

\section{Welfare}

We are fortunate to be able to include a work by Gordon that was in progress at the moment of his untimely death. He and Xiaoyuan Shang theorise the concept of welfare entrepreneurship, which was sparked by Gordon's abiding concern with the responsibility he arrogated to the state to guarantee its citizens the basic conditions for a humane livelihood, his realisation of Chinese state's declining capacity and political will to discharge that responsibility, and his awareness that civil society was beginning to step into the breach. They also flesh out the rise of welfare entrepreneurship in urban Chinese communities.

Sarah Cook follows suit with a study of welfare entrepreneurship in Chinese rural collective enterprises. In terms of the two meanings of 'politics in development', both papers show first how local institutional arrangements and financial incentives affect capacity of local governments to promote welfare development, and then in turn how such development reshapes government. Gordon was a practical scholar who sought results, and if the central Chinese state would not provide for the poor (and, ipso facto, for its own political security), he sought out with relish the ways in which local, socially-rooted authorities might do so. Roger Goodman reflects on how this pragmatism refashioned his own approach to the study of Japanese welfare homes. Finally, Huck-ju Kwon builds upon the interests 
and published work he shared with Gordon and Roger in the comparative study of East Asian welfare systems, focusing again on both meanings of 'politics in development': first, how welfare policies affect state budgets, women, and inequality, and, second, how the 1997 financial crisis refashioned the state's capacity to provide welfare.

\section{Globalisation}

Globalisation was, for Gordon, a new direction. He had not yet written on it, but in his last years, as China's 'opening up' grew more and more central to its economic and political development, he increasingly engaged in active debate with his colleagues (mainly the economists among them) on issues of globalisation. His approach was, as always, distinctly political. First, it reflected his central concerns with the political economy of development, grounded in his foundational belief that the purpose of development is the betterment of human lives. That led him to focus on the effects of globalisation on labour.

Second, Gordon was interested in the effect of globalisation on China's state and politics. Both papers reflect both sets of concerns about globalisation, as well as the dual meanings of 'politics in development'. Paul Bowles and Xiao-Yuan Dong inquire directly into the capacity of China's own political 'walls' to withstand and moderate globalisation, and to refashion the juggernaut to the country's own purposes and interests. The interests of labour feature as a key arena in their inquiry. They also show how globalisation is developing Chinese politics, by knocking down some but not all the country's 'walls'. Raphael Kaplinsky argues that the concatenation of China's policies on 'opening' generally and on labour are affecting global development generally, in ways that are not particularly salutary for the world's poor. In terms of the second meaning of 'politics in development', he draws out the implications for political action to limit the effects of globalisation. He forcefully links analysis, policy and political advocacy, as Gordon did.

Acknowledgements: The conference and the IDS Bulletin reflect the contributions of many people. Ideas were generated from many of Gordon's friends and colleagues, some of whom were unfortunately unable to attend the conference. Mick Moore organised the conference with Sarah Cook and Bob Benewick, and Jenny Edwards provided excellent administrative support for both the conference and Bulletin. Several discussants provided stimulating comments which have helped to improve many of the papers, while others also contributed to a panel discussion of 'Where is China headed?'. The IDS generously provided financial support for which we are grateful. 


\title{
Social Politics, the State, Policy, Comparison: Gordon White's Contribution to China Studies
}

\author{
MARC BLECHER
}

Early on in his career, in the thick of Maoism's most radical days, Gordon White discovered that Chinese society was politically engaged with the state, and throughout his career he elaborated the multiple, shifting contours of their complex encounter. Starting with his work on class politics in the Cultural Revolution and on teachers, and ending with the studies of civil society, the central thread of Gordon's massive oeuvre on China was the lively, active interplay of classes and groups with the state.

Gordon was not alone among political scientists in 'bringing society back in' to the study of Chinese politics. Many of his generation reacted to the field's overwhelming focus on elites, which flowed from the concatenation of the cold war, the traditions of Sinology, and the overwhelming fact that starting in 1949 China did, after all, develop a state with a great deal of capacity over and autonomy from society - one in which political elites arrogated a great deal of power to themselves, even if some of them used it radically to challenge the new state. In the 1970s, the field quickly downshifted to studies of grassroots politics. Some of the new studies conceived of state and society in terms analogous to a happy marriage blessed by the mass line. Others saw an oppressive and even violent bond like that between domineering father and child or abusive husband and wife. Still others made out the clever, heroic struggles of the underlings to protect themselves or, better yet, to strike back and even to overthrow their oppressors and create a new world in which oppression would be banished.

In contrast to all this sturm und drang, Gordon discovered a relationship between state and society that was much more businesslike and normal - no small feat in the study of a country that had been anything but.' In seeing even in revolutionary socialist China a state and society that engaged each 
other politically through ongoing negotiations, signals, threats, and offers, in which each side developed and used a rich panoply of strategies and tactics to advance its positions, in the end Gordon developed an astute appreciation of China's polity, society, and ultimately, its economy as well. His was appreciation not only in the analytical sense of apprehension, but in the normative sense of approbation. Where others of his generation of critical scholars evinced their awe for China by focusing on the struggles of its people - whether through their new state or against it - to realise noble values of equality, democracy and socialism, Gordon showed China genuine respect by treating it more as an equal, as a country whose state and society engaged in ordinary politics.

Awe implies greater distance between subject and object than does respect. The difference is one key to Gordon's extraordinary perspicacity about China. For while many scholars of his generation focused on the overt and seductive revolutionary machinations that were, after all, right before our eyes (even if we could only glimpse them from our then remote outposts), Gordon chose the far more arduous path of unearthing the normal, workaday politics that were so hard to see through all the thrilling if often bizarre radicalism. Where the work many of us did took us down a road that now appears to have been an exciting but ultimately sobering, even depressing dead end, Gordon's lifelong work illuminated the path that China is still traversing - the unavoidable political engagement of classes and groups with their state. Analytically, his achievement was more awesome than his colleagues' precisely because he never regarded China with awe.

For example, his first scholarly monograph focused on the bitter struggles over the definition of class, on which lives literally hung in the balance - for to be on the wrong side of the class struggle often meant ruination if not death. Amid the maelstrom, though, Gordon somehow found that 'the continuing ambiguity over "class" reflects the political compromise arising from the Cultural Revolution'. ${ }^{2}$ Where many other radical scholars looked to the Cultural Revolution debates over class for inspiration about ways to adapt Marxist categories in order to address the bureaucratism and elitism of 'actually existing socialism' so that its liberatory potential could finally be realised, Gordon spoke in a rather different analytical lexicon: 'This study intends to go beyond the analysis of theoretical innovation by relating changes in the ideological definition of "class" to practical policy issues and to the nature of socio-political interests at various levels of the Chinese political process.' 3

I am not in a position to discuss Gordon's second monograph Micropolitics in Contemporary China: A Technical Unit During and After the Cultural Revolution (White Plains, New York: M.E. Sharpe, 1979) - 
because as Gordon's co-author I cannot judge it disinterestedly. It is fair to say, though, that nuts-and-bolts interest-based politics and coalition formation formed central parts of the argument, even amidst a horrific story that included pitched battles and a suicide. Likewise, in his third monograph, on the teaching profession, Gordon found not just schoolmarms but politically savvy citizens. At crucial moments they made truly symbiotic alliances with potentially sympathetic leaders like Deng Xiaoping, in which they not only benefited themselves or influenced educational policy but also helped swing the national political balance.

[A]lthough much of the fluctuation in official educational policies over the past two decades can be attributed to competing tendencies within the CCP leadership, it was also in no small part subject to the political influence - negative and positive - of teachers. Teachers have not been an inert social force subject to unrestrained political manipulation. They have provided one weight in the political balance which has, over the long run, swung power away from the radicals toward the modernizers ... They are one part of a 'grand coalition' of social forces which supported the removal of the Shanghai group in 1976 and underpins the strategy of the post-Mao leadership. ${ }^{4}$

Moreover, teachers' political tactics shifted smartly with the times. In radical periods, they exerted 'negative' power through 'passivity and silent opposition' that

frustrated the intentions and reduced the impact of official educational policies. During modernizing periods, on the other hand, teachers have been allowed to exert positive power over issues of educational policy and professional status. In periods when they did so effectively, their relationship with the Party has been a form of 'interest group politics'.

Gordon's greatest scholarly achievement lies in the fact that the politically-engaged society proved to be a durable theme in Chinese politics, traversing both the Maoist and Dengist periods despite their vast differences. Gordon was better prepared than most of us to analyse the political bargaining, conflict and compromise among social classes and groups, and between them and the state, that became apparent in the Dengist period precisely because he had developed his tools in the Maoist period, when they were harder to use. His focus on the politically engaged society continued in the work on basic-level government, banking, and, of course, reform in general, where it infused the overall conception as well as every chapter of Riding the Tiger. ${ }^{6}$ In one more late example, Gordon found that pension reform involved debate among institutional actors but also social groups, including people from various regions, state- versus collective-sector workers, the 'public sector as a whole and the rest of the formal sector', and 
'employees in the formal sector, particularly in state enterprises, and those who have been cast adrift from it'. ' It reached its climax in In Search of Civil Society, of course. The book's penultimate sentence forms the coda: 'the organized forces of emergent civil society could be the architects of the new post-Communist China.' Ever tempering what Gramsci called pessimism of the intellect with optimism of the will, the book ends: 'However, given their current diversity and potential for conflict, the transition to a new political order is likely to be a rough and rocky one. ${ }^{18}$ In these last two sentences of Gordon's last book on China, we see his scholarly honesty ultimately tempering, though never triumphing over, his visions and hopes for China's politically-engaged society.

If this society is at the core of his analysis of political and economic change, he always situated it in a complex matrix of historical, cultural, ideological, institutional and economic forces. He was a serious enough scholar of history in general, and of the specific history and culture of China, to be careful to position his grasp of society in these terms. ${ }^{9}$ But his commitment to social science and to purposive social change driven by human commitment and always drove him to see history and culture as malleable. To put it in terms of his modernism, he saw them as obstacles to be overcome.

He was less taken with cultural explanation. It never figures significantly, even as an object of criticism, in his work on China. ${ }^{10}$ But in the end, egged on perhaps by his co-author, he rejects cultural explanations of East Asian welfare as bad social science - in the sense that they operate only tautologically, analogically, ahistorically, and with only residual explanatory power at best." At the end of his own substantive contribution to the book, he concludes a section on the distinctiveness of China's social security reforms by giving in to rhetorical temptation:

In contrast to these 'culturalist' approaches [to explaining that distinctiveness], which contain more than a modicum of ideological flannel, this chapter has emphasized the over-determining role of historical, structural and political factors in shaping the trajectory of Chinese welfare reform. ${ }^{12}$

This passage, with its rare evocation of Althusserian terminology, also reminds us that Gordon, a committed and powerful modernist scholar and political citizen, also rejected post-structuralist culturalism.

Gordon was much more focused on the ways in which politicallyengaged society was situated by the economy. Political actors' economic resources feature prominently in his work. He took a broad view of what constituted such resources, including in them anything of value in the political arena. By treating the market as an institution, Gordon took an equally complex view of the ways in which such resources were constituted, 
organised and exchanged. Finally, he was able to discern the importance of economic resources in society's negotiations with the state even in situations in which state institutions and policies obscured them. For example, he showed how even amidst the Maoist-era hostility to markets and skills, teachers were able to trade on their valuable knowledge and their location as one of the linchpins of social reproduction. ${ }^{13}$

Yet for Gordon economic factors, even when broadly and institutionally conceived in terms such as the mode of production, were never enough by themselves to explain very much. Society's engagement with the state was too rich to be reducible to the pursuit of material gain. The teachers he studied may have engaged in 'interest group politics', but they were no mere interest group. They were also, as his title features them, trained experts with specific ideological, existential and professional interests. From a structural point of view on the economy, a concept such as 'capitalism' was also too simplistic. China had taught Gordon that modes of production such as socialism and capitalism are protean (for example, 'social capitalism' and 'market socialism'). The reason is obvious from this example: economic forms are fundamentally situated socially and politically.

As a political scientist and an intensely political person, ${ }^{14}$ for Gordon society is situated mainly by the state and politics. When he sketches his analytical models, the political usually comes first. In setting out his chapter on social security reform:

I shall be using a political economy approach which analyses the policy process in terms of a dual interplay: first, among various politically influential forces and interests and, second, between these and certain basic economic, social and demographic constraints and pressures. ${ }^{15}$

Or, in the work on civil society:

[O]ne can identify a dual dynamic in the emergence of civil society. The first is a political dynamic which reflects the impact of totalistic political institutions on a society and the political tensions and conflicts to which this gives rise ... The second dynamic of 'civil society' is a market dynamic. ${ }^{16}$

There is, to take Gordon's own phrase, a duality in his approach to the state. At one level he treats it as something of a given. State formation was one of those grand historical questions that did not suit itself terribly well to his middle-range analytical concerns. A primarily institutionalist focus on the ways that specific features of state organisation per se shaped society's political engagement was too narrow for him. ${ }^{17}$ The machinations of elite politics were best left to Pekingologists and journalists, who could not really understand them because they could not situate them in their wider contexts. 
For all these reasons, Gordon did not focus on the state itself (that is, by itself). It figures in his work mainly (though, as we shall see, not only) as a powerful 'given' that necessarily shapes China's politically engaged society.

The process by which it does so is dynamic, usually divided, and itself political. For example, in his early work on the politics of class in the Cultural Revolution, the story begins in the 1950s, when the state shaped the lives and, therefore, the interests of a huge proportion of society through its politicised policies on the distribution of economic resources, social power and political position. When serious conflict between the top elites and their respective supporters broke out, these state-created 'classes' joined in a pointed debate over the normative definitions of class. ${ }^{18}$ In another example, developmental phases of the Maoist period afforded teachers greater latitude to practice their profession and pursue their interests compared with radical periods. ${ }^{19}$ In yet another arena, Gordon, writing with Jude Howell and Shang Xiaoyuan, adumbrated four modalities - political, managerial, developmental and bureaucratic - by which the state situates the organisation of civil society. Because they are uncoordinated, they set up a complex and fragmented nascent pluralist pattern of social engagement with the state.

But if in general Gordon took the state as a 'given' - an institutional and political matrix within which the politically engaged society was situated and by which it and its politics were shaped - he also regarded the state as neither static nor unassailable. He thought that social classes and groups engaged in the kinds of politics Gordon studied in order to advance their interests, not to reshape the state. He was not particularly interested in direct assaults on the state, for example, in China's revolutionary politics during the Maoist period, or in dissident politics in the Dengist years. But he was also acutely aware of the ways in which society's political engagement could bring about profound political change over a long period of time and in ways that it might not have intended. Riding the Tiger concludes with a trenchant disquisition on China's alternative political futures. By and large it fits the pattern of his work: the state's strategic postures and decisions will set parameters that will shape society's political engagement with the state. But then he takes the next step: the resulting pattern of engagement will be salutary or detrimental for the future of the state. For example,

There may be a form of Chinese 'Brezhnevism' to see out the millennium as the current leadership tries to stay in power. If this is indeed the case, then the political contradictions and trends which I have identified will intensify and make it more likely that the transition, when it comes, will be sudden, radical and possibly violent. ${ }^{20}$

Alternatively, were the state to take the constitutional and institutional steps to open space for civil society, by undertaking legal reforms, redefining the 
role of the Party, and enlivening and granting some autonomy to existing state corporatist institutions, the result would be 'social democratisation' pursued under a 'grand accommodation' between the state and a more politically engaged society, in turn increasing the chances of a smooth transition. ${ }^{21}$

Even In Search of Civil Society, completed at a time when Gordon was edging towards a more socio-centric conception of politics, follows the theoretical posture that begins with the state setting the parameters for society's political engagement.

In the Soviet case, for example, a democratic transition was sponsored and organized by reformist elements within the existing political elite, in a situation in which civil society in any organized form was virtually non-existent. In South Korea, the state elites of the ancien régime retained a commanding position in the transition, but were forced to deal with an increasingly assertive business elite in the chaebol sector and opposition politicians bolstered by widespread mobilization of public support by social organizations such as labour unions and church groups. In Zambia, by contrast, the previous one-party system was collapsing, and it was the elites of civil society - from the unions, church groups, and business - who sponsored and commanded the transition to democracy. In terms of the balance between state and civil society, China may perhaps be situated somewhere between the Soviet Union and South Korea: the key elites of the Leninist regime - in the Party, the state bureaucracy, and the military - are still the overwhelmingly dominant political force, but the new social groups and organizations resulting from the economic reforms are creating an increasingly influential counter-force ... .

The viability of this scenario of bargained or crafted transition depends partly on the emergence of a reformist leadership within the CCP ... It also depends on the ability of influential social forces ... to come together and agree on the form of new political arrangements. By so doing, the organizations of civil society and their leaders can play a crucial constitutive role not only in impelling and organizing the transition to a democratic polity, but also in defining its distinctive institutional shape and political character. ${ }^{22}$

In each case, the extent and form of civil society's emergence is a function of state action. In turn, the emergent civil society engages with the state in specific ways. Finally, that pattern of engagement can reshape the state itself.

This section has argued that Gordon White's greatest contribution to the study of China was his analysis of the politically engaged society. Beneath the surfaces of Maoist-era totalistic authoritarianism punctuated by serious bouts of genuine popular revolutionary mobilisation, and of Dengist-era repression and market-driven demobilisation, Gordon was consistent in unearthing and exposing to our view real political bargaining, strategising, posturing and, ultimately, influence by a breathtaking range of social classes and groups engaging with the state. The content of these politics changed a great deal over time, as the parameters that the economy and particularly the state set for society changed radically. But the genuineness of these politics was there consistently, and they inevitably continue. Gordon illuminated 
them for the first half century of the People's Republic of China, showing how teachers, workers, farmers, bureaucrats, scientists, bankers and ordinary citizens caught in the complex matrix of class-based Cultural Revolution politics all became involved in politics to advance their material, professional, sectoral and ideological interests. In doing so, he also showed us how to continue to analyse politics for the coming decades. Finally, in discovering that the Chinese people engaged in normal politics even in abnormal and inhospitable times, he demonstrated the profoundest respect for them.

\section{THE STATE}

Gordon's focus on China's politically engaged society did not preclude an appreciation - again in both the analytical and normative senses - for the role of the state. We have already seen how he saw that it was the most important factor shaping society's political engagement. But he also took the state seriously in functional terms. He may have treated it as a 'given' in developing his analysis of social politics in particular times and places. And he may have rejected a primarily institutional approach to the state and its politics in favour of his much more socially, economically, ideologically, historically and culturally grounded one. But he cared deeply about the state because he thought it had specific, inescapable social roles which are also political and moral responsibilities.

A committed democratic socialist immersed in the study of state socialism, he had a profound grasp of the role of the state in economic development and in socio-economic distribution. He pioneered work on the developmental state, never forgetting the achievements of import-substitution in China and other state socialist countries during their early phases of industrialisation even as he was recognising that such policies, and the regimes that instituted them, had outlived their usefulness. In article after article, he wrote of the inegalitarian effects of the market, even as he welcomed its role in improving allocative rationality and economic growth, and in opening political and social space. He noticed approvingly that in East Asia, where society was not in a position to impel the creation of welfare systems, they were none the less created by states. ${ }^{23} \mathrm{He}$ wanted the state with which society was engaged to be a strong state.

Even if the market becomes predominant through radical reform and even if it takes a capitalist form, which is very probable, there is a continuing need for a new form of developmental state to tackle ... social and economic problems [such as market failure and its consequences for the poor]. In the short term, moreover, the role of the state is even more crucial because of the need to break through the 'hard policy 
constraint' and manage the transition from a planned to a market economy. This is a process ... which is fraught with instability and tensions arising from the opposition of vested interests, threats to economic security, inflation and growing inequality. A strong state is needed to provide the political order and direction necessary to underpin this transition and regulate an emergent market economy in a huge and increasingly complex country. ${ }^{24}$

To be both effective and democratic (or at least not excessively authoritarian), this state would, despite its strength, require support from society, which it would do well to cultivate. Gordon showed us how, for example, Deng Xiaoping sought the support of teachers for the reconstruction of the state in the late $1970 \mathrm{~s}^{25} \mathrm{He}$ laid out the ways in which, during the Cultural Revolution, rival elites advanced different postures on class and class conflict in order to cultivate popular constituencies for their political programmes. He understood acutely that the Chinese state pursued welfare programmes as a 'political strategy of accommodation with key groups', to win their support or at least acquiescence, and even thereby to stave off democratisation. ${ }^{26}$

Gordon was, of course, no fan of political authoritarianism. He decried as much as anyone the Draconian restrictions which the Maoist and Dengist states placed on citizens. Yet he never associated himself with dissidents, politicians, pundits and political scientists who campaigned for democracy and political freedom in China. One reason is that where their concern was usually focused on enhancing individual rights, Gordon's was with the development of space for society to engage itself as fully and effectively as possible with the state. Since he had demonstrated that it was already able to do so under the People's Republic of China, he argued that it was not necessary to tear down the state in order to democratise it. Instead, the envelope could be pushed open; the parameters by which the state constrained (but never eradicated) social politics could be relaxed. A second reason that he drew up well short of calling for the end of the People's Republic of China was his surmise that - at least for the foreseeable future - the alternative could be worse. He was deeply concerned that the sudden collapse of the state could have disastrous effects on economic development, distribution, rationalisation of the market, and social order. The problems of postSoviet society, which had not yet emerged at the time that he was finishing Riding the Tiger - the book in which he most pointedly explicated these concerns - demonstrate his perspicacity and prescience. So does the emergence in China of civil society-like forms in the 1990s, despite the fact that the decade began with a violent crackdown against protesters and several years of tight repression. 


\section{POLICY}

Gordon's concern with the necessary roles of a strong state led him, of course, to an interest in policy. A modernist, he wanted a better world here and now, and he saw good policy as a key tool to achieving it. Yet he never got involved in policy advising. This had Sinological roots, since for so much of his life he studied a country to whom offering advice was a nonstarter. More important, though, were the intellectual roots. Gordon was profoundly cognisant of the complexity of the specific social, political, economic, cultural and historical settings and cross-pressures within which policy had to operate. Thus he was deeply suspicious - contemptuous, even - of the policy-wonk with the quick fix. Policy problems were always 'difficult', their context 'complex', and their prospects of success 'ambiguous'. His hesitation also had political roots, first in his commitments to antiimperialism and to self-determination, and second in his abiding appreciation of the capacity of the politically engaged society to work out (or at least work on) solutions for itself.

Yet he did hope to influence policy in more intellectually and politically honest ways: by providing cautionaries for policy-makers and consultants, and by writing for and working with social scientists in other countries, especially China. In one of his last published works, he clearly relishes, in his sympathetically critical way, the lively colloquy he had had with Chinese welfare planners, and that they were having with various foreign models. ${ }^{27}$ His final projects were his most policy-relevant. Yet they were scholarly research, not policy studies or consultancies. Gordon had sufficient respect for Chinese policy-makers, administrators and citizens simply to put his scholarship before them and let them do what they would with it.

\section{COMPARISON}

Gordon went further than any China specialist in placing China squarely in comparative contexts. In Revolutionary Socialist Development in the Third World, he led the way in getting not just China, but also Cuba, Mozambique, North Korea, Vietnam and Yemen, out of the 'communist' closet and into the mainstream of theory, analysis and debate over 'development'. For example,

Third World socialist countries face many of the same external constraints as their non-socialist counterparts: distorted post-colonial economies, a weak base of available resources, dependence on a few commodities, chronic balance of payments deficits, etc. ${ }^{28}$ 
His capacity to see through and beyond the conceptual juggernauts of 'capitalism' and 'socialism' sprang in part from the fact that he did not reify the mode of production or treat it as a deterministic explanans. Rather, in Gordon's hands 'socialism' and 'capitalism' were shorthand for complex, variegated, and often contradictory forms of organising activities that all economies must undertake: ownership, allocation, management, planning and distribution. Thus, Revolutionary Socialist Development developed a conceptualisation of third world revolutionary state socialism that was distinct both from its Soviet and East European ancestors-cum-siblings, and also from its non-revolutionary 'socialist' associates such as Tanzania. Moreover, Revolutionary Socialist Development was able to show that third world revolutionary socialism tended (for it itself was a variegated category) to have some specific developmental advantages (such as the capacity to mobilise resources for rapid import-substitution industrialisation, control problematic international economic relations, and promote developmental and distributional balances) and disadvantages (such as long-term productivity and efficiency problems and prolonged political authoritarianism).

Likewise, he was the first China scholar to locate China within the paradigm of East Asian developmental states, a club that had previously been reserved for capitalist states. Comparativist development scholars - both in the mid-1980s, when this work began to see print, and certainly now - might regard this move as neither earth-shattering nor, perhaps, particularly helpful, since in joining the club China was bringing not its eroding state socialism but its emerging capitalism, with which they were already familiar. But Gordon's innovation was stunning from the point of view of China studies, which, even in its anti-Sinological, more social-science-oriented forms, was still focused on the country's distinctiveness. Yet China studies gained enormously from Gordon's bold stroke. The field had suddenly found itself forced by history to make its own structural adjustment from the theoretical and analytical worlds of totalitarianism, command central planning, and Maoist revolutionary politics to capitalism, the market, political economy, and a political hybrid of depoliticised Leninism and run-of-themill authoritarianism. Gordon lightened the load by providing invaluable and, by now, well-used tools such as the guided market, indirect planning, regulation in lieu of planning, the dynamics of transition from import-substitution to export-led growth, and the developmental state.

It is not surprising, then, that his work on welfare too brought China into the wider analyses of distinctively East Asian forms. It is for others to say how much his analysis of what was now not China but the Chinese case has contributed to the understanding or even development of welfare systems in other countries. But the palpable effect on China is visible both from 
Gordon's own work ${ }^{29}$ and from the activities of myriad scholars, agencies and government officials who are hard at work trying to improve life for China's poor.

Gordon's achievement in bringing China into the mainstream of comparative social science was also related to his views on politics and the state. His analyses of the politically engaged society and of the state were not distinctively Chinese (though he always applied them carefully, with 'Chinese characteristics' always in full view). Because, rather, social engagement in politics was distinctively human, it happened everywhere. Again, it is for others to say how much his work contributed to their grasp of politics in, say, Taiwan, South Korea, Vietnam, or beyond. But the perspicacity with which Gordon White was able to strike an academically and politically honest balance on the question of China's present political predicament and its proximate prospects ${ }^{30}$ is a testimony to his scholarly genius as well as his profound humanity.

\section{NOTES}

1. For the word 'normal' my computer's thesaurus offers synonyms such as 'balanced', 'sensible' and 'rational', all of which remind us of Gordon's personality and scholarship (even though, thankfully, they do not sum him up).

2. See White, The Politics of Class, p.64. Emphasis in original, though it is also particularly pertinent to my point here.

3. See White, The Politics of Class, p.1.

4. See White, Party and Professionals, pp.89-90.

5. See White, Party and Professionals, p.86. Emphasis in original.

6. See White, Riding the Tiger.

7. Gordon White, 'Social Security Reforms in China: Towards an East Asian Model?' in Goodman, White and Kwon (eds.), The East Asian Welfare Model, pp.183-4.

8. Gordon White, Jude Howell and Shang Xiaoyuan, In Search of Civil Society, p.218.

9. He came to China studies with his Oxford bachelor's and master's degrees in Classical Mods and greats and a master's degree in Mycenaen Archaeology from Cornell. A fellow graduate student of Chinese politics at Stanford related a telling anecdote. They were sitting through a graduate seminar on an arcane topic in Chinese history, and she wondered out loud to Gordon about its relevance to their more modern concerns. Gordon replied, 'You have to immerse yourself in it.' It is no accident that he was one of the very few students of modern Chinese politics who referred to the field as 'Sinology'.

10. Though Gordon was a person with strongly critical views, in his published work he hewed to a positive approach, out of a conviction that the best way to argue against his foes was to outdo them rather than attack them. That in turn sprang from his modernist impatience to advance scholarship rather than dwell on its existing fallacies, as well as his sheer humanity and gentlemanliness.

11. Gordon White and Roger Goodman, 'Welfare Orientalism and the Search for an East Asian Welfare Model', in Goodman et al., The East Asian Welfare Model, p.15.

12. See White, 'Social Security Reforms', p.194.

13. In White, Party and Professionals, pp.84-6. 
14. Gordon's choice of profession was driven by his commitments, not the other way around. He was never loyal to political science for its own sake. Yet, his political commitments never clouded his scholarship; indeed, they only only enlivened it.

15. See White, 'Social Security Reforms', p.176.

16. See White, In Search of Civil Society, p.7. Moreover, even this second(ary?) 'market dynamic' turns out to be thoroughly political and sociological. The latter part of the passage reads in full: "The second dynamic of "civil society" is a market dynamic, analogous to the "Great Transformation" wrought by the spread of market relations in Western societies. In this context, civil society is a consequence of a separation between state and society resulting from the rise of a market economy and the concomitant redistribution of social power away from the state to new strata which are thereby empowered to rein in and restructure the state.'

17. The best illustration of this particular 'road not taken' is the contrast between White's Riding the Tiger and Shirk's The Political Logic of Economic Reform in China, two major statements on the politics of reform that appeared in the same year. Shirk offers a tightly focused, nuanced study of how the decentralisation of China's state institutions itself promoted reform. By contrast, Gordon offers a more comprehensive, complex explanation that includes politics within the state but also between state and society.

18. See White, The Politics of Class Origin.

19. See White, Party and Professionals, Ch.5.

20. See White, Riding the Tider, p.255.

21. Ibid., pp.252-3.

22. See White et al., In Search of Civil Society, pp.217-18.

23. See Goodman et al., East Asian Welfare Model, p.15.

24. See White, Riding the Tiger, pp.238-9.

25. See White, Party and Professionals, p.89.

26. See Goodman et al., East Asian Welfare Model, p.178.

27. Ibid., pp.188-93.

28. See White, Murray and White, Revolutionary Socialist Development in the Third World, pp. 15-16.

29. See Goodman et al., East Asian Welfare Model, pp.188-93.

30. For example, at the end of White, Riding the Tiger and of White et al., In Search of Civil Society.

\section{REFERENCES}

Goodman, Roger, White, Gordon and Huck-ju Kwon (eds.), 1998, The East Asian Welfare Model: Welfare Orientalism and the State, London: Routledge.

Shirk, Susan, 1993, The Political Logic of Economic Reform in China, Berkeley, CA: University of California Press.

White, Gordon, 1976, The Politics of Class and Class Origin: The Case of the Cultural Revolution, Canberra: Contemporary China Centre, The Australian National University.

White, Gordon, 1981, Party and Professionals: The Political Role of Teachers in Contemporary China, Armonk, NY: M.E. Sharpe.

White, Gordon, 1993, Riding the Tiger: The Politics of Economic Reform in Post-Mao China, London: Macmillan.

White, Gordon, Howell, Jude and Shang Xiaoyuan, 1996, In Search of Civil Society: Market Reform and Social Change in Contemporary China, Oxford: Clarendon Press.

White, Gordon, Murray, Robin and Christine White (eds.), 1983, Revolutionary Socialist Development in the Third World, Lexington, KY: University Press of Kentucky. 


\title{
Gordon White and Development Studies: An Appreciation
}

\author{
MARK ROBINSON
}

The purpose of this short essay is to draw attention to the wider intellectual and practical significance of Gordon White's work. It begins by summarising several key aspects of Gordon's contribution to the development studies community. Second, it outlines some of the more enduring concepts and approaches that Gordon developed in the course of his research. Third, the essay moves on to demonstrate some of the practical applications of his ideas and their policy relevance.

\section{INFLUENCES}

A hallmark of Gordon White's approach to research was his ability to maintain a strong disciplinary foundation in political science as a basis for his forays into development studies, while at the same time retaining a deep specialist knowledge of one key developing country, namely China. The energy and excitement he exuded in exploring new avenues of scholarly enquiry was infectious. He was quick to respond to and engage with new concepts in the political science literature. Gordon's skill lay not just in engaging with new ideas but in reinterpreting their potential relevance to development studies and using them as signposts for prospective new research projects. At times, some of these ideas would seem questionable or even suspect, but he would provide them with a fresh gloss or direction and their creative potential would gradually become apparent. Gordon would tenaciously defend new avenues of thinking, but accept and listen to counterarguments with an open mind.

Solitary endeavour was rarely Gordon's preferred approach to research. Much as he enjoyed reading and writing alone, a great deal of his work was in collaboration with others, as is readily apparent from his impressive list of 
publications. Many scholars in Britain, Canada, China and the United States, worked with Gordon on joint projects which he had gestated. For younger researchers this was an important learning process, as it exposed them to a critically inquisitive approach, one that was theoretically grounded but cognisant of the value of solid empirical research. Gordon was fastidious in acknowledging the contribution of co-authors in books and publications, even if their contribution had been relatively modest. This gave younger scholars useful exposure and contributed to the development of their own academic careers.

Gordon's influence on scholarly activity was not restricted to his academic research and publications. He was a very committed teacher. Colleagues and students alike were struck by his fierce commitment to teaching, especially to graduate teaching to which he devoted serious time and effort. He was an inspiration to students new to the politics and political economy of development. Gordon was also supervisor to numerous Ph.D. students, many of whom have gone on to become prominent academics in their own right. Towards the end of his life Gordon often lamented that he did not have enough new doctoral students to supervise, since he was convinced of the fresh and valuable insights that can arise from sustained field exposure.

\section{IDEAS}

Gordon was most comfortable when engaging in intellectual debate and critically assessing the value of new ideas and concepts. His critical disposition was always underpinned by a pragmatic streak, even if he was scathing about the ways in which some concepts were applied in development studies. As the essays in this book amply demonstrate, Gordon was fundamentally preoccupied with the relationship between human agency and institutional design. This is perhaps best captured by the following questions: how do conscious social actors organise around and collectively express shared political and class interests, and how do institutions respond and adapt to such organised interests in ways that are politically expedient and developmentally significant? There were four main concepts that Gordon found useful in seeking answers to these questions in his work in the 1990s: civil society, social capital, synergy and institutional design.

\section{Civil Society}

Gordon responded positively to the contemporary revival of the idea of civil society and its newer derivatives, social capital and synergy. His response 
was invariably measured and pragmatic. He would read widely to ascertain the varied intellectual roots of social science concepts as a basis for determining their academic viability and utility in guiding applied research. In his writing Gordon's approach would be to render concepts intelligible and analytically useful within the ambit of development studies. Unlike the tendency of some scholars to abjure concepts that have attained some degree of popular currency, because they are seen as crude and academically debased, Gordon preferred to engage, refine and reinterpret, as a means of integrating new ideas into wider frameworks of enquiry.

Civil society entered the development studies lexicon in the early 1990s and has since assumed major importance in the policy discourse of aid donors. Gordon was quick to assess the relevance and potential applications of the concept, and subjected it to careful scrutiny and analysis.' His conceptual pragmatism was evident in several of his writings, encapsulated in the notion that civil society could be defined as an intermediate realm situated between the state on the one side and the basic building blocks of society on the other (individuals, families, and firms), populated by social organisations that are separate, and enjoy some autonomy from, the state and are formed voluntarily by members of society to protect or extend their interests or values' [White et al., 1996: 3]. Gordon recognised the limits of a sociological definition shorn of normative political intent, but he wanted an interpretation of the concept that would be widely understood and provide an entry point for empirical research. Far from acceding to a non-Marxist, pluralist approach in which all groups and associations are considered to have benign and legitimate claims on the public sphere, he was acutely aware of the fact that civil society is inherently contradictory and inhabited by opposed social and class forces, and that its character and trajectory are fundamentally shaped by state action.

It was this perspective that underpinned his work on civil society in China, which had been considered by many scholars to be either irrelevant or completely absorbed by the all-pervasive state. Gordon, in association with two other China specialists, authored a seminal book on this theme, in which they examined the rise of new forms of state-society relations in contemporary China. ${ }^{2}$ By means of careful empirical investigation they were able to demonstrate how associational life in China is intimately shaped and circumscribed by the state, both through direct political control and managed economic liberalisation. In the process they were able to question conventional wisdom concerning the rise of civil society in the West where it was closely associated with capitalist transformation and the carving out of an independent public sphere by an ascendant bourgeoisie. This experience also sets China apart from other developing countries and raises important 
qualifications about the capacity of civil society associations to perform the democratising role frequently ascribed to them in the literature.

\section{Social Capital}

A second major concept that attained widespread acceptance in the development parlance of the 1990s is that of social capital. This concept, which is used by Robert Putnam and others to refer to social relationships grounded in structures of voluntary association, norms of reciprocity and co-operation, and attitudes of social trust and respect, was judged by Gordon to have analytical value, even if it had shortcomings in the way that it was applied in the development studies literature. According to Putnam [1993], effective developmental performance is closely associated with the accretion of social capital exhibited in norms of trust and reciprocity among social actors, fostered by dense networks of horizontal associations.

Gordon found the concept of social capital attractive but did not accept its premises uncritically. In his characteristically incisive manner he raised the problem of what he labelled the 'Putnam paradox':

Since stocks of social capital accumulate over centuries and cannot be built up overnight, if you haven't got it you're not likely to get it. Moreover, since the amount of social capital is associated with actual and potential developmental performance, the localities which are the most needy in developmental terms are also likely to be the least endowed with social capital. Lack of social capital then operates like some kind of social debt, the burden of which debilitates groups and communities and intensifies the gaps between them and their counterparts with greater social assets [White and Robinson, 1998: 105].

The implication is that the social capital argument, premised on a putative correlation between the density of associational life and positive developmental performance, is tautological if pursued to its logical extreme. It is evident that stocks of social capital vary considerably among similarly structured communities as well as among those exhibiting very different social characteristics, and that a host of other intervening factors shape development outcomes, which makes it difficult to establish strong causal connections. It is also the case, as Gordon observed, that the very process of development can itself undermine associational ties, for example through economic liberalisation which can entail social disruption and cutbacks in government expenditures. A more circumspect understanding of the social capital argument would therefore seem warranted, where some forms of associational ties might be developmentally benign, buttressed by particular forms of productive engagement with state agencies. This led Gordon to consider the utility of a third closely related concept, namely that of 
synergy, which made its appearance in the development studies literature in the mid-1990s.

\section{Synergy}

Synergy, according to one of its leading proponents, can be defined as 'mutually reinforcing relations between governments and groups of engaged citizens', founded on a 'complementary division of labor between bureaucracy and local citizens' [Evans, 1996: 1119]. This definition presupposes some form of collaborative relationship between institutions in the public and private sectors in pursuit of a common set of developmental objectives. It invariably focuses attention on productive forms of institutional collaboration between community groups, voluntary organisations and state agencies.

Gordon was not content with this restricted interpretation of public-civic collaboration and sought to extend the potential utility of the synergy concept by focusing on socio-political and structural variables that influenced the feasibility of such collaboration. In particular he emphasised the significance of a society's degree of social cohesion, which depends on the amount of structural inequality and the intensity of social conflicts: 'Where gaps between social groups are wide and political power is consequently highly skewed, and where social relationships and fragmented and conflictual, systematic efforts at organizing the kinds of complementarity which can produce the public goods and distribute them throughout the population are likely to be wasted' [White and Robinson, 1998: 104]. He also stressed the importance of the nature of the political regime in shaping the space available to civic associations to operate within and to engage with state agencies, and as a conditioning factor, which affects the potential for synergistic relationships to develop.

Evans [1996] and others have argued that the institutional foundations of government-civic complementarity extend beyond horizontal ties between associations in the form of social capital. Other key factors are the creation of accountable and efficient state institutions that are staffed by people committed to the idea of public service, and the relations of mutual trust, respect and co-operation which serve to break down the barriers between state and society. While appreciating the significance of these arguments, Gordon recognised that current thinking about the role of the state in the process of organising synergy was inadequate in a number of key respects. $\mathrm{He}$ argued that the role of the state in generating synergy was sometimes reduced to creating a conducive environment in which civic action could flourish. This is certainly important, since excessive regulation of voluntary activity can stifle the potential for complementarity between state and civic 
actors, but its role is more profound.

Gordon also questioned a prevalent assumption in the literature which holds that state officials are motivated exclusively by self-interested behaviour that negates any potential for building collaborative relationships for virtuous developmental purposes. He also recognised that a predisposition towards constructing synergy on the part of public officials would often not occur without demands being placed on the state from below. This he termed 'political synergy', where 'pressures exerted by social organizations to stimulate government provision of public goods and enforce government accountability to popular demands for them' [White and Robinson, 1998: 99]. This notion adds a valuable extension to the concept of synergy by highlighting the importance of the political context and purposeful behaviour by state actors in cementing inter-institutional complementarities.

\section{Institutional Design}

Gordon's interest in the developmental potential of civil society and social capital was tempered by his fundamental concern with the nature of the state. His critique of the concept of synergy outlined in the previous section is redolent of this preoccupation with state power. His penchant for analysing the role of the state was sometimes wrongly construed as a predilection for statist solutions to development problems. In his earlier work he saw the potential for virtuous state action embodied in revolutionary socialist regimes that came to power in the aftermath of liberation struggles in Africa and Asia in the 1970s [Murray et al., 1983]. Gordon cultivated the concept of the developmental state in his analysis of the successful East Asian 'tiger' economies, arguing that the deliberate construction of a set of institutions geared towards a clear vision of development under the guidance of a motivated political leadership was key to their success [White, 1988].

This preoccupation with the potential for virtuous state action underpinned one of Gordon's last research endeavours on the democratic developmental state. The changed political context of the 1990s, where many former authoritarian states had successfully accomplished a transition to democratic rule, posed new development challenges. Put simply, how can democratic states in poor societies articulate and implement successful development strategies? Gordon argued that part of the solution lay in designing political institutions in ways that could produce developmental benefits. This led him to consider the respective merits of presidential versus parliamentary forms of government, federal political arrangements, affirmative action in the form of guaranteed representation in legislative bodies, and the scope for enhanced participation in decentralised political institutions [White, 1998]. 
Despite the potential he saw for conscious political and institutional design in fostering the conditions for developmental success, Gordon recognised that these conditions could only be reproduced in a very specific set of circumstances. In this respect he was unusually pessimistic, arguing that 'Democratic developmental states may turn out to be the exception rather than the rule' [White, 1998: 42]. He suggested that most cases of successful developmental states tend to be historically contingent, regime characteristics are not adequate explanations in their own right, and that the underlying dynamics of social and material inequality may ultimately frustrate redistributive efforts. Despite his own normative preference for developmental social democracy, he acknowledged that in view of formidable political and material constraints, 'many countries may not succeed either in consolidating democratic institutions or in achieving socio-economic development' [ibid.: 44]. For Gordon, the more likely candidates for developmental democracy were authoritarian semi-democracies of the East and South-east Asian variety, or elitist democracies along Latin American lines.

\section{POLICY SIGNIFICANCE AND PRACTICAL APPLICATIONS}

Gordon was not, by inclination, primarily concerned with policy issues. But as Blecher (in this volume) has noted, Gordon appreciated the complexities of the broader policy context, and at times explicitly considered the policy applications of his research findings. More commonly, the policy significance of Gordon's work was latent and implicit, and needs to be consciously drawn out with reference to some of his ideas sketched out earlier in order to demonstrate their practical relevance.

His writing on the potential of civil society to play a role in peaceful democratic transition in China exemplifies this latent policy significance. In line with his circumspect understanding of civil society, Gordon was deeply sceptical of the transformative promise of civil society in China, since 'it is so diverse, fragmented and potentially destabilising. To this extent, civil society is as much of an obstacle as an impetus to democratization' [White et al., 1996: 217]. For this reason, he argued that 'The tendency towards idealizing the political potential of civil society should be minimised' [ibid.]. While he did not spell out the policy implications of this argument, it is evident that Gordon departed significantly from the prevalent assumption in the literature concerning the democratising potential of civil society. He thus viewed with some suspicion the perception of western leaders and policymakers concerning the desirability of rapid political transition premised on an expanded societal and economic role for civil society. Rather, drawing on 
comparative experience elsewhere in the developing world, he thought that a stable and peaceful political transition could be best accomplished through a process of bargaining and accommodation between elites in the state and civil society.

A similar ambivalence underlay his assessment of the potential for synergistic relationships to be established between state and civic providers of social services. His scepticism of the political potential of civil society was mirrored by his cautious assessment of the role of civic organisations in social service provision. Contrary to advocates of voluntary and private sector provision as alternatives to services provided largely by the state, Gordon was cognisant of the problems of market failure. In this respect he argued that 'Over the long term the state is likely to be of crucial importance in organizing and financing social services ... no comprehensive system of social provision, whether civic or commercial, is likely to work satisfactorily without properly constituted state authority and institutions' [White and Robinson, 1998: 113].

Gordon saw enormous potential in organising synergy between state and civic providers but recognised that the process is complex and requires an acknowledgement that relationships of reciprocity and trust are not only confined to civil society but extend to the public realm. Drawing out the implication of this observation for practical purposes he concluded that 'the detailed experience of action to organise various forms of synergy, coproduction and partnership can be drawn together in the search for potential lessons and best practice, and new models of project/programme design which can be successful in achieving effective complementarity between state and voluntary agencies' [ibid.: 113-14]. It is notable that this approach is beginning to inform practical programming decisions of some external agencies, which question the received wisdom concerning the putative selfinterest of state officials and the perceived superiority of the market in shaping allocative decisions, and foster collaborative relations between state and civic agencies as the basis for a more effective and participatory approach. $^{3}$

Gordon was known for his general distrust of non-governmental organisations (NGOs). He tended to see them as a somewhat artificial intermediate category, lacking a distinct social base and level of autonomy, and thus marginal in relation to other organised actors in civil society [White, 1994]. Nevertheless, he appreciated that in circumstances where governments and communities are operating under conditions of economic stress and fiscal austerity the role of NGOs with external links can be important: 'They act in a substitutive capacity to restore associational capacities when these would otherwise be weak or collapsing' [White and Robinson, 1998: 106]. In this 
way he saw NGOs as providing a bridge between the state and civil society in particularly adverse circumstances, and as a form of organisational glue which could help to cement social capital, but as organisations which were essentially ephemeral and therefore not a long-term substitute for state and civic organisations.

Finally, while Gordon was pessimistic about the prospects for building successful democratic developmental states, he continued to see the normative potential for constructing regimes that could best achieve effective and equitable development in the interests of the broad mass of the poor in developing and transitional states. His interest in the potential for the emergence of this type of regime, however, was not purely driven by normative concerns, since he recognised that successful developmental performance would protect new democracies from a downward spiral of mutually reinforcing political and economic decline.

Alert to the possibility of this perilous outcome, Gordon outlined a set of circumstances which he thought would be conducive to the construction of democratic developmental states. Although it would be difficult to cast these as policy prescriptions, they do have practical validity. They include the following: societies at a higher level of socio-economic development with a relatively homogenous population, a strong sense of national identity, cohesive social structure, and lacking in gross inequalities; the ability of forces of civil society to construct development coalitions that can both strengthen state capacity and tackle problems of poverty and insecurity; well-developed and integrated political party systems organised on programmatic rather than personalistic lines; the legitimate concentration of institutional authority in a parliamentary or a presidential system; and societies where the autonomy of political elites is not compromised significantly by economic or political dependence [White, 1998: 45-6]. By implication, Gordon would have considered these conditions to be sufficiently propitious to democratic development so as to warrant policies aimed at their strengthening; hence it is only where such conditions obtain that external efforts to promote democratic developmental states have a chance of succeeding.

Although such a set of conditions largely emanate from the historical circumstances germane to particular societies, they are susceptible to some degree of outside influence. The most obvious source of external influence is that of foreign aid, which can influence institutional design and enhance the capacity of state and civic organisations if devised in a sensitive and appropriate manner. Gordon usually fought shy of foreign aid policy, in part because he was circumspect about outside intervention, but also because he was sceptical of the tendency of policy-makers to devise simplistic solutions. He rarely steered his conclusions to aid policy concerns, though there were 
exceptions and Gordon did not underestimate the significance of external actors.

The nearest Gordon got to aid policy prescription was in the conclusion to the volume he edited with Robin Luckham [1996], where they considered the various ways that aid donors might address problems of democratisation through their development assistance programmes. Gordon was doubtful about the merits of democracy assistance, since he believed that the interplay of internal regime dynamics and organised collective action would ultimately be a more significant locus for sustained political change, and because he was doubtful about the possible negative impact of external intervention. Mindful of such issues he wrote:

The exercise of both economic and political conditionality should be preceded by care, caution and knowledge. The dangers of ill-conceived intervention are patent. An excessively harsh regime of economic reform imposed on a reluctant government struggling to establish its democratic credentials is one such ... Political conditionality can backfire where it commands strong domestic support and donors should refrain from pushing for multi-party elections in circumstances where they might exacerbate deep-rooted social antagonisms [Luckham and White, 1996: 282-3].

In this respect he concluded with Luckham that a modest approach to democracy assistance, premised on micro-level and indirect interventions, was preferable to comprehensive institutional models based on legal and constitutional reform.

\section{CONCLUDING REMARKS}

It is a measure of his academic stature that his work and ideas have had a profound impact, both in contemporary China studies and development studies, united by a strong disciplinary loyalty and orientation. Gordon's contribution to development studies has been evident in many spheres, ranging from his influence over colleagues and students, through to injecting vigour and interest into conceptual debates, and by enriching thinking on more applied policy issues.

Colleagues, friends and students will remember with a mixture of fondness and appreciation the qualities that Gordon evinced in his work: adherence to academic rigour underpinned by a strong political commitment; a sustained engagement with theory while remaining rooted in empirical research; deep insights into the politics of contemporary China combined with an up-to-date knowledge of the comparative literature; and critical engagement with policy issues while remaining sensitive to the practical implications of his research. 
Gordon's contribution to development studies cannot be summarised with ease or simplicity, nor can it be done full justice in a short appreciation; suffice to say that it continues to inform and enrich the ideas of those he worked with and nurtured. Balzac once said of a great French surgeon: 'Like all men of genius he had no heirs; he carried his skill within him and carried it away with him.' In Gordon's case his skill lives on and continues to influence the theory and practice of his successors to the ongoing benefit of the development studies field.

\section{NOTES}

1. This was very much evident in the article published in Democratization on the use and application of the concept of civil society. See White [1994].

2. White, Howell and Shang [1996].

3. One example is the Ford Foundation, which has sought to identify and highlight the conditions under which public officials promote excellence and innovation in government in its recent programming work in Brazil, the Philippines and the United States. Various bilateral and multilateral aid agencies are now beginning to perceive the benefits of a more collaborative approach in which state and civic capacity are mutually reinforced.

\section{REFERENCES}

Evans, P., 1996, 'Government Action, Social Capital and Development: Reviewing the Evidence on Synergy', World Development, Vol.24, No.6, pp.1119-32.

Luckham, R. and G. White (eds.), 1996, Democratization in the South: The Jagged Wave, Manchester: Manchester University Press.

Murray, R., White, G. and C. White, 1983, Revolutionary Socialist Development in the Third World, Sussex: Harvester.

Putnam, R., 1993, Making Democracy Work: Civic Traditions in Modern Italy, Princeton, NJ: Princeton University Press.

White, G. (ed.), 1988, Developmental States in East Asia, London: Macmillan.

White, G., 1994, 'Civil Society, Democratization and Development (I): Clearing the Analytical Ground', Democratization, Vol.1, No.3, pp.375-90.

White, G., 1998, 'Constructing a Democratic Developmental State', in M. Robinson and G. White (eds.), The Democratic Developmental State: Politics and Institutional Design, Oxford: Oxford University Press.

White, G., Howell, J. and Xiao-yuan Shang, 1996, In Search of Civil Society: Market Reform and Social Change in Contemporary China, Oxford: Oxford University Press.

White. G. and M. Robinson,1998, 'Towards Synergy in Social Provision: Civic Organizations and the State', in M. Minogue, C. Polidiano and D. Hulme (eds.), Beyond the New Public Management: Changing Ideas and Practices, Cheltenham: Edward Elgar, pp.94-116. 


\section{POLITICS AND THE STATE}





\title{
Reform and the Role of the State in China
}

\author{
TONY SAICH
}

The programme of economic reform that has been under way for over 20 years has been accompanied by significant changes in the role of the state apparatus. These changes are especially clear if the state's role is compared with the Maoist period when the economy was guided by the central plan overseen by a centralised political and administrative system. Now, there is far less direct involvement in the economy and people's lives, new and revamped institutions have been created to deal with law, international trade and a market economy, and the education level of administrators has improved considerably. However, while these changes are considerable, it is still the case that the Chinese Communist Party (CCP) is wrestling with what the correct role of the state should be in overseeing an increasingly marketised economy and pluralised society.

In 1978 before reforms began the state controlled almost all output from the service sector, 94.4 per cent of agricultural production and 97.5 per cent of industrial production was sold at state-fixed prices.' There was no notion of an independent financial or banking sector but rather they simply acted as the state's cashier, providing finance for state directed development projects. The situation has changed dramatically with major consequences for the role of the state. The degree of market reliance has risen from 25 per cent in 1979 to 63 per cent in 1992 before the more dramatic reforms of the 1990s. By 1999, Hu Angang estimated the degree of marketisation to be almost 80 per cent. ${ }^{2}$ The share of the non-state sector in industrial output rose from 22.4 per cent in 1978 to 73.5 per cent in 2000 while the private sector grew from two per cent in 1985 to 16 per cent in 1998. ${ }^{3}$ The People's Bank of China has estimated that by the end of 1998, the private sector contributed 43 per cent of GDP, 48 per cent of employment and 31 per cent of fixed asset investment. ${ }^{4}$ The Chinese economy is now to all intents and purposes a mixed economy. 
Despite these changes, the policies of the state and its organisational structure still do not reflect governance of a mixed economy with the continuation of preferential policies for the state-owned sector, progress but continuing bias against the private sector, and an administrative structure that cleaves too closely to that of the pre-reform era. One clear example is with credit policy where banks exist essentially to fund state-owned enterprises (SOEs), which receive 70 per cent of bank lending.

Many observers expected that with the expansion of the market economy, the role of the state would decline in transitional economies, including China. However, this has not been the case and reform has brought with it state expansion into new areas while old functions have not necessarily been terminated. Indeed, a withering away of the state may not be the most appropriate approach. One of the primary problems in post-communist Russia has been the lack of an effective state apparatus to guide the process of market transition. A market economy without an effective enabling environment of rules and regulations implemented by a relatively impartial judiciary results in an anarchic free for all.

First and foremost an effective, as distinct from strong, state structure is a precondition for any hope of successful reform. Certainly, the role of the state in the economy will change with a narrower set of interventions and less direct administrative interference. However, an increase in state capacity is a prerequisite for an effective market to function. The state must adjudicate the increasingly contentious nature of economic market transactions. This means that it is the obligation of the state to establish a sound legal system. In addition, the state must manage the key macroeconomic variables and ensure that economic and investment policy is not distorted by price fixing or subsidy supports that have outlived their rational lifetime. It must deal with revenue collection and distribution, and this will help the state to provide minimum social services and welfare guarantees to protect those who are vulnerable in the shift to a market economy. ${ }^{5}$

Far from making governance easier, the shift to less administrative interference and curtailing the direct provision and administration of services makes it more complex. The Chinese state has added to its old monopoly functions new regulatory roles that are broader and more complex than before and that will become even more complex as China eases its way into WTO. The Chinese government needs to dismantle old ministries and organisations, adapt the roles of others while creating new ones to serve the needs of a WTO world. The required regulatory development is mind-boggling and extremely expensive. For example, it costs a typical developing country $\$ 150$ million to implement requirements under just three of the WTO agreements (customs valuation, sanitary and phytosanitary measures, and intellectual property rights). ${ }^{6}$ 
Most current administrators are less familiar in a role where they would act as an indirect provider or a regulator. These new roles will require them to acquire additional skills and capacities to manage within a markedly different administrative framework. Pension reform is a good example of the new challenges. The central government has decided to shift responsibility for the pensions of the privileged sector of the working class from stateowned enterprises to the local government. This entails local administrations dealing with complex matters of collection, pooling and disbursement. However, many localities lack the skills to manage these funds effectively and with insufficient transparency and regulation many have simply used pension funds as state assets to be invested as they see fit in their pet development schemes. Even at the national level there are problems.

During preparations for the establishment of the Ministry of Labour and Social Security (formally established in 1998) I visited officials overseeing pension fund policy and development. It was obvious that there were no trained economists working in the department who could provide projections of future funding needs based on demographic trends and differing projections for retirement age. This is just one small example of the new kinds of skills that have to be acquired by government officials to make the new system of governance effective. Given such problems of adjustment, it is little wonder that administrative reform is resisted and many ministries prefer to cleave to well understood tasks and roles rather than adapting to the new.

However, the experience of Russia provides a salutary warning that it is preferable to start with the existing social and political institutions and try to stimulate incremental transformation through the judicious use of incentives. An unregulated and ungoverned market will produce chaotic results. The alternative approach is what Stiglitz denounces as an 'institutional blitzkrieg'. Neither is wholesale privatisation of functions an answer. The precise role that property rights plays in the transition process is more ambiguous than orthodoxy might suggest. As Rawski suggests, they may play a less important role than economists usually ascribe to them. Market structures and the institutional arrangements surrounding business enterprises often exercise greater influence over performance, efficiency and profitability than the nature of ownership. ${ }^{8}$ Private monopolies will not necessarily function any better than state-run ones, what matters is how the competition is regulated. The key factor is 'control' rather than 'ownership'. As Rodrik has noted formal property rights will not have a significant effect unless they confer control rights and 'sufficiently strong control rights' might be effective in the absence of formal property rights. ${ }^{9}$ The development of township and village enterprises in China might be a good case in point. 
So how are we to make sense of this with reference to the role of the state in China? Merquior's general assessment that 'The truth is that we have simultaneously too much state and too little state' applies well to China. ${ }^{10}$ Or put another way, the Chinese state is too directly involved in those areas that can be better left to the market or civil society and has absented itself from certain key areas where the public goods' argument supports greater involvement. Grindle qualifies Merquior's comment as 'too much' meaning that government is too interventionist and often intrusive in terms of state-led development combined with an emphasis on centralised political control. The 'too little' means that these large and intrusive public sectors often have little effective capacity to formulate policy, implement it and perform routine administrative functions." While the first is applicable to China, the latter is not the case across the board, but it is relevant to social policy development.

In the remainder of this chapter I shall consider three issues. The first concerns the 'too much' of inappropriate industrial policy. The second concerns the 'too little' of inadequate healthcare provision. The third concerns the state's fiscal capacity of which there is both 'too little' and poor direction. As in many developing countries, the Chinese state is trying to do more than its resources can support. This requires the state to refocus its capabilities and concentrate on those areas where it can provide added value.

\section{Too Much: Industrial Policy}

One of the government's most significant policy challenges is how to reconfigure an industrial policy and associated fiscal policy that is premised on support to the state-owned sector of the economy. Indeed one might even ask if China needs an industrial policy. While there are strong political and ideological reasons for this bias, the sector has been a net destroyer of state assets while the rapidly growing and more productive non-state sector is penalised and starved of the necessary capital for development.

The role that an active industrial policy plays in development has been much debated with many seeing this as a key factor in the success of the East Asian economies before the economic crisis. ${ }^{12}$ A number of writers have highlighted the Japanese and Korean policy of 'picking winners' and then setting up trade barriers to protect them while providing them with directed credit from the banking system to help them expand. Depending on one's viewpoint, this is either seen as a sound strategy that contributed to take-off or the source of the ruin that came with the Asian Financial Crisis. On balance I would tend to agree with Stiglitz that this approach had some value in the early stage of development by protecting nascent industries and allowing them to develop and take advantage of economies of scale. ${ }^{13}$ However, recent 
research on Japan has suggested that subsidies in fact tended to shift resources from high to low productivity users and that declining industries were favoured over those that were fast growing..$^{14}$ In addition much of the support went to those industries that only had modest future prospects but that for a variety of reasons were deemed in the national interest such as coal, petroleum and textiles. ${ }^{15}$

This has certainly been the case in China where industrial and fiscal policy has supported declining sectors of the state-owned economy that the CCP created from the 1950s onwards. In addition, whether such a strategy of protectionism and 'picking winners' did or did not work in the past, it is not feasible in a world of WTO. Rightly or wrongly, WTO regulations and practices try to prevent the kind of development strategy that was practiced throughout East Asia from the 1960s onwards. It is clear that international pressure will force the Chinese government to undertake a more market-based strategy. Should China not adjust its policy it will run the risk of substantial friction with the world trading body and especially from the USA.

It is clear that state-owned enterprises, on the whole, are struggling. Certainly rapid growth has been attained while maintaining a relatively large state-owned sector. Since 1978 GDP growth rates have averaged ten per cent per annum, 10.7 per cent in the 1990s; by contrast those for Russia declined by 6.1 per cent per annum in the 1990s. Government strategy has been to let the non-state sector grow up around the state-owned core in a process that Naughton aptly refers to as 'growing out of the plan'. ${ }^{16}$ The share of the nonstate sector in China's industrial output rose from 24.4 per cent in 1980 to 71.8 per cent in $1999 .{ }^{17}$ The private sector has been growing at 41 per cent per annum between 1991 and $1997 .{ }^{18}$ SOEs now provide only 38 per cent of urban employment.

However, maintenance of the SOE sector has become increasingly problematic and it is causing increased financial fragility throughout the system while distorting investment patterns. For example, between 1991 and 1997 less than one per cent of working capital loans went to the private sector. ${ }^{19}$ Reforming the industrial sector is the most difficult governance challenge for the CCP as it goes to the core of the economic system that was set up under the central plan. Reform undercuts the interests of powerful bureaucracies that were established to run the system and the working class that the CCP was to represent the most advanced elements of. Not surprisingly reform attempts have been stop-go but by the latter part of the 1990s it was clear that difficult reforms could be delayed no longer. The problem of SOE reform provides a good example of the advantages and disadvantages of delayed reform. Gradualism allowed the non-state sector of the economy to develop alongside that of the SOEs providing alternative employment opportunities 
for new entrants and for laid-off industrial workers. In the absence of an effective government unemployment scheme, keeping superfluous workers in the SOEs provided an alternative to turning them out onto the streets where they may have formed a reservoir of the politically discontented. This is no longer financially viable. Economic pressures have made it impossible for the Centre to remain on the fence while the localities were pursuing de facto privatisation. The state simply did not have the money to keep bailing the sector out.

Some figures display the seriousness of the problem faced in the mid1990s. Of the 100000 plus industrial SOEs, World Bank figures suggest that perhaps less than ten per cent were fundamentally viable. SOEs absorbed 60 per cent of national investment; received total subsidies amounting to onethird of the national budget; and net credit to SOEs reached over 12 per cent of GDP in 1995. Importantly, 50 to 75 per cent of household savings, mediated and directed by state banks, went to finance SOE operations. The World Bank estimated that in 199650 per cent of SOEs lost money (unofficial estimates are higher).$^{20}$ By 1997 total net losses of SOEs were $\$ 4.86$ billion and around $\$ 8.4$ billion the following year.

Delay in fundamental reform derived from the lengthy learning process that the leadership has undergone in grappling with this sector. It took a long time for central leaders to realise that simply stressing technological upgrading, improved management, limited autonomy, and expanded market forces did little to improve the health of SOEs unless the external environment was significantly reformed and a proper sequencing of reforms introduced. Indeed, tinkering with these aspects could actually make the situation worse. China lacks the key institutional mechanisms needed to make corporate governance and by extension property rights function for producers in complex market settings. The problem is compounded by the fact, as noted above, that many SOEs have become net destroyers of assets, with what they consume being of far greater value than what they produce. The dilemma for the government is that they still provide significant revenue for all levels of government: in 1995 this amounted to 71 per cent of total revenue.

By the late1990s China's leaders became aware that over the long-term government resources would be insufficient to pay depositors and bondholders if SOEs were unable to service bad debts. At the same time, the state with a declining revenue base was unable to offer the same kind of bailout and subsidies declined. This made it virtually impossible for many SOEs to meet their full range of social obligations, and even salary payments, thus in turn speeding up the need for pension, medical, and housing reform. Showing the range of the activities, SOEs employ fully one-third of China's medical staff and some 600,000 teachers and administrators. ${ }^{21}$ The cost of 
social insurance and welfare funds as a proportion of the total wage bill rose from 13.7 per cent to 34 per cent in $1995 . .^{22}$ It is not surprising then that bankruptcies in 1996 rose by 260 per cent on the year before and that lay-offs are rising despite official concern about the pace. The total of 6232 bankruptcies exceeded the total for the previous seven years combined.

Such statistics led the party leadership to decide, in a risky venture, to cut themselves loose from the working-class that they created in the $1950 \mathrm{~s}$ and to reduce working class expectations about what the state can provide. Rhetoric is still paid to the importance of working-class leadership and policy is to give priority to finding work for laid-off workers. The reality, however, is that for many they are on their own to find new work in an economy that is increasingly unfamiliar to them and that requires very different skills than those they learned under the Soviet-inspired system.

A number reform initiatives related to governance have been pursued including: encouraging SOEs to pull out of certain sectors of the economy where there is adequate alternatives and no clear case for state involvement, clarifying ownership rights, separating the enterprise from government administration, and forming large enterprise groups that would be able to compete on the international market while allowing smaller SOEs to diversify ownership. This policy for the 500 (originally 1,000) or so largest enterprises may seem strange given the problems that the chaebols of South Korea and the keiretsu of Japan have run into. The Chinese leadership believes that this strategy is still viable at its development stage. In addition ideological factors, the remnants of socialist ideas on industrial development, and nationalistic ones, to get a number of Chinese companies at the top of the Fortune 500 list (there are currently 11 on the list), have perpetuated the desire to privilege this sector. Last but not least this sector has formed the core of the socialist system and vested interests entrenched over 50 years make a substantial policy shift more difficult. Most of the ministries and related institutions are loathe to relinquish powers and would only be willing to allow a greater role for the market when it is clear that they can dictate its terms.

From the mid-1990s two important further reforms were introduced to attempt to improve the sector. The first was the establishment of a social welfare system independent of the individual enterprises and regulated through the government. The second was to harden the budget constraints by gaining control over bank loans, trying to introduce better discipline over lending, and commercialising loans.

Has the policy of revitalising the SOE sector worked? On paper yes, but emphatically no in reality. By the end of 1999 and throughout 2000, officials were beginning to highlight figures that showed the situation for loss- 
making SOEs beginning to turn around. In 2000 official estimates of profits for the sector were $\$ 11.7$ billion, a 78 per cent increase over 1999 , with a further rise in gross profits in the first eight months of 2001 of $\$ 18.7$ billion. ${ }^{23}$ In March 2001, the head of China's State Development and Planning Commission declared that the 6599 loss-making SOEs that made losses in 1997 had been cut by over 70 per cent. This turnaround is not surprising. First, many of the really hopeless cases have been taken off the state books through mergers and acquisitions with more profitable companies. Second, from 1994 on, the state has sold off, bankrupted or contracted out many of the small and medium-sized SOEs that were owned by non-central authorities. One survey found that in 19 provinces, by the end of 1999, 75 per cent of such SOEs had changed their ownership system. ${ }^{24}$ Third, Asset Management Companies (AMCs) have bought up the debt for many of the larger enterprises and thus it has been moved off the books of the SOEs.

In 1999 and 2000 some $\$ 140$ billion worth of bad loans was transferred to the AMCs. ${ }^{25}$ Of this amount only six per cent has been disposed of and recovery rates have not surpassed ten per cent. ${ }^{26}$ Most importantly, the SOE is no longer paying a large amount of interest on its bad loans. In this way many bankrupt SOEs have turned around from basket cases to seemingly profitable enterprises overnight. ${ }^{27}$ Whether the problem of SOE inefficiency is really resolved or not is an entirely different matter and many of the SOEs have avoided the necessary structural reforms to enable them to compete in the future WTO market. In fact, recent figures suggest that the benefits of these one-shot measures are diminishing. Little has come from the kind of increased efficiency that would signal a lasting turnaround. For 2001, it was estimated that 43 per cent of SOEs would lose money, while some 5,200 out of 6,600 SOEs that have formed the core of the reform efforts would report losses. Also, in September 2001, for the first time since early 1999 the rate of SOE losses increased..$^{28}$

China will need to move more quickly on governance in this area unless it wants to provoke a financial crisis that will be exacerbated by WTO entry. The state needs not only to withdraw from direct involvement in the sector but also to end preferential policies and lending practices that redirect valuable resources to a declining sector that is unlikely to turn around. However, this does not mean there is no role for the state. China needs to develop a better capacity to guide economic development through indirect mechanisms and to develop more effective regulatory structures that support competition. While reducing its direct control over the economy, it needs to develop new skills to manage economic affairs through fiscal and monetary policy, an area that is gaining ground in China. For those areas where the government is reluctant to withdraw, it needs to develop practices that provide greater transparency and accountability. 


\section{Too Little: Rural Healthcare Delivery}

By contrast with industrial policy, there has been too little state involvement in healthcare, especially with respect to the delivery of services in poor rural areas. However, this should not be taken to mean that the state should cover all forms of health care and while privatisation may be possible for some services, high-end urban healthcare for example, or for public-private partnerships, the poor are a clear case for state provision. While curative care could be considered a pure private good for which all but the poorest could find alternative cost coverage, the same is not true for preventive medical care. Preventive care is a clear public good with large externalities. No matter how much the private sector and the market develop, provision will be inadequate without state support.

Reforms, especially financial decentralisation, have produced new inequalities, a dramatic rise in the disparity between welfare provision in rural and urban China, and an abandonment of the compact for cradle-to grave social welfare for the privileged working class. While the reforms may have raised the standard of living for the vast majority and shifted China along the road to a market economy, China's policy-makers have not been so successful in devising policies to bridge the social transition. This is not surprising, as reforms entailing major institutional change are inherently slower and more complex than macroeconomic stabilisation and liberalisation measures. ${ }^{29}$

Financial pressures resulting from the reforms have caused many workunits and local authorities to cut services or turn them over to a fee-forservice system. Individuals are left increasingly to find the best support available with their own resources. This has been particularly noticeable in the provision of healthcare.$^{30}$ Combined with the rising income inequality, the financial pressures on the local state in China are accounting for the huge variation in the provision of public goods and services during the transition. As the World Bank has shown, access to health and education services was still widely available in the 1980s but became more dependent on incomes in the 1990s. ${ }^{31}$ For example, in 199822.2 per cent of those in high-income areas were covered by co-operative medical facilities but only one to three per cent in poorer areas were covered. ${ }^{32}$

Government health spending has been inadequate and the budgetary allocations are heavily biased toward the urban areas. Annual healthcare spending is only around 3.8 per cent of GDP, as against WHO recommended levels for developing countries of five per cent. ${ }^{33}$ In fact the state's financial commitment to rural health services has been declining as a percentage of the total medical and health expenditure from 21.5 per cent in 1978 to 12.1 per 
cent in 1985 to 10.5 per cent in 1991. Rural spending was two-thirds of the national average while that for urban China was almost twice the national average. $^{34}$

During roughly the same period, the actual cost of care increased dramatically. The impact for poor rural households on healthcare access is particularly dramatic. Annual medical expenses per capita rose from between two to three per cent of total income around 1990 to eight to 11 per cent of income in poor areas 1998 and has continued to rise. ${ }^{35}$ With the loss of the pre-paid collective medical system with the disbanding of the communes in the early 1980s, some 90 per cent of rural households have to pay directly for almost all of the health services used.36 Thus, not surprisingly, illness has a close correlation with poverty and cost of provision is a major factor influencing utilisation by the poor. One 1995 survey of 60 poor families cited major medical expenses as the most important cause of poverty. ${ }^{37}$

The basic problem of healthcare delivery derives from the change of the ownership structure of village networks and the nature of the incentive system that has arisen from these changes. ${ }^{38}$ From 1981 health care facilities were instructed that they should cover recurrent costs, with the exception of staff, from user charges and by the mid-1980s preventive care facilities were also charging on a fee-for-service basis. This caused the drop in participation in the cooperative medical schemes noted above and the shifting of health cost burdens to the household. Thus in terms of national health spending, while the collective schemes accounted for 20 per cent in 1978, by 1993 they only accounted for two per cent. ${ }^{39}$ As the World Bank concluded in its 1996 report, 'the downturn in China's health performance relative to its income level coincided with agricultural reform that reduced the ability of the village to tax the peasants'. ${ }^{40}$

In addition, direct government support has been dropping. One intent of the financial decentralization was to allow townships to increase healthcare funding. This may have been the case in wealthier areas but on average it has not been the case, especially in the poorer townships. In Donglan County, Guangxi Autonomous Region, government covered 46 per cent of the income of the county's health centres in 1981 but this had declined to only 32 per cent in $1994 .^{41}$ A 1992 study of three poor counties showed that government funds supported 18 per cent of county hospital budgets and 26 per cent of those for township health centres, down from 34 and 38 per cent eleven years earlier. This means that increasingly such facilities are raising funds from fees from patients and from drug prescriptions. ${ }^{42}$

With medical facilities there has been a growth in private medical provision and a shift away from preventive medical care to fee-for-service with local governments in poor areas less able to provide adequate support. This 
increases the financial burden on the rural household that in the absence of sufficient state financing must provide the necessary social support.

The Central government has now recognised that its health system is in significant distress, especially in the rural areas. The change in tone at the December 1996 National Conference on Health was remarkable as the leadership shifted from presenting its system as a shining example to other developing countries to one of concern about its collapse. ${ }^{43}$ The Conference called for spending in the national budget to be raised from two to five per cent, something that has not been achieved.

A number of measures could be taken to improve the lot of the poor regions but without a strong constituency of support at the political centre it will be very difficult. The most beneficial change would be to abandon the urban bias, and more particularly the bias toward the state industrial sector, of development policy that has been a hallmark of CCP rule since 1949. This will not happen given the strong vested interests of the CCP and the marginality of rural constituents in the policy process. However, if the CCP could clean up the state-owned enterprise sector, a prime destroyer of state assets, this could have enormous beneficial effects for rural China if part of the current subsidies were diverted to productive investment in the countryside.

Rural healthcare provision appears to be a clear case where the 'public goods' argument applies. The central government needs to tighten the regulatory framework to ensure that guidelines on health are followed and that in poor areas better provision needs to be provided at central government expense. The central government would be well served to be the provider and supporter of public health, ensuring more equitable access, rather than focusing its efforts on subsidising the salaries of those in the health system. ${ }^{44}$ Comparative research in a number of developing countries has shown that especially in the social sectors it may be better to boost direct provision of services by government agencies rather than setting up new contractual deals. $^{45}$

\section{Not Enough: Fiscal Capacity}

For China to meet its governance aims effectively, it requires an adequate fiscal capacity but its finances are insufficient and some are not directed optimally. During the Maoist period, the state used revenues from SOEs with government controlled prices and distribution mechanisms to ensure that the enterprises enjoyed high profitability. This meant that the national savings rate was high. ${ }^{46}$ As we have seen above the reforms have undermined this structure and the state is severely challenged to meet its investment needs and to supply adequate public goods and services. With limited revenues, the 
government must select those activities where it can have the greatest impact or as in the case of rural healthcare provision have an obvious public good function.

Most writers have correctly pointed to the decline in central revenue as a primary cause of the reduction in central state capacity. However, the more important factor is the shifting balance between central and local budgetary streams and the incentive system for local officials. State revenues only amounted to 14.2 per cent of GDP in 1999, down from 36 per cent in 1978 and they had dropped as low as 11 per cent. This has severely restricted the central state's redistributive capacity and has meant that local governments have been largely left to their own devices to raise the necessary funds for development priorities. The relative decline in state revenues has created pressures at all levels and in all Chinese government agencies to meet recurrent costs from the locally generated revenues. This means that local resources and power structures increasingly determine political outcomes. Within the same province and even in adjacent counties one can see radically different socio-political outcomes deriving from the reforms.

Before the most recent fiscal reforms (1993-94), only about one-quarter of all state expenditures occurred at the central level and the major responsibility for financing infrastructure and providing social welfare occurred and still occurs at the local level. Thus, the localities are still dependent on their own income generation to fund activities. This comes from two main sources: extra-budgetary funds (EBF) and self-raised funds (zichou zijin). Not surprisingly, it is difficult to calculate what the real value of the EBF is. Christine Wong has estimated that the EBF amounts to 12 per cent of GDP, compared to an official budget of 14 per cent. ${ }^{47}$ If one adds the self-raised extra funds that by their very nature do not turn up in the statistics, the total sum of revenues available were the same in the early 1990s as at the start of the reforms; 39.5 per cent as compared with 40 per cent. ${ }^{48}$ This means that those observers who have suggested that there has been a major decline in the state's extractive capacity have relied on the official budgetary revenue and this has indeed declined by almost 60 per cent (but not in absolute terms as the economy has been growing at a rapid rate). There has not so much been a decline in the extractive capacity of the state under reforms but rather a realignment between the Centre and the localities with the localities controlling far greater amounts of revenue than previously. ${ }^{49}$

This realignment has had a significant impact on the nature of the central and local state. By 1992, the central government's share of revenue was almost 39 per cent, having declined from 51 per cent in 1980, while collection had risen to 28 per cent from 20 per cent, and expenditure had dropped from 51 per cent to 31 per cent. ${ }^{50}$ The 1994 fiscal reforms have redressed this 
situation somewhat. The ratio of the budget to GDP has been raised as well as the ratio of centrally collected revenue to total budget revenue. The share of centrally collected revenue rose from 22 per cent in 1993 to 56.5 per cent by 1997. ${ }^{51}$ For the first quarter of 1997, the growth of centrally collected revenue was reported to be on a par with that of locally collected revenue, thus overcoming the initial tendency of the localities only to collect for themselves. The Centre's share of budgetary revenues grew from 2.8 per cent of GDP to 6.2 per cent in $1998 .{ }^{52}$ This is not sufficient, however, for the central state to play a major role in redistributive policy given its other financial obligations. The original objective was to provide the Centre with a sufficient financial surplus so that it could cover both its own obligations and certain redistributive needs. It was estimated that the Centre would need some 60 per cent of collected revenues; of which ten per cent could be used to meet the redistributive and related goals..$^{53}$ This objective of the 1994 reforms has not been met. These factors are is of vital importance for understanding the incentives for the local state.

The interest for local governments is still to concentrate on raising EBF and self-raised funds. Once a fee collected by a local government is reclassified as a tax, it is subject to revenue sharing agreements with higherlevel administrations. The fees are the funds that the localities can use to finance their own requirements, including their own salaries and related administrative costs. Particularly important are the management of local enterprises that can provide revenue to the local government and the use of other state assets such as land to rent out for commercial activities. In fact, rather then frowning on commercial activity, local governments are positively encouraged to use state assets to raise funds to cover their management and operational costs. This became especially important with the return to household-based farming that removed agriculture as a source of viable financing for local governments. ${ }^{54}$ The 1994 reforms have heightened the tendency to seek off-budget revenues, as they require local counties to hand over 75 per cent of value added taxes but they have increased obligations.

It is important for the central state to bring these EBFs into the formal fiscal system if it wants to meet any redistributive goals. The EBFs are a major contributor to inequality across administrative regions in China and the implicit tax rates of the EBFs are certainly higher in poorer regions. ${ }^{55}$ In addition, the central state needs to boost further its work to prevent tax evasion. It is clear that China, like many other developing countries, only collects a small amount of the taxes that are owed. Local governments allowing a myriad of tax breaks for investors and various forms of exemption have also weakened fiscal capacity. The government will need to create a regulatory environment and institutional framework that can support a more diversified 
financial system and to develop domestic capital markets. At the same time, it needs to move further to ensuring that the financial system is not essentially geared to financing the SOE sector.

\section{Concluding Comments}

The role of the state in China has changed enormously over the last 20 or so years reducing its direct role in the economy, curtailing interference in the daily life of its citizens, and with its slow and somewhat grudging acceptance of the need to develop the institutions of civil society. However, much remains to be done if it is to shift, to use the World Bank's phrase from 'rowing' to 'steering' future development. ${ }^{56}$

Increasing the state's fiscal capacity will go a long way to resolving many of the governance challenges that China is facing. However, as the study has argued this alone is insufficient. A major re-think of the state's role is required to adapt the current governing structures to an increasingly marketised economy open to international competition. In some areas such as industrial policy this will mean doing less and doing it in different ways through indirect levers such as fiscal and monetary policy. In other areas such as rural healthcare, it will involve greater targeted state involvement to benefit those who have not profited so well from the economic reforms. In yet others such as the financial sector and environment (not discussed above) it brings new challenges to create new institutions and policies. This all suggests that with increased marketisation and openness the state in China far from withering away needs to strengthen its capabilities in many areas of regulation and enforcement to provide an enabling environment for the market and civil society to grow. At the same time the state needs to shed many of the functions that it has inherited from the days of central planning.

In particular, state officials need to recognise that they are no longer the sole actors guiding development in China and indeed in some areas may no longer be the most important ones. This will entail considering how to develop new partnerships with the business sector and with its citizens. This could include the creation of public-private partnerships for the provision of goods and services, or in some cases, contracting the provision out entirely or relinquishing the role to society. ${ }^{57}$ If the Chinese state is not able to meet these challenges it will find itself as a break on further development rather than a facilitator. 


\section{NOTES}

1. UNDP [1999: 20-21].

2. Ibid. p.39 and personal communication from Professor Angang Hu.

3. See Yusuf [2000: 24-5].

4. Presentation to the conference 'Economic and Enterprise Reform in China: The Challenges for Government and Business', Wilton Park, Nov. 2001.

5. See World Bank, World Development Report 1997 [1997: 4-5].

6. See Rodrik [2001]. (A revised version of this draft appeared in Foreign Policy, March/April 2001 under the title 'Trading in Illusions'.)

7. See Rawski [1991].

8. For China see Steinfeld [1998].

9. See Rodrik [1999].

10. See Merquior [1993].

11. See Grindle, 'The Good Government Imperative: Human Resources, Organizations, and Institutions', in Grindle (ed.) [1997: 3-5].

12. See Stiglitz [2000: 517-19].

13. See Stiglitz [1996].

14. See Noland and Bergsten [1993].

15. See Beason and D.E. Weinstein [1996].

16. See Naughton [1995].

17. See Zhongguo Gongye Jiaotong Nengyuan 50 Nian Tongji Ziliao Huibian (Fifty Year Compendium of Statistical information for Chinese Industry, Transportation and Energy) (Beijing: China Statistics Press, 2000), pp.1-20.

18. See China's Emerging Private Enterprises: Prospects for the New Century (Washington, DC: International Finance Corporation, 2000), p.14.

19. Ibid., p.17.

20. See World Bank, China's Management of Enterprise Assets [1997].

21. See Hughes [1998: 73].

22. See UNDP [1998].

23. See Agence France Press, 28 Oct. 2001.

24. Presentation to the conference 'Economic and Enterprise Reform in China: The Challenges for Government and Business', Wilton Park, Nov. 2001.

25. See Agence France Press, 28 Oct. 2001.

26. See Lardy [2001].

27. For a critical review of this policy see Steinfeld [2000, 2001].

28. Agence France Press, 28 Oct. 2001.

29. See Nelson [1997: 256].

30. See Bloom, Tang and Gu, [1995] and Liu, Hsiao and Eggleston [1999].

31. See World Bank, Financing Health Care [1997: 23].

32. See Zhu [2000: 41-3].

33. See Bland [2000].

34. See Economics Research Department of the Ministry of Public Health and the Institute of Development Studies [2000: 25].

35. See Liu, Zhen and Wen [2000].

36. See World Bank, Financing Health Care [1997: 47].

37. See Kaufman [1998].

38. See UNDP [1998: 36, 38].

39. Ibid., p.37.

40. See World Bank [1996: 127].

41. See Tang and Bloom [2000: 194]. 
42. Bloom, Tang and Gu [1995: 426-7].

43. Discussions with participants and Caillez [1997: 42-3].

44. On these issues see Saich and Kaufman [2001].

45. See Batley [1997].

46. See UNDP, 1999 China Human Development Report [1999: 75].

47. Presentation by C. Wong at the workshop on 'Mapping the Local State in Reform-Era China', University of California, Los Angeles, June 2000.

48. See Zhang [1999: 123].

49. See D. Yang, 'Reform and Restructuring of Central-Local Relations', in Goodman and Segal [1994: especially 61, 64].

50. See Zhang [1999: 120].

51. Ibid., p.131.

52. See Chung [2000: 46].

53. Information from Pieter Bottelier.

54. See Oi [1992: 115].

55. See UNDP, 1999 China Human Development Report [1999: 83].

56. See World Bank, World Development Report [1997: 164].

57. On this issue see Saich [2001].

\section{REFERENCES}

Agence France Press, 2001, 28 Oct.

Batley, R., 1997, 'State as Brokers of Change: Do the New Uniforms Fit?', Insights, No.23.

Beason, R. and D.E. Weinstein, 1993, 'Reconcilable Differences? United States-Japan Economic Conflict', Institute of International Economics, Washington, DC.

Bland, I., 2000, 'Medical Services in China', Australia New Zealand Journal of Medicine, No.30, p.273.

Bloom, G., Tang, S.-L. and X.-Y. Gu, 1995, 'Financeing Rural Health Services in China in the Context of Economic Reform', Journal of International Development, Vol.7, No.3.

Caillez, C., 1997, 'The Collapse of the Rural Health System', China Perspectives, No.18, pp.42-3.

Chung, J.H., 2000, 'Regional Disparities, Policy Choices and State Capacity in China', China Perspectives, No.31, p.46.

Economics Research Department of the Ministry of Public Health and the Institute of Development Studies, 2000, International Conference on China's Rural Health Reform and Development, Beijing: n.p., Nov.

Goodman, D.S.G. and G. Segal (eds.), 1994, China Deconstructs: Politics, Trade and Regionalism, New York: Routledge.

Grindle, M. (ed.), 1997, Getting Good Government: Capacity Building in the Public Sectors of Developing Countries, Cambridge, MA: Harvard University Press, pp.3-5.

Hughes, N.C., 1998, 'Smashing the Iron Rice Bowl', Foreign Affairs, Vol.77, No.4, p.73.

Kaufman, J., 1998, 'Financing, Provision and Use of Reproductive Health Services in China', in the Working Group on Reproductive Health and Family Planning, The Implications of Health and Rights, Washington, DC: The Population Council, p.68.

Lardy, N.R., 2001, 'China's Worsening Debts', The Financial Times, 22 June.

Liu, W, Zhen, X. and M. Wen, 2000, 'Gender Analysis on Household Health Expenditure in Rural Areas of China', paper presented to the 'Conference on Rural Health Reform and Development', Beijing, Nov.

Liu, Y. Hsiao, W.C. and K. Eggleston, 1999, 'Equity in Healthcare: The Chinese Experience', Social Science and Medicine, No.49.

Merquior, J.G., 1993, 'A Panoramic View of the Rebirth of Liberalism', World Development, Vol.20, No.8. 
Naughton, B., 1995, Growing Out of the Plan: Chinese Economic Reform, 1978-1993, New York: Cambridge University Press.

Nelson, J.M., 1997, 'Social Costs, Social Sector Reforms, and Politics in Post-Communist Transformations', in J.M. Nelson, C. Tilly and L. Walker (eds.), Transforming Post-Communist Political Economies, Washington, DC: National Academy Press.

Noland, M. and F.C. Bergsten, 1993, 'Reconcilable Differences? United States-Japan Economic Conflict', Institute of International Economics, Washington, DC.

Oi, J., 1992, 'Fiscal Reform and the Economic Foundations of Local State Corporatism in China', World Politics, Vol.45, No.1, p.115.

Rawski, T.G., 1999, 'Reforming China's Economy: What Have We Learned?', The China Journal, No.41.

Rodrik, D., 1999, 'Institutions for High Quality Growth: What They Are and How to Acquire Them', p.5. Paper prepared for the International Monetary Fund's conference on 'Second Generation Reforms', Nov.

Rodrik, D., 2001, 'The Developing Countries' Hazardous Obsession with Global Integration', manuscript, p.5.

Saich, T., 2001, 'Social Welfare Provision and the Transition: Towards Pluralism in Service Delivery', paper prepared for Infocus Programme on Socio-Economic Security, International Labour Organisation, Dec.

Saich, T. and J. Kaufman, 2001, 'Financing Reform, Poverty, and the Impact on Reproductive Health Provision: Evidence from Three Rural Townships', paper presented to the conference 'Financial Reform in China', Kennedy School of Government, Sept.

Steinfeld, E., 1998, Forging Reform in China: The Fate of State-Owned Industry, New York: Cambridge University Press.

Steinfeld, E., 2000, 'Free Lunch or Last Supper? China's Debt-Equity Swaps in Context', The China Business Review, Vol.27, No.4.

Steinfeld, E., 2001, 'China's Problem of Debt Equity Swaps: Government Failure or Market Failure?', paper presented to the Kennedy School of Government Conference 'Financial Sector Reform in China', Sept.

Stiglitz, J.E., 1996, 'Some Lessons from the East Asian Miracle', The World Bank Research Observer, Vol.11, No.2.

Stiglitz, J.E., 2000, 'From Miracle to Crisis to Recovery: Lessons from Four Decades of East Asian Experience', in Stiglitz and Yusuf [2000: 517-19].

Stiglitz, J.E. and S. Yusuf (eds.), 2000, Rethinking the East Asian Miracle, New York: Oxford University Press.

Tang, S. and G. Bloom, 2000, 'Decentralizing Rural Health Services: A Case Study of China', International Journal of Health Planning and Management, Vol.15, p.194.

United Nations Development Programme (UNDP), 1998, China. Human Development Report: Human Development and Poverty Alleviation 1997, Beijing: UNDP, p.65.

UNDP, 1999, 1999 China Human Development Report: Transition and the State, Beijing: China Financial and Economic Publishing House.

World Bank, 1996, Country Report: China, Washington, DC: World Bank.

World Bank, 1997, Financing Health Care: Issues and Options for China, Washington, DC: World Bank.

World Bank, 1997, World Development Report 1997: The State in a Changing World, Washington, DC: World Bank.

World Bank, 1997, China's Management of Enterprise Assets: The State as Shareholder, Washington, DC: World Bank.

Yusuf, S., 2000, 'The East Asian Miracle', in Stiglitz and Yusuf [2000: 24-5].

Zhang, L.-Y., 1999, 'Chinese Central-Provincial Fiscal Relationships, Budgetary Decline and the Impact of the 1994 Fiscal Reform: An Evaluation', The China Quarterly, No.157.

Zhu, L., 2000, 'Who Can Provide the Farmers with Medical Services', Liaowang (Outlook), No.16. 


\title{
Managing Central-Local Relations During Socialist Marketisation: A Changing Role for the Chinese Communist Party
}

\author{
AKIO TAKAHARA
}

The Chinese Communist Party aims to complete the transition to a socialist market economy by the year 2010 and to develop China economically to the level of a middle-income country by the middle of the twenty-first century. The question that arises is what impact economic development with marketisation will have on China's political system. This is probably one of the most important issues for researchers of modern Chinese politics.

There are two approaches to considering the effect of economic growth and marketisation on the political system. The first is an approach from the societal level. This pays attention to the social effects of marketisation and growth, such as the pluralisation of interests, and the advent of a middle class with heightened political consciousness, and investigates the possibility of an eventual pluralisation of politics. Influenced by research on Eastern Europe where one-party rule collapsed, there has been a lively discussion in the 1990s about the advent of civil society in China. One such study was conducted by Gordon White, Jude Howell and Shang Xiaoyuan, who examined China's budding civil society from a sociological perspective [White, Howell and Shang, 1996].

The second approach analyses changes to the state or party, and discusses their causes and future developments. Studies by native Chinese scholars residing and working in Japan have recently attracted attention. Tang Liang has elucidated the relationship between the state and the party and how it has been reformed, while Zhao Hongwei has discussed the nature of China's political regime and identified central-local relations as its major characteristic [Tang, 1997; Zhao, 1998]. My study focuses on changes in the role of the party and its organisational and personnel systems. I shall investigate the interrelationship between the three dynamics of marketisation, changes in the political and economic role of the party, and developments in central-local relations. 
Party-state and central-local relations have entered a new phase in the era of marketisation. At the Third Plenum of the Eleventh Party Central Committee in 1978 the party switched its central activity from class struggle to economic development. The Plenum communique criticised the defects of the economic management system, blaming the over-concentration of power at the centre and in the party [Chinese Communist Party Central Documents Institute, 1982: 6-7]. The communiqué argued for enlarging the economic powers of the localities and enterprises, and for altering the situation under which the party substitutes for the government and the government substitutes for the enterprise. Since then, except for a period after the 4 June Incident in 1989, the basic orientation of reform has been to decentralise power to localities and enterprises and to do away with the party's interference in administrative and economic activities. Judging by common sense, it seemed these were the natural requirements of marketisation.

Since 1993, however, progress towards marketisation has brought about a new development in central-local and party-state relations. First, macroeconomic control by the centre has been reinforced, since the localities and enterprises took advantage of the acceleration of reforms and embarked on reckless projects in pursuit of their own development, causing serious imbalances in the national economy. At the same time, policy-makers mobilised the party system to enforce discipline among the localities. The role of the party in marketisation was gradually reasserted, and the central economic work conference in December 1998 even called specifically for the strengthening of party leadership in economic activities (People's Daily, 10 Dec.1998).

Thus, after the advent of reform and opening up, the reduction of the party's power and decentralisation took place hand-in-hand; since 1993, however, the party's leadership and supervision has been reinforced as part of the measures to strengthen central control. While the contradiction between socialism and the market economy has sharpened along with marketisation, there has emerged an ironic situation in which the party organisation has to be called in for the smooth management of the market economy.

The major aim of this contribution is to analyse the political economy of this development and investigate the role of the party in the marketisation of modern China. In the following analyses, I shall examine the politics of marketisation in the first half of the 1990s, focusing on the interaction between marketisation, changes in the party's role, and developments in central-local relations. Then I shall investigate the reassertion of the party's role since the eruption of the Asian financial crisis, and discuss some specific measures which appear to embody a modern Chinese resolution of the contradiction between socialism and the market economy. 
THE POLITICS OF MARKETISATION IN THE

FIRST HALF OF THE $1990 \mathrm{~S}$

The strengthening of the party's political and economic role has happened twice since the advent of reform and opening up. First, there was an attempt to strengthen party leadership in all areas of politics, economy and society after the 4 June Incident in 1989. There was no more official talk of separating the party and government, and party groups' which had been abolished in some of the central ministries were revived. In addition, it was decided to reverse the decline in the role of party organisations within enterprises and to reinforce the party's leadership of mass organisations. Also, the new leadership emphasised the importance of a planned economy and attempted to reinforce central control over the economy through planning.

In early 1992, Deng Xiaoping embarked on his 'southern tour' to reverse the setback of reform. Deng successfully called for a bold promotion of reforms and consequently there was a surge in marketisation and opening-up policies. However, although growth was accelerated, serious imbalances emerged in the macroeconomy caused by over-investment in some sectors by local authorities and enterprises. To tackle this problem, since mid-1993 Zhu Rongji has attempted to strengthen macro-control of the national economy through the establishment of fiscal and monetary systems. Nevertheless, it has proved difficult to enforce discipline among the localities and enterprises through conventional means. Thus, the second expansion of the role of the party was introduced in the context of progress in marketisation and the strengthening of central control through fiscal and monetary means. In this section, I shall review the development of arguments and conflicts over reform policies at the centre since the late 1980s and clarify the difference in the political and economic settings in which the two expansions of the party's role took place.

\section{(a) Late 1980s-Early 1990s: A Setback in Marketisation}

The party's role was enlarged after the 4 June Incident in 1989. This was a reaction against the programme of political system reform adopted by the Thirteenth Party Congress in 1987. The programme, drafted under the auspices of Zhao Ziyang, included specific measures to restrict the role of the party. These included: abolishing party organisations that functionally overlap with government organs; gradually abolishing party groups in government departments; preventing the Party Committee for Discipline and Inspection handling cases relating to legal and administrative regulations; establishing a civil service system, and putting an end to the party's appoint- 
ment of officials and leaders of mass organisations and state enterprises. While the party organisations of some enterprises had been under the vertical leadership of higher-level party organs, a decision was made gradually to switch their leadership to the local party committee. Thus, the enterprise management continued to receive instructions through the vertical, departmental system (tiaotiao, in Chinese), but the enterprise party cell was to start receiving instructions through the local system (kuaikuai, in Chinese). This was considered conducive to the separation of party and government.

The arguments of Deng Xiaoping and Zhao Ziyang for a separation of party and state included their assertion that this would not only improve administrative efficiency but actually strengthen party leadership. They argued that if the party engaged in 'front line' administrative work, it was likely to become directly involved in various contradictions. Therefore, it could play the role of managing the overall situation and coordinating various interests and ideas only if it stood aloof and above administrative work. At the same time, it could effectively provide supervision and prevent bureaucratism only if it kept some distance from the government. Deng and Zhao also asserted that party leadership meant political leadership, namely, making important policy decisions and recommending candidates for important posts in state organs. In fact, such arguments for the separation of party and state were not directly related to marketisation. For instance, they had also been made in the Soviet Union since the 1970s [Hill, 1984]. In the view of Deng and Zhao at the time, however, swift marketisation had been hampered by the bureaucratism of the swollen state-party apparatus, and political reforms, including the separation of the party and the state, were indispensable for the promotion of economic reforms [Deng, 1993: 176-80].

It was inevitable that these attempts at political reform were met with opposition from within the party. For instance, the Party Central Organisation Department, which is in charge of personnel affairs, produced a document in 1988 claiming that conditions were not yet ripe to implement a civil service system [Chen, 1990: 119]. ${ }^{2}$ According to Jiang Zemin, who assumed the post of party General Secretary after the 4 June Incident, many comrades of the organisational front had resisted the mistakes of Zhao Ziyang who had weakened party leadership [Liao et al., 1991: 997]. Premier Li Peng went further and asserted that Zhao had actually tried to eliminate the leadership of the party [Liao et al., 1991: 998]. Thus, many of the measures adopted at the Thirteenth Party Congress were reversed after Zhao's downfall. Party groups in government departments were revived, party committees within enterprises were again endorsed to take part in important decisions concerning enterprise management, the party's leadership of mass organisations was reinforced, and the shifting of enterprise party organisa- 
tions from under the leadership of the party organisations of upper-level administrative departments to that of local party committees was halted. Ever since this reversal, the separation of party and state has not been officially discussed except in some localities experimenting with reform of party and government organs [Central Committee for Organisation and Staff, 1993: 377-405].

As for economic reforms, price reforms were frozen from the autumn of 1988 and stringent fiscal and monetary policies were implemented. As a result, inflation was contained, but the growth rate declined and failed to pick up despite the relaxing of monetary policy. At this point, conflict emerged over the appropriate approach to achieving a more efficient distribution of resources. Some argued for the strengthening of directive planning and central control over investment and goods, while others insisted on promoting marketisation. The former option became dominant among the top leadership and in academia. At a time when socialist regimes in Eastern Europe were collapsing, the argument became influential that difficulties in those countries, as well as the mistakes of Zhao Ziyang, all stemmed from setting marketisation as the goal of reform. Deng Xiaoping repeatedly refuted the argument that identified the planned economy with socialism and the market economy with capitalism. From April to September 1991, however, organised criticisms were levelled at writings that were based on Deng's remarks [Wu, 1992: 22-3, 137-8].

In sum, marketisation, the role of the party, and central-local relations from the late 1980s to the early 1990s were as follows. Deng Xiaoping and Zhao Ziyang promoted the separation of party and government, and of the party and enterprise management, with a view to strengthening party leadership and overcoming the bureaucratism that was hampering marketisation. Also, they decided to cancel the leader-follower relationship between the party organisations of upper-level administrative bodies and those within the subordinate enterprises, in order to reinforce the command of local party committees vis-à-vis the command of vertical departmental systems. Within the party, however, there was strong resentment against these reforms, especially in the Organisation Department, whose vested institutional interest was at risk. Among the six members of the Politburo Standing Committee, newly selected in the wake of the 4 June incident, General Secretary Jiang Zemin, Premier Li Peng, Vice-Premier Yao Yilin, and Director of the Central Organisation Department, Song Ping, were in favour of the reversal of the policy to separate the party and the government. Li Peng, Yao Yilin and probably others supported the implementation of a centrally planned economy. Thus, expansion of the party's role, and reinforcement of central control by planning rather than marketisation, became mainstream policy. 


\section{(b) After 1992: Progress in Marketisation}

Deng Xiaoping acted with a sense of crisis over the reversal of reform policies when he made his inspection tour in January and February 1992 of Shenzhen and Zhuhai, two of the three Special Economic Zones in Guangdong Province. He called for the liberation of thinking from the shackles of ossified ideology and for the acceleration of bold reforms, with a view to defining the political keynote for the Fourteenth Party Congress to be held in the autumn. Since the domestic propaganda department was under the influence of anti-reform forces and uncooperative towards Deng, it was the Hong Kong media that first reported Deng's tour and his remarks. The localities, which had been suffering from lagging economic growth, responded strongly and in February seventeen provinces declared they would accelerate reform [Ling, 1998: 187]. In March, the centre did a political about face, and the Politburo issued a communiqué fully agreeing with Deng's remarks. The Fourteenth Party Congress in October declared for the first time that the target of reforms was to establish a socialist market economy. On the other hand, there was no change in the judgement that those viewpoints and measures that questioned, negated or weakened the leading role of the party were all fundamentally mistaken. The pre-4 June policies which restricted the role of the party were not revived.

The remarkable progress in marketisation in the wake of Deng's so-called southern tour brought about a staggering rise in the economic growth rate. The rate of increase in GDP was in double figures for four consecutive years from 1992 to $1995 .^{3}$ On the other hand, local leadership at various levels engaged in the reckless development of their localities with no consideration for macroeconomic balances, resulting in the overheating of the economy. For instance, not only provincial-level localities but county-level localities nationwide constructed so-called development zones with a major aim to attract foreign capital. There were 1900 of them by September 1992 (Daily China News, 1 Oct. 1992). The localities also liberally granted permission to establish non-bank financial institutions, which, together with financial malpractices such as illegal inter-bank loans and careless lending, caused financial disorder [cf. Bowles and White, 1993: 105-7]. As a result, inflation was aggravated, government bonds were left unsold, and a number of national construction projects were not implemented because the localities diverted the funds for their own purposes. ${ }^{4}$ The localities actively promoted and in many cases implemented development projects that contributed to enhancing growth and employment in the region. In particular, they were keen to carry 
out projects that increased their revenue. A sense of competition was strong among the localities, which each insisted that their economy was not overheated even though others' were [Wen Hui Bao (Hong Kong), 5 July 1993; Ling 1998: 323].

Faced with this situation, vice-premier Zhu Rongji took the initiative and sought the implementation of bold reforms. In early 1993, a conflict of opinion between premier Li Peng and Zhu about the pace of reform was brought to light. At the closing session of the national meeting of local bank and insurance firm managers in January, Li argued that specialised banks had to continue providing unprofitable loans to achieve policy aims, while Zhu insisted that they should swiftly separate the investment banks for policy purposes from the commercial banks (People's Daily, 18 Jan. 1993). It was at this sensitive time that $\mathrm{Li}$ took sick leave, and Zhu took over and brought in monetary and fiscal measures to strengthen macroeconomic control. For instance, control of the People's Bank over the localities was strengthened by further restricting the provincial branches' ability to allocate credit. It was also decided that loans from the People's Bank to specialised banks were to be made mainly from headquarters and only loans for the purchasing of agricultural products were left to the provincial branches. The central bank system was provided with a legal basis by the China Central Bank Law of February 1995. The Commercial Bank Law, promulgated in July that year, stipulated the independent status of the former specialised banks which were now expected to be more prudent in making their loans. In addition, a bold step was taken in reforming the fiscal and taxation systems to suit the needs of a market economy. An epoch-making measure was the 1994 tax reform, which aimed to increase central revenue. The centre had failed to bring it in for ten years, and it was only made possible at this time after Zhu Rongji persuaded local leaders one-by-one [Takahara, 1997].

From the above analysis, we can see that economic policy shifted from one which paid great attention to planning to one which promoted growth with the direct participation of local authorities, and then to one which paid utmost attention to maintaining macroeconomic balances by central control through fiscal and monetary systems. It is worth noting that central control through non-planning methods was supported by personnel policies. In July 1993, for example, Vice-Premier Zhu Rongji gained an additional office by replacing Li Peng's supporter, Li Guixian, as Governor of the People's Bank. In July and August that year, ten work groups whose members included the director and deputy-directors of the central organisation department were dispatched by the Party Centre and the State Council to twenty provinciallevel localities to inspect and press for the implementation of central directives [Wen Hui Bao (Hong Kong) 15 July 1993; Zheng, 1994: 1, 55; Ling, 
1998: 322]. At the same time, the Director of the Central Commission for Discipline and Inspection also personally led an inspection team to particularly problematic localities (South China Morning Post, 15 Aug. 1993).

Thus, while some people were arguing for the strengthening of macroeconomic control through legislation, in order effectively to implement macroeconomic control over the national economy, where 'rule by person' prevails over 'rule by law', and where the party fully controls personnel affairs, there was little choice but to rely on the party system to enforce discipline. That is, as reform policy developed from a pattern that emphasised the promotion of economic growth by entrepreneurial localism to one that paid more attention to achieving macroeconomic balances and efficiency by financial centralism, there was a greater need to mobilise the organisational and personnel system of the party, in place of the underdeveloped legal system, to enforce economic discipline among the localities.

\section{THE ASIAN FINANCIAL CRISIS AND THE REINFORCEMENT OF PARTY ORGANISATION}

The question of the maintenance of financial order attracted attention once again after the so-called Asian financial crisis. The economic and currency crises of the Asian countries that erupted in 1997 were regarded first of all as financial crises by the Chinese. In this section, we examine the establishment of a new party organisation, the Central Financial Work Committee (FWC), which was assigned a significant new role in the process of marketisation.

The economic and currency crises in Asia, triggered by the Thai Baht crisis in July 1997, struck the Chinese leaders who had been trying to emulate the rapid growth of the Newly Industrialising Economies and ASEAN countries. In particular, since the cause of the crises was identified to be in the financial area, they were urged to come up with effective measures to tackle the latent financial crisis in China. In fact, as early as August 1996 Jiang Zemin and the Central Leading Small Group on Finance and Economics had received the work report on financial risks and their solutions (People's Daily, 14 Jan. 1999). In February 1997, the Party Centre decided to draft a document and hold a special meeting on preventing financial risks. The first conference jointly convened by the Party Centre and the State Council after the Fifteenth Party Congress was the National Financial Work conference in November 1997.

The specific problems of China's financial system were as follows (People's Daily, 21 Nov.1998; People's Daily, 25 Dec. 1998]. First was the high percentage of non-performing loans. The percentage of non-performing 
loans of the four state-owned commercial banks, that is the Bank of Industry and Commerce, the Bank of Agriculture, the Bank of China and the Bank of Construction, was 24.4 at the end of 1996, and rose to 29.2 by the end of June $1997[\mathrm{Li}, 1998] .{ }^{5}$ Second, there were cases of illegal financial institutions and non-financial institutions engaging in finance. Third, there was too much speculation in the stock market. Fourth, a lack of supervision and personnel management led to financial crimes and misdemeanours or incompetent behaviour, resulting in losses to the financial institutions.

The causes of these problems included the following: the soft-budget constraint of state enterprises had not been reformed and the loans that they had taken out were regarded as fiscal allocations which did not have to be repaid; the financial institutions themselves lacked a sense of risk; the system of supervision and management, including the legal system, was not developed in the financial sector; and local authorities intervened in the activities of the financial department, which, in principle, were under the vertical control that extended from the centre. Such intervention undermined the independence and effectiveness of the People's Bank in implementing financial policies and supervising the financial sector (People's Daily, 21 Dec. 1998).

The financial reformers led by Zhu Rongji attempted to solve these problems by introducing further reform. According to Dai Xianglong, current governor of the People's Bank, the most serious lesson they learnt from the Asian financial crisis was the need for a sound banking system (People's Daily, 17 Jan. 1998). Therefore, three significant reform measures were adopted in 1998. First, in order to standardise the relationship among the government, the bank and the enterprise, a bold reform of the central government was implemented and a number of ministries in charge of production and circulation abolished. A similar reform was to take place in the localities. ${ }^{6}$ Second, with a view to enhancing managers' operational independence and their awareness of profits and losses, the commercial banks were no longer subject to the lending quota defined by the People's Bank, and were to manage their loans using indicators such as the debt/asset ratio. And third, in order to get rid of local intervention and enhance the authority and supervisory independence of the central bank, the provincial-level branches of the People's Bank were abolished and nine regional branches, each covering two to five provinces, were established (People's Daily, 16 Nov. 1998). ${ }^{?}$

Also worth noting was the establishment of the FWC and the Financial Institutions System Party Committees, which aimed to establish a vertical command system extending from the centre to the local branches of the financial institutions. ${ }^{8}$ The FWC, which is stipulated as an agency of the 
Party Central Committee, is not directly engaged in financial work itself. Its terms of reference include: securing the thorough implementation of the policies and instructions of the party and the State Council; appointing and removing, in co-operation with the central organisation department, those cadres in the financial department whose posts are under central management; supervising the leading cadres of the financial department at various levels; and co-ordinating the opinions of party committees in financial institutions and local party committees. The former party groups in the financial institutions were concurrently upgraded to party committees, by which a chain of command was established linking party committees from the FWC at the top to the local branches of each financial institution at the bottom layer of its organisational hierarchy. There would be vertical command in personnel affairs as well. In addition, the party discipline and inspection committee was established on each layer of party committees.

In order fully to understand these measures, we need briefly to review the reforms in the management of personnel. Since 1982, party groups had generally lost the power they previously enjoyed to appoint the cadres of lowerlevel units. It was only the party committees that were able to do so [Editing Committee, 1990: 132]. In 1979, however, the banking sector had been designated as a department whose personnel affairs would be managed under the dual leadership of the bank and the locality but taking the bank as the main institution in charge. ${ }^{9}$ Therefore, the head branches of the banks continued to appoint and remove local bank officials. ${ }^{10}$ This was actually conducted by the party groups of the banks, due to the party's organisational principle that all the personnel affairs were to be managed by the party. There was another twist, though. In reality, the directors of local bank branches came under pressure from the local leaders to extend excess loans in breach of the working principles of the banking sector. The local party committees held the right to discuss the appointment or removal of the branch director with the bank, and controlled other means such as the provision of housing, children's education and other perks of the job. Although officially appointed by the bank, a local branch director was after all a member of the local government. Itn light of this situation, the party centre decided to strengthen central control in the financial departmental system by abolishing the provincial-level branches of the People's Bank, and by upgrading the party groups of all the financial branches to party committees that were subject to the command of the upper-level party organisation."

Thus, the financial centralists who held the upper hand in policy-making heightened the sense of crisis in the face of the Asian financial crisis and the aggravation of China's financial problems. At the same time, they shrewdly took advantage of the crisis and promoted systemic reforms to strengthen 
central control. Significantly, an important method that was adopted by the central leadership to achieve this was the reinforcement and mobilisation of party organisations. That is, while the scale and role of finance, a core element of the market economy, increased substantially, it became obvious that the economic and legal systems to support the orderly functioning of the financial system were lacking. In order swiftly to make up for this defect, there was no better way than to mobilise the party organisations, which were the most effective instrument for maintaining the discipline of localities and financial institutions.

\section{CONCLUSION}

Twenty-odd years after the advent of reform, an authoritative answer has not yet been given to the most important question of what the leadership of the party should look like in a market economy. On the one hand, those who attach great importance to efficiency and to the economy insist that the role of the party should be separated from those of the government and the enterprise, and that the party should concentrate its efforts on the co-ordination of various interests, stand aloof from daily work, preside over the overall situation and strengthen its supervision over government officials and enterprise managers. On the other hand, there are others who believe power and politics to be more important, fear the undermining of party leadership and the socialist system by marketisation, and argue for the maintenance of party leadership over the government and the enterprise as in the days of the planned economy. The Jiang Zemin administration is unable to decide which position to take, since the socialist market economy which they aim to establish is supposedly a system in which party leadership and the market coexist. As is clear from the above analyses, however, there is a growing gap between political and economic principles in practice. We cannot but point out that there is an inherent contradiction in Deng Xiaoping theory.

It is true that the party centre under the auspices of Jiang Zemin took some bold measures in certain areas of ideological contention. A most significant step was virtually to abandon the principle of public ownership, which was a decision made at the Fourth Plenum of the Fifteenth Party Central Committee in September 1999. Then it was determined to the effect that, the so-called basic economic system of socialism, that is the ownership system with public ownership as the main body, could be maintained if and only if the ownership of the key sectors of the economy, such as infrastructure, public utilities, defence industries and leading industries, were dominantly public. ${ }^{12}$ This was tantamount to a significant change in the definition 
of socialism, as public ownership no longer needed to be superior in terms of quantity. Once this decision was made, the next question for the party was to define the political relationship with the rising social force, namely, the owners of the private and privatised enterprises. The answer was the theory of the 'three represents', that is for the party to represent the development of the productive forces, the advancement of progressive culture, and the basic interests of the most wide-ranging people, which proved to be the theoretical foundation of Jiang Zemin's July 2001 declaration to admit the owners of private enterprises into the party [Jiang, 2001: 169-70].

However, neither the abandonment of public ownership nor the admission of capitalists to the party meant that the party was loosening its grip over state and society. The decision of the Fourth Plenum of the Fifteenth Party Central Committee also called for the strengthening of party leadership in enterprise reform and development. One specific measure was for the central and local party committees to reinforce their control over the leading personnel of important enterprises. About two months later in December 1999, the party centre circulated the decision to abolish the Central Large Enterprise Work Committee and newly establish the Central Enterprise Work Committee. ${ }^{13}$ While the former, established in the previous year, had been meant only to administer the leading cadres of the party organisations in the enterprises, the new committee was designated to appoint and remove both the managers and the party cadres. The Central Enterprise Discipline and Inspection Committee was established at the same time. Thus, in its relations with the enterprise, the party expanded its function and organisation in personnel management in the name of revitalisation and discipline in marketisation.

We should not forget that marketisation is also making an impact on another important area of the political system, namely, central-local relations. The tug-of-war between the centre and localities over power and interest was of course taking place regularly under the planned economy. This was intricately related to the relationship between the party and the state. In the days of planning, the strengthening of party leadership vis-à-vis the government meant the strengthening of the power of the local party committee against the vertical departmental system of the government. In accordance with the transition from plan to market, however, there emerged a new combination of central-local and party-state relations. As far as central-local relations were concerned, there was a new pattern of conflict. The tug-of-war was fought between financial centralism on the one hand, which aimed at achieving macroeconomic balances by stronger central control not through planning but through fiscal and monetary policies, and entrepreneurial localism on the other, which placed priority on measures that were advantageous 
to regional development and increased local revenue and employment. Under this situation, the financial system failed to function properly due to the intervention of localism. The central leadership, which was particularly concerned with the impact of the Asian financial crisis on China's frail financial system, established a vertical leadership system in the financial sector through a reinforcement of the party organisation. Therefore, the strengthen-

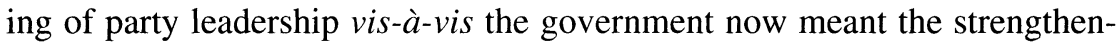
ing of the vertical chain of command of the party committees against the local government.

Vice-premier Wen Jiabao, who was appointed as secretary of the FWC, called this a measure that summed up China's experiences in modernisation and established and perfected her modern financial system (People's Daily, 26 June 1998). The key question was how to enforce discipline among the localities and economic and financial institutions in the transition from plan to market, in which macroeconomic control of the centre was to be implemented not through administrative directives but through indirect means. In addition, the management of personnel, admittedly the most effective leverage for enforcing discipline, is still under the firm control of the party. In the light of this reality, it can be said that establishing a vertical leadership system of the party at the core of a market economy, namely, in the financial system, was in a sense a modern Chinese way of settling the contradiction between socialism and the market economy.

\section{NOTES}

1. Party groups are the party organisations that are established in non-party organs and function as the de facto leadership of those organs.

2. According to Chen this document was drafted under the order of Song Ping, the then director of the department.

3. In percentages, they were 14.2 in 1992, 13.5 in 1993, 12.6 in 1994 and 10.5 in 1995.

4. For instance, only 20 per cent of the funds actually reached the key construction projects of the Ministry of Electricity by June 1993. The projects were to cost 10.2 billion yuan in total. While not a single yuan was provided to the 22 key construction projects of the Ministry of Coal.

5. $\mathrm{Li}$ is a member of the Economics Group of the Central Policy Institute, the think-tank of the Party Centre, and her data should be more reliable than others'. According to Li, the percentage of bad loans in Thailand was 7.9, and that in Indonesia 17, much lower than in China.

6. The original idea was to implement reform in the provincial- and prefectural-level localities in 1999 and in the county- and township-level localities in 2000. As the local officials dragged their feet, however, the reforms at the provincial level were implemented behind schedule in 2000 , and the rest were to be introduced from 2001.

7. The nine new regional branches (and the provinces that they cover) are as follows: Tianjin (Tianjin, Hebei, Shanxi, Inner-Mongolia); Shenyang (Liaoning, Jilin, Heilongjiang); Shanghai (Shanhai, Zhejiang, Fujian); Nanjing (Jiangsu, Anhui); Jinan (Shandong, Henan); Wuhan (Jiangxi, Hubei, Hunan); Guangzhou (Guangdong, Guangxi, Hainan); Chengdu (Sichuan, Guizhou, Yunnan, Tibet); Xian (Shaanxi, Gansu, Qinghai, Ningxia, Xinjiang). The Department 
of Business Management and the Department of Chongqing Business Management of the headquarters are in charge of Beijing and Chongqing, respectively.

8. 'The CCPCC Circular on Questions Related to Perfecting the Party Leadership System and Reinforcing and Improving the Party Work in the Financial Department', 19 May 1998, collected in Legal Office of the General Office of the Party Centre et al. [2001: 11-21].

9. 'The State Council Document Approving and Transferring the Summary of the People's Bank of China National Meeting of Branch Directors', State Council Document No.99, 1979, collected in Personnel Bureau of the People's Bank of China [1985: 1-8].

10. In the initial period of reforms, the director of the provincial-level branch was appointed and removed by the party centre, and the head branch appointed and removed the deputy directors and the division chiefs (chuzhang, in Chinese) of the provincial-level branch. Then, along with the decentralisation of personnel affairs in 1984, the power to appoint and remove the division chiefs was handed down to the provincial-level branches.

11. This did not mean, however, that the localities totally lost their say in the appointment and removal of the bank officials. In appointing the leading cadres of the nine regional branches of the People's Bank and those of the provincial-level branches of other financial institutions, the opinions of the local party committees at the branch sites had to be sought. Moreover, the FWC was to act as an intermediary if the local party committee did not agree with the views of the party committees of the financial institutions.

12. 'The CCPCC Decision on Some Important Questions Regarding the Reform and Development of State Owned Enterprises', passed at the fourth plenum of the fifteenth CCPCC, collected in Legal Office of the General Office of the Party Centre et al. [2001: 46-63].

13. 'The CCPCC Circular on Establishing the CCPCC Enterprise Work Committee and Related Questions', collected in Legal Office of the General Office of the Party Centre et al. [2001: 122-5].

\section{REFERENCES}

Bowles, Paul, and White, Gordon, 1993, The Political Economy of China's Financial Reforms: Finance in Late Development, Boulder, CO: Westview Press

Central Committee for Organisation and Staff (ed.), 1993, The Great Trend of Administrative Reform in China (in Chinese), Beijing: Economic Science Publishers.

Chen, Y., 1990, China: Ten Years of Reform and the Democracy Movement in 1989 (in Chinese) Taipei: Lian Jing Publishers.

Chinese Communist Party Central Documents Institute (ed..), 1982, Selected Important Documents since the Third Plenum (in Chinese), Beijing: People's Publishers.

Deng, X., 1993, Selected Works of Deng Xiaoping, Vol. Three (in Chinese), Beijing: People's Publishers.

Editing Committee, 1990, Practical Handbook of Party Work (in Chinese), Beijing: Economic Management Publishers.

Hill, R.J., 1984, Political Reforms in the Soviet Union (translated into Japanese) Tokyo: Sekai Shisoh-sha.

Jiang, Z., 2001, On 'Three Represents' (in Chinese), Beijing: Central Documents Publishers.

Legal Office of the General Office of the Party Centre et al. (eds.), Selection of Intra-Party Regulations of the Chinese Communist Party (1996-2000) (in Chinese), Beijing: Legal Publishers.

Li, X., 1998, 'To Look at the Hidden Financial Danger in Our Country from the East Asian Financial Crisis' (in Chinese), Reform, No.3, 31-9, 86.

Liao, G., et al (eds.), 1991, The Encyclopedia of Modern Chinese Politics (in Chinese), Changchun, Jilin province: Jilin Wenshi Publishers. 
Ling, Z., 1998, Ups and Downs: A Memorandum Book of China's Economic Reform (in Chinese), Shanghai: Eastern Publication Centre.

Personnel Bureau of the People's Bank of China (ed.), 1985, Collection of Documents on Personnel Work (Part on Cadre Management) (in Chinese), Beijing: China Finance Publishers.

Takahara, A., 1997, 'The Development of Central-Local Relations and the Sense of Crisis Among the Chinese' (in Japanese) in S. Amako (ed.), Is China a Threat?, Tokyo: Keisoh Shoboh, pp.198-219.

Tang, L., 1997, Party-State Relationship in Modern China (in Japanese), Tokyo: Keio University Press.

White, G., Howell, J. and Shang, X., 1996, In Search of Civil Society: Market Reform and Social Change in Contemporary China, Oxford: Clarendon Press.

Wu, J., 1992, Planned Economy or Market Economy (in Chinese), Beijing: China Economic Publishers.

Zhao, H., 1998, China's Multilayered Centralised Regime and Economic Development (in Japanese), Tokyo: University of Tokyo Press.

Zheng, L. (ed.), 1994, Analyses of Macroeconomic Policies, 1993-94 (in Chinese), Beijing: China Planning Publishers. 


\title{
Treasuring the Word: Mao, Depoliticisation and the Material Present
}

\author{
ROBERT BENEWICK and \\ STEPHANIE HEMELRYK DONALD
}

'Whatever accords with Mao Zedong thought is right, while whatever does not accord with Mao Zedong thought is wrong' -

Zhou Enlai, Letter to Capital University Red Guard Revolutionary Rebels, 27 Sept. 1966; Schoenhals [1996: 27].

The Quotations of Chairman Mao Zedong, the Little Red Book, has endured as one of the infamous images of the Great Proletarian Cultural Revolution. The Little Red Book has generally been portrayed, particularly in the western media, as a collection of slogans to be learned by rote, recited, shouted, and used to test and intimidate those categorised as the 'nine bad elements'.' As a material object, it was a book to be waved, thrusted upon and used as a centre piece in demonstrations, and in visual culture. This is to a degree an accurate portrayal, and the Little Red Book takes up formal and representational space in the traces of the times. It is visible, blatantly so, in posters, badges, photographs and even alarm clocks. To leave it there, however, is to play the easy game of describing revolutionary cultural objects as propagandistic, with all the assumptions of 'bad' art and 'bad' literature that the term carries. It is to miss the significance of the Little Red Book as an icon of power, with its own aesthetic force within revolutionary visual politics. In order to understand the nature of Mao's power and continuing effect, one needs also to understand the penetration of popular communications through politics and society. The Little Red Book was the narrative and visual instrument of the largest experiment in the politicisation of society ever undertaken.

In this contribution we argue that the iconisation of Mao Zedong thought was fundamental to the development of a revolutionary political culture. We derive this argument from an examination of three related themes: its material manifestation as packaged in the Little Red Book; the visual repre- 
sentation of the Little Red Book as an icon of political activism in posters and related visual cultural and material objects [Evans and Donald, 1999: 1-6; Gittings, 1999: 32]; and the parallels between the Maoist politicisation of society and the personalisation of power and the depoliticisation of society and depersonalisation of power under the leadership of Deng Xiaoping and Jiang Zemin. ${ }^{2}$ We suggest finally that the depoliticisation of China has involved the strategic reinvention of Mao in popular memory. The story of Mao, and therefore the lasting significance of the Little Red Book, may be understood to be a travelling site of national memory in China's thrust towards global economic power.

\section{POWER, CULTURE AND ICONOGRAPHY}

The personalisation of power through the promotion of the cult of Mao Zedong during the Cultural Revolution is well documented. Less well known, but no less important, is the cult of Mao Zedong Thought, which predated the Cultural Revolution and which contributed to the development of a revolutionary political culture and to the politicisation of Chinese society. The personalisation of power and the politicisation of society were intimately connected. Mao Zedong Thought contributed to the promotion of the cult of Mao Zedong's personality and the writings would not have acquired their authority and cult status independent of Mao's power.

First, the view that informs the approach in this paper to China's development of a revolutionary political culture derives from the nature of power and rests on the notion of tacit approval [Lukes, 1974; Teiwes and Sun, 1996]. That is, those exercising power with or on behalf of Chairman Mao did so in accordance with and knowledge of his authority. The responsibility and motivation for the promotion of the cult of personality and the campaigns to politicise society have been the subjects of considerable debate focusing on the career of Lin Biao. One interpretation which accords to the official view emphasises Lin Biao's ambition for personal power, consolidating his power as Mao's designated successor in 1969, and ultimately his alleged attempt to assassinate Mao two years later [Fu, 1993; Gray, 1990: 340]. The second version characterises Lin Biao as a weaker figure, something of a cipher caught up in the exigencies of the political system, political culture, the authority of Mao and the pressures from his own family [Jin, 1999; Teiwes and Sun, 1996].

This debate is important in so far as it charts the ways in which power is maintained through the ambition of others. Mao's hegemonic rule meant that it is unthinkable that those acting in Mao's name would risk his disapproval. 
Mao did not have to participate in formal decision-making for his exceptional power and presence to be felt. Much has been made, for example, of his absence from Beijing in the early months of 1966, but this speculation does not take into account the depth of power evinced by personal absence in an environment saturated by one's representational and textual presence. Thus, even if one follows the argument that much of the early impetus for the canonisation of the Selected Works (Mao Zedong Xuanji), and their dissemination in the format of the Quotations (Mao Zhuxi yulu) was due to Lin Biao's ambition, it is difficult to disavow the common observation that partly through this very dissemination - Mao became the metonym for revolutionary China in this period. The lasting aspects of revolutionary consolidation before Liberation are also a factor in assessing Mao's influence. Apter and Saich have argued that Mao built his prominence through 'exegetical bonding' during the Yan'an period [Apter and Saich, 1994]. The apparent ease of his transition to post-revolutionary eminence in popular lore and folk religion [Xin Yuan, 1996: 195-8], and even the ironic/nostalgic backlash in popular art [Barmé, 1996: 46-8] underlines the depth of his effect and affect as a political leader. Nevertheless, reading the publications of the period, it is possible to draw the conclusion that Lin Biao was trying to be in charge, ascribing the successes of daily politics to the huge insistence of Mao's words, face and body in the revolutionary imagination.

Whatever narrative one espouses in the debate, contemporary and period images tell a story of Maoist saturation that transcends the presence of Maoas-leader whilst insisting on his centrality in the meaning of political culture of the nation and the meaning of the nation in revolution.

Second, it is crucial to be clear on the conceptualisation of revolutionary culture. Blecher warns against the pitfalls of the use of political culture in relation to China [Blecher, 1997: 208-13; He Baoyang, 1992: 92-113]. These include implicit ethnocentrism and stereotyping; the presence of contradictory values and multiple cultures; and the need to take account of how politics shapes culture as well as how culture shapes politics. These considerations are not unique to the Chinese case, but span the spectrum of political systems from totalitarian to democratic. We would add to his impressive list the warning not to confuse political ideologies and/or political styles with political culture, that a political culture is not self-contained or inclusive but draws upon beliefs and values from other and preceding cultures and most of all that political cultures are not static, and like constitutionalism and civil society, are developmental in character.

In the terms of Cultural Studies, one would argue that revolutionary culture is made up of residual and emergent practices, beliefs and material manifestations. It is fluid and susceptible not merely to ideological input, but 
also to the shifts in subjective relationships to the Revolution. Time, space and generation will take their part in the constant formation and reformation of revolutionary culture as of any other. To this extent, the notion of continuing revolution is a political concept that emerges quite legitimately within the sustaining experience of cultural change, but which is ultimately thwarted by attempting to determine the nature of culture itself. The manifestation which describes this in China is the uses and meanings of the colour red, a colour which makes the journey from tradition to revolution to national Liberation and then to tradition within modernity [Lary, 1998: 307-19]. It does so by retaining a residue of its traditional significance, whilst responding to emerging and established cultural norms. Redness 'survives' Communism, just as Mao has seemed to do, by working within culture as well as serving ideological requirements.

The Cultural Revolution is only one period, albeit the most intense, in Mao's attempt to develop a revolutionary political culture. Moreover, although it is possible to identify a shift in emphasis during the Cultural Revolution from the Paris Commune model toward the Leninist conception of the dictatorship of the proletariat, this may have as much to do with the absence of a coherent theory of the cultural revolution as with a developmental dynamic.

As Blecher explains, however, the recognition of the limitations to the political culture approach is not an argument for abandoning its use but for appreciating its complexities. This applies to a revolutionary political culture as well, where decisions, policies, programmes and campaigns are justified in the name of revolution. Wasserstrom offers a comprehensive approach for the development of revolutionary political culture involving 'all of the decisions, values, and implicit rules that express and shape collective action and intentions, determine the claims groups may (or may not) make upon one another, and ultimately provide the logic of a revolutionary action' [Wasserstrom, 1991: 10-11; Wasserstrom and Perry, 1994]. In the case of China the Maoist attempt to found and develop a revolutionary political culture was based on class struggle and predated the Cultural Revolution, which was its apotheosis. The challenge for the Dengist reformers and their successors has been to create or restore a political culture compatible with the development of a market-orientated economy that in turn would shape a political culture.

Thirdly, political iconography was an important vehicle for transmitting political power and a revolutionary political culture particularly during the Cultural Revolution. Writing about posters is no easy matter, since they are about the projection of political power and yet must appeal to the intended audience [Evans and Donald, 1999: 8-9]. The nature of political power and 
the political culture will influence the appeal. The same holds true, perhaps even more so, for the Little Red Book. Originally published in 1964 under the direction of Lin Biao, then Minister of Defence, for consumption within the People's Liberation Army (PLA) the Little Red Book encapsulated both the cult of Mao's personality and the politicisation of society accessing the population, sometimes violently, to a revolutionary political culture. Before its publication the PLA had been a testing and training ground for the assimilation of Mao Zedong thought - the creation and institutionalisation of a revolutionary political culture in miniature. Now it was to lead the campaign for dissemination among the masses [Landsberger, 1998: 28].

\section{THE LITTLE RED BOOK AS VISUAL NARRATIVE}

Mao's writings were legitimated as 'Marxism-Leninism, Mao Zedong thought'. As 'thought' it is of a lower rank than Marxism-Leninism, but, in turn, as the official ideology it legitimated the regime and the Communist Party's monopoly of power and provided the framework for the decisions and actions of the political leadership [G. White, 1993: 147-66]. The political leaders and Mao in particular had the further ambition of promoting his personal power and stamping his world view based on class struggle upon the population.

Mao Zedong Thought served other purposes too. It was employed in the factional struggle between the Maoists and the party-state. Each faction could feed upon the scriptures whether imbibing revolutionary inspiration or advocating practical caution. The Little Red Book like the posters was also meant for discussion [Gray, 1990: 360] and, like Mao Zedong badges was an icon of power carried or clutched in the hands of millions of people. Above all, as Lin Biao wrote in the Foreword to the second edition of the Little Red Book, 'the large-scale publication ... is a vital measure for enabling the broad masses to grasp Mao Zedong thought and for promoting the revolutionisation of people's thinking' [Lin, 1966: Foreword]. As such it was the progenitor of a revolutionary language setting the tone, scope and, vitally, the limits of public discourse.

The Little Red Book as the distillation of Mao Zedong thought, or more specifically the contents of the four volumes of the Selected Works, became a chosen instrument for the politicisation of Chinese society. The sheer scale of production dominated public discourse and invaded private space. Estimates of the number of copies printed range as high as ten billion, (quoted in Barmé [1996: 207]). This was saturation coverage and not inappropriate for a largely illiterate population. And for the literate 150 
million sets of the Selected Works of Mao Zedong and 140 million sets of the Selected Readings of Mao Zedong were issued between 1 January 1966 and 30 November 1968, the high tide of the Cultural Revolution [Lynch, 1999: 25]. In addition, quotations and exhortations from the Chairman appeared daily in the press, were issued as posters, occupied public space ranging from billboards to matchbox covers and were even printed or hand-stamped on letterheads, envelopes, bills and receipts. ${ }^{3}$ Extracts drawn from the Little Red Book were printed as a series of ten stamps in 1968 including the opening sentences 'The force at the core leading our cause forward is the Chinese Communist Party. The theoretical basis guiding our thinking is MarxismLeninism' (opening address at the First Session of the First National People's Congress of the People's Republic of China, 15 Sept.1954). ${ }^{4}$

First, and perhaps so obvious as to be axiomatic, the presence of Mao as an image on posters, postcards, badges and large public portraits was a powerful method of monopolising of public space, dominating domestic quarters and even 'landscaping the body' itself [Benewick and Donald, 1996: 38]. Second, Mao's image did not work alone. It was tied to well-worn icons of nationhood and local effect: that is, children; Tiananmen; the noble trinity of worker, peasant, soldier;', the colour red and the hatred of foreign intervention in Chinese affairs and history. These in turn may also feature an icon of Mao Zedong Thought, and its developing material presence in the hands of ordinary Chinese citizens. For example, a children's painting shows several young children holding copies of the Selected Works, and a quotation is chalked up on the blackboard around which they cluster: 'The world is yours, as well as ours, but in the last analysis it's yours. You young people, full of vigour and vitality, are in the bloom of life, like the sun at eight or nine in the morning. Our hope is placed in you.' Here, the sentiment of the generational handover is vested in the children, who are in turn linked back to Mao by their study of his works. Their status as the next generation of revolutionary successors (hongse houdai) is reaffirmed by his saying so, and his right to say so is confirmed by the presence of a traditional icon of hope and prosperity, children themselves. Again the emergent culture is vested in the currency of the present and through the residue of older cultural certainties.

Both the colour and size of the Little Red Book were deliberate. Red was the colour of revolution and internationalism but it also promoted visibility and signified Mao as 'the red sun in the hearts of the Chinese people'. In, perhaps, the best of the memoirs of those who played a part as Red Guards in the Cultural Revolution, Rae Yang recalls that 'China was engulfed in a turbulent red storm':

Everybody was a Red Guard, a little Red Soldier, or a Red Rebel. Chairman Mao was our red commander in chief. We called ourselves 'his little red devils'. We read 
and quoted his little red book. Wore his red buttons on our chests. Red flags. Red armbands. Red blood. Red hearts... We could not tolerate anyone who was of a different color. Peach was guilty. Yellow was criminal. Black and white were definitely counterrevolutionary [R.Yang, 1997: 230$].{ }^{6}$

Its size encouraged portability, fitting neatly into the pocket of a uniform or 'Mao jacket'. Once again Yang offers a vivid description: 'When we went out ... we always put on the complete outfit of a Red Guard; army uniform with long sleeves and long pants, caps on our heads, belts around waists, armbands, army sneakers, canvas bags, and little red books [our italics]' $[R$. Yang, 1997: 135]. The Little Red Book, like the Mao badge then, was a mark of identification and loyalty, but one that could be brandished, the quotations shouted or even sung (365 were set to music) [Barmé, 1996: 191, n10] as the situation demanded. As a mark of loyalty it was used by the Red guards to test, harass and victimise those labelled 'capitalist roaders'. There were also reports that it acted as a talisman, protecting the carrier, working miracles [Short, 1999: 550] and bestowing upon the Red Guards a myth of invincibility in their orgy of destruction against the 'four olds' (old ideas, old culture, old customs and old habits). Perhaps, most of all, the quotations could be carried to the endless compulsory study sessions or opened and read whenever and wherever convenient. China Pictorial, published in 15 language editions in addition to Chinese, heralded the message. Photographs of study sessions being held in work places, fields, schools and on marches and workers, peasants, soldiers, children, minority nationalities engaged in deep contemplation were prominently featured. For example, the caption to a photograph of a study session at the Dazhai Model Production Brigade reads: 'there are many factors contributing to the tremendous changes in Dazhai, but the basic one is studying Chairman Mao's writings, following his teachings and acting according to his instructions' (China Pictorial, 1968, XVIII, pp.1, 26).

As for the contents, the Little Red Book was in essence a political reaffirmation and rallying call for the development and application of the 'mass line' (see Chapter XI) [Schram, 1969: 315-17; Gray, 1990: 359-62]. This was the process whereby the Communist Party would learn from the masses and translate their ideas into action under its leadership. The Little Red Book had the quality of a handbook divided into thirty three chapters covering the Communist Party, classes and class struggle, democracy as well as the mass line; imperialism, patriotism and internationalism; self-reliance, self-cultivation and self-criticism; women and young people, culture, art and, in particular, the PLA. The entries were drawn from Mao's speeches, reports and writings prior to the Cultural Revolution. Some were simply epigrams extracted from longer passages such as 'Political [our emphasis] power 
grows out of the barrel of a gun', or the equally famous 'A revolution is not a dinner party ...', which in full reads 'A revolution is not a dinner party, or writing an essay, or painting a picture, or doing embroidery; it cannot be so refined, so leisurely, restrained and magnanimous. A revolution is an insurrection, an act of violence by which one class overthrows another.' The passage in turn is an extract from Mao's Report on an Investigation of the Peasant Movement in Hunan (March 1927). Other inclusions were substantial in length and substance, difficult to absorb, and belie sloganeering. They might appear in more than one chapter as deemed appropriate. These included extracts from 'On Practice', 'On Contradiction', 'Talks at the Yan'an Forum on Literature and Art', as well as extracts and an entire chapter devoted to 'On the Correct Handling of Contradictions Among the People'. Mao's version of the fable, 'The Foolish Old Man who Removed the Mountains', a metaphor to conquer imperialism and feudalism, appears in full.

The Little Red Book, then, was not only slogans and mantras as often characterised. ${ }^{7}$ The method drew upon precedents in Chinese history of learning through memorisation by recitation, for example, of Confucius' Sayings, a method, that is still prominent in Chinese pedagogy. Lin Biao, in his introduction to the Quotations, instructed units to select the passages for study and application 'that are relevant to the situation, their tasks, the current thinking of their personnel, and the state of their work' [Lin, 1966: Foreword]. In sum, the Little Red Book was a distillation, and the main vehicle for the propagation, of Mao Zedong thought or the official ideology, and provided the acceptable and conceptual vocabulary for public discourse and perhaps for private contemplation.

The Little Red Book, however, was not the exclusive text for the distillation and propagation of Mao's writings and thoughts. Its contents drawn from Mao's speeches and writings prior to the Cultural Revolution were known as 'the Highest Directives' while his pronouncements during the Cultural Revolution were known as 'the Newest Directives'[M.M. Yang, 1994: 252]. For example, what appear to be bespoke quotations were published in the People's Daily from 1967. This set a political style that persists in the post-Maoist era as evidenced by the release of 50 aphorisms by the Communist Party for the celebrations of the fiftieth anniversary of the founding of the PRC. Some are cobbled together from Mao's writings and the Little Red Book, such as 'Adhere to the goal of serving the people and socialism, to the policy of letting a hundred flowers blossom and a hundred schools of thought contend and promote socialist science, literature and art', while others are of more recent vintage like 'Warmly hail the great success in China's reform and opening up and socialist modernisation drive' (New York Times, 19 Sept. 1999). 
The reach of Mao's image-power was also supported by blanket press coverage of his sayings, new political objectives, and films. It was noted that in October 1966 the sayings of Mao replaced the contents list and weather forecast on the front page of some national news-sheets (China News Analysis, 21 Oct. 1966, No.631). The relationship between image and power was not a simple matter of juxtaposition, however. Knowledge of Mao's Thoughts was tied to the claim to redness (hongse), then under scrutiny and re-evaluation as part of a continuing revolutionary ethic. In May 1963 the film Red Sun (Hong Ri) was shown at the prize festival run by the Film of the Masses journal. It won a citation at the same venue in 1964. It was described as 'an excellent picture, and it shows the victory, in the midst of complex events, of the military thoughts of Chairman Mao, and the wickedness of the enemy who, while carrying on a war, spoke of peace' (Film of the Masses, Shanghai, 12, 1963, p.22). By May 1966 the film had been reappraised by the Liberation Army press and found seriously wanting. The mood against the film was picked up by major newspapers who produced new reviews:

Red Sun is a thoroughly wicked film ... the retreat was justified because, when the enemy are strong, according to the military thoughts of Mao Zedong, one should let them penetrate into the liberated areas and then wait for a propitious moment to attack. But in this picture military thought is not shown, only our army beaten by the enemy and retreating before them ... in the film even military commanders ... do not show any sign of understanding the Thoughts of the Chairman' ( $D a$ gong bao, 14 May 1966).

These conflicting reviews reveal the practice of re-evaluation built into a state media control system. They also highlight the degree to which demonstrating a knowledge of the Chairman's Thought had become crucial. A narrative adventure film is criticised for showing action without the theoretical context from which strategy may have been planned. The second writer is careful not to criticise the historical events in themselves, which could be taken as a critique of past military leadership and ultimately of Mao himself. S/he does however voice an expectation that the Thought is explicit in the surface and dialogue of the screen text, and not assumed within the events of history and the collective knowledge of the audience. This expectation is strategic and symptomatic of the deepening politicisation of society and culture at this period. It is no longer enough to know what might have been the motivations for a military decision, or even to assume appropriate political training in legendary military commanders. By 1966 it is imperative to show the process of political thinking, and to attribute it directly to the words and materiality Mao's thought. The debate around the film places these images into sharper focus. The representation of the material object, whether it be 
the Selected Works, the Quotations or a specific publication is now a necessary part of the political sphere in cultural public space.

This brings us to one more observation in regard to the strategies of politicisation. These works are intense. They are intense numerically, in terms of print runs and distribution, and of themselves. Each image is suffused with redness. From one perspective this allows very little room for ideological interpretative manoeuvre. From another this is a strategy of cultural inclusivity that interpolates Chinese popular memory into an emotional acknowledgement of the colour as both contemporary and traditional. The layering of textual, iconic and historiographical data is a mechanism of intensification that structures each image through political intention. For example, in a poster captioned 'The People of China cannot be Humiliated: We must win! Hong Kong English must lose!' the call to arms in Hong Kong is unreserved. Young people in westernised, but not decadent, clothes march abreast within the frame. They all carry Little Red Books. The slogan is printed within the image as though it were painted on a wall. Any space not taken up by rebellious Hong Kong youth is taken by their banners:

The Chinese (nation / people) must not be humiliated! Imperialism and all reactionaries are paper tigers! Be Resolute! Do Not be Afraid of Sacrifice! Eliminate Impossibility! Go to battle and take Victory!

The urgency in these slogans, coupled with the energy of the event described, the lack of un-peopled or un-inscribed pictorial space, as well as the style of writing in the main caption, encodes intensity into the image. Describing the strategies of intensity might therefore provide a way into measuring the politicisation of visual culture.

The development of a revolutionary political culture was being promoted through two related campaigns: the cult of Mao Zedong's personality and the cult of Mao Zedong thought. These in turn involved the personalisation of power and the politicisation of society. Jonathan Spence cites an announcement from the Beijing Number 26 Middle School Red Guards dated August 1966 which sets out such a programme including the renaming of their School, 'The Maoism School': every street would display a quotation from Chairman Mao and loudspeakers would broadcast them. Every bookstore would stock the Little Red Book and every person would possess a copy. Mao's portrait would dominate both public and private space. Dress and behaviour would be strictly regulated. Housing and medical care would be reformed. The 'nine bad elements' would be required to wear identification. Children would criticise their elders and students their teachers. Study would be combined with productive labour [Spence, 1999: 179-80]. Similar documentation is abundantly clear in its intentions and inspiration: 
People are talking about the violent changes in nature'. Let us look forward to the future. Our educational position must be a new type, of the great school of Mao Zedong's thought, and a good classroom for training successors to our proletarian revolutionary cause.

Amid the clarion songs of triumph, the great red banner of Mao Zedong's thought will forever flutter high on the position of education!

\section{The Jinggangshan Fighting Corps of Beijing Normal University for Smashing the Collective Boarding Schools of Children of Cadres, and Liaison Center for Smashing the Collective Boarding Schools of Children of Cadres.}

[Benton and Hunter, 1995: 120].

The programme, if totally successful, may well have created a revolutionary political culture. Certainly the icons of Mao and Maoist power were ubiquitous. The mind-set that led to drafting the programme would be even more revealing.

\section{THE POLITICS OF DEPOLITICISATION}

This Mao image in Chinese political discourse operated as a mark of the correct and the possible in a highly controlled media system. It is also possible to hypothesise on the ways in which the strategies of saturation have contributed to the post-Maoist political culture. The story of the Mao cult is a story of accumulated material-cultural meaning [Donald, 2000: 1-2] and national emotional investment. Its sequel can be thought through in terms of collective memory and the activation of hindsight in the form of nostalgia. The sequel is thus dependent on the original passionate narrative, and also on its present context. The sequel is the brainchild of popular memory, working to retrieve the emotional investment of an earlier time by removing trauma from the cultural materiality of history. Contributory factors in the creation of such a self-conscious collective memory might be the perception of loss in the national psyche. The speed of modernisation is observed as both welcome and horrific. Residual culture is hard to recognise in the rush of the new.

As Dai and Russo have observed with different emphases [Dai, 1999: 42-8; Russo, 2000] ${ }^{8}$ class is a disappearing act in political and intellectual discourse in China as the Communist Party struggles to re-invent itself. It is just one of the structural casualties of the immediate past and of the re-made present. As Pierre Nora has argued for France, the sense of 'the acceleration of [national] history' can produce ' a general perception that anything and 
everything may disappear', a crisis of memory and history focused on 'les lieux de mémoire' [Nora, 1989: 7]. Mao appears as a lieu de mémoire in contemporary China. In some senses he does not fit with the speed and direction of history. Yet he is an undeniable element of collective memory and national consciousness. He intrudes upon the contemporary and is co-opted as a continuum of history and national self-consciousness.

There are, then, several starting points for analysing the extent to which images of Mao have passed through revolutionary time into the present versions of Chinese state capitalism. Mao's transition from political icon to deity has been noticed by professional anthropologists and tourists alike. He may be visited in his Mausoleum, or spotted as a statue in a rural temple. He may be sold as geegaw, in the form of a taxi amulet or fob watch, but then transmogrified by the belief of the wearer in his power to safeguard against danger, perhaps even against the future? He has entered into a material world of souvenirs and kitsch commodity, which arguably bears traces of both political nostalgia, and a modern resurgence of religion in the face of political disillusionment. The meaning of Mao is extremely mobile, and subject to the requirements of individualistic consumption - and all the ironies of history that thought brings with it. It is also, however, hostage to the whims and requirements of collective memory. Mao is symbolic of a large proportion of communist time. His association with the Party goes back to its inception in 1921 , and his manipulation of party history has configured his name as central to its policy shifts and military achievements. The vexing question of his 'fault' in the occurrences between 1966 and 1974 has been largely shifted to others, whilst he has himself shifted to a quasi-religious status. This shift reiterates the mobility of his image, a facility at disappearance and consolidation noted in early 1966.

So, what kinds of spaces does Mao occupy in the 1990s and 2000s? Mao is a religious icon in so far as he is 'used' in temple worship. He is a consumable icon, both in (domestic and international) tourist paraphernalia and in the collectable 'junk' found at retro markets. He also occupies residual state space in his continuing portraiture in Tiananmen, his Mausoleum and Remembrance Hall. However, his writings are not nearly as prominent in public or national space as during the red tide of the 1960s. These occupations of residual space might on the one hand be understood as a retreat (as per the tactics used in Red Sun!), or on the other as a cultural re-deployment of political meaning. Mao's image is now operating in the consumer sphere, and in the religious arena. His saturation has levelled out to a standard feature of Chinese daily life. As such he will always be recognised - at least by the older generations, but it will be a routine acknowledgement of the multiple connotations of his image rather than an intense experience of great 
political proportions. Nevertheless, his presence in the religious sphere coupled with his smooth shift into the popular discourse of the market place indicates that the condensing of the Mao cult does not preclude political renewal for this endlessly dispersed and reconstituted memory.

Mao is deified, reified and quotidian. His astonishing mobility in the practices of modern China is due not simply to an enduring legacy of cultural saturation - but also to a strategy of depoliticisation that allows formations of collective memory to contain Mao as an adhesive force around which the present may be configured. Perhaps in Jiang Zemin - the ordinary and unprepossessing - we see a political analyst who understands political culture. Power is not available to him on the symbolic level because of the effect and affect of the Mao saturation in the 1960s and 1970s. It is far wiser to operate on the level of economic goals, and pragmatic policy - at least until the intensity of affect has worn off or been thoroughly supplanted by the commercial effects of the market.

As Dai Jinhua argues in her work on guangchang, the consumption of political icons in an era of depoliticisation is both destructive and constructive [Dai, 1999: 36] She uses the changing signification of guangchang from political space to shopping mall as an example of the trivialisation, or even vulgarisation, of the past. The (advertising) space between now and then is a shared space not a combative one. The commercial effects of the market are to a degree dependent on the selective, collective memory of the immediate past. It is a carefully measured sell out [Dai, 1999: 40] One could extrapolate that the mobility of Mao as an icon of daily consumption has likewise shifted from the political centre to the market-place. It is useful, however, to retain some analytical respect for those residual traces which are thus carried into the contemporary. Is the trivialisation of Mao also a sacralisation of commercial modernity and the new-found popular access to its apparently apolitical pleasures? If, to cite a very trivial instance, tiny statues of both Mao and the Buddha are enclosed in identical plastic paperweights, purchased in Beijing and Brighton UK respectively, must this common commercial materiality attest to the mutual denigration of the two icons, or solely to that? Might we also reserve some room in analysis for a valorisation of affordable culture and of the small souvenirs of popular memory and beliefs? As we have seen, if political culture is to be an analytically useful concept we must take stock of its dynamic and complexities in the cultural marketplace. The rapid pace of politicisation was matched by the equally rapid pace of depoliticisation during the post-Maoist reform period since 1978. It follows that depoliticisation calls into question, if not the scope of politicisation of the Cultural Revolution, then at least its singular nature and certainly its depth. In this sense politicisation takes on the mantle of political 
theatre and reminds us that despite economic and political chaos the state continued to function [Benewick, 1999: 17-22; Esherick and Wasserstrom, 1994: 32-70]. Secondly, the depoliticisation of society that involved devaluing, if not replacing, the cult of Mao Zedong thought and the depersonalisation of power that involved dismantling the cult of Mao's personality were pragmatic political decisions more than an attempt to create a new revolutionary political culture. They were part of the strategy of reform associated with the development of a market-oriented economy. ${ }^{9}$

Thirdly, political cultures are not discrete entities. They interact with and build upon the organisation of society. For example, Mao's cult connected to the feudal Bao-Jia system which binds households into units of collective responsibility and control, what Jan Wong has described as a 'culture of snitching' [Wong, 1996: 272]. Moreover, the dates assigned to the Cultural Revolution are political and to some degree arbitrary having more to do with institutionalising the legitimacy of Mao's successors than locating the course of history. Drawing the boundaries of a revolutionary political culture can be even more complex. Although one of the intentions was to destroy the 'four olds', traditional symbols were employed in the iconisation of power, or failure. This was not simply a highly selective and instrumental approach to what is meant to be signified. For, as Michael Dutton has noted, 'the relationship between the revolutionary and the traditional is always flexible for the revolutionary goal always stresses the profitable use-value of the traditional in the service of the political and economic struggle' [Dutton, 1998: 168].

Fourthly, there is the relationship between boundaries and its constituent parts. If the boundaries of a revolutionary political culture are stretched to cover the entire Maoist period, what were its defining characteristics and what distinguished the Cultural Revolution? Can it be described as developmental? Was the iconisation that featured during the Cultural Revolution merely a measure of intensity. Stated differently, how revolutionary was the iconisation of power? When these icons were commodified or translated into objects of fashion or nostalgia or satire, it would seem that their points of reference were still the Cultural Revolution or the Maoist revolutionary political culture, but only to the extent that they helped the nation deal with the psychic implications of the consumer revolution of the Dengist period of depoliticisation and depersonalisation of power.

\section{MATERIAL MEMORY}

However untidy the conceptualisation of a revolutionary political culture, an attempt at systematic comparison can provide a better understanding of 
China in the post-Maoist era of reform. The Maoist period, the Cultural Revolution, and the Dengist reform period are marked by the attempts of their leaders to introduce far-reaching changes. The Maoist changes were inspired and justified in the name of revolution. Class struggle was meant to be the motor of the campaigns against the legacies of feudalism and imperialism [Mao, 1966: 201-2]. Marxist-Leninism legitimated Mao Zedong thought for the elite while Mao Zedong thought, in turn, legitimated their rule. The Cultural Revolution was a massive and violent campaign to 'cleanse' the past and to involve the population, particularly the young, not just through education or indoctrination but also through participation. Iconisation of the cults of Mao Zedong's personality and of Mao Zedong thought were principal features of the campaign.

The Dengist project of the reformers and their successors had a twofold task: to bury the revolutionary political culture and instil a political culture attuned to a market-orientated economy. The absence of a body of legitimating beliefs and values has meant that the reformers have had to rely more on delivering results to legitimate their rule. Mao Zedong thought has been discredited in the immediacy of personal memory, whereas his cultic appeal to collective memory is a sop to history but not to contemporary policies. However remarkable the economic progress, the enormousness of the task exceeds that of politicising society which had functioned as a means of control. A cultural vacuum in these circumstances is not unexpected but is also problematic as manifested in the recent rise of semi-mystical movements such as the Fulan Gong.

The centrality of the Communist Party must also feature in a comparison of the two periods. China is still a Leninist party-state, with or without Chinese characteristics, but during the Cultural Revolution it was a target for factional strife, struggles for power, and for a fierce challenge to its dominance [L. White III, 1989; Yan and Gao, 1996; Zheng, 1997]. The introduction of a market oriented economy was, in part, perceived by the reformers as a move to revive and invigorate Party dominance. At the same time the development of a market-orientated economy challenges the Leninist partystate by further undermining the political culture, ushering in new centres of potential political power [White, Howell and Shang, 1996] and raising popular expectations. The rapidity of the reforms, initially in the countryside, weakened Party organisation. Steps have been taken to restore Party hegemony [Benewick, Howell and Tong, 2001] through a campaign to give 'social stability' equal billing with market reforms. It is, however, equal billing with a difference as expressed in the numerous variations of the slogan 'promote the socialist market economy and maintain social stability'. The first part of the slogan is clear but 'social stability' is not a simple but multi-faceted code 
referring to the maintenance of public order, upholding 'spiritual civilisation' (a code in itself) but most of all to the embedded status of the Communist Party as a dominant promoter and beneficiary of 'market socialism'.

The Third Plenum of the Eleventh Central Committee of the Chinese Communist Party in December 1978 set in train the programs of economic modernisation beginning with the agricultural sector. The reformers also embarked on an assessment of the Party and of Mao's achievements and failures which was finally issued by the Sixth Plenum of Eleventh Central Committee in June 1981. The 'Resolution of Certain Questions in the History of Our Party since the Founding of the PRC' (Beijing Review, 6 July 1981, pp.10-39) blames Mao for arbitrary leadership since 1958 in general and for the Cultural Revolution in particular. At the same time he is celebrated as a revolutionary and Mao Zedong thought is embedded with Marxism-Leninism as official ideology. The Little Red Book sits in the shadows of a state bent on material change without a loss of the power which it once represented. It also sits waiting for foreign collectors on market stalls in Beijing. ${ }^{10}$ Mao's legacy seems to materialise in both serious and trivial ways. Mao's image has been chosen to adorn the new currency issue. As such it is the intended or even unintended instrument for the promotion of a market-orientated economy while at the same time signalling to its WTO partners that it will remain (and endure as) an economy with Chinese characteristics. Perhaps, however, its trivialities are most interesting. Mao's word is still treasured as his iconic, nostalgic, image travels to the aid of a history he made impossible.

\section{NOTES}

1. Thanks to Agnes Toh, Murdoch University, for her help with translations, and to Marc Blecher for his incisive comments.

2. Landlords, rich peasants, counter-revolutionaries, moral degenerates, rightists, renegades, enemy agents, capitalist roaders, and intellectuals. Intellectuals were particularly seized upon as the 'Stinking Number Nine' (Chou Lao Jui).

3. For depoliticisation and depersonalisation also read repoliticisation and repersonalisation.

4. The latter are now collectors' items offered for sale as are postage stamps at auctions.

5. Note that the Red Guards attacked the Communist Party in the name of Mao Zedong. there was an echo of this paradox in the Tiananmen protest movement of 1989.

6. An 'intellectual' replaced the soldier in the Deng Xiaoping era. Readers might wish to speculate on a current update.

7. The Quotations was not the only little red book, for example, see Five Articles, by Chairman Mao Zedong [1968].

8. It should be clear that when the Red Guards, the PLA and others shouted or recited 'Long live invincible Mao Zedong thought! Long live our great leader Chairman Mao! May he live ten thousand years! (mao zhuxi wansui) ', they were not quoting the Little Red Book.

9. Alessandro Russo's comments are unpublished, but were discussed at the 'New Approaches to 
Contemporary Chinese Cultural Studies' Conference in January 2000, hosted by the Centre for the Study of Democracy, University of Westminster.

10. Our preference is for 'market oriented economy' which is more recognisable than the Chinese styled 'socialist market economy'. Western commentators also label the reforms 'market Leninism and even 'market Stalinism'.

11. During labour unrest in Liaoyang City Liaoyang province, protesters were reported to have carried a portrait of Mao mounted on a chariot with red banners. (Associated Press, 20 March 2002).

\section{REFERENCES}

Apter, D.E. and T. Saich, 1994, Revolutionary Discourse in Mao's Republic, Cambridge, MA: Harvard University Press.

Barmé, J.R., 1996, Shades of Mao: The Posthumous Cult of the Great Leader, Armonk, NY: M. E. Sharpe.

Benewick, R., 1999, 'Politics First: The Maoist State and the Political Process during the Cultural Revolution', in Benewick, Blecher and Cook (eds.), 'Politics in Development: Essays in Honour of Gordon White', IDS Bulletin, 30, pp.17-23.

Benewick, R. and S. Donald, 1996, 'Badgering the People: Mao Badges, A Retrospective 1949-1995', in Benewick and Donald (eds.) [1996: 28-39].

Benewick, R. and J. Howell, and I. Tong, 2001, 'Self-governance and Community: A Preliminary Comparison between Villagers' Committees and Urban Community Councils', International Symposium on Villager Self-government and Rural Social Development in China, Beijing, pp.3-11.

Benewick, R. and S. Donald (eds.), 1996, Belief in China: Art and Politics, Deities and Mortality, Brighton: Green Centre, Royal Pavilion.

Benton, G. and A. Hunter (eds.), 1995, Wild Lily, Prairie Fire: China's Road to Democracy, Yan'an to Tian'anmen 1942-1989, Princeton, NJ: Princeton University Press.

Blecher, M., 1997, China Against the Tides, London: Pinter.

Dai, J., 1999, 'Invisible Writing: The Politics of Chinese Mass Culture in the 1990s', Modern Chinese Literature and Culture, Vol.11, pp.31-60.

Donald, S., 1999, 'Children as Political Messengers: Art, Childhood and Continuity', Evans and Donald (eds.) [1999: 79-100].

Donald, S., 2000, 'La Chine in Culture/China', New Formations, Vol.40, No.1, April-June, pp.1-11. Dutton, M., 1998, Streetlife China, Cambridge: Cambridge University Press.

Esherick, J.W. and J.N. Wasserstrom, 1994, 'Acting Out Democracy: Political Theatre in Modern China', in Wasserstrom and Perry [1994].

Evans, H. and S. Donald, 1999, 'Introducing Posters of China's Cultural Revolution', in Evans and Donald [1999: 1-26].

Evans, H. and S. Donald (eds.), 1999, Picturing Power in the People's Republic of China: Posters of the Cultural Revolution, Lanham, MD: Rowman \& Littlefield.

Fu, Z., 1993, Autocratic Tradition and Chinese Politics, Cambridge: Cambridge University Press.

Gittings, J., 1999, 'Excess and Enthusiasm', in Evans and Donald [1999: 27-46].

Gray, J., 1990, Rebellions and Revolutions. China from the 1800s to the 1980s, Oxford: Oxford University Press.

He, B., 1992, 'A Methodological Critique of Lucian Pye's Approach to Political Culture', Issues and Studies, Vol.28, pp.92-113.

Jin, Q., 1999, The Culture of Power: the Lin Biao Incident in the Cultural Revolution, Stanford, CA: Stanford University Press.

Landsberger, S.R., 1998, Paint it Red: Fifty Years of Chinese Propaganda Posters, Gröningen, The Netherlands: Gröningen Museum. 
Lary, D., 1998, 'Chinese Reds', in I. Germani and R. Swalls (eds.), Symbols, Myths and Images of the French Revolution. Essays in Honour of James A Leith, Regina, Saskatchewan: Canadian Plains Research Centre, University of Regina.

Lin, B., 1966, 'Foreword to the Second Edition of Quotations from Chairman Mao Zedong', in Z. Mao, Quotations from Chairman Mao Zedong (English edition), Beijing: Foreign Languages Press.

Lukes, S., 1974, Power: A Radical View, London: Macmillan.

Lynch, D.C., 1999, After the Propaganda State, Stanford, CA: Stanford University Press.

Mao, Z., 1966, Quotations from Chairman Mao Zedong (English edition), Beijing:Foreign Languages Press.

Mao, Z., 1968, Five Articles by Chairman Mao Zedong (English edition), Beijing:Foreign Languages Press.

Nora, Pierre, 1989, 'Between Memory and History: Les Lieux de Mémoire', Representations, 26, Spring, pp.7-25.

Schram, S.R., 1969, The Political Thought of Mao Tse Tung, Harmondsworth: Pelican Books.

Short, P., 1999, Mao: A Life, London: Hodder \& Stoughton.

Spence, J., 1999, Mao, London: Weidenfeld \& Nicolson.

Teiwes, F.C. and W. Sun, 1996, The Tragedy of Lin Biao, Honolulu, HI: University of Hawaii Press.

Wasserstrom, J.N., 1991, Student Protest in the Twentieth Century, Stanford, CA: Stanford University Press.

Wasserstrom, J.N. and E. Perry (eds.), 1994, Popular Protest in Twentieth Century China, Boulder, CO: Westview.

White, G., 1993, Riding the Tiger: Politics of Economic Reform in Post-Mao China, London: Macmillan.

White, G., Howell, J. and X. Shang, 1996, In Search of Civil Society: Market Reform and Social Change in Contemporary China, Oxford: Oxford University Press.

White III, L., 1989, Policies of Chaos: The Organizational Causes of Violence in China's Cultural Revolution, Princeton, NJ: Princeton University Press.

Wong, J., 1996, Red China Blues: My Long March from Mao to Now, Toronto: Doubleday.

Yan, J. and G. Gao, 1996, Turbulent Decade. A History of the Cultural Revolution, Honolulu, HI: University of Hawaii Press.

Yang, M.M., 1994, Gifts, Favors and Banquets: The Art of Social Relationships in China, Ithaca, NY: Cornell University Press.

Yang, R., 1997, Spider Eaters: A Memoir, Berkeley, CA: University of California Press.

Zheng, S., 1997, Party as State in Post-1949 China, Cambridge: Cambridge University Press.

Zhou, E., 1966, 'Letter to Capital University Read Guard Revolutionary Rebels, 27 September 1966', in M. Schoenhals (ed.), China's Cultural Revolution 1966-1969: Not a Dinner Party, Armonk, NY: M. E. Sharpe.

\section{FILMOGRAPHY}

Red Sun (Hong Ri), 1963, Tianma Film Studio, B/W Director: Tang Xiaodan, Screen play: Ju Baiyin. 


\title{
State Enterprise Reform and Gender: One Step Backwards for Women?
}

\author{
JUDE HOWELL
}

The participation rate of women in the labour force in China is high compared to many countries in the North and South, standing at 80.3 per cent in 1995 compared to 70.8 per cent in the USA as of 2000, 59.6 per cent in Japan as of 2000 and 56.9 per cent in Brazil as of 1998 [ILO, 2002].' Yet such a sanguine picture of women's participation in the formal economy masks the gendered changes in employment that have been taking place over the last two decades of reform. Although the economic reforms have created new employment opportunities for certain categories of women, the restructuring of state and collective enterprises has often left women the first to be retrenched and the last to be re-employed. The gendered consequences of state enterprise reform have been much noted in the Chinese press and in scholarly publications, with numerous studies of the particular challenges facing female laid-off workers [Xu, 2000; Guo, 1999; Ding, 1998]. Yet there has been little exploration of the processes through which such a repositioning has been achieved and legitimated.

It is the purpose of this chapter to examine the combination of processes which have led state enterprise reform to have gendered outcomes. Gendered outcomes are understood here to include not only the gendered effects of retrenchment as evidenced in the disproportionate number of laid-off female workers, but also the redefinition of the gendered division of labour, an aspect which has received remarkably little scrutiny in the literature. In particular it is argued that state policy, market forces and socialisation processes have combined to reposition women in the economy in a way that departs radically from the pre-reform era.

We begin by reviewing the different theoretical explanations of gendered economic activity and examining these in the context of China. Having sketched a brief overview of state enterprise reform, we then consider its gendered consequences and the processes through which these are achieved. 
In the final section we look at attempts by workers to resist these gendered processes and argue that resistance has been articulated through the consciousness of status rather than perceptions of gender discrimination. The study draws upon interviews with 50 male and female laid-off workers, ${ }^{2}$ government officials, cadres in the local trade union and Women's Federation, and local scholars, conducted in Chengdu City, Sichuan province in 1999, as well as relevant secondary literature. ${ }^{3}$

\section{ENGENDERING THE ECONOMY}

In most societies there is a gendered division of labour in the waged economy, whereby men and women come to dominate certain sectors of employment. ${ }^{4}$ Furthermore, in most societies the labour of women in the household remains unwaged and thus unrecognised as a legitimate form of economic activity. Throughout the world average women's wages are lower than those of men and women's participation tends to be higher at the less skilled and more junior end of employment than men's.

Attempts to explain the gendered nature of economic participation have centred on the needs of capitalism, the role of state policies and legislation, and patriarchy. Writers such as McIntosh [1978], Land [1980] and Rogers [1980] have drawn attention to the impact of particular government policies and regulations around employment and family in shaping the way women and men become positioned in the waged and unwaged economies. Others have pointed to how the drive for profits and the concomitant need for a cheap, flexible and compliant labour force have shaped at different historical moments the pattern of male and female participation in the waged workforce, and the complex gendered relations between waged and domestic labour [Elson and Pearson, 1981; Mackintosh, 1981]. Dissatisfied with material explanations of the gender division of labour, feminist scholars such as Hartmann [1979] underline the centrality of patriarchy and its intersection with capitalism. Patriarchal relations are reproduced and perpetuated through institutions of socialisation such as the family, educational system and the media, justifying and rendering natural the different roles of men and women in social, political and economic life.

A major contribution of this extensive literature on gender and labour markets has been to undermine the notion that the gendered nature of economic participation is 'natural' and inevitable. Structural, institutional and discursive factors all play a role in positioning men and women differently in the waged and unwaged economies. The struggles of women's groups to address inequalities in the workplace and to give recognition to women's 
unwaged domestic labour in turn unsettle normative assumptions about the role of men and women in economic life. By documenting such struggles and highlighting the positive role of government policies in facilitating women's entry into the waged labour force, feminist scholars and activists demonstrate the possibility of transforming gender relations.

China stands out as an example par excellence of how state intervention could radically alter the gendered nature of economic participation and undermine patriarchal ideology. After the Liberation of China in 1949 the Chinese Communist Party actively encouraged the participation of women in the waged economy. ${ }^{5}$ This was in part because of the need to reconstruct the country rapidly after many years of war and in part because of its ideological commitment to a Marxist-Engelsian view of women's liberation, which linked women's oppression structurally to their exclusion from the waged labour force. During the radical Maoist days of the Cultural Revolution the Party propagated roles and images of women which broke fundamentally with traditional conceptualisations of women's social and economic position. ${ }^{6}$ Illustrative of the latter was the oft cited epithet ' $n a n$ zhu wai, nu zhu nei' (man lives outside, woman lives inside), which legitimated not only the gendered division of space but also the types of economic activities that women could engage in without violating social norms and practices. ${ }^{?}$

Women were thus encouraged to enter sectors and undertake tasks that previously would have been the domain of men, such as employment in the steel industry, heavy manual labour, welding and construction work [Stacey, 1983; Croll, 1980; Davin, 1976; Johnson, 1983]. Discourses weaving the themes of equality, modernity and revolution legitimised the changing role of women and redefined gendered notions of work. ${ }^{8}$ Furthermore, the state introduced policies to facilitate women's entry into the workforce such as the socialisation of child-care, the provision of kindergartens, and in the radical period of the Great Leap Forward (1958-61), the socialisation of catering. Whereas in 1950 urban women workers made up only 7.5 per cent of the urban workforce, by 1996 this had risen to 38 per cent [Gao, 1998].

Following the introduction of market reforms from 1978 onwards women's position in the economy began to change. The development of Special Economic Zones in the coastal part of China opened up new opportunities for young, rural migrant women in the foreign-invested factories. However, for female state enterprise workers, the increased market competition and the new emphasis on profits and efficiency cast a shadow over the security of their employment. As managers in state-owned enterprises became responsible for the performance of their unit, they became increasingly reluctant to recruit women [Summerfield, 1994]. From the mid-1980s 
onwards there was a growing number of reports of female graduates failing to gain positions in state enterprises and government offices [ $L u, 2000: 4-9]$. It was argued that women added to the financial burden of enterprises because of their childcare responsibilities and maternity leave entitlements [Honig and Hershatter, 1988]. Some economists proposed that women should stay in the home and leave the openings for waged employment to men. Enterprises began to pay women a reduced wage to stay at home and offer extended maternity leave up to two years as a way of dealing with surplus labour [Woo, 1994: 284-5]. Structural adjustment and the logic of the market chipped away at past commitments to gender equality.

At the ideological level the party-state no longer urged women to enter sectors that had traditionally been the domain of men. Indeed the images of womanhood and femininity were rapidly changing as Chinese society became increasingly exposed to foreign films, music, and commercial advertising and notions of modernity closely intertwined with market consumerism [ $\mathrm{Liu}, \mathrm{Bu}$ and Chen, 1997]. The Maoist images of asexual, earnest, steely-eyed revolutionary women plummeted in appeal as advertising boards, magazines and videos increasingly propagated representations of women as fashionably dressed, made-up, and sexually active. The diminishing salience and effectiveness of official ideology as well as the competing market-driven representations of women created for women a cacophony of often conflicting aspirations for life-style, employment and womanhood.

The introduction of market reforms did not mean that the Chinese Communist Party had abandoned its goal of female emancipation. However, the expansion of the private sector, the decline in political campaigns and the gradual shift away from direct towards indirect state economic intervention rendered it more difficult for the state to intervene to such a degree in people's everyday lives. The political priority given to rapid economic growth privileged the goals of efficiency and profit over political ideals of gender equality. As a result the divergent interests of different parts and levels of the party-state in issues of gender equity, and especially women's role in the economy, surfaced increasingly.

In this context of shifting values and priorities the stance of the partystate towards gender emancipation shifted from transformative to defensive. As reports of sexual harassment, poor employment conditions, and exploitative management practices in foreign enterprises, particularly in small-scale Overseas Chinese companies, came increasingly to light from the late 1980s onwards, the All-China Women's Federation (ACWF) mounted a campaign for more effective protective legislation, setting it at loggerheads with local governments keen to attract foreign investment. The 1988 Regulations on the Protection of Women Staff Members and Workers, the 1992 legislation on 
the protection of women's rights and interests and the new Labour Law of 1994 included measures to protect women against exploitative practices and to secure their rights to child-care and maternity leave. The starting-point of this protective legislation was that there were essential physiological differences between men and women, signalling a departure from the notion of gender equality celebrated in the Cultural Revolution, namely, that women could do whatever men could do regardless of any biological differences. ${ }^{9}$ As will be seen in the following section, the acceleration of state enterprise reform from the mid-1990s onwards marked a further episode when the economic goals of efficiency and profit clashed with and indeed predominated over the political values of gender equality.

\section{STATE ENTERPRISE REFORM AND ITS EFFECTS ON WOMEN}

The process of state enterprise reform illustrates the contradictory pressures within the party-state on the one hand to restructure the economy and on the other hand to uphold certain political principles and values such as gender equality. Attempts to reform state enterprises began in the early 1980s with the introduction of management responsibility contracts, holding individual managers responsible for the performance of enterprises. From the mid1980s onwards, piecemeal efforts were made to close enterprises which were loss-making. Although a law and policy measures on bankruptcy were introduced, very few enterprises declared bankruptcy in the 1980s. Not only was any move towards privatisation highly sensitive because of its implied rejection of socialised production, but also a system for providing basic allowances for retrenched workers had not yet been established. ${ }^{10}$ It was not until 1993 that state enterprise reform got underway in earnest. The performance of state enterprises came under increasing scrutiny and various ways were introduced to address this, such as merging profitable with less profitable enterprises, transforming the enterprises into shareholding companies, encouraging joint ventures, setting up subcontracted service enterprises to absorb surplus labour, selling assets and so on.

The pace of reform accelerated from the mid-1990s. Aware that closures could trigger large-scale unrest, at the end of 1993 the Ministry of Labour piloted a re-employment project in 30 Chinese cities, aimed at placing redundant state-owned enterprise workers in alternative employment [Wu, 1995]. In 1995 the scheme was extended across the country and the new category of 'laid-off worker' (xiagang gongren) was created. This was distinct from 'unemployed worker' (shiye renyuan) in that the 'laid-off worker' technically still had employment relations with their enterprise. In 1998 the central 
government issued Document 64, outlining a three-year scheme for laid-off workers. ${ }^{11}$ According to the regulations laid-off workers were to be issued with a special card designating their status. With this card they could claim minimum living expenses (zuidi shenghuo fei), the amount of which varied according to the wage level in the enterprise and the general performance of the enterprise. Laid-off workers could retain this status for a period of three years. ${ }^{12}$

As well as establishing a de facto minimum safety net for the new subcategory of laid-off workers, the party-state also took concrete measures to organise a system for re-employment and re-training. Document 64 required state enterprises to establish special re-employment service centres. These centres had the authority to issue the special card for laid-off workers, pay out the basic living expenses, and provide social security fees, pensions and medical care. ${ }^{13}$ They had the responsibility to assist workers to find re-employment and also were supposed to provide re-training, or at least to direct workers to training opportunities. Additionally, laid-off workers were encouraged to search themselves for jobs by responding to advertisements, attending labour markets, and going to the employment agency run by the local Department of Labour. The central government issued special provisions, which local authorities elaborated upon, to encourage laid-off workers to establish small businesses. Although these various policy initiatives were intended to alleviate the hardships experienced by laid-off workers and miti-gate the potentially destabilising effects of mass redundancies, they did not take into account the gendered experiences of workers in the redundancy, re-employment and re-training processes. In a context where traditional ${ }^{14}$ attitudes towards women were resurfacing and the force of state-projected images of women was diminishing, these initiatives worked to reposition women in the economy in a way that was compatible with conservative norms.

There is widespread evidence that women, and especially older women, are often the first to be retrenched from state and collective enterprises under reform. The average national figure puts the percentage of female retrenched workers at 60 per cent, ${ }^{15}$ though women have constituted 42 per cent of the labour force in state-owned enterprises. In sectors dominated by women, such as the textile industry, a higher absolute number of retrenched women workers might be expected. However, even when women form a smaller portion of the workforce, as in predominantly male sectors of employment such as heavy industry, the numbers retrenched often exceed that proportion. ${ }^{16}$ In such industries enterprise managers argue that they had been compelled under the old system of planned labour allocation to absorb surplus labour and accept inappropriate labour, hence their desire to shed unnecessary labour was only rational. 
The gendered process of retrenchment occurs in a context where increasing social and economic value is attached to youth. In promoting rapid development and modernisation, the reformers have prioritised speed, efficiency, productivity and information and technology skills. Against this background older generations of workers cradled in the state planning era are depicted as inefficient, unskilled and backward. This contrasts starkly with the Cultural Revolution image of state workers as revolutionary heroes, self-sacrificing in their striving for socialism, and at the centre of industrial progress and modernisation.

In the process of retrenchment and re-employment this reworking of the economic and political value of age intersects with changing notions of the relative worth of men and women in the waged labour force. While both older male and female workers encounter difficulties in gaining alternative employment, the age barrier sets in at much lower levels for women, namely, at 35 years, and sometimes even as low as 30 years. According to Sichuan Provincial Trade Union, over 70 per cent of retrenched female workers are over 35 years old. ${ }^{17}$ In her account of the work of Jiangsu Provincial Women's Federation in promoting the re-employment of laid-off women workers, Cao [1996: 32] discusses not only the problem of discrimination against women by employers but also the imposition of age barriers, often as low as under 30 years, for certain jobs. Such age and sex discrimination is readily visible in the job advertisements in local newspapers and employment agencies. Employers not only openly specify the required sex and age of the applicant, but also physical attributes such as height and beauty. For example, in a People's Vocational Introduction Centre in Qing Yang District, Chengdu, advertisements such as the following discriminated in terms of age and physical features: 'Sales person sought. Female. Must be taller than 1.6 metres. Must speak putonghua' or, '10 waitresses for restaurant sought. 17-25 years. Must be 1.55 metres tall'. Employers are also reluctant to recruit women because of preconceived notions about the impact of women's domestic responsibilities upon their productivity. As a local scholar explained: '.. But there is also the problem that some bosses do not want to employ women because they think they are a lot of trouble - because women have too many matters to deal with, such as parents, children, family'. ${ }^{18}$

Without national or local laws prohibiting age and sex discrimination in advertisements, older women cannot achieve equal opportunities with men in seeking re-employment. Furthermore, enterprises under reform are encouraging older workers to retire early. However, whilst the retirement age for men is lowered to 50 or 55 years from the statutory 60 years, women aged only 40 years are being encouraged to retire, way ahead of their male colleagues. ${ }^{19}$ These different retirement ages for men and women mark a 
continuity with the past, reflecting the protectionist orientation of the partystate towards women. However, by linking youth with modernity, productivity and progress, the party-state implicitly redefines and devalues the labour of older workers as a drag upon economic development. The earlier retirement of women and lower age barrier to re-employment in turn reinforces the evaluative notion that women are weaker and less skilled than men and constitute a burden on the economy.

The perception of age discrimination was a recurring theme in the interviews with both male and female workers, as illustrated vividly in some of the extracts of interviews with female workers below:

I am forty years old. I think it is still all right if you are a man and forty years old. But if you are a woman, it is not easy to find work then because you are too old. If you are in good health, it is OK, but many enterprises say you are too old ... (Interviewee C18).

I am old - thirty-two years old. This is a problem. Employers want twenty-yearolds. It is easy if you are twenty. I couldn't pretend to be twenty years old, even though I look young, because they would look at my identity card and see I was thirty-two years old (Interviewee C13).

Employers want eighteen-year-olds. If you go to the places where they hire people, they say that anyone over forty years is too old. But I am forty years old. I am healthy and I can still work for a few more years and then retire. But they all want people from eighteen to thirty-five years old (Interviewee C12).

The gendered effects of state enterprise reform are visible not only in the higher percentage of retrenched female workers and the lower age barriers for women, but also in the types of employment that women have access to after retrenchment. It is here that state policies, market forces and gendered social norms and expectations combine to reposition women in the waged labour force, channelling them into low-skilled, low-waged and low-status employment. With the emphasis upon the production of goods and heavy industry in the pre-reform era, both consumer products and services were neglected. In the 1980s economic reforms expanded dramatically the production of consumer products such as household goods, electrical appliances, and coloured TVs. As the incomes of urban residents rose, the demand for domestic services such as cleaning and child-care increased, providing employment for female rural migrant labour. According to estimates of the Ministry of Labour and Social Security the demand for a range of 'community services' such as care of the elderly, domestic cleaning, cooking and washing, street-cleaning, care of the disabled far exceeds the supply of labour. In Chengdu, for example, research by the provincial trade union found that in 1999 there was a potential 447,000 jobs in community 
services. ${ }^{20}$ As the number of retrenched workers came to 331,900 , it followed that community services could absorb the surplus labour from the state and collective sectors.

However, central and local government policy to expand the services sector in the light of expanding market demand is a gendered process, affecting the way men and women are positioned in the economy. Government officials in labour departments, cadres in mass organisations, staff in vocational training centres and employment points in neighbourhood committees interpret such policy through a normative, gendered lens, which assigns women and men to particular occupations and tasks. The types of re-training offered to men and women channel them into particular occupations. ${ }^{21}$ For example, the women's committee of the trade union in Chengdu focused on re-training retrenched women workers as community service workers, carrying out tasks such as domestic cleaning, taking care of the elderly, sick and disabled, assisting new mothers, and child-care, tasks which it saw as particularly suited to women. ${ }^{22}$ Social norms not only shape the occupational choices made by men and women but also legitimate these as natural. Thus, men tend to select retraining programmes in welding, electrical repairs, security work and driving taxis, whilst women are directed towards activities which reproduce their role in the household, such as child-care, domestic cleaning and catering.

While in the Cultural Revolution era party-state organs propagated the idea that women could do anything men could do, in the context of reform state cadres no longer intervene to resist what is otherwise understood as a natural process. Interviews with cadres in the local trade union and Women's Federation point to an unquestioning acceptance of the natural appropriateness of certain activities for men and women. In particular it was repeatedly stated that community services work, and especially waged domestic work was 'suited' to women. As a cadre from Sichuan Provincial Women's Federation put it:

We encourage retrenched workers to move towards the community. Women can work in the community - in services, snacks, nurseries, taking children to school, non-productive work, managing public telephones. Women are suited to this kind of work. Men don't like to do this kind of work which requires fine work and attention to detail. Men can't do these things as well. Women are suited to all these types of work ... Men cannot do women's work. This is a physiological matter and a matter of personality. ${ }^{23}$

A cadre from the Sichuan provincial Trade Union Women's Committee echoes this theme: 
Chinese families depend on the mother. So it suits women to do community service work. We saw their superiority (youshi) and decided to develop this. ${ }^{24}$

These references to women's role as mother and to her essential superiority in household management and child-care reinforce gendered norms around the division of labour within the household and in the waged economy. The portrayal of domestic tasks requiring few skills or even as unskilled contrasts with the recognition accorded to activities by men outside of the household. The discursive de-skilling of waged domestic labour is reflected in turn in the lower remuneration awarded women working in community services. By emphasising the scope of work available in this sector and thus the greater opportunities open to women compared to men, the process of deskilling and devaluing of women's labour is subtly disguised. These words of a scholar illustrate the glossing over of reality:

Male workers face more pressure trying to get re-employed. The quality (suzhi) of female textile workers is lower. They have fewer technical skills, so it is easier for them to find work. They can sell steamed bread, do tailoring; if they are young and pretty, there are a lot of openings. ${ }^{25}$

With similar enthusiasm a cadre from the provincial Women's Federation recounted to me: 'Women have wider opportunities than men because they can do household services and don't just rely on jobs in the manufacturing sector. ${ }^{26}$ Given the age discrimination faced by retrenched workers in seeking re-employment, the community services sector is seen to provide an appropriate avenue for older women workers, conforming to gendered and ageist norms and values. As a government official pointed out to me, 'Age is also a problem. For older women with less education they can more easily get work in the community'. ${ }^{27}$ Such depictions of reality not only take for granted the implicit gendered nature of work but also leave aside the possibility that such divisions of labour between men and women might be problematic and amenable to change.

The repositioning of women into low-skilled, low-waged employment in the service sector is achieved not only through the gendered interpretation of state policies by implementing agents but also through the internalisation of social norms and values by male and female laid-off workers. Interviews with male and female laid-off workers revealed a common pattern of normative expectations about the nature of work that men and women could do. These were that laid-off women workers could work as shop assistants, hotel floor-staff, or domestic helps, and that men could work as security guards, drivers, and businessmen. For example, as these interviewees explained: 
a man over forty to become a guard. For a young woman I'd advise them to become a secretary or sell things or work in a hotel as floor-staff. As for a young man, he could work in a hotel as floor-staff, or in a factory, or do construction work, if he agrees, though this may be too hard for him (Female interviewee, C11).

For women, they could be shop assistants, or work for a private enterprise, or be an accountant. Men can be manual workers cleaners, drive rickshaws or work as a guard. If they have skills, they could do repair and maintenance work (Female interviewee $\mathrm{C} 16$ ).

Although some women noted that men could theoretically do waged domestic work, they pointed to the social norms that prevented men from taking up such employment, as seen in the following extract:

Men, too, could work in a kindergarten but most wouldn't agree to do this. They can't take off their face to do that. They could do things like market and sales, selling goods, repair work, work as an electrician, or do machinery maintenance work (Female interviewee $\mathrm{C} 23$ ).

I want to work as a domestic help or as a receptionist in a unit. Men can do domestic work and can do it better than women but employers don't want them. Men won't agree to come here to this market [domestic help recruitment market] and find work in a family (Female interviewee C15).

The difficulties women workers encountered in finding alternative employment as well as their growing dominance of waged domestic work is explained and justified not only through references to their natural reproductive roles but also to their fundamental lack of skills and motivation. As a local scholar explained:

Third, there is the problem of the different quality (suzhi) of men and women. This does not refer to technical ability but something much broader. It includes a person's culture (wenhua), ability, concepts, personality and aspirations. The problem with some women is that they have low aspirations. Perhaps they did one job only for years. So they cannot easily adapt to the new situation. Such people are traditional. We say they are not modern people. ${ }^{28}$

In a similar vein a cadre of the local Women's Federation draws attention to the problem of 'quality' and the lack of adaptability to the market:

Women's quality is weak and they are less competitive. The cultural level of female retrenched workers is low and their labour is monotonous. They are slow and backward ... It is harder for women to find work because of their quality and also, though it is not too common, because of sexual discrimination. Employing units want to employ men rather than women. It is physiological discrimination. ${ }^{29}$ 
This portrayal of women as deficient, low skilled and inflexible discounts the history of state planning which assigned workers to one unit for life and attributes the effects of structural disadvantages in access to education between the sexes to personal failings of individual women. In this way a structural, historical episode is translated into an essential feature of women. Once the semantic bearer of modernity, progress and social transformation, the female state worker is cast as a symbol of the unmodern and traditional, an obstacle to reform and modernisation.

Central government required both the ACFTU and ACWF in 1998 to prioritise the needs of laid-off state enterprise workers. As well as meeting government targets for retraining and re-employment, they also are expected to assist in changing the attitudes of retrenched workers to re-employment, and especially to help them adapt to new competitive market conditions. In this way both mass organisations have extended their role from mediating between the state and their constituencies to mediating also between the market and their constituencies. As expressed by a trade union leader, 'the trade union serves as a bridge linking workers and the market' ${ }^{30}$ Both organisations reiterate neologistic maxims aimed at stimulating the initiative of workers, devices which serve to individualise the process of restructuring. In describing the work of the local women's federation in re-employment and re-training, a cadre explained that:

We try to change their old-fashioned ideas about employment. Previously we had the iron rice bowl system. People preferred to work in the state sector. There is an expression - 'the first is the state sector, the second is the collective sector, there isn't a third or a fourth, it is working on your own' (di yi quanmin, di ar jiti, bu san, bu si, gan geti). The status of working in the private sector was very low and people looked down upon such workers. So we provide conceptual guidance. Now we have to change people's ideas, tell them they can't depend on the state. They should work on their own and find work themselves (zizhu zhiye, zimou zhiye). So we lead this process of changing ideas. ${ }^{31}$

This new market maxim of individual self-reliance recurred repeatedly in the interviews with workers. Often they would end their accounts by reiterating the words 'rely on yourself' ( $k a o$ ziji), thus internalising the notion that they are responsible for their own fates and so reflecting the changing relationship between the state and urban workers. ${ }^{32}$

\section{RESISTING ENGENDERED LABOUR MARKETS}

In any context resisting retrenchment and protecting the interests of the unemployed is notoriously difficult. The removal of the workplace as a site 
of collective action and identity leaves retrenched workers stranded and vulnerable. While trade unions emerged to represent the interests of employed workers, they have proved less able to address the needs of the unemployed. The All-China Federation of Trade Unions (ACFTU) has been no exception to this general pattern.Although the ACFTU at all levels has tried to protect very poor workers and those close to retirement in the retrenchment process and has organised re-training programmes for retrenched workers in line with government policy, ${ }^{33}$ for many workers the trade union is not the institution to which they would turn when in difficulties. In the interviews several workers described the trade union as 'useless' and closely allied to management. As a former (male) decorator from a state-owned construction company in Chengdu stated: 'I didn't go to them [TU] for help when I was laid-off. The TU doesn't have any strength. The TU and leaders are one and the same' (Interviewee B11). Similarly, a former (female) packer in a stateowned enterprise stated: 'Nobody thinks of going to the TU for help. I have this feeling. My relationship with the leaders wasn't good so I never think of going to the TU. The TU can't speak for you. We didn't think of going to them at all' (Interviewee C3).

Compared to the ACFTU, the ACWF has taken a more proactive role in challenging gender discrimination in the workplace. Although ACWF cadres have on the one hand reproduced gendered social norms through the design of retraining and re-employment programmes for women, they have also vociferously resisted any suggestion that women should return to the home. As a cadre in Sichuan Provincial Women's Federation argued: 'Women should go out to work. If you stay at home for two months, you don't know what is going on outside. If you go out to work, the husband can't hold you in contempt. We didn't liberate women to send them back into the home. ${ }^{{ }^{34}}$

There is a tension within the ACFTU and Women's Federation between fulfilling their auxiliary functions to government and representing the interests of workers. On the one hand they have a goal to meet government-set targets for training and re-employment and thus participate in the circulation of gendered discourses about the appropriate roles of men and women in the waged economy and the need for changing attitudes to the state and market. On the other hand they are supposed to represent the interests and voices of their respective constituencies. This tension is reflected in a tendency at times to reproduce certain myths about state enterprise workers such as 'being lazy and shunning hard work', and at other times to challenge these. Interviews with government officials and mass organisation cadres reflect not only a perception of state enterprise workers as low skilled and inflexible, but also as industrious and resilient. On several occasions they underlined positively the Cultural Revolution experiences of workers aged over 
40 , which demonstrate their ability to suffer hardship and undertake physically demanding tasks, thus countering the stereotypical construction of laidoff workers as lazy. As a local Women's Federation cadre commented: 'Some enterprises are supportive and try to employ retrenched workers. They think that retrenched workers especially value this work and that they can work hard because of their experiences in the Cultural Revolution. ${ }^{{ }_{35}}$

Although there are numerous reports of demonstrations by retrenched workers, less confrontational forms of resistance are much more common, such as challenging negative stereotypes, identifying a common enemy in the rural migrant worker and refusing to accept the status of 'xiagang'. Interviews with laid-off workers revealed a 'hidden transcript' ${ }^{36}$ which challenged dominant images of retrenched workers and upheld their integrity as a class and generation. While press reports, statements by government leaders and officials frequently alluded to the 'unskilled, lazy' generation of workers of the Cultural Revolution period, such workers subverted such tropes by presenting this experience as an asset, equipping them with the ability to endure hardship and undertake challenging tasks. In the words of several retrenched workers:

I grew up in the period of the famine between 1962 and 1965. At that time the food was poor so my generation's health is not good now. I studied with the peasants, the army and went through the Cultural Revolution. Then when I should have gone to university, I was sent down to the countryside. Now I am old [she is 47 years old] and you need diplomas to get jobs. I have had a broad life experience. I can absorb a lot of psychological pressure. I can take being laid-off. Now China is stable despite all the laid-off workers because my generation has experienced a lot. So we can face all these things. But my generation sacrificed a lot and now we have lost our jobs (Female interviewee $\mathrm{C} 14$ ).

Similarly, a 42-year old woman, who was a welder in a construction company, stated: 'I am old but I can do things. I went through the Cultural Revolution, the Gang of Four and all of that. I can do a lot. I can eat bitterness' (Female interviewee C12).

Some felt that losing their jobs was a double hardship, having lost opportunities during the Cultural Revolution. A male worker, who had worked for over 35 years in a semi-conductor factory and who stated his grievances to all the leaders upon being retrenched, expressed his double experience of loss:

I complained to everyone. I went to the TU. I went to the Party secretary. I went to the leaders of the section. I went to all the leaders. They said they would arrange something for me but in the end they didn't. So I'm not happy at all. I'm still looking for work but it is difficult to find because I am old and not in good health ... I have had a tragic life. I went through everything. There was the Cultural 
Revolution. I was sent to the country-side and now I have lost my job. I should retire soon but now suddenly I am laid-off' (Male interviewee B19).

By referring back to their Cultural Revolution experience, laid-off workers indirectly attribute their apparent 'lack of skills', or mono-skillism to government policy rather than to any personal deficits. Similarly by rejecting allegations that they are 'stupid' or 'lazy', retrenched workers challenge dominant discourses which seek to blame them for their own fate of unemployment. The following extracts illustrate this vividly: 'Because of the Cultural Revolution I have no education. Now I am old and have no education. I am not stupid. I want to do things but there is no opportunity' (Female interviewee C8). Or, 'I don't agree that laid-off workers are lazy or stupid. I have done shift work and caught a bus to get there and it was very far away. So I'm not lazy' (Female interviewee C11). Or,

I went through the Cultural Revolution. I only have primary school education and now I am forty years old. Now what am I supposed to do? Hotels want young people from the countryside. They say that I am a laid-off worker and ask whether I can eat bitterness. Of course I can eat bitterness. Employers don't have confidence in you but I feel I have confidence in myself that I can work hard and do any kind of work (Female interviewee $\mathrm{C} 12$ ).

The hidden transcripts of resistance amongst laid-off workers not only subvert dominant representations but also identify a common enemy to blame for their misfortunes. By making rural migrant workers the scapegoat for their difficulties, laid-off workers not only reinvent rural/urban divisions at a time when migration is simultaneously diluting such divisions, but also avoid making any systemic analysis of their predicament. Desperate to find work in the city, rural migrants are more willing to accept lower wages and to work longer and more unsociable hours than urban workers. Several interviewees referred to discrimination by employers in favour of cheaper, rural labour and some saw the solution in restricting migration to the cities. One worker reported that already in the early 1990 s, her construction company was favouring rural migrants, who were cheaper than urban labour:

I was formally 'dingti' ${ }^{37}$ The factory wanted to employ rural people because they thought people who were dingti didn't like to work and expected a higher wage. The enterprise didn't want to employ dingti workers because their costs were too high and they thought they were lazy compared to rural people. The factory had shifts but dingti workers wouldn't work nights so the factory preferred to hire rural people. What happened in the end is that they didn't give us any work and told us to stay at home (Interviewee C7).

Another former worker in a construction company recounted her difficulties 
in finding hotel work because employers preferred to recruit rural migrants:

Rural people can work on the land but city people don't have any land to work on. I don't have any land and there is no room to breed pigs or chickens. I'd like to work as a floor-staff in a hotel but they say I am too old. I'd like to do cleaning. I can work very hard. But it is not easy to get such work because they all want young people from the country-side. Some of the rural people let someone else till the land and then they come to the city to work. So we can't get work. They can work hard and accept lower wages.

Although she did work for two years in a hotel, she felt the manager, who was from the country-side, discriminated against employing city people:

... Most of the people working there [in the hotel] are from the countryside. They don't want to employ laid-off workers from the city. But young rural women can't work hard. They come to the city and are impressed by everything and want to have a good time (Interviewee C12).

In response to the question as to how the government could assist laid-off workers, her reply centred on the restriction of migration:

There are too many laid-off workers. The government should solve the problem of laid-off workers in the city. Some are only getting Y200-300 per month. It is very difficult for them, especially if they have children. The government should limit rural people coming to the city. They can work on the land. It should ensure that city people have work (Interviewee C12).

Similarly, 'The government should use local people and restrict rural people from entering the city. They take away the jobs of urban people. Rural people have land. They can work on this' (Interviewee C24). Others have resisted the process of retrenchment by refusing to accept the status of 'xiagang'. A former packer in a state-owned enterprise recounted how the enterprise would only give them two years of living expenses. Aware that laid-off workers were supposed to receive three years of support, she and other colleagues refused to register at the re-employment centre in the enterprise, forfeiting thereby any living expenses. ${ }^{38}$

The shift from a transformative to a defensive approach by the party-state to gender inequality has left women exposed to the effects of a resurging wave of patriarchal values and attitudes with consequences for their participation in the economy. A lack of critical attention to gender issues and analysis of its structural roots in economic change has resulted in state enterprise reform evolving in a way that has different implications for women and men. Yet noting the gendered effects of retraining and re-employment programmes is not to tell the whole story. The changing position of female state 
workers has not gone unchallenged. However, resistance to retrenchment and to re-employment in waged domestic work has been felt and articulated in terms of a decline in social status.

While government agencies and mass organisations try to push laid-off women workers into waged domestic work, using normative arguments about the suitability of such work for women, women workers themselves resist this channelling, but for reasons of status rather than feminist consciousness. In particular, these perceptions of social status are embedded in meanings attached to work in the state and private sectors, to rural and urban divisions, and to women's role as collective bearer of morality and status for husband and family. As a former supervisor in a collective enterprise producing medical equipment explained:

At first it was difficult to bear [changing from a worker to domestic help]. I had been a worker, then became a supervisor, then suddenly I became a domestic help. This did not have a good meaning. But at this labour market [for domestic helps], they gave me a lot of encouragement and told me not to be afraid. Then gradually I got used to it but I had a lot of conflicting thoughts in my head (Interviewee C16).

Similarly a former packer in a collective enterprise stated that she would do waged domestic work, provided that she was treated as an equal: 'I'd like to work in a hotel, do cleaning, or do domestic work. I don't want to do work where I'm treated like a servant. I want the relationship to be different to that of a servant. There should be mutual respect' (Interviewee C6).

For many retrenched female workers, waged domestic work was the domain of rural female migrants. To do such work means not only a shift from state to private sector, from manufacturing to service, but also from 'worker' to 'peasant'. As a cadre from the local Women's Federation explained:

We run training courses in cooking, beauty care, electrical goods repairs, health care. Now the idea of domestic work is very different to before. Before it just meant cooking, cleaning and so on, something that would be done by a household help $($ baomu $)$. Now it involves lots of different types of work such as electrical work. ${ }^{39}$

Through the provision of training courses validating the diversity of skills of domestic work and the granting of diplomas and certificates, waged domestic work carried out by urban retrenched female workers is distinguished from the unskilled, formally unqualified work carried out by rural migrant women. This segmentation of the domestic labour market is reflected linguistically in the use of the term 'zhongdiangong' for retrenched women workers and 'baomu' for rural migrant workers. Furthermore, it is manifested in the physical location of markets for domestic help. In a well-known 
domestic labour market in Qing Yang district in Chengdu, the space is divided according to whether the women were rural migrants or urban, retrenched workers.

The fall in social status associated with working in the domestic sector is also linked to pressures on women to bear the collective status of the family and household. As explained to me by a leading trade union cadre:

Most people don't want to do this work [community services] because the income is low. It means working for different families and a loss of face because working in a state-owned enterprise had high status. Some people want to do it, but their husbands don't want them to, or the parents don't want them to, so the family pressure is great. $^{40}$

When the local trade union prepared to present awards to retrenched women workers for their community services work on 8 March, International Women's Day, several women reportedly were reluctant to accept the awards because of the perceived 'loss of face'. ${ }^{41}$ Similarly, a local Women's Federation cadre recounted how a woman who registered for a training programme with the Federation wanted to do domestic work but her husband would not let her. For him this was a loss of face as it suggested that he was unable to support his wife. ${ }^{42}$ Thus, the perceived loss of social status in moving from a state sector job to a service sector job in the community highlights the way the bearing of status is both gendered and collective. Women's status is perceived to impact upon the status of men and extend to the family.

\section{CONCLUSION}

This chapter has underlined the gendered nature of the processes of state enterprise reform and re-employment. Women workers tend to be the first to be retrenched and they encounter age discrimination at an earlier point than their male counterparts in the labour market. Although re-employment and training programmes have created opportunities for some women to find alternative employment, the content of these courses steer women into sectors which are low-paid and low status. Furthermore, gendered social norms about the appropriate division of labour between men and women in the waged economy and household facilitate and justify the re-positioning of women into economic activities in the service sector, which reproduce their roles as mothers, carers and care-takers of the household.

The central government has called upon the ACFTU and ACWF to assist the Ministry of Labour and Social Security in finding alternative employment for laid-off workers and retraining workers. In doing so cadres have 
been caught in the classic dualist dilemma of Leninist state organisations, namely, having to reconcile compliance with the state with meeting the interests of their constituencies. This dilemma is reflected in the contradictory discourses circulating in the texts and practices of these institutions, ranging from an articulated acceptance of the need for 'inflexible' and 'low skilled' state workers to adjust to the needs of the market to a firm rejection of the idea that women should stay at home to make available jobs for men.

Interviews with workers reveal on the one hand a tendency to internalise a market ideology of individuals as responsible for their own fate, and on the other hand a hidden transcript of resistance to the process of redundancy and stereotypical constructions of state workers as lazy, inflexible and shunning hard work. The reluctance of some women workers to enter the services sector as domestic cleaners, cooks and carers reflects a concern with status rather than with the emerging gender dimensions of this expanding economic sector.

In brief the process of state enterprise reform has not been gender neutral. State policy, gendered social norms and the changing needs of the marketplace have converged to re-draw the sexual division of labour. Although the expanding demand for domestic help, child-care and care of the elderly bodes well for the re-employment of retrenched female state workers, the repositioning of retrenched women into this sector and out of state-owned manufacturing reinforces gendered social norms which serve to undervalue both in pay and status the economic activity of women. What is on the one hand a pragmatic and expedient solution for problems of the economy marks on the other hand a step backwards in the quest for gender equity.

\section{NOTES}

1. The participation rate of women measures the number of women in the labourforce as a percentage of the number of women of working age. The ILO Statistical Database provides a figure for China only for the year of 1995. According to the World Bank [2000], the number of women in the labourforce as a percentage of the total labourforce is relatively high for China at 45.16 per cent in 1998 , compared to Germany at 42.14 per cent, Japan at 41.16 per cent and Brazil at 35.38 per cent.

2. Altogether interviews were conducted with 100 male and female workers in Chengdu City and Shanghai in 1999 and 2000 respectively. This chapter focuses on the Chengdu field-site. It should be noted that these interviews make no claim to be representative of all laid-off workers in China. Their role is to illustrate some of the perceptions and views of some laid-off workers.

3. I am grateful to the Leverhulme Trust for providing a grant to carry out the fieldwork for this research in China and to the Development Research Centre at the Institute of Development Studies, funded by the Department for International Development, UK, for supporting the completion of this work.

4. We use here the term gender division of labour rather than sexual division of labour to emphasise the point that such a division is socially constructed, rather than naturally given by any 
physiological or biological differences between men and women. The term sexual division of labour was first used to express this idea of social construction. Once the differentiation between sex and gender became established in feminist theory, the phrase gender division of labour became current, although both 'sexual' and 'gender' division of labour continue to be used interchangeably to refer to the process of social construction of genders.

5. However, this was always conditional upon economic needs. In the mid-1950s, for example, when the economy was sluggish, women were encouraged to return to the home as 'socialist housewives' [Honig, 2000: 100].

6. Honig [2000] argues persuasively that state propaganda promoted contradictory models of women's roles in society and the economy. The Iron Girl Model, which has come to symbolise interpretations of gender relations during the Cultural Revolution, was but part of a complex array of competing models of women propagated by the state.

7. For a detailed discussion of the inside/outside dichotomy and its complex interweaving with ideas about womanhood, feminine virtue and labour, see Rofel [1994: 234-8].

8. For an excellent discussion of the changing concept of work and women's relation to it, see Rofel [1994: 226-49].

9. For an excellent discussion of protective legislation for women workers and the growing emphasis in the reform period on the biological basis of this legislation, see Woo [1994: 279-95].

10. In 1986 central government introduced regulations on 'wait for employment insurance' for workers in state-owned enterprises who had been dismissed for disciplinary reasons, whose contracts had been terminated, or who had been laid off because of bankruptcies. In 1993 this system of unemployment insurance was extended to cover workers in enterprises that had been merged, or closed down temporarily or permanently [Lim and Sziraczki, 1999].

11. Interview, Sichuan Academy of Social Sciences, May 1999.

12. If after three years, they had not found employment, then they were moved into the category of unemployed. As an unemployed person, they no longer had employment relations with their former enterprise and fell under the charge of the Ministry of Labour and Social Security, which provided them with unemployment relief (shiye jiuji) and social security (shehui baoxian). If after two years they were still unemployed and in difficulties, then their status changed to unemployed person (shimin) and they could claim civil relief (minzheng jiuji) from the Ministry of Civil Affairs. Alternatively, they could receive urban resident disaster protection (chengzhen jumin zai de baozhang). Interview, Sichuan Provincial Employment Administration, May 1999.

13. Interview, Sichuan Province Employment Service Administration, May 1999

14. The term 'traditional' is always complex, not least because it conflates historical periods into an artificial unity for the purpose of contrasting these with modernity and suggests a lack of dynamism and change. Here it is used as a shorthand for practices, institutions and attitudes, which conceive women as inferior to men and which the Chinese Communist Party has condemned in its rhetorical promotion of gender equality. In particular it refers to the institution and practices of patriarchy, and attitudes, values and social norms which reinforce the notion of male superiority.

15. According to Tong [1999: 40], in some cities it comes to 73 per cent. There is also considerable variation across sector and firms. For example, in one company in Chongqing, women made up over 70 per cent of the laid-off workers [Chongqing Fulian, 1997: 34].

16. For example, a survey in Hubei province found that women made up 44 per cent of surplus workers but accounted for only 35 per cent of the labour force in enterprises [Lim and Sziraczki, 1995: 13].

17. Interview, Sichuan Provincial Trade Union, May 1999.

18. Interview, Sichuan Academy of Social Sciences, May 1999.

19. Retirement ages for men and women are different both for professional and manual occupations. According to Labour Insurance Regulations of 1979 men retire at 60 years and women at 
50 years. This discrimination has drawn the attention of the All-China Women's Federation and numerous women scholars have written passionately on this subject.

20. Interview, Sichuan Provincial Trade Union, May 1999.

21. As Molyneux [1981: 196] pointed out in an early review of gender relations in state socialist societies, such states collude in the perpetuation of women's subordination through gender-type training programmes. In addition, promoting the idea that women are or are nearly emancipated as well as propagating an ideology of motherhood contribute to perpetuating gender inequality.

22. Interview, Sichuan Provincial Trade Union, May 1999.

23. Interview, Sichuan provincial Women's Federation, May 1999.

24. Interview, Sichuan provincial Trade Union Women's Committee, May 1999.

25. Interview, Sichuan Academy of Social Scienes, May 1999.

26. Interview, Sichuan Provincial Women's Federation, May 1999.

27. Interview, Sichuan Provincial Trade Union, May 1999.

28. Interview, Sichuan Academy of Social Sciences, May 1999.

29. Interview, Sichuan Provincial Women's Federation, May 1999.

30. Interview, Sichuan Trade Union Women's Committee, May 1999.

31. Interview, Sichuan Provincial Women's Federation, May 1999.

32. As a 37-year-old women, who was retrenched after 13 years in an electrical switch factory in Chengdu, stated: 'The Trade Union didn't give me any help when I was laid off. You have to help yourself, rely on yourself' (Interviewee C25). Similarly, another laid-off worker, who had attended a TU training course for domestic helps, said, 'The TU says we should help ourselves ... You have to depend on yourself' (Interviewee C6).

33. Interviewee C6, C26 and B23, interviews with Sichuan Provincial Trade Union and Sichuan Provincial Trade Union Women's Committee, May 1999.

34. Interview, Sichuan Provincial Women's Federation, May 1999.

35. Interview, Sichuan Provincial Women's Federation, May 1999.

36. I have borrowed this term from James Scott, who uses it to refer to the 'discourse that takes place 'offstage', beyond direct observation by powerholders' [Scott, 1990: 4].

37. 'Dingti' refers to a common practice in some state enterprises to recruit new workers by hiring the children of favoured employees. For a further discussion of this see Walder [1986: 58].

38. Interviewee C3, May 1999.

39. Interview, Sichuan Provincial Women's Federation, May 1999.

40. Interview, Sichuan Provincial Trade Union, May 1999.

41. Interview, Sichuan Provincial Trade Union, May 1999.

42. Interview, Sichuan Provincial Women's Federation, May 1999. 


\section{REFERENCES}

Cao Haiqing, 1996, 'Kaituo Xiagang Nugong Zaijiuye Qudao - yi Jiangsu Sheng Fulian Gongzuo Weilie', Funu Yanjiu Luncong, Vol.3,No.19, pp.29-32. Chongqing Fulian, 1997, 'Shishi Xiagang Nuzhigong Zaijiuye Gongcheng Qingkuang', Funu Yanjiu Luncong, No.3, issue 23, pp.34-6.

Croll, Elisabeth, 1980, Feminism and Socialism in China, New York: Shocken Books.

Davin, Delia, 1976, Woman-Work: Woman and the Party in Revolutionary China, Oxford: Oxford University Press.

Ding Juan, 1998, 'Guanyu Nuzhigong Xiagang - Zaijiuye Qingkuang de Diaocha Baogao', Funu Yanjiu Luncong, No.3, issue 27, pp.13-19.

Elson, D. and R. Pearson, 1981, 'The Subordination of Women and the Internationalisation of Factory Production', in Young, Wolkowitz and McCullagh [1981: 144-66].

Gao Lin, 1998, 'Wo guo funu jiuye de zhuangkuang yu duice' (The Situation of and Policies Towards Women's Employment in My Country) in Funu Fazhan yu Duice (Women's Development and Policies), Dangdai Zhongguo Chubanshe, May, Beijing, pp.175-221.

Gilmartin, Christina K., Hershatter, Gail, Rofel, Lisa and Tyrene White (eds.), 1994, Engendering China: Women, Culture and the State, Cambridge, MA: Harvard University Press.

Guo Fang, 1999, 'Yinshi Lidao, Fazhan Xiagang Nugong Ziying Jiuye', Funu Yanjiu Luncong, No.3, pp.58-9.

Hartmann, H., 1979, 'The Unhappy Marriage of Marxism and Feminism: Towards a More Progressive Union', Capital and Class, No.8.

Honig, Emily, 2000, 'Iron Girls Revisited. Gender and the Politics of Work in the Cultural Revolution, 1966-1976', in Barbara Entwistle and Gail E. Hendersen (eds.), Re-Drawing Boundaries. Work, Households and Gender in China, Berkeley, CA: University of California Press, pp.97-110.

Honig, Emily and Gail Hershatter, 1988, Personal Voices: Chinese Women in the 1980s, Stanford, CA: Stanford University Press.

ILO Statistical Database, 2002, Key Indicators of the Labour Market, 2001-2002, Geneva: ILO.

Johnson, Kay Ann, 1983, Women and the Family and Peasant Revolution in China, Chicago, IL: University of Chicago Press.

Land, H., 1980, 'The Family Wage', Feminist Review, No.6.

Lim, Lin Lean and Gyorgy Sziraczki (eds.), 1995, Employment Challenges and Policy Responses: Chinese and International Perspectives, Beijing: International Labour Office.

Liu Bohong, Bu Wei and Chen Xinxin, 1997, 'Shixi wo guo dianshi guanggao zhong de nannu juese dingxing', Funu Yanjiu Luncong, No.2, pp.19-24.

Lu Fangwen, 2000, 'Zhiye xingbie qishi: yuanyin he duice' (Sexual Discrimination in Employment: Causes and Counter-measures), Funu Yanjiu Luncong, pp.4-9.

McIntosh, M., 1978, 'The State and Oppression of Women', in A. Kuhn and A.M. Wolpe (eds.), Feminism and Materialism, London: Routledge.

Mackintosh, M., 1981, 'Gender and Economics: The Sexual Division of Labour and the Subordination of Women', in Young, Wolkowitz and McCullagh [1981: 1-15].

Molyneux, Maxine, 1981, 'Women in Socialist Societies: Problems of Theory and Practice', in Young, Wolkowitz and McCullagh [1981: 167-202].

Rofel, Lisa, 1994, 'Liberation Nostalgia and a Yearning for Modernity', in Gilmartin, Hershatter, Rofel and White [1994: 226-49].

Rogers, B., 1980, The Domestication of Women: Discrimination in Developing Societies, London: Tavistock.

Scott, James, 1990, Domination and the Arts of Resistance. Hidden Transcripts, New Haven, CT and London: Yale University Press. 
Stacey, Judith, 1983, Patriarchy and Socialist Revolution in China, Berkeley, CA: University of California Press.

Summerfield, Gale, 1994, 'Effects of the Changing Employment Situation on Urban Chinese Women', Review of Social Economy, Spring, pp.40-59.

Tong Xin, 1999, 'Shehui Bianqian Yu Zhongguo Funujiuye de Lishi yu Qushi', Funu Yanjiu Luncong, No.1, issue 29, pp.38-41.

Walder, Andrew, 1986, Communist Neo-Traditionalism. Work and Authority in Chinese Industry, Berkeley, CA: University of California Press.

Woo, Margaret, Y.K., 1994, 'Chinese Women Workers: The Delicate Balance between Protection and Equality', in Gilmartin, Hershatter, Rofel and White [1994: 279-98].

World Bank Statistical Database, 2000, World Development Indicators 2000, Washington, DC: World Bank.

Wu Naitao, 1995, 'Government Adopts New Employment Strategy', Beijing Review, 30 Oct.-5 Nov. $\mathrm{Xu}$ Min, 2000, 'Guanyu Xiagang Nugong Zai Jiuye Qingkuang de Wu Nian Huigu yu Pingjia', in Zhongguo Funu Yanjiuhui and Lianheguo Xingbie Zhuti Zu, 1995 Shijie Funu Dahui Wu Zhou Nian Yanjiuhui. Lunwen Ji, Beijing, pp.206-8.

Young, K., Wolkowitz, C. and R. McCullagh (eds.), 1981, Of Marriage and the Market: Women's Subordination in International Perspective, London: CSE Books. 



\section{CIVIL SOCIETY}





\title{
Corporatist Capitalism: The Politics of Accumulation in South India
}

\author{
ELISABETTA BASILE and \\ BARBARA HARRISS-WHITE
}

THE SOCIAL MATRIX OF ACCUMULATION

In our tribute we summarise the initial results of field research on one aspect of civil society which was energised in conversations about the politics of markets with Gordon White [White (ed.), 1993]. While the output of Gordon's work on the politics of civil society in China ran rapidly to six papers and a substantial book [White et al., 1996] and then flowed on into fertile intellectual distributaries - civil society and democratisation [Luckham and White, 1996; Robinson and White, 1998]; the politics of social provision [Goodman, White and Kwon, 1998] and the political conditions for effective developmental states [Luckham and White, 1996] - our work on the social regulation of the Indian economy required ethnographic field research, proceeded comparatively at a snail's pace and, in the decade since the original conversations, has generated but three papers and one book [Basile and Harriss-White, 2000; McCartney and Harriss-White, 2000; Harriss-White, 2002a: 2000b]. Three strands of Gordon's work have been indispensible to the framework we use here to examine the impact of the politics of urban organisations on accumulation in South India: civil society, the politics of market organisation and corporatism. In this introduction, first, we will outline the framework of 'social structures of accumulation' (henceforth SSA) and then weave in these strands.

\footnotetext{
The authors are very grateful for swift and constructive comments on the first draft from Neil Armstrong, Chris Fuller, P.J. Krishnamurthy. They also wish to thank M.V. Srinivasan and hundreds of citizens of Arni for their co-operation over the period 1993-97; and Kaveri and Elinor Harriss for tackling some of their parents' fieldnotes from 1983 and 1973 and Maxine Molyneux and the editors for their comments at and after the Gordon White Memorial Conference, IDS, April 1999. They take sole responsibility for any errors which remain.
} 
The school of SSA challenges the conventional double reductionism of capitalism to markets and of markets to the economic domain. While orthodox economics externalises the regulative environment, SSA gives it pride of place. It seeks to examine the growth and change in capitalist systems through the complex of social institutions that enable the collection of factors of production, the transformation of money into the means of production, the organisation of production and the reconversion of the product into money [Kotz, McDonough and Reich, 1994]. Institutions and their interrelationships evolve as a period of accumulation comes into being and is sustained, but the consolidation of this institutional matrix has the capacity eventually to undermine the very system it has created. The motors of accumulation may include: institutions structuring labour and management and those managing demand and consumption; the character of industrial organisation; the institutions of finance; the role of the state and of political parties; social institutions of race and gender and the dominant culture or ideology. At the core of this ambitious intellectual agenda is a question about how this continually changing set of structures ensures or undermines stability, by reducing class conflict, conflict within capital and conflict between concentrations of capital.

We use this framework here to help answer the question: within the set of institutions underpinning capitalist accumulation, what is the role played by organisations of civil society? In his political analysis of markets, White [1993: 7] grants civic organisations a prominent and contradictory role as shapers of the politics of market organisation. Competition has to be subordinated to collective action for purposes of endogenous regulation. Yet these conditions 'protect the market position' of participants, through unearned rents, to the detriment of those excluded. The balance between positive (regulatory) and negative (exclusionary) effects of such organisations, White concluded, 'needs more thought and investigation' [ibid.]. That is our purpose here. Beforehand, however, we need briefly to introduce and define other key analytical building blocks: civil society, caste and corporatism.

\section{Civil Society, Caste and Corporatism}

White et al. define civil society as 'a sphere of free social interaction and organisation which is separate and independent of the State' [1996: 1]. But the term is heavily contested, depending on the terms of the juxtaposition of state to civil society [Keane, 1988]. To add relevance to our study of civic organisations and a new structure to the SSA, we draw some insights from Gramsci [1975]. Civil society consists of the political, cultural and ideological hegemony which a social group exercises over society and by 
means of which the economy is regulated. The Gramscian concept of civil society combines two spheres of social life: economic interests and ideology. The institutions which result (including those crucial for accumulation) are the outcome not only of social contradictions and conflicts but also of the ideological factors by means of which social consent is gained and interests are imposed. Ideology is then recognised as being a major component of the institution-building process.

Two aspects of Indian development - rapid social and economic change and an increasing social complexity - reinforce the relevance of a Gramscian approach. Caste, in both its ideological and its politically organised forms, is central to both aspects.

Caste is 'a specifically Indian form of civil society', characterised by both 'continuity and change' [Fuller: 1996]. Legitimated directly from, 'inextricably intertwined with', Hindu religion and yet transcending Hinduism, caste persists in the foundations of Indian society. The constraint of caste on Indian economic performance has long been debated. That economic liberalisation, and modernity more generally, will dissolve the caste system is now a common insight [Mendelsohn, 1993; Panini, 1996; Jayaram, 1996], seeding hypotheses about determinants and consequences. While castes contribute to the architecture of Indian civil society, each individual caste is a 'dynamic force in interest articulation' [Jayaram, 1996]. While 'modernisation' has undermined or transformed the organisation of caste, it has also revealed its 'tremendous flexibility' [Jayaram, 1996]. Caste groups have shifted ritual position, due to the increasing contact of lower castes with the 'great Hindu tradition' [Karanth, 1996]. The process whereby 'a low caste takes over the customs, ritual, belief, ideology and style of life of a high caste' with the objective of improving 'the economic and political position of the group' is known as 'Sanskritisation' [Srinivas, 1989: 56]. Sankritisation in turn accompanies 'modernisation' by which is meant - very specifically - an increasing dissociation of castes from their hereditary occupations. The combined effect of 'modernisation' and of the contested implementation of positive discrimination via the Reservations policy of the Indian Government has been the emergence of a 'dual culture' [Karanth, 1996; Radhakrishnan, 1996]. Castes attempt to claim a low or backward status in relation to the state, while claiming and protecting a high status in relation to society.

The secularisation of caste in India is widely thought to have involved a separation between the Hindu religious sphere and the social-economic sphere. As Béteille suggests [1996: 158], the caste system has been 'truncated': its future 'not with religion but with politics'. If 'modernisation' has reworked caste, the question then is what kind of political society is currently 
being shaped by this transformed institution. The recent literature shows how caste still plays a major continuity role as the economy diversifies. Many occupations, particularly dirty ones, remain caste-clustered. This clustering, however, can be (and has been) explained by the distribution of skills and resources, by the imperfections of the labour markets affecting the control of individuals over information on economic opportunities, rather than with reference to the caste hierarchy per se [Panini, 1996]. Instead of dissolving caste, liberalisation has revealed a deeply segmented social structure in which caste is connected with networks of other civil organisations that comprehensively regulate economic and social life [Uphadya, 1997; Reiniche, 1996]. The point to note is that distinctions of status, even if they might still be expressed in the idiom of caste, are rooted neither in a caste system nor a caste hierarchy, whose legitimacy has been eroded, but rather in social groups whose differences are legitimated in economic terms [Fuller, 1996].

We can now turn to our hypothesis: that the form of social regulation emerging from the secularisation of caste is corporatist. Corporatism is a form of regulation of the relations between labour, capital and the state, which is based on a specific economic order entirely compatible with authoritarianism [O'Sullivan, 1988]. The play between interest groups defines the associative order that governs social interaction and shapes the SSA. The role of the state may vary, and a common distinction is made in literature between state and societal corporatism (reviewed in White [1996]). In the first form, the state plays a 'directive' role and dominates the relationship both with the corporatist associations and between them. In the second form, theorised by Schmitter [1974] and Cawson [1985], corporatist associations are relatively independent from the state. Here the state performs the role of 'interest intermediation'. Corporatist political exchange combines three sets of interests: the state, capital and labour. The state is no neutral arbiter; instead it is the active synthesiser of corporatist ideals and values, the repositary of a vision of society in which the power of capital and labour is unsymmetrically distributed and biased towards capital. In a corporatist economy, civil society, political society and economy overlap [Mancini, Perrillo and Zagari, 1982].

The neo-corporatist argument is highly relevant to our project on contemporary India. Organisations of economic interests may be created and/or controlled by the state for its own project of accumulation. Such institutions may not contribute to the democratisation of society. Quite the reverse. An alternative conception of the role of institutions of collective economic interest (business and trade associations) is opened up - from that of narrow advancement to that of the mediation of potentially conflicting 
interest. And in the concrete circumstances of South India attention is alerted to the relationship between caste as a means of organising occupation and its evolving relation to the state.

\section{THE TOWN}

Our empirical material is of two types: a series of three field enquiries into the organisation of local urban capital, labour, commodities and their politics, by means of business histories obtained from random six per cent samples of commercial enterprises in 1973-74, 1982-84 and 1993-94 [Harriss, 1991]; and a systematic set of histories, gathered in 1997, of almost all the groups and associations with which the business economy of a small town is linked and in which it is embedded: market organisations, political institutions and civil society associations.

The market town is Arni, located in northern Tamil Nadu and acting as a central place for more than a hundred villages. It is $150 \mathrm{~km}$ south-west of Chennai with an economic base of administration, commerce (increasingly wholesale), paddy trading and milling, silk saree weaving and the workshop manufacturing of gold ornaments. Five per cent of its population is agricultural. According to the censuses, its population has grown from some 39,000 in 1971 to over 60,000 in 2001 . The municipality, created in 1951 and upgraded in status 1971, has already engulfed 11 revenue villages. In fact the population directly associated with Arni's urban economy is likely to approach 100,000 , the census population being inflated by transients and by regular commuters from its ring of satellite villages. These resist incorporation into the municipality because of the increases this would make in local taxation - a fact which makes local urban government chronically relatively underfunded.

During the last 20 years the number of businesses visible to our census record of businesses in Arni has trebled. In late 1993 the transformation in its economic base over the previous decade had been nothing short of astonishing. A number of agricultural and 'traditional' artisan activities have declined significantly or disappeared altogether. Agricultural inputs firms have stagnated (as had agricultural production). The activities comprising the economic base ten and twenty years ago have consolidated their position: rice mills have doubled in number as have food wholesaling firms and durable consumer goods retail units, goldsmiths and pawnbrokers. Urban silk manufacturing units have increased by 50 per cent and have spilled over massively into the countryside. Deregulation has led to a threefold increase in fuel depots and increased urban and rural incomes have generated demand for a 30 -fold increase in businesses dealing in non-food agricultural products. 
New businesses attest not only to the metropolitanisation of economy and culture but to its rapid globalisation. Brand new telecommunications technologies have appeared: satellite and cable TV (and ways to poach it) and new telecommunications rental markets have spread throughout the urban area along with courier services, xerox and video libraries. The town can now give up at least 20,000 'doses' of cinema per day. The explosion of finance companies and chit funds, many not registered, many run with black money, the appearance of insurance, stocks and share dealing services, specialised commercial agencies for corporate industry, architectural, accountancy and real estate professions attest to the emergence of sizeable elite markets. Tuition centres, typing and computing institutes and students' hostels indicate new patterns of skill acquisition and freedom for young people (although the town is extremely underdeveloped with respect to education). Auto sales and rentals, tourist cars and vans businesses have responded to local piety, curiosity and incomes (for tourism is inextricably linked with pilgrimages and shrine-hopping). Prominent expansions of hotels, bakeries and sweets stalls and booths indicate new patterns of commensality. Modernisation has not simplified the institutional fabric. Quite the reverse. All these developments have added to the institutional complexity of the town. But while in terms of numbers of enterprises the town appears a model of a growth centre, the prevalence and distribution of black finance capital suggests that there is a substantial element of accumulation which is non-productive. From field research we estimate that the output from trade and the income from finance equals or exceeds that from productive industry in Arni.

The vast mass of businesses are family firms with small labour forces. The average number of livelihoods (seven to eight per firm) has not changed much over the period 1973-93. The proportion of purely family firms (petty commodity producers and traders) has risen from 28 per cent to 35 per cent over the 20-year period, while the proportion of family labour in the entire labour force has remained static at around a quarter. The composition of this work force has changed with the entry of female family members of all castes. The mills however have become increasingly 'satanic' over time, through the casualisation of their labour force. Casual labour has increased from 23 per cent of jobs to 57 per cent between 1973 and 1993.

Forward Caste control over business is stable in absolute terms and their apparent proportional decline masks the massive increase in concentration of their capital. Backward Castes (BCs) have gained ground as owners, while Most Backward Castes (MBCs) and Scheduled Castes (SCs) make up around 80 per cent of the casual labour force.' Ten to 15 per cent of firms still only employ labour of their own caste. In the great majority of firms using wage 
labour, workers form an emulsion of caste.

In the 1990s, the town has swept by a new wave of accumulation from the lower agrarian castes that is primitive in two senses of the term. First, though capitalist production relations have been long entrenched, each individual capitalist has to develop his (sic) own starting point for accumulation. This primary capital may be obtained by inherited profits and assets but may also be got legitimately from loans and from savings from wage work. Second, however, another element in these initial resources, even when acquired in the modern economy, is got in 'primitive' ways through the exploitation of informalised and rightless labour, through crime, fraud and corruption [Harriss-White, 1996]. Not accustomed to the concept or practice of state-mediated accountability, never having been taxed as agricultural producers, their subsequent trajectories of accumulation are also fuelled by tax evasion.

\section{THE POLITICS OF ACCUMULATION IN ARNI}

Field material shows that of late Arni's economy has been organised into a large number of private and state institutions (66 of them in 1997), covering all aspects of social and economic life, and regulating it at the levels of the (male) individual, the household and the collective. Some are of long standing. Public service and public sector unions, together with some of the politically militant but numerically small service castes, were the first institutions to be created in the early part of the century. But over half have appeared since 1980 and 35 per cent in the 1990s. The latter are based on new principles of organisation: new political parties, town level, cross-caste organisations, trade associations for new goods and services, organisations for scheduled castes and a handful for women. Many associations have a cross-class nature and individuals (men) participate irrespective of their class position. This aspect of corporatist organisation is most apparent in the castecum-occupational associations but it holds for others, particularly welfare and charitable organisations. The interests of culture and religion also come to be organised increasingly through caste associations. Then such organisations come not only to reflect culture and religion but also political and business objectives. Indeed the latter come to dominate the organisations and the urban economy cannot operate without them.

There is a strong ideological element to these groups. Alongside a regulative economic agenda and claims from the state, practically every caste association aims to improve their own welfare and solidarity, reproducing within a caste an echo of the distributional rules that formerly operated between castes in this region. Groups representing more economically 
powerful interests also aim to improve (or to be seen to improve) the welfare of the town itself, albeit through small acts of redistributive charity which are also open to interpretation as legitimating accumulation. These attempts at self-regulation and economic governance are supported by a widespread ideology that conceals class interests under the veil of the wider interest of the 'community'. It is worth stressing that the strength of 'town-unity' extends across religions. Of some significance is the role of Muslim businessmen not only as Muslims but also as businessmen, as representatives of the town and as collective investors in (secular) educational infrastructure egregiously neglected by the state [Harriss-White, 2002a].

Caste is also a key pillar of the ideology in which the town presents itself a 'unified body'. To date it is showing no sign of the erosion foreseen by Panini and others. Instead it is being selectively reworked to mean different things at different positions in the economic system of the town. Among Scheduled Castes and Most Backward Castes, caste remains a condition of hierarchy in which higher castes are repelled from low-caste occupations, in which access to higher-caste occupations is prevented. Caste is the more subtly present when it cannot even be used as an idiom in the organisations struggling for income and status. These have to be labelled by occupation: sanitary workers, fruit and vegetable sellers organisations. By contrast, among Backward Castes, caste is more a matter of difference, economically competitive and increasingly internally differentiated. Here we see the contradictions of practices signifying a rise in status on the one hand and pressure on the state to lower status for the purposes of positive discrimination on the other. At the top, caste ceases to have an apparent role to play in formal economic regulation, though it certainly does not cease to have a role in economic and social life. It continues to supply the grounds for marriage alliances, which in turn structure joint control over commercial assets, the reputation of firms and access to credit. So there is a distinct interplay between the economy and caste (and caste-based occupational) associations, which reveals the flexibility of caste, the reworking and distancing between caste and religion and the adding of economic regulative functions both to the institution of caste per se and particularly to its formal associations. For if castes are 'truncated and secularised' institutions which have lost their religious bearings, they are ineluctably vital as regulators of the economy. It seems that the sanskritising agenda of the caste associations has been sacrificed on the altar of the economy.

The interplay between caste and the economy may be differentiated but it is consistent with corporatism. Corporatism, let us recapitulate, limits class conflicts inter alia by involving both capital and labour in the 'self-government' of the economy. It rests on two pillars, one institutional and one ideo- 
logical. Toegther they impregnate production relations and link economy and society in a distinctively corporatist manner. In this we think caste plays a triple role. First, it provides an ideological backcloth for the corporatist 'project'. Second, it generates, and is consistent with the formalisation of, the institutional structure on the back of which corporatist organisations have evolved. In this urban society, caste still supplies the kind of hierarchical order that was entrusted to the state in the Italian case [Mancini et al., 1983]. Through the caste system, the link between ideology and institutions is particularly strong. The ideology itself, in distinguishing castes, is the source of the institutions - caste and closely related, finely defined occupational associations. Third, caste helps in the creation of the conditions for the overlap between economy and society that are necessary for the working of the corporatist project. The corporatist ideological and institutional framework imprints production relations, the main features of which can be distinguished through: (1) class relations; (2) gender; (3) the local territorial organisation of the urban economy and (4) relations between the urban economy and the state.

\section{Capital-Labour Relations}

The town is organised according to the needs of local 'big' capital. However, local 'big' capital does not act in concert, but is divided by commodity and by caste. It is not weakened by such a political configuration. Rather the latter may be seen as the hydra-headed alignments of a numerically small sector which maximise a set of tactical advantages. Witness for example the ubiquitous atttempts collectively to regulate and control via the state where necessary the markets in which these firms are enmeshed: those for raw materials, money, rates in derived markets and most particularly labour. The modalities of labour control include wage rates but also the means of increasing 'absolute surplus value' (the terms and conditions of work, the length of the working day and week, the extent and periodicity of holidays, the deliberate use of casual female and child labour).Through this control, capital is able to transform labour productivity extensively and without a rise in mass consumption. In so doing capital frequently flouts the laws regulating and protecting labour. At the same time accumulation is permeated with petty crime and with widespread fraud particularly with respect to every aspect of taxation.

Labour is weak and not organised. Independent trade unions are almost non-existent and party political support is opportunistic. Associations of low castes and unions of workers are no different from big commodity associations in this respect. There is practically no organised complaint or rebellion about working conditions, in spite of the fact that, as the major business asso- 
ciations reported, the town is close to full employment. A modern proverb has it that 'Caste is the strongest trade union', but even among low-caste workers, caste is not organising 'labour' in opposition to 'capital'. In certain castes, occupations with a long history of caste-identification are vigorously defended for a mixture of purposes, such as social identity, insurance, trust and economic reputation, job security and credit, but extremely rarely for class identity. Caste has become an instrument to regulate workers' participation in the economy, rather than to legitimate caste/class opposition or to position people in a ranking of ritual status.

Capital and labour are out of balance as far as class consciousness is concerned. The capitalist class has a strong identity that is reinforced by convictions about the duties of the local elites in promoting urban welfare, while labour has a very weak perception of its class identity due to the absence of political representation and to the pervasive presence of caste. But there are other institutions than caste which structure accumulation and with which caste is more or less entwined: gender, locality and the state.

\section{Gender}

While just under half the workforce is female, while a handful of businesses are managed by women, practically no business is owned by women and corporate associational life is intensely male. Educated women, extremely few of whom are Scheduled Caste and even fewer Backward Caste, have economic niches in clerical jobs in local government, medicine, teaching, and a toehold in the professions. It is very rare to find a woman lawyer or member of the police force. Even in the late 1990s, those with other skills, such as computing, worked in organised-sector firms outside the locality, on the outer periphery of Arni's collective life. The economic role of women is largely confined to being the vehicles for transfers of assets at marriage and to buttressing the ideological legitimation of the business/caste elite through cross-caste and class philanthropy. Women are but tiny minorities in a few caste and trade associations and where they form an important minority their corporate affairs are managed by men, just as the interests of labour are frequently managed by capital. As labour, women are deliberately casualised and attempts to organise them are crushed. Urban civil society therefore tends towards the reinforcement of patriarchy in the market economy. By contrast, it is the local state which has provided opportunities for the relative empowerment of women, through education and through employment, though women are still conspicuous by their absence in the higher ranks of the administration. 


\section{Locality}

There are two aspects of locality which shape the organisation of the economy. First, since the tidal wave of commercial capitalist expansion in the 1960s, the town has organised itself as a social unit across caste and to a lesser extent across class and gender. The purposes of this unity have evolved. At first socially redistributivist, they developed to include enabling and claiming activity and latterly to substitute for the state. In its new, composite role, 'town unity' is pitted against the state as much as providing a crutch for it.

The second aspect of the organisation of locality concerns its spatial and political dynamics. Those civil-social organisations which are not federated operate politically at the level of local municipal government, monitoring the local state and demanding public infrastructure. But the majority of civil social organisations are components of hierarchical federations with their apexes in state or national capitals. This has two further ambivalent consequences: local organisations have access to higher levels of skill and resources in their political and economic projects; but they may also be construed as passive conduits of information and instructions from headquarters and/or to be mobilised reactively in a competitive political arena sited elsewhere.

\section{State}

The economic role of civil-social organisations is part self-regulative but for the most part it is directed towards the state. The state in the town is empowered to organise, mediate, protect, regulate and redistribute economic resources. In doing so it redistributes economic power between the genders, shapes the fortunes of castes, creates and regulates classes and formalises locality. If it ever was a secular institution, it is definitely being desecularised in the current era. Its efficacy is being shaped by the private social status of its officials [Harriss-White, 2002b]. At the same time, it is also riddled with incompetence, arbitrary bureaucratic behaviour and oppressive practices. Private interest and private discretionary power generate corruption and the party-political capture of discretionary bureaucratic power feeds rivers of private tribute. Much more quantitatively important than corruption, however, is fraud, in which the benefits of non-compliance are shared between individual politicians and the local business elite. Clearly, this is a collaborative state. But one thing its collaboration does not involve is control over the civil-social institutions described here. The state does no more than permit and tolerate this form of corporatist regulation. 
It is this state to which political appeal is made through caste and trade associations. Our field material suggests seven aspects to this set of claims: (i) price controls and subsidies to combat the unruliness of market exchange; (ii) regulation (particularly of urban space while other aspects of the state's regulation of markets are energetically contested); (iii) direct commercial intervention (trading in raw materials or finished products, regulation of access, terms and conditions of finance and loans); (iv) infrastructure (not only physical infrastructure but also financial and social); (v) reservations and employment; (vi) collusion over control of labour; (vii) taxation. The sites, scales and political outcomes of these seven fronts for civic contestation vary. But as long as the state is embroiled in these struggles - and from our evidence its role is intensifying rather than declining over the decade of liberalisation [McCartney and Harriss-White, 2000] - there will persist not only the well-chronicled tension between political inclusion and economic exclusion but also the less acknowledged tensions about the terms of political inclusion. Those terms require the state to have an active redistributive role in the economy, while the resources with which to carry out this role are threatened by domestic tax evasion and international loan conditionalities.

An increasingly restive political society with new, and newly assertive parties and organisations representing lower castes, many of which have democratic formal structures of authority, does not necessarily mean that civil society is democratising. Instead, as electoral democracy deepens, a politics other than party-electoral politics is also emerging. Electoral politics is suffused with caste competition and caste blocs. Party political alignment and caste compete as principles for votes. The town is at a stage in its political development when electoral politics takes the shape of 'capitalist business', requiring private investment, employing labour and yielding profit. Returns accrue not simply through the crude and time-bound mechanism of votes but through more subtle and enduring returns to corrupt intermediation, fraud, non-compliance and contractual allocations that are all possible once in power.

\section{CONCLUSION}

So Arni's societal corporatist regime of accumulation accords with a Gramscian concept of civil society. In Arni's civil society can be found the political, cultural and ideological hegemony of a single social group - the capitalist class - over the entire society. This class exerts its hegemony with the important support of a strong ideology based on transformations to caste. Due to the reinforcement of caste, patriarchy and the rhetoric of the town 
unity, economic interests and ideological factors overlap in exactly the manner Gramsci thought to be the essence of civil society. In this sense, the institutional framework of civil society is the outcome of social contradictions and conflicts, that are resolved thanks to an ideological framework the main role of which is to gain consent for the hegemonic project of the local capitalist class. Through the caste system and through patriarchy, ideology comes to form a significant component in the local social structures of accumulation.

\section{NOTE}

1. See Basile and Harriss-White [2000: footnote 18] for a discussion of caste nomenclature.

\section{REFERENCES}

Basile, E. and B. Harriss-White, 2000, 'Corporative Capitalism: Civil Society and the Politics of Accumulation in Small Town India', QEHWPS 38, www.qeh.ox.ac.uk: (Queen Elizabeth House Working Paper Series).

Béteille, A., 1996, 'Caste in Contemporary India', in Fuller [1996a].

Cawson, A., 1985, 'Varieties of Corporatism: The Importance of the Meso-level of Interest Intermediation', in A. Cawson (ed.), Organised Interests and the State, London: Sage.

Fuller, C., 1996a, Caste Today, Delhi: Oxford University Press.

Fuller, C., 1996b, 'Introduction: Caste Today', in Fuller [1996a].

Goodman, R., White, G. and H.-J. Kwon, 1998, The East Asia Welfare Model: Welfare Orientalism and the State, London Routledge.

Gramsci, A., 1975, Quaderni del carcere, Torino: Einaudi.

Harriss, B., 1991, 'The Arni Studies: Changes in the Private Sector of a Market Town, 1971-83', in P. Hazell and C. Ramasamy (eds.), The Green Revolution Reconsidered: The Impact of High Yielding Varieties in South India, Baltimore, MD and London: Johns Hopkins, pp.181-212.

Harriss-White, B., 1996, 'Liberalisation and Corruption: Resolving the Paradox', in B. HarrissWhite and G. White (eds.), Liberalisation and the New Corruption, IDS Bulletin, Vol.27, No.2, Brighton: Institute of Development Studies, pp.31-40.

Harriss-White, B., 2002a, India Working: Essays on Economy and Society, Cambridge: Cambridge University Press.

Harriss-White, B., 2002b, 'India's Religious Pluralism and its Implications for the Economy', QEHWPS82, www.qeh.ox.ac.uk (Queen Elizabeth House Working Paper Series).

Jayaram, N., 1996, 'Caste and Hinduism: Changing Protean Relationship', in Srinivas [1996].

Karanth, G.K., 1996, 'Caste in Contemporary Rural India', in Srinivas [1996].

Keane, J., 1988, 'Introduction', in J. Keane (ed.), Civil Society and the State, London and New York: Verso.

Kotz, D.M., McDonough, T. and M. Reich, 1994, Social Structure of Accumulation: The Political Economy of Growth and Crisis, Cambridge: Cambridge University Press.

Luckham R. and G. White (eds.), 1996, Democratisation and the South: The Jagged Wave, Manchester: Manchester University Press.

McCartney, M. and B. Harriss-White, 2000, "The "Intermediate Regime" and "Intermediate Classes" Revisited: A Critical Political Economy of Indian Economic Development from 1980 to Hindutva', QEHWPS 34, www.qeh.ox.ac.uk (Queen Elizabeth House Working Paper Series). 
Mancini O., Perrillo, F. and E. Zagari (eds.), 1982, La teoria economica del corporativismo, 2 vols., Napoli: ESI.

Mendelsohn, O., 1993 'The Transformation of Power in Rural India', Modern Asian Studies, Vol.27, No.2, pp.805-42.

O'Sullivan, N., 198), 'The Political Theory of Neo-Corporatism', in A. Cox and N. O'Sullivan (eds.), The Corporate State. Corporatism and the State: Tradition in Western Europe, Aldershot: Edward Elgar.

Panini, M.N., 1996, 'The Political Economy of Caste', in Srinivas (ed.) [1996].

Radhakrishnan, P., 1996, 'Mandal Commission Report: A Sociological Critique', in Srinivas (ed.) [1996].

Reiniche, M.L., 1996, 'The Urban Dynamics of Caste: A Case Study from Tamilnadu, in Fuller [1996a].

Robinson, M. and G. White (eds.), 1998, The Democratic Developmental State, Oxford: Oxford University Press.

Schmitter, P.C., 1974, 'Still the Century of Corporatism?', Review of Politics, Vol.36, No.1.

Srinivas, M.N., 1989, The Cohesive Role of Sanskritisation and Other Essays, Delhi: Oxford University Press.

Srinivas, M.N. (ed.), 1996, Caste: Its Twentieth Century Avatar, Delhi: Viking.

Uphadya, C., 1997, 'Culture, Class and Entrepreneurship: A Case Study of Coastal Andhra Pradesh', in M. Rutten and C. Uphadya, Small Business Entrepreneurship in Asia and Europe, Delhi: Sage.

White, G., 1993, 'The Political Analysis of Markets', in G. White (ed.), The Politics of Markets, Institute of Development Studies, IDS Bulletin, Vol.24, No.3.

White, G., 1996, 'Chinese Trade Unions in the Transitions from Socialism: Towards Corporatism or Civil Society?', British Journal of Industrial Relations, Vol.34, No.3.

White, G., Howell, J. and Shang Xiaoyuan, 1996), In Search of Civil Society in China, Oxford: Clarendon Press. 


\title{
Bias and Capture: \\ Corruption, Poverty and the Limitations of Civil Society in India
}

\author{
ROB JENKINS and ANNE MARIE GOETZ
}

This chapter seeks to explain why India's otherwise vibrant and diversified civil society has, for the most part, been so unsuccessful at combating forms of corruption that disproportionately afflict the poor. Contemporary thinking on governance assumes civil society's comparative advantage in representing the poor, concluding that associations representing the interests of non-elite groups can act as 'watchdogs' on the state, compensating for failures by formal accountability institutions at curbing corruption. Indeed, some analysts have suggested that the state can 'foster' the emergence of civil society associations capable of articulating the views of the poor - for instance, through decentralisation, programmes that extend legally enforceable rights to the poor and the creation of forums for policy dialogue.

In this chapter we argue that for any of these 'state-fostered' forms of civil society to be effective in combating the corruption of particular concern to the poor they must be empowered to scrutinise the details of public-sector spending. This degree of transparency is much greater than normally envisaged in recent efforts by states to foster better representation for excluded groups. Likewise, the intensity of confrontation with the state that results once access to official documents reveals specific evidence of corrupt acts tends to be greater than expected by the state when it 'fosters' civil society engagement. Using a selection of case study material from India,' this chapter takes issue with these currently fashionable views on the state's ability to foster the emergence of civil society associations that can effectively challenge faulty or corrupt state decision-making. We also contribute to the wider debate on the capacity of civil society to act as an effective accountability institution for less privileged citizens. We do this in two stages. First, we review the relationship between accountability failures and the types of human development deprivations from which the poor suffer. Second, we analyse the means by which the state can undermine the 
autonomy or compromise the integrity of the very civil society associations which might most be expected to represent the poor: trade unions, for instance, or associations of marginalised people.

Thus we focus in this chapter on two key factors that account for the shortcomings of civil society as an effective vigilance institution. First, corruption that directly affects the poor is embedded in a network of accountability failures that includes both other varieties of institutional 'capture' as well as forms of institutional 'bias'. Bias seriously erodes accountability for marginalised people, but is qualitatively different from the overt venality and collusion that characterise 'capture'. The mutually reinforcing properties of capture and bias - the tendency for one type of injustice to create the conditions for the perpetration of another - has consistently undermined efforts by peoples' organisations to combat forms of corruption that afflict the poor.

The second factor concerns the nature of civil society itself: its capacity to curb corruption is hampered by the extent to which crucial actors in India's associational domain are themselves 'compromised'. The lens of capture and bias is useful here as well. Whereas debates about corruption and accountability have neglected bias while focusing on capture, it is the reverse with respect to the issue of civil society. The bias of civil society organisations towards middle-class concerns has been well documented. This is particularly so when civil society groups promote anti-corruption campaigns: these often focus on spectacular instances of high-level venality, but not on the more mundane and regular pilfering of development funds which so profoundly undermines the quantity of resources and quality of services reaching the poor. But the capture half of the equation has not received much attention. And yet, it is the state's capture of civil society that is undermining pro-poor movements against corruption.

The Indian cases demonstrate the potential for state-fostering to produce precisely the kinds of 'compromised' civil-society organisations which inhibit the emergence of the most effective form of anti-corruption movement: one based upon the premise that citizens have a right to audit government finances in minute detail. This raises suspicions that state-fostering of civil society, whatever its merits, comes at a heavy price: the proliferation of associations unwilling to migrate from 'safe' forms of participation to those which involve confronting powerful elites and challenging the state's prerogative of auditing its own financial conduct. Such groups appear disinclined to demand and obtain sensitive government records, let alone organise ordinary people to analyse such information to determine where funds allocated for their benefit have actually gone.

On the other hand, some surprising groups - operating mainly in the 
realm of identity politics - have emerged in some regional contexts to demand accountability on issues of social justice. This has implications for conceptions of civil society and its relationship to the state.

\section{THE INDIA CASE MATERIAL AND ITS RELEVANCE}

An innovative movement in the state of Rajasthan has substantially altered India's public discourse on how best to combat forms of corruption which particularly afflict the poor. Spearheaded by the Mazdoor Kisan Shakti Sangathan (MKSS), or Workers and Farmers Power Organisation, this movement demands and frequently obtains access to official expenditure records which citizen-activists then cross-check in a 'jan sunwai' - a public hearing, or a kind of people's audit. The MKSS's collective process has exposed fraud in several local governments, deterred further malfeasance in others, influenced legal debates, ${ }^{2}$ and generated a wider campaign for legislative and regulatory change at the state and national level.

Several organisations within India's vast and varied civil society share either the MKSS's concern for empowering the poor by halting the theft of public resources intended for them, or its enthusiasm for actively challenging the culture of bureaucratic secrecy - but not both. Many environmental activists, for instance, demand access to government information; their primary aim, however, is not checking misuse of public funds intended for the poor. Other groups share the MKSS's preoccupation with combating corruption, but without emphasising the type of popular auditing which only access to official records makes possible. In short, no other group has brought together the otherwise overused and underspecified ideas of transparency and accountability in such a creative, consistent, and collective fashion. This chapter suggests reasons why it is particularly difficult for civil society to organise effectively to curb forms of corruption which disproportionately harm the poor.

In the process, we engage with ongoing debates in the international literature on civil society's contribution to accountable governance, and on the state's ability to 'foster' the emergence of pro-poor forms of civil society. The Indian case material highlights the unpredictability of state-civil society interactions at the best of times, and the outright undesirability of many associational forms that have been fostered through state action. Their willingness, let alone ability, to contribute to a campaign against corruption is doubtful. Our argument is not that state-fostered forms of civil society are always dysfunctional, just that they often are. Moreover, even those that do produce desirable outcomes fail to challenge the state in one critically 
important area: auditing the financial performance of government itself. Even in Latin America - where most of the evidence for the optimistic view of state-fostered civil society has been drawn - efforts to promote popular auditing (as opposed to participatory planning) are conspicuous by their absence. Few governments are willing to endow citizens with the extensive rights to information which are required for effective auditing of public spending. But in addition, few state-sponsored civil society associations are willing to engage in the adversarial tactics required for a meaningful audit of government decision-making and spending. They may be unwilling to jeopardise their relationships with the state, or may not be anxious to invite excessive scrutiny of their own accounts, organisaiotnal relationships, or decision-making patterns.

This is a particularly suitable theme for a volume celebrating Gordon White's contribution to development studies. Gordon's intellectual inclinations, particularly his scepticism about 'the current idealisation of the democratic character of civil society', indicate a thinker far more alert than most students of democracy to the potential for civil society to evolve in ways that defy conventional understandings, and sometimes even to serve undemocratic ends. ${ }^{3}$ Much of his work on China, for instance, illustrated with complex empirical evidence the ambiguous character of civil society, and above all the unpredictability of associational entities created through state action [White et al., 1996].

This is by nature a perverse paper: it uses the case of a highly effective anti-corruption movement - a success story if ever there was one - to illustrate why it is so difficult for other civil society groups that promote the interests of poorer groups to combat corruption. But the more one learns about the MKSS - and the more one examines other anti-corruption movements which at first glance seem to parallel the MKSS approach, but turn out to lack crucial ingredients - the more exceptional this grassroots movement seems. What is needed is an explanation for the overwhelming tendency of nascent anti-corruption movements to fail in their efforts to recruit allies among civil-society organisations oriented towards mobilising the poor. This requires an introduction to what makes the MKSS and its struggle for a constitutional right to information such an unusual phenomenon, bearing in mind that it is the contrast between this ideal type and the many other less effective organisations that is the analytical starting point. 
The MKSS is a grassroots organisation of mainly poor people based in Rajasthan's economically underdeveloped Rajsamand district. It has described itself as a 'non-party political formation'. ${ }^{5}$ It relies for support less on its relatively small formal membership than on its much larger informal following. The driving force behind the MKSS is a combination of local people from socially excluded groups and a handful of committed activists from other parts of India who, since the late 1980s, have made the area their home. The MKSS distinguishes itself from conventional non-governmental organisations (NGOs): it accepts no external institutional funding and it does not focus on service delivery. It uses adversarial mass action and confrontation with the state administration to expose the misuse of public funds on anti-poverty programmes, and to struggle for a formal right to information so that it can gain better access to official accounts.

The MKSS's interest in the right to information arose from its work in the late 1980s and early 1990s on livelihood issues, particularly the failure of the state government to enforce minimum-wage regulations on employmentgeneration programmes in drought-prone areas. This generated a belief that access to official documents was an essential part of the struggle to demand accountability from local authorities. The MKSS's campaign to secure minimum wages for employees on drought-relief works highlighted the role of corruption in the underpayment of wages, as it became clear that local authorities were billing the central and state governments for amounts that far exceeded what workers were paid. This could only be confirmed by examining the financial documents pertaining to specific schemes, and checking these against the experience of workers. Other malpractices included inflated estimates for public-works projects, the use of poor-quality materials, and over-billing by suppliers. To combat these forms of fraud, access was required not only to balance sheets, but also to supporting documentation which could be cross-checked by workers organised through the MKSS - for instance, employment registers and bills submitted for the purchase of materials.

The MKSS gets this documentation by appealing to the virtue of sympathetic bureaucrats, or through public protest action aimed at those with less active consciences. Its key innovation is the collective analysis of official information. In locally organised jan sunwais - or 'public hearings' expenditure statements derived from official records are read aloud to assembled villagers. These orderly hearings are presided over by a panel of respected individuals from within and outside the area. Local people are invited to give testimony which identifies discrepancies between the official 
record and their own experiences as labourers on public-works projects or applicants for means-tested anti-poverty schemes. Through this direct form of 'social audit' many people discovered that they had been listed as beneficiaries of anti-poverty schemes, though they had never received payment. Others were astonished to learn of large payments to local building contractors for works that were never performed. This approach depends upon a principle of collective and very local verification of official accounts, as it is only at the local level that the many small diversions of funds, which go unnoticed in massive formal audits, can be detected.

Although successful in exposing corruption in a number of localities, $j a n$ sunwais have been relatively rare because of the difficulty in obtaining certified copies of government accounts from reluctant officials. In response, the MKSS developed a parallel strategy involving large-scale public protests demanding legislative and regulatory reforms to provide a legal basis for local efforts to obtain official records. The main demand is that citizens be entitled to photocopy government documents, except those with nationalsecurity implications. The state government vacillated in response to this demand throughout the latter half of the 1990s. In spring 2000, after a change of government, the new Congress administration finally passed a right to information law, supported by an amendment to the Panchayati Raj (local government) Act to institutionalise public audits of local government spending by village assemblies. ${ }^{6}$

\section{THE LIMITS OF CIVIL SOCIETY}

Robert Klitgaard has set forth several factors that he sees as accounting for civil society's poor track record at organising to fight corruption:

it is difficult to form a political constituency for an anticorruption effort. Unlike lobbies for, say, soya production or education, no well-organized citizens' group has a clear stake in fighting corruption. Moreover, civil servants often find anticorruption campaigns threatening. Honest officials may fear being tarred with a reckless accusation; dishonest ones will raise obstacles against efforts to expose and punish their illicit activities. It is possible to launch an anticorruption campaign during a wave of public resentment, but institutionalizing public concern is difficult [Klitgaard, 1991: 97].

This argument has added weight when we consider the many, mutually reinforcing, ways in which corruption can afflict the poor. India's right-to-information movement has focused attention on the way in which impacts can be felt across three dimensions of citizenship. Each corresponds to a critical relationship in which citizens must engage - with the state, with the market, 
and with civil and political society. The first is the pilfering of state resources intended to benefit the poor (such as subsidised food). When resources devoted to programmes intended for universal provision (for poor and nonpoor alike) are diverted through corrupt practices, this has a disproportionately negative impact on the poor, since unlike many other segments of society they are ill-prepared to substitute private provision.

Second, the ability of the poor to achieve market gains is also impaired by corruption. Not only does the draining of public resources for such public goods as education and healthcare impair the market prospects of the poor, but the failure to enforce laws regulating market behaviour - which is due more to corruption than administrative incompetence - has dire consequences for many of their number. When policing of the market is lax, collusive relationships between firms and other organised economic agents (such as agricultural co-operatives) can diminish whatever scant benefits poorer citizens may have been able to derive from their productive activities or from redistributive programmes implemented by the state.

The third dimension of citizenship through which corruption affects the poor concerns participation in civil and political society. The skimming of state resources at local levels tends further to enrich those groups in rural society responsible for denying social and economic opportunity to the poor in the first place. Their collective prestige and influence, combined with the collusive relationships they forge with state officials, can thwart the nascent self-help activities of poorer groups in the political sphere. For instance, state officials whose services have been bought to rig agricultural markets and evade taxation are not likely to call out the police against their powerful accomplices when they engage in violence or intimidation to prevent poorer people from attending village assemblies or organising their own public meetings. It is through such sustained relationships between local elites and the state administration that networks of corruption - spanning the domains of developmental activity, market transaction and organised politics - have their most devastating impact on the poor.

\section{RECOGNISING CAPTURE AND BIAS IN HUMAN \\ DEVELOPMENT DEPRIVATIONS}

Awareness of corruption's multiple impacts - seen through the lens of citizenship - is the first step in understanding why corruption is a particularly difficult ill for civil society intervention to help rectify. Injustices are interlocking and cumulative, while adversely affected groups are fragmented and fight one battle at a time. Campaigning and advocacy work has been pursued 
in relatively self-contained issue areas, which tend to correspond to one of the varieties of deprivation that accountability failures create for poor people. This has blunted its force.

But if we look beyond the citizenship model to a perspective informed by 'human development' concerns, it is possible not only to see the importance of other kinds of specificities - such as the diversity of means by which people are subjected to human development deprivations - but also the larger phenomenon of institutional accountability failure of which corruption is just a part. To understand this it is worth looking at the ways in which some of the critical deprivations that afflict the poor can be traced back to a lack of genuine accountability.

The next section of this chapter outlines accountability failures afflicting poor people with respect to three key deprivations which are both a cause and a symptom of poverty. These are the lack of access to:

- Sustainable Livelihoods, particularly land and fair wages.

- Capability-Enhancing Services, particularly education and health-care.

- Physical Security, particularly freedom from abuse (and neglect) by police.

A range of accountability institutions is supposed to prevent the systemic abuses that lead to these deprivations, or to punish those responsible for them and thus deter future violations. That they fail with depressing regularity is evident from the persistence of these deprivations.

However, as is suggested by the analysis of case-study evidence in this section - which ranges beyond India to demonstrate its relevance to global debates - the reasons for institutional failure are not reducible to corruption, defined generically as the abuse of public office for private gain.

The failure of accountability institutions - especially those that allow human deprivation to thrive unchecked - is caused by two interrelated, but analytically distinct phenomena: capture and bias.

The category of capture consists mainly of corruption, but also other forms of undue influence that do not, technically speaking, constitute corruption in that they stem from the intimidation faced by officials (from, for instance, politicians and the criminal underworld) rather than from an interest in direct pecuniary gain.

Bias-related accountability failures, on the other hand, occur when the poor remain disadvantaged because of built-in impediments to the reduction of the deprivations they face. This takes at least two forms. First, accountability 
institutions may simply have no remit for punishing officials whose actions produce a pattern of bias against the poor. In other words, their terms of reference focus on procedural correctness rather than the achievement of positive outcomes for the poor. Even when policy or programme design - the eligibility for a welfare entitlement, for instance - is clearly biased against underprivileged sections of society, accountability systems are often unable to take action, or at least perceive themselves to be impotent to intervene.

Second, there are often anti-poor biases built into the mechanisms through which disadvantaged people are entitled to use accountability mechanisms directly, such as the access restrictions that face litigants who might wish to seek judicial remedies against powerful state or non-state actors.

The human development deprivations discussed in this section have their roots in the failure of four main accountability institutions, each of which fails for reasons of both capture and bias, as indicated in the descriptions below:

- Reporting systems within bureaucratic hierarchies, in which subordinates are accountable to their superiors, but in which disciplinary procedures are either insensitive to the special conditions facing the poor or too remote from the sites of injustice that require remedy, allowing collusion between officials and their supervisors.

- Oversight or regulatory agencies that fail to take action against the public or private bodies over which they exercise jurisdiction, either due to outright corruption or the undue influence exerted by political leaders or interest groups.

- Electoral systems that fail to create incentives for representatives to promote the interests of the poor, or which are infested with fraudulent practices or legally permissible avenues for influence peddling.

- Judicial proceedings that provide little direct or indirect protection for the poor because of the limited access they provide, their use of foreign languages, their reliance on investigative machinery of biased executive agencies, or simply bribery of judges and court officials.

\section{(a) Sustainable Livelihoods}

The opportunities for disadvantaged people to engage in sustainable livelihoods is impaired by the failure of accountability institutions. A good deal of this is due to the anti-poor 'bias' variant of accountability failure. For 
instance, economic policies routinely discriminate against people working in the informal sector. But corruption and other forms of 'capture' also impede the ability of accountability institutions to defend the livelihood prospects of the poor.

Access and secure title to land are among the most important assets that can help people to improve their chances of a better life. However, many public actions ostensibly designed to promote access to productive resources fall prey to accountability failures. Land reform legislation is one area which has rarely produced the desired results because of collusion between sellers and buyers to overstate land prices, divide the surplus between them, and let the government absorb the costs. Conventional financial monitoring of such transactions often fails to stamp out such abuses because on paper, the transactions appear legitimate. This accountability failure is largely one of capture compounded by bias.

Accountability institutions have also fared poorly in the task of ensuring that poor and vulnerable people have access to credit for productive purposes. This happens both directly and indirectly. The indirect form arises when failures related to other sorts of livelihood concerns take their toll on the ability of people to access credit. The more direct route by which oversight mechanisms fail to ensure access to credit for the poor involves their inability to detect or prosecute cases of corruption in government credit programmes. This is particularly important as corruption in formal credit markets can affect the rates offered through informal sources [Gupta and Chaudhuri, 1997: 331-43]. A study by Transparency International Bangladesh found that people accessing credit from the formal banking sector paid a direct bribe of between two and 20 per cent of the loan value. This wide range reflected the diverse socioeconomic profile of respondents, but the '[1]arger percentages are extorted from uneducated rural applicants'. Moreover, these farmers faced higher demands for bribes than the more affluent borrowers seeking commercial loans, 'because the bribe is usually shared with government officials that may be involved in the loan review process', including the many functionaries at the local level. The bribes received by local officials 'percolate up to District and higher levels and neutralize the monitoring function of the administrative hierarchy' [Munshi, 2000].

But these fees are just for obtaining the loan. In order to obtain an assurance from rural branch managers of state owned banks that they will not actually have to repay the loan, borrowers pay up to 50 per cent of the value of the loan. These promises are not generally honoured, but an audit by Bangladesh Bank, revealed that branch managers had forgiven at least 1.6 billion taka in interest payments without authorisation. The very fact that 
poorer Bangladeshis are forced to collude in such illicit transactions - and to pay a fee for the right to access credit under such conditions - undermines their willingness to play a role in demanding accountability or protesting against corruption, a theme developed in the second half of this chapter.

\section{(b) Capability-Enhancing Services}

Appropriate and affordable basic services are essential for the poor to enhance their human capital base and to make the most of their physical assets such as credit or land. The key services for building human capital are education and health care. Whether these services are provided by the state or the private sector, ${ }^{7}$ all over the world poor people experience serious obstacles to accessing and fully benefiting from basic capability-enhancing services, obstacles which are a combination of capture and of bias in service delivery and design.

It is well known that elite biases among both designers of basic services, and the service providers themselves, produce a marked preference for urban and high-cost tertiary-level social services, such as hospitals and universities, as well as for new and high-technology investments in infrastructure, rather than in maintenance of existing facilities or their extension to poorer areas. This skewed distribution of basic services reflects the lack of voice of the poor in determining the types of public services that should be available, their physical location, terms of access to services, and the nature of interactions between service providers and clients.

Elite bias in public-service design and delivery is also reinforced by high-level corruption, which directs public funds away from basic social services and into investments that produce bigger commissions for corrupt officials, such as defence contracts and large-scale infrastructure construction projects, and diverts funds from the types and levels of services which the poor most desperately need, such as spending on textbooks and teacher training.

Accountability instruments such as administrative reporting procedures, professional and service-level performance standards, and oversight bodies often fail to correct for the social biases embedded in application procedures for basic services that end up disqualifying the most needy applicants. Longdistance travel, literacy, or eligibility requirements which demand possession of scarce formal documents, become insurmountable access barriers to basic services and act as screening mechanisms to exclude poor clients.

Where poor people overcome access barriers to public services, they may encounter a fresh set of problems: contemptuous treatment by service providers, or else discrimination in service provision that endows poor 
clients with less of the public resource which is their due. Examples abound of high-handed, patronising, rude, or outright abusive nurses, teachers, police, and local government officers. Where service providers use their discretion to deny full services to their least privileged clients, patterns of discrimination may follow class, race, ethnic, or gender lines. Health care workers in India, for example, selectively provide less information on contraceptive choices and side-effects to poorer women or women from remote areas [Murthy, 1999]. Such examples reinforce the impression that bias and capture go hand in hand. Accountability institutions that simply address capture will remain unable to address these 'bias' problems until they adopt new norms for assessing performance.

Beyond the failure of audit institutions and oversight agencies to control for corruption in the funding and delivery of services, inadequate disciplinary and reporting systems within the public administration are the greatest culprits for the many exclusions, humiliations and poor-quality services endured by the poor. These represent the institutionalisation of bias. Performance standards used to asses quality in public services may fail to measure whether access barriers to the poor have been lowered, or to assess whether their particular needs in relation to services such as health, education or housing are addressed. Regulatory oversight bodies and licensing systems run by independent or government-supported professional bodies are very unlikely to report to the disadvantaged clients of services; their reporting patterns are oriented towards the top levels of the bureaucracy and government. Informal accountability institutions that cultivate quality controls among service providers, like the peer reviews and self-regulation that are provided by medical associations or teacher training systems, may not only fail to encourage professionals to address the particular problems and needs of the poor, but usually function to preserve the self-interests of professionals over their clients.

\section{(c) Physical Security}

The poor are often the primary victims of violent crime and human rights abuses, whether committed by fellow citizens or by state agents such as the police. Certain types of violations of physical security affect specific vulnerable groups almost exclusively. Crimes such as rape and domestic battery, for instance, are mostly suffered by women and children, while racial and ethnic minorities can be subjected to systematic, organised physical assault.

While physical insecurity is itself a form of diminished human development, it also undermines health and well-being, and causes poor people to shy away from investing in their futures or broadening their income- 
generating efforts. Girls may not be sent to school for fear of sexual assault on the way there or in the classroom.

In some countries, the police, far from acting as defenders of public order and security for all citizens, can be the agents dispensing violence and terror. Or they can preside over polarised justice systems, by under-policing or ignoring lawlessness and violence in poor communities, while protecting the property and rights of the wealthy. Where violence is perpetrated by the police, and left unpunished by the courts, the poor rarely expect to receive fair treatment from state officials. Multiple accountability failures produce this impunity in police behaviour. The organisational culture of the police, which should act as an accountability institution by supporting professionalism and respect for the law, reinforces the difficulties of checking police lawlessness. But judicial systems support the police's assault on the poor by prosecuting and convicting crimes committed by the poor, and not elite crimes, such as tax evasion or financial crimes. The judiciary also fails to prosecute crimes from which the poor suffer more than other groups, particularly violent crimes in low-income neighbourhoods or in rural areas.

Corruption and intimidation of the judiciary account in part for the failure to prosecute police impunity. But a bias in favor of police impunity and against a fair hearing for the poor is built into several important procedural aspects of the legal system. For instance, human rights activists argue that judicial systems that consider confession the key form of evidence create incentives for the use of torture [Bolivar, 1999: 43]. The emphasis on written procedures also creates access barriers - alienating non-literate plaintiffs. Other access barriers that keep the poor from prosecuting abuses against them more effectively are laws of legal standing, which may make it difficult for the poor to sue the government collectively in civil suits and thus overcome informational, financial, and psychological barriers to holding officials to account.

Perhaps the most disturbing accountability failure behind the inadequate prosecution of crimes of violence against the poor is at the level of public tolerance for police brutality directed against the poor. In many countries impunity is virtually assured for those who commit offences against people considered 'undesirable' - for instance, against ethnic minorities, or social outcastes such as the homeless, sex workers, orphans, and the extremely destitute. In such cases the law and the police serve as a form of 'border guard' not just protecting elites, but acting as an instrument of elite domination and oppression [Pinheiro, 1999: 7]. This is the extreme case where capture intersects with bias. 
As argued in the introductory section of this chapter, the existence of these multiple forms of deprivation, combined with the tendency for accountability failures to consist of both capture and bias - with each reinforcing the other - has presented a very inhospitable environment for anti-corruption civil society groups, even those seeking to focus specifically on forms of corruption that afflict the poor. The existence of other variants of state capture, and the pervasive anti-poor bias in state institutions, means that gains in one field are often easily offset in others, due to the recurrence of accountability failures by other agents of the state.

\section{COMPROMISED ALLIES}

This discussion of capture and bias, and how the two combine to produce various forms of human development deprivations, is only the first of two key reasons why civil society activism has faced such serious obstacles when it has sought to combat corruption. The second has less to do with the accountability deficits of the state than with the corrupted nature of civil society itself. There are several seemingly natural civil-society allies for any movement to tackle forms of corruption which particularly afflict the poor, and yet they fail consistently to provide the kind of support required. What the MKSS's experience seems to indicate is that anti-corruption campaigns require both broad-based participation in protest action and grassroots initiatives to involve ordinary people in auditing public expenditure at the local level. The latter in particular is missing. This is because many organs in civil society that would be expected to contribute substantially to pro-poor anticorruption movements are themselves 'compromised'; they are implicated in the system which perpetuates corruption, and indeed accountability-related deprivations more generally. There are three worth considering.

The first is perhaps the most well known: traditional non-governmental organisations (NGOs), many of which engage in dubious business practices. In India, as elsewhere, many are outright crooked, siphoning funds to those who control them. Others are more complicated: their lack of institutional capacity means that they are unable to monitor intermediaries who deliver funds and services, leading to resources being pilfered further down the line. Another segment of the NGO community consists of organisations which are both clean and efficient, but nevertheless dependent on the government's goodwill to operate with any degree of effectiveness. They are vulnerable to intimidation, especially if they receive foreign funding.

Surveying India's NGO community for potential replicators of the collective-verification approach pioneered in Rajasthan's jan sunwais, one 
finds few signs of hope. Senior representatives from two large foreignfunded NGOs in southern Rajasthan told us that they had no intention of pursuing the sorts of methods the MKSS had, though they were willing to acknowledge the positive impact of both the right-to-information campaign and the jan sunwai approach. ${ }^{8}$ They voiced elaborate justifications for why the MKSS method was not suited to their way of working, or why the MKSS, because it focussed on government-administered employment-generation schemes, was uncritically accepting the state-directed 'development paradigm' - thus neatly attempting to out-flank the MKSS on the left ideologically. The fear of backlash from the state appeared a more convincing explanation of these NGOs's unwillingness to champion participatory auditing despite their involvement in projects ostensibly designed to make local government more responsive to the poor. The state could, if it wanted to, detect any number of real procedural or ethical lapses on the part of NGO staff, and is more than capable of inventing others to get its intimidatory message across.

The second seemingly natural civil-society contributors to a transparency-based anti-corruption movement are trade unions - often the only force in a political system with the organisational muscle required to mount a sustained campaign to promote the interests of non-elite groups. Though sometimes derided as a 'labour aristocracy', unions in the organised sector have a direct interest in combating forms of corruption that undermine hardwon worker rights - for instance, ensuring that illicit income does not undermine the integrity of occupational-health inspectors. A democratic virtue often claimed for the trade union sector of civil society is a capacity to act as a watchdog over government's performance of its regulatory duties - something for which access to information is critical.

What is preventing organised labour from playing this role in India? Among other things, corruption. While in theory the ability of workers to switch union affiliation or vote out their representatives should reduce union leaders' scope for obtaining corrupt income, in practice the grip of mafialinked syndicates on union organisations is often strong enough to prevent the emergence of serious alternatives. The case of the textile workers' union in Mumbai illustrates how corrupt civil society organisations can pose a considerable obstacle to the emergence of movements to make the state accountable to the poor. The legally recognised union, the Rashtriya Mill Mazdoor Sangh (RMMS), is under the direct control of criminal gangs operating under the patronage of senior politicians. The RMMS has systematically undermined the efforts of a dissident mill-workers' union, the Girni Kamgar Sangharsh Samiti (GKSS), to combat corruption. The GKSS has charged company managements with failing to live up to their commitments 
under government-sanctioned mill-modernisation plans. Their further charge is that government regulators have turned a blind eye in exchange for a share of the spoils.

The central government's statutorily created Board for Industrial and Financial Reconstruction approves plans put forward by chronically lossmaking companies, and many of these have been in the textile sector. The revival packages include permission for mills to sell portions of their century-old real estate holdings in central Mumbai in order to raise funds for industrial modernisation. The officially recognised RMMS is permitted to learn all of the details of the approved plans, as are the regulatory bodies within the state and municipal governments. However, the RMMS has failed even to look interested in performing its watchdog function. In the absence of information detailing the exact concessions granted to the companies and their corresponding commitments under the revival plans - for instance, the amounts of land to be sold, the proportion of the proceeds earmarked for jobsaving modernisation, the timeframe and sanctions stipulated in the agreement - it is impossible for the GKSS effectively to challenge the managements (and the government agencies charged with regulating them) for their failure to fulfil their responsibilities. The unquestionably corrupt and violent RMMS leadership holds a monopoly over that information - or rather holds civil society's stake in the tripartite information oligopoly that also includes the state and the private-sector mill owners. The RMMS is quite clearly a civil-society organ impeding efforts among other actors in civil society to use transparency to combat corruption.

The third seemingly natural civil-society allies of an anti-corruption movement are associations which poorer people have been able to build on the basis of claims made against the state - for instance, radical groups of forest dwellers, who have none of the mainstream anxieties of NGOs or trade unions. Leadership figures, such as resource-rights activists, are no more susceptible to elite backlash because of their activism than they already are due to their social and economic marginalisation.

Ordinary members of these organisations are, however, beset by a problem with potentially serious implications for their ability to take up active roles in campaigns demanding greater transparency, or to pursue variants of the jan sunwai method. Like trade unions and NGOs, they are implicated in corruption, though in a very different sense. The case of people living on designated forest land helps to illustrate this point. Many have had their traditional sources of livelihood drastically undermined by government forest policy. A good many occupants of government forest land are illegal encroachers who are able to remain in place by paying off forest and other land-revenue officials. While this sort of coerced bribery is not the moral 
equivalent of the kickbacks pocketed by trade-union leaders, it nevertheless leaves the participants vulnerable. Rather than forming an extra battalion in the anti-corruption army, the people who make up organisations of this type can be disproportionately unwilling to risk exposure of what is, after all, illegal behaviour. Many fear, not unreasonably, that they (not the powerful landowners doing the same thing on a larger scale) will be the targets of a biased crackdown. They do not possess legal title to their land, and could be shoved off quickly. At the very least they are susceptible to scare stories of this type from local elites who might try to discourage them from contributing to anti-corruption efforts.

\section{IMPLICATIONS FOR THEORIES OF 'STATE-FOSTERED' CIVIL SOCIETY}

Two of these three seemingly natural, though ultimately unhelpful, allies in the struggle against corruption share the characteristic of having been brought into being largely through interaction with the state. NGOs are the most clear-cut case: they receive state funds in many cases, and carry out what were conventionally state tasks. As for labour organisations, industrial relations legislation in many sectors (including textiles) recognises specific unions, which are then granted far-reaching exclusionary powers over their competitors. The poor people's movements are in a different category. They may not have direct relationships with state organs, but very often are largely the creation of misguided state interventions - for instance, associations of people displaced by large hydro-electric dam projects. They exist politically to demand compensation from the state for particular actions, and to insist upon a radical overhaul of state policy.

That trade unions and NGOs are products of state action acquires analytical significance in the light of recent theoretical tendencies in the study of civil society's contribution to accountable governance. Stemming from a sense that the pendulum had swung too far in the direction of dichotomising state and civil society, conceiving of them as natural antagonists operating in zero-sum terms, several recent studies have emphasised the state's role in catalysing the emergence of specific civil-society organisations, or promoting conditions under which a 'thickening' of civil society can take place [Evans, 1996; Rueschemeyer et al., 1985]. Unfortunately, while seeking to rectify a conceptual imbalance, the new theoretical wave has taken an unnecessarily benign view of the state's part in this dialectic.

Rebecca Abers's [1998] study of a participatory budgeting process in Porto Alegre, Brazil, is perhaps the best example of this theoretical tendency. 
Abers argues that the conventional wisdom has got the relationship between civil society and democracy all wrong. The accepted position has long been that states tend to crowd-out civil society - that is, that social networks are most likely to solidify into agents for change when the state is in retreat. But Abers argues persuasively that the participatory municipal budgeting process in Porto Alegre was a particularly striking case of what she calls 'statefostered civic organising'.

In Porto Alegre, neighbourhood associations and other defined interests have an almost continuous influence over the process of setting agendas, establishing spending priorities, scrutinising budget line items, and so on. The views of these associations enter the municipal budgeting process through their participation in a range of state-created debating and decisionmaking bodies. Abers's empirical evidence supports her basic theoretical claim: that a government programme can result in 'a successful state-sponsored effort at capacitating civic groups'. She thus contests the view that the state is 'highly unlikely actually to encourage autonomous civic groups to form' [Abers, 1998: 514].

Abers's work is part of a longer-term effort, dating to the mid-1980s, to recast debates on the origins and growth trajectories of civil societies by 'bringing the state back in' to our understanding of how polities evolve [Rueschemeyer et al., 1985]. Peter Evans [1996] subsequently elaborated this concept to include the mutually constructive roles that states and mobilised communities can play in supporting each others' developmental activities through 'state-society synergies' [Evans, 1996: 1119]. Much of the evidence for this synergy is coming from Latin America.

Empirical evidence from India broadly affirms the argument that states can indeed foster new forms of civil society. There is, however, one extremely important modification suggested by the Indian experience: while states can help to foster the diversification of associational life, the result is not always along predictable or even desirable lines. This is ignored by almost all of the work which supports the 'state-fostered civil society' perspective. It raises, further, two kinds of suspicions: first, that by focusing on isolated instances in which there were fortuitous outcomes, the literature gives short shrift to those cases of state-fostered civil society that did not produce the desired results; and second, that even successes like the Porto Alegre experiment might, because of their parentage at the hands of the state, be congenitally incapable of confronting the most self-preserving instincts of the state by demanding that details of financial outflows be subjected to public scrutiny.

Indeed, there is no mention in the literature on participatory budgeting of complementary procedures for a participatory approach to auditing expendi- 
ture. There is no systematic mechanism for opening up all the supporting documentation which makes an accounting statement meaningful and makes it possible for ordinary people to carry out the time-consuming task of verifying and falsifying the state's 'account' of development - by inspecting physical premises and interviewing ordinary people to obtain their testimony. Whether in Brazil ${ }^{9}$ or Uruguay [Chavez, 1999], the civil society actors spawned by the structure of state programmes and processes have not gone beyond vague references to transparency and 'open government'. In Bolivia, where the 'Law of Popular Participation' has taken the concept of collective engagement furthest, there is evidence that some of the local associations involved in the budgeting process have themselves become implicated in patronage politics, and in some cases outright corruption [Blackburn, 1999: 12]. Moreover, in the case studies on which Evans constructs his vision of state-society synergies, which centre on cooperation in the delivery of services, it is striking that there is no discussion of states facilitating the critical auditing function civil society groups need to play if they are to hold the state accountable to their poorer citizens.

\section{UNINTENDED CONSEQUENCES: IDENTITY POLITICS AND THE ACCOUNTABILITY GAP}

The emphasis thus far has been on the extent to which state-fostered forms of civil society either become corrupt - and thus unhelpful in fighting corruption - or appear disinclined to develop in the radical directions which would support the more optimistic claims of those who study them. This is not the same thing as saying that the state's role in shaping and indeed inducing the emergence of particular expressions of civil society will always produce negative results. Rather, it highlights the substantial likelihood that outcomes will deviate from original expectations - something which aid and development organisations fail to recognise at their peril. The other side to this story of unintended consequences is that other instances of state-fostered civil society - in fact, those originally viewed with suspicion - can end up generating capacities to make the state accountable to poor and vulnerable people. We illustrate this point with two examples from India's fragmented efforts to promote transparency.

The first illustrates how miscalculation on the part of governing elites can throw open unexpected spaces for civil society. In late 1997, the Goa state government passed a landmark right-to-information law. The intent of the original bill had little to do with increasing either access to or dissemination of information which might make government more accountable. 
Instead, the bill included provisions which appeared to discourage press freedoms. Fears that an attempt was being made to muzzle the media triggered a protest campaign organised by the Goa Union of Journalists - until then, a fairly moribund organisation. This mobilised a tremendous cross-section of civil-society groups working on issues such as the environment protection, sustainable tourism, and gender equality. Ultimately, the government bowed to pressure and removed the law's anti-press provisions.

The irony is that in an attempt to control the press the state government provided Goa with India's only reasonably solid right-to-information legislation. By grossly miscalculating the level of opposition the bill would generate, the state created an opportunity for a diverse array of civil society groups to coalesce over a procedural matter and a liberal right which affects them all. These groups have continued to work together to pressure the state government to implement the law's provisions for citizen access to information, and have embarked on a campaign to motivate even more organisations in civil society to make use of the act.

The second example of unintended consequences of state-fostered civil society concerns another phenomenon neglected in the theoretical literature: the tendency for distinct 'sectors' in civil society to redefine themselves and assume new roles in response to state action. An examination of the civilsociety actors which have used the transparency provisions grudgingly put in place by India's state governments in recent years reveals a curious phenomenon: the great interest shown by associations based on ascriptive identity. Such groups, it is important to note, are often portrayed as the enemies of norm-based governance: by pressing for benefits for specific communities they are seen to promote patronage, populism, and in some cases sectarian conflict. No development agency would encourage an aid-recipient state to 'foster' them deliberately.

And yet in India they are performing the important function of demonstrating to other less well-organised associations the potential relevance of government transparency to poorer people. In Goa, for instance, the Gomantak Bahujan Samiti (GBS), a federation of 'backward caste' associations ${ }^{10}$ has used the state's new right-to-information legislation to expose the politically motivated process by which 'backward' status was granted to a large and, according to the GBS, socially and economically privileged caste. The GBS filed a petition under the Goa Right to Information Act (GRIA) requesting access to the administrative files pertaining to that decision. One of the cabinet notes prepared by the Social Welfare Ministry indicated that the decision of whether to award backward-caste status to this group was referred not to the legally sanctioned Goa State Commission for Backward Classes, but to the legislature caucus of the ruling Congress Party. The 
decision, not coincidentally, was made during an election campaign, and the caste group in question was considered a potentially important electoral constituency for the ruling party. Following the GBS's presentation of its documentary evidence, the High Court halted the implementation of the government's decision to confer backward-caste status on this group. The GBS subsequently used the GRIA to research compliance with affirmativeaction laws by obtaining information from all government bodies about their staff composition. These experiences have placed the GBS at the forefront of civil society's attempts to promote use of the law and to pressure the bureaucracy to implement it.

Another instance of ascriptive associations performing the functions one might have expected from other more 'functionally defined' groups in civil society comes from the southern state of Kerala. By setting aside 40 per cent of plan funds for Kerala's elected village councils - and enacting institutional reforms to support this process - the state's Left Democratic Front coalition government, in office between 1996 and 2001, went a long way towards involving people in the process of setting their own developmental priorities. In addition, right-to-information provisions have been added to Kerala's local-government legislation. One of the few civil society organisations to make use of them sought to trace whether funds intended for socially excluded groups actually reach their targets. The Kerala Pulayam Maha Sabha (KPMS) has pressed a number of village councils to reveal how they spent funds ostensibly earmarked for dalits, the most oppressed members of the Hindu social hierarchy. State law stipulates that 11 per cent of villagelevel plan funds be devoted to activities to benefit dalits. And on paper they are. The reality can be very different. For instance, village councils often count the entire cost of constructing a road against the 'special component' (that is, dalit) budget head because one or two dalit families happen to reside alongside it. To reveal these misleading accounting practices requires access to and analysis of actual expenditure documents. The KPMS has thus far been unable to obtain these, despite staging sit-ins in front of village- and district-council offices.

There are numerous other examples of identity-based associations stepping in to fill the gap where other, more 'modern' organisations have failed to establish a practical link between transparency and accountability. Organisations of tribal people in the state of Andhra Pradesh, for instance, have forced the government of chief minister Chandrababu Naidu to make good on its commitment to responsive government: they have obtained access to land records dating back decades as part of a process for adjudicating claims to land expropriated over the years by both state and private entities. 
Apart from being based on appeals to ascriptive identity, the other thing these groups have in common is a credible claim to having been statefostered. The electoral system in India reserves a proportion of seats in elected bodies for India's dalit and tribal communities. Government jobs and places in educational institutions are also awarded on a quota system which gives priority (in theory) to dalits, tribals and members of 'other backward castes'. These legal provisions have given rise to associational entities that would otherwise not likely have emerged in anything resembling the form they have now.

Thus, civil society elements whose emergence is fostered by the state can end up serving purposes very different to those originally intended by either side. ${ }^{11}$ In the light of Gordon White's theoretical work on civil society, it is worth briefly mentioning one other conclusion that can be drawn from this case: that civil society's 'ascriptive-identity' facet has more in common with the 'functional-interest' facet than is often acknowledged. He pointed out that the literature on civil society's role in expanding civil liberties excludes 'ethnic associations seeking sectional advantage' as much as it does 'business groups bent on buying political influence' - both of which are seen to promote undemocratic 'forms of public behaviour and political accountability'. But, as he consistently maintained, the 'argument that only certain types of civil society can perform this [democratising] role, namely those that emerge from a process of modernisation', greatly limits our understanding of the complexity of civil society and the potential contribution of civic associations excluded from this narrow definition [White, 1994: 383]. ${ }^{12}$

\section{MISSING PUBLIC AUDITING'S TRANSFORMATIVE POTENTIAL}

Despite these welcome, if unintended, contributions, the relative paucity of civil society organisations capable of promoting the interests of poor and marginalised people threatens to return the right-to-information idea to its bourgeois-liberal roots, depriving it of the transformative potential the MKSS has demonstrated. For instance, despite the GBS's good work in Goa, the main users of the new right to information have been urban middle-class people, using the law not to hold the government to account for its commitments to social equity, but to protect their own property rights, pursue business interests, or to improve the quality of tertiary education enjoyed by their children [Jenkins and Goetz, 1999a]. There may thus be additional hidden costs to some variants of state-fostered civil society: the tendency to produce 'trickle-down politics' - that is, the hope that the initial over-representation of middle-class concerns will give way to agendas relevant to disprivileged 
groups. To date, there is very little evidence of this taking place in India.

In short, state-fostered forms of civil society seem not to be good at demanding and obtaining opportunities to engage in perhaps the most sensitive area of governance: auditing the performance of government itself, particularly with respect to the expenditure of resources. Indeed, India's most impressive example of state-fostered civil society has in its early years also proven notably disinclined towards popular auditing. The self-help and neighbourhood groups established under the People's Planning Campaign in Kerala have generated a great number of democratic benefits, but (the work of the KPMS notwithstanding) organising to strike at the local roots of the corrupt system has not been one of them. Again, the state's hand in fostering the emergence of this form of civil society appears at least partly responsible for this shortcoming. The NGO contracted by the state government to 'assist' in forming local associations is closely connected to the main party in the state's ruling coalition. As with the participatory budgeting processes in Latin America, the substantive involvement of Kerala's people in development planning has not yet led to greater demands for inclusion in systematic public auditing of actual expenditure. Another way of stating this as a more general proposition is to say that state-fostered civil society organisations do not seem well-suited to operating along the lines pioneered by MKSS.

But could not the MKSS - the benchmark against which others are being measured - itself be seen as state-fostered? If it can be, then the entire concept of state-sponsored civil society becomes so all-encompassing as to signify nothing. Indeed, this question throws into sharp relief a more basic conceptual problem with the theoretical literature: it is unclear what forms of state action qualify as 'fostering'. A start in the right direction would be to identify two qualifying categories. The first consists of civil-society responses organised directly by the state, with roles corresponding to the functional requirements of specific government programmes. The classic cases are public-works projects or complex subsidy bureaucracies, where social forces coalesce around a set of reasonably concrete demands pertaining to the operation of a programme. The Porto Alegre case, as a clear example of a process which produced a particular form of civil society response, sits fairly comfortably in this category. In the second category are cases which indicate the influence of the state's institutional structure on the formation or operation of civil society; these include such variables as the relations between tiers of government and the details of the electoral system. Again, the Porto Alegre experiment would qualify to the extent that the autonomy of municipal governments in Brazil shaped the willingness of the local authorities to incorporate civil society so closely into the process of participatory budgeting. In India, electoral rules which include measures to 
support the representation of women or of people from 'backward castes' create incentives for these people to organise themselves to benefit from reserved seats and other earmarked opportunities and resources.

As for the MKSS, one could argue that it has been shaped by the necessity of acting within the framework of India's decentralised political arenas, and that it should therefore be considered a product of the institutional structure. But the MKSS - and indeed its first round of jan sunwais - preceded the Rajasthan government's establishment of new, constitutionally autonomous local-government structures. Alternatively, it could be argued that the MKSS focuses primarily on one set of government programmes employment-generation schemes. And yet, this seems flimsy grounds on which to classify the MKSS as 'state fostered'. The MKSS is in fact the alternative to precisely those forms of civil society which the Rajasthan government has deliberately sought to foster. In 1996, the state government sought to demonstrate that a right to information was unnecessary by instituting its own programme of social audit. People were encouraged to 'participate' in their localities - mostly by handing complaints to 'touring' bureaucrats, but also by setting up local vigilance committees. And yet even senior bureaucrats responsible for staging the fairly elaborate logistics admit that the programme was superficial ${ }^{13}$ - the supporting documentation required for a genuine audit was not made available - and more importantly that it generated virtually no sustainable civil-society response. ${ }^{14}$ Thus, on neither count can MKSS be considered a product of state-fostering.

\section{CONCLUSION}

This chapter has highlighted two factors that help to account for the inability of India's otherwise impressive civil society to contribute effectively to fighting forms of corruption that afflict the poor. The first is the fact that corruption is just one sub-species of accountability failure, and efforts to combat it face difficulties when they cannot simultaneously address other forms - either additional manifestations of institutional 'capture', or else one or more varieties of institutional 'bias', another species of accountability failure entirely.

The second factor is the compromised (or in some cases outright corrupted) nature of key sectors of civil society - those, in fact, that should be the natural allies of the poor. This impedes efforts to build a broader movement for accountability based on the principle that ordinary citizens are entitled to scrutinise government expenditure records.

It has also questioned generalisations in the theoretical literature 
concerning the capacity of 'state-fostered' forms of civil society to make the state more accountable to the poor. The Indian case demonstrates the potential for state-fostering to produce precisely the kinds of 'compromised' civil society organisations which inhibit the emergence of effective anti-corruption movements based on local-level popular auditing.

State-fostering, it has been argued, can also produce a range of unintended consequences which can offset this disadvantage. But the very unpredictability of this process undermines the notion that states (or development agencies) can deliberately generate such outcomes. One unintended consequence from the Indian case - ascriptive associations testing the limits of government transparency - also helps to expose the shortcomings of theories which assume a functional differentiation between the 'modern' and 'ascriptive' categories within civil society. Ironically, in Latin America - whence most of the evidence for the optimistic view of state-fostered civil society has been drawn - the kind of focused right-to-information approach which the MKSS has used so effectively in Rajasthan is nowhere on the horizon. This raises suspicions that state-fostering of civil society, whatever its merits, comes at a heavy price: the proliferation of associations unwilling to move from 'safe' forms of participation (for instance, in the setting of budget priorities) to those which risk direct confrontation with government officials and their powerful accomplices in the elite-oriented sector of civil society. Such groups appear predisposed to shy away from effectively demanding and obtaining government records, let alone organising ordinary people to analyse such information to determine where money allocated for their benefit has actually gone.

\section{NOTES}

1. Case study data were gathered in India between 1998 and 2002 by the two authors. They are grateful to the following institutions for their financial support for this research: The UK Economic and Social Research Council (grant number R00023885), the Social Science Research Unit at the UK Department of International Development, and the Ford Foundation, Delhi Office.

2. We have addressed this issue at greater length in Jenkins and Goetz [1999b].

3. This phrase is drawn from the second instalment in Gordon's two-part article on civil society and democratic development, a sceptical commentary on the optimistic and under-examined assumptions regarding the democratising role of civil society. See White [1994, 1995].

4. Space constraints limit the background which can be provided. For fuller accounts, see Mander and Joshi [1999], MKSS [1996] and Dogra and Dogra [1996].

5. In using this descriptor, the MKSS follows a stream of thinking on the role of voluntary organisations in Indian politics which can be traced to the theorising of Rajni Kothari, who coined the term in the mid-1980s. For a later elaboration of this concept, see Kothari [1990].

6. The passing of these two pieces of legislation has changed the terms of what the MKSS does. It can now better access local government expenditure data (though local bureaucrats and politicians remain deeply resistant to parting with this information, and do their best to doctor it). 
Armed with better information, its people's audits have exposed even more spectacular corruption than before - for instance in the April 2001 jan sunwai in Janawad, where such extensive corruption was exposed that there was no avoiding the holding of an official inquiry (which confirmed all of the prima facie evidence of corruption which had been exposed at the hearing). However, rather than focus on these spectacular exposures, the MKSS is hoping to encourage more effective public audits by village assemblies. It is encouraging local civil society organisations to research the gap between official spending accounts and the physical evidence of development resources spent, as well as local people's accounts of wages received or services delivered.

7. There is much current experimentation in both developed and developing countries today with privatisation of public services and public-private partnerships in service delivery. Private sector engagement in the provision of basic pubic services is supposed to increase efficiency through competition. The introduction of profit motives in service delivery is supposed to increase responsiveness to consumer choice, and also, in principle, to distance political considerations from decisions on service design and delivery. See for instance, Batley [1996: 723-57]; or the discussion of this issue in World Bank [1997].

8. Interviews, 16 and 17 March 1999, Udaipur.

9. In addition to Abers's piece, see Santos [1998].

10. Indian law provides job quotas (or 'reservations') in public-sector employment for members of Scheduled Castes (formerly known as untouchables; currently termed dalits), Scheduled Tribes, and 'other backward castes'. The latter are groups which are considered to have suffered nearly as much historical discrimination as the two former groups.

11. For a more nuanced approach to the relationship between ascriptive associations and civil society, see Chapter 8 ['Civil Society and the Politics of Identity'] of Wood [1995: 238-63].

12. This theme is elaborated in greater detail in Chapter 7 of Jenkins [1999].

13. Interview, 24 Dec. 1997, Jaipur.

14. See 'Social Audit Scheme Comes a Cropper', The Hindu (20 Dec. 1996). In February and March 2002, a more evolved set of public audits of panchayat accounts was ordered by the government in the highest-spending village panchayat in every one of the state's 237 blocks. In most of these panchayats a public official rapidly read the accounts to the village assembly the lists of monies spent on various projects, housing loans to named individuals, and so on, and marked the accounts 'approved' if there was no audience reaction. Villagers were too intimidated, or too ill-informed, in most cases, to contradict official accounts. Only where an autonomous civil society group - in ten places the MKSS itself - had the alacrity to collect the expenditure information and do the research to verify whether funds had been spent as indicated, were objections to the official accounts registered..

\section{REFERENCES}

Abers, Rebecca, 1998, 'From Clientelism to Cooperation: Local Government, Participatory Policy, and Civic Organising in Porto Alegre, Brazil', Politics and Society, Vol.26, No.4, Dec., pp. $511-38$.

Batley, Richard, 1996, 'Public-Private Relationships and Performance in Service Provision', Urban Studies, Vol.33, Nos.4-5, pp.723-51.

Blackburn, James, 1999, "Popular Participation" in a Prebendal Society: A Power Analysis of Participatory Municipal Planning in Sucre, Bolivia', seminar paper presented at the Institute of Development Studies, University of Sussex, 2 June.

Bolivar, Ligia O., 1999, 'Comments', in Mendez et al. [1999].

Chavez, Daniel, 1999, 'Cities for People', Red Pepper, June, pp.19-21.

Dogra, Madhu and Bharat Dogra, 1996, MKSS: Working for People, Learning from People (New Delhi), pamphlet. 
Evans, Peter, 1996, 'Introduction: Development Activities Across the Public-Private Divide', and 'Government Action, Social Capital and Development: Reviewing the Evidence on Synergy', both in World Development, Vol.24, No.6, pp.1119-32.

Gupta, Manash Ranjan and Sarbajit Chaudhuri, 1997, 'Formal Credit, Corruption and the Informal Credit Market in Agriculture: A Theoretical Analysis', Economica, No.254, May, pp.331-43.

Jenkins, Rob, 1999, Democratic Politics and Economic Reform in India, Cambridge: Cambridge University Press.

Jenkins, Rob and Anne Marie Goetz, 1999a, 'The Goa Right to Information Act, One Year On', Transparency, New Delhi, March.

Jenkins, Rob and Anne Marie Goetz, 1999b, 'Accounts and Accountability: Theoretical Implications of the Right to Information Movement in India', Third World Quarterly, Vol.20, No.3, pp.589-608.

Klitgaard, Robert, 1991, 'Political Corruption: Strategies for Reform', Journal of Democracy, Vol.2, No.4, Fall, pp.86-100.

Kothari, Rajni, 1990, 'The Rise of People's Movements', Social Action, Vol.40, No.3, pp.232-40.

Mander, Harsh and Abha Singhal Joshi, 1999, 'The Movement for Right to Information in India: People's Power for the Control of Corruption', paper presented at the Commonwealth Human Rights Initiative Conference on 'Pan-Commonwealth Advocacy for Human Rights, Peace and Good Governance in Africa', Harare, 21-24 Jan.

Martin, Robert and Estelle Feldman, 1998, 'India and Access to Information', Ch.8 of Access to Information in Developing Countries, Berlin: Transparency International, pp.72-87.

Mauro, P., 1996, 'The Effects of Corruption on Growth, Investment, and Government Expenditure', IMF Working Paper WP/96/98.

Mazdoor Kisan Shakti Sangathan, 1996, 'We Will Know, We Will Live: People's Struggle and The Right to Information', Rajasthan (Jaipur), mimeo.

Mendez, et al. (eds.), 1999, The (Un)Rule of Law Law and the Underprivileged in Latin America, Notre Dame, IN: University of Notre Dame Press.

Munshi, Jamal, 2000, 'Corruption in the Banking Industry in Bangladesh', Working Paper, March, Transparency International Bangladesh.

Murthy, N., 1999, 'The Quality of Family Welfare Services in Rural Maharashtra: Insights from a Client Survey', in M. Koenig and M.E. Khan (eds.), Improving Quality of Care in India's Family Welfare Programme: The Challenge Ahead, New York: Population Council.

Pinheiro, Paulo Serio, 1999, 'The Rule of Law and the Underpriveledged in Latin America: Introduction', in Mendez et al. [1999].

Rueschemeyer, Dietrich, Skocpol, Theda and Peter Evans (eds.), 1985, Bringing the State Back In, Cambridge: Cambridge University Press.

Santos, Bonaventura de Sousa, 1998, 'Participatory Budgeting in Porto Alegre: Toward a Redistributive Democracy', Politics and Society, Vol.26, No.4, Dec., pp.461-510.

Transparency International, 1998, 'Civil Society', Ch.6 of the National Integrity Systems Source Book, Part B: Applying the Framework (www.transparency.de/documents/source-book/b/ Chapter_6/index.html).

White, Gordon, 1994, 'Civil Society, Democratisation and Development (I): Clearing the Analytical Ground', Democratization, Vol.1, No.3, Autumn, pp.375-90.

White, Gordon, 1995, 'Civil Society, Democratization and Development (II): Two Country Cases', Democratization, Vol.2, No.2, Summer, pp.56-84.

White, Gordon, Howell, Jude and Shang Xiaoyuan, 1996, In Search of Civil Society: Market Reform and Social Change in Contemporary China, Oxford: Clarendon Press.

Wood, Ellen Meiksins, 1995, Democracy against Capitalism: Renewing Historical Materialism, Cambridge: Cambridge University Press.

World Bank, 1997, The State in a Changing World: World Development Report, 1997, New York: Oxford University Press.

'Social Audit Scheme Comes a Cropper', The Hindu, 20 Dec. 1996. 


\title{
Between Cant and Corporatism: Creating an Enabling Political Environment for the Poor
}

\author{
MICK MOORE and ANURADHA JOSHI
}

\section{PREAMBLE}

The political science that Gordon grew into in the 1960s was full-bodied: it dealt above all with contentious politics as a means of societal transformation. If the prospects for radical change from the left had continued to look bright after the mid-1970s, he no doubt would have hung on in there. He never became conservative by instinct. But the world did become a more conservative place. Gordon's attention shifted to more routinised forms of politics. His interest in social transformation was re-focused first on the (capitalist) developmental state and then, more latterly, on civil society. He adapted, but refused to move down either of two roads on which many of his contemporaries embarked. First, he had neither political nor professional sympathy with neo-liberalism. He would tolerate colleagues dabbling on the fringes of neo-liberal political economy (for example, public choice), but would neither encourage it nor indulge in it himself. Second, he could rarely bring himself to respect or engage with the vapidities that pass for theory or grand ideas in the formal policy statements of aid and development agencies. A rapid steer in another direction, toward real politics, awaited any student indicating an interest in writing a termpaper on, for example, 'institution building and aid' - or 'governance', 'empowerment', 'participation' and any of the other jargon terms into which development agencies continually tried to breathe life. Cant was not a word that Gordon often used. He preferred more earthy terms. He would approve of our using it here to describe the insincerity, hypocrisy and emptiness that characterises so much aid-speak.

\footnotetext{
The authors are grateful to Peter Houtzager and Judith Tendler for detailed, helpful comments on an earlier draft; and to the Department for International Development for support to the IDS poverty research programme, within which the ideas here were developed.
} 
He would be less enthusiastic about the volte face that follows immediately: our attempt seriously to address the concerns of aid agencies and to suggest how they might think about putting their money where their mouths are.

There is a substantial disjuncture between what international aid and development agencies say they want to do and what they actually do. Most have for many years accepted the principle that effective poverty alleviation should have significant collective and mobilising dimensions: they talk in terms of 'empowerment', 'participation', and framing programmes that are responsive to the demands of poor communities. In practice, they do little to advance these goals. Indeed, in some respects they have regressed: in recent years, large amounts of money have gone to new programmes that may undermine the scope for collective action on the part of the poor - while proclaiming that to be the goal (see section on 'Enabling Institutional Environments'). That is the cant to which the title refers. Aid and development agencies are probably forced into hypocrisy mainly because of the structural contradictions they face, notably the pressures to continue to disperse money and to find ways of legitimating their activities that appeal to very diverse constituencies. But genuine inability to see through the fog of fashionable jargon and to think clearly about the political and institutional issues may be part of the problem. The purpose of this chapter is to develop a set of concepts and a language that help us better to understand how 'external agencies' could contribute to the (collective) empowerment of poor people through the ways in which they design, organise, and implement antipoverty programmes in poor countries.

This definition of the problem raises several questions about meanings of the terms we use. For present purposes, some of them can be left fairly open. 'External agencies' refers essentially to government and to other organisations, mainly NGOs, that are involved in development activities. 'Anti-poverty programmes' covers any programmes that are directed mainly or solely at poor people, whether or not 'poverty' is formally part of their brief. Primary education in rural areas of most poor countries would therefore be included. 'Mobilisation', that we use as a synonym for collective empowerment, connotes both action (that is, people being involved in doing things) and organisation. Forms of mobilisation vary widely.

How might 'friends of the poor' in government or other external agencies help increase the effectiveness of anti-poverty programmes by designing organising, or implementing them so as to stimulate the mobilisation of the poor? They cannot provide, qua bureaucrats, the full range of resources that contribute to creating mobilising structures. In particular, they are poorly placed to provide ideological resources: the ideas and values around which collective action can be built. They are however potentially better placed to 
provide certain kinds of organisational resources and political opportunities. ${ }^{1}$ In principle, one can distinguish four different mechanisms (or strategies) that external agencies can use to encourage the mobilisation of the poor. Two or more may be combined in practice, but they are best treated separately for purposes of exposition.

\section{(i) Provocation}

This may in reality be the most widespread mechanism through which governments in particular succeed in mobilising the poor: angering them by treating them badly in some way - failing to truck in emergency drinking water supplies during drought; forcibly displacing people to build highways, dams or shopping malls; compulsorily acquiring foodgrains from producers at low prices, etc. Provocation is potentially a powerful instrument, but one that rarely can be wielded with finesse or precision - and which anyway involves first hurting the poor. It does not merit further discussion.

\section{(ii) Conscientisation}

This is the practice of despatching 'social mobilisers' to mobilise the poor by encouraging them to examine their situation (usually collectively) and, hopefully, to decide collectively to do something to change it. This technique is most commonly adopted by non-state organisations - political parties, religious organisations, and other NGOs of various kinds. Agencies that employ social mobilisers to work with the poor in relation to their own programmes - and there are plenty of such cases in the development field, including government agencies - are vulnerable to two kinds of moral hazard.

First, they have every incentive to discourage mobilisation once it becomes uncomfortable for them, and thus to keep it closely under control. Second, as we illustrate in section on 'Water in Nepal' below, the agencies and their field staff easily slip into the role of salespersons, trying to 'sell' to their clients (the poor) the products that the agency has available, even if they are inappropriate. Casual evidence suggests that conscientisation initiatives rarely result in much authentic mobilisation. There is little scope for agencies that are themselves running development programmes to employ conscientisation effectively in relation to their own programmes. Conscientisation is far more likely to be effective if employed by one external agency to mobilise the poor in relation to the activities of other agencies or parties. 


\section{(iii) Organisational Preference}

Government agencies, in particular, are well placed to mobilise the poor by giving preferential treatment to particular grassroots organisations that (claim to) represent the poor. This preference can have two main components, that tend to go together: recognition and licensing of certain categories of organisations (and not others); and channelling resources to the poor through those organisations, to encourage the poor to become involved. These kinds of arrangements are generally labelled 'corporatist'. But corporatism has a bad reputation. Whose interests might be served? Are we not just opening the door to co-optation: institutional arrangements through which the state mobilises and organises socio-economic groups in its own interests, and in ways that closely circumscribe the autonomy of the organisations and their capacity genuinely to represent societal interests?

The ambiguities in the corporatist relationship are captured in Philip Selznik's description of participation as 'a technique for turning an unorganized citizenry into a reliable instrument for the achievement of administrative goals'. Co-optation is a potential threat whenever a grassroots organisation enters into any relationship with a powerful external agency; ${ }^{2}$ this is especially true within corporatist structures. But co-optation and demobilisation of the grassroots organisation is not the only potential 'unbalanced' outcome of corporatism. There is an equally well established tradition of political analysis that focuses on the opposite process: the 'capture' of state agencies by the societal interests that they are attempting to organise. True the poor have limited resources through which to effect such capture. But they do have some room to manoeuvre.

Grassroots organisations may be exploited by external agencies, but at the same time exploit those relationships for their own purposes. In particular, they can enjoy leverage and bargaining power if the external agencies (a) are disunited, with elements seeking support and allies from elsewhere (b) focus their attention and energies elsewhere, leaving grassroots organisations with considerable local autonomy by default; ${ }^{3}$ or (c) are dependent in some way on a level of performance from grassroots organisations that can only be achieved through permitting them autonomy and initiative. Even explicitly corporatist systems can generate organisations that bring to the poor both resources and some degree of - often heavily contested - organisational autonomy. For grassroots political entrepreneurs have incentives to move into these organisations and to try to expand their scope and autonomy.

For example, the corporatist rural workers unions that were established in rural Brazil by military regimes in the 1960s provided both (a) 'cover' behind which local politicians, trades unionists and social activists could 
operate and (b) legitimacy for parallel organising activities conducted by the Catholic Church. They helped to lay the basis for the rich network of social movements for the rural poor that are found in present day Brazil [Houtzager, 1998]. The very existence of privileged corporatist unions encouraged opposition trades unionists to enter them and compete for power. In some cases this has generated levels of union activism and responsiveness to members well in excess of the standard expectations of corporatist arrangements [Pinhanez, 1997].

Similarly, the corporatism practised by Mexico's dominant ruling party (the PRI) has provided the means for the development of partly-autonomous local movements of the poor by opening up competition for control of public resources at local level. For example, locally-organised Food Councils were given control of food stores, supplies of subsidised basic foods and means of transport. Not all Food Councils were dominated by the local elites or by the local representatives of the PRI. There was continual struggle, which partly reflected divisions within the PRI itself. Jonathan Fox views the struggles around these programmes as an important part of the story of the gradual widening of the scope for autonomous associational activity in Mexico [Fox, 1994].

Depending very much on the political context, corporatist arrangements for giving organisational preference can encourage the poor to organise on their own behalf. We should not dismiss them as irrelevant to our concerns. They are however less than ideal. There are three significant characteristic problems:

- any degree of local organisational autonomy that is achieved is constantly under threat, and has continually to be reasserted;

- in so far as the organisations receive and redistribute public money, they may become a major charge on the government budget, with much of the benefit going to the non-poor (for example, the Mexican case above);

- granting permanent organisational preference may result in local organisational monopoly, and then in lack of accountability and misuse of resources and power. This was often the case, for example, with the corporatist rural workers unions in Brazil, with their guaranteed income from the state and monopoly control over pension funds [Houtzager, 1998].

Corporatist sponsorship of poor people's organisations is potentially a useful means through which 'friends of the poor' within state agencies can help empower the poor. But there are further options. 


\section{(iv) Creating an Enabling Institutional Environment}

The conscientisation and organisational preference strategies are activist: they involve external agencies and agencies directly doing things on behalf of the poor - and that activism itself leads to moral hazard. The main argument of this paper is that there are considerable opportunities to stimulate the effective, autonomous organisation of the poor by adopting what Gordon White would have called a more parametric strategy: establishing and maintaining a framework that would encourage poor people themselves to take a more active role. This is now orthodoxy in the context of government policy toward the private sector: do less directly, and concentrate more on creating an enabling environment. We suggest that the same argument applies to public action and the political organisation of the poor. The environment in which poor people and external organisations interact is frequently inimical to collective action by the poor. It is characterised by so much uncertainty, arbitrariness and inequality that investment in collective action is not worthwhile. External agencies should focus more on creating incentives to collective action, above all by removing the obstacles that they themselves create. Four dimensions of the 'performance' of external agencies - are of special interest to us:

- Tolerance. We take it as given that collective action on the part of the poor is more likely where the political environment is not hostile and punitive. The fact that no more is said on this reflects our belief that the point is obvious, not that it is unimportant.

- Credibility. This is essentially a behavioural concept: the extent to which, in their relations with the poor, public officials can be relied on to behave like good partners in an enterprise, that is, to do their job correctly; and to be reliable.

- Predictability. This refers to the form of external programmes: the extent to which they are stable over time in content, form, and procedural requirements.

- Rights. The extent to which (a) the benefits received under external programmes are recognised as moral or, better, legal entitlements, and (b) there are recognised (preferably legal) mechanisms that the beneficiaries can access to ensure that these entitlements are actually realised.

This looks like a wish list. The key point, illustrated by the case studies in the following two sections, is that it is not a list of preconditions for the 
creation of an enabling institutional environment. A relationship can be highly enabling in one or two of these dimensions even when the general environment appears quite bleak. External agencies do not have to perform well on every dimension in order to generate positive results. Context is all. The relationship between poor people and external agents may be enabling, in the sense in which we have defined it, both when it appears concordant (that is, co-operative and harmonious), and when it is discordant.

\section{WATER IN NEPAL: CREDIBILITY AND CONCORDANT COLLECTIVE ACTION}

The first case is a rural drinking water supply programme in Nepal that was funded by the Finnish aid agency, FINNIDA, and implemented by a Finnish consultancy company with expatriate and local staff. ${ }^{4}$ The programme design was relatively orthodox. Water projects in the mountains of Nepal are expensive; most costs were met by FINNIDA. Communities that chose to participate were required to organise themselves to make inputs into planning, construction, fee collection and maintenance. Although they contributed only a fraction of construction costs, their total commitments, in terms of cash, labour and self-organisation, were significant to them: this was not an exercise that a community would embark on lightly. Nepali government agencies undertook the investigation and design work, and much of the construction, under the eye of the aid project staff. The programme had been in operation for six years - long enough for us to judge it a success in terms of both process and outcome. A large number of water supply schemes had been built, without glaring design or construction failures. As far as we could judge, villagers had made a substantial input in most cases and exhibited a degree of ownership.

We asked villagers why and how they became involved in this programme. The lessons we learned are encapsulated in two responses:

Village A: 'We had wanted water for a long time. We heard that the Fanta Company had done a good job in Villages V and W, so we talked to them about their experience and then approached the Company.' (In many places, the term FINNIDA had been transmuted into 'Fanta Company'. Fanta is a popular soft-drink in South Asia.)

Village $B$, where we asked why it had taken the villagers three years from the time the water project was first mooted until they began to make serious progress to get themselves organised and raise resources: 'We have had at 
least four different survey teams here from the Local Government Department over the past 15 years, promising us water. They come when there is an election. We don't really trust people who come and talk about bringing us water. It took us a long time to learn to trust these Fanta people. We discovered that they had done good work elsewhere and seemed reliable.'

The reliability of which the villagers talked is what we have termed credibility. It refers to both technical competence and dependability when interacting with others. Water projects are expensive and vulnerable to poor location (especially via landslips), poor design and bad construction. If Nepali villagers invest their efforts and savings in a water project that fails or is simply never completed - they lose a great deal. The perceived credibility of the external agent is central to the willingness of communities to mobilise their own contributions. These conversations heightened our awareness that much of the interaction between poor people and external agencies is shaped by rational lack of trust on the part of poor people. Increasingly, they are bombarded by visitors from outside who ask for something from them (even if only their time in meetings) and often promise or imply some reward for co-operation. 'Someone will be back.' 'You will hear more.' 'Ask the Council Chairman in a couple of months.' To us, these outsiders fall into distinct categories: politicians; researchers; government officials; students; census officials; aid agency staff on familiarisation tours; Christian missionaries; NGO staffers; consultants, etc. It is much more difficult for villagers to draw such distinctions, to get any accurate sense of what the agenda actually is, or, above all, to get any kind of binding commitment from outsiders in return for co-operating with them. By contrast, external agencies that have established a reputation for reliability on the basis of their performance are at least serious candidates for trust.

People who know the rural water sector in Nepal might be tempted to read this case as an illustration of the badness of the government sector and the virtues of NGOs. For, while formally in the public sector, the 'Fanta Company' in practice enjoyed the operational and budgetary autonomy of an NGO. There is however a clear and important contrast between the strategies employed by the 'Fanta Company' on the one hand and most NGOs on the other to tackle the problem of villagers' rational suspicion of outsiders promising water. The staff of Nepali NGOs working in the sector presented an image of their relative strengths that could have been obtained in almost any developing country. Government agencies were inefficient and corrupt; they took a very long time to get anything done; did it at high cost; and then only delivered standard designs in standard ways, completely disregarding the 
specific needs, preferences and capacities of different groups of clients.

By contrast, we were told that NGOs could find out what people wanted, work with local communities, ensure that appropriate low-cost designs were used, and generally get a good job done cheaply. There was in Nepal at that time friction between NGOs and government water agencies, fuelled by competition for aid funds. This was articulated in terms of relative professional competence. The government water agencies were equally critical of the NGOs, claiming that the NGOs were working with shoddy designs that of course could be constructed cheaply and quickly, but soon fell apart; and that they were experimenting so much, without consistency or good records, that the government agencies were left with an almighty mess when they were asked to maintain and rehabilitate the water facilities that the NGOs had constructed in ones and two all over the country.

It was no surprise to us that spokesmen of government agencies made little reference to what we have termed credibility issues. Such concerns rarely feature in the public discourse of government officials in South Asia. That the NGOs were aware of these issues is implicit in the procedure they typically adopted: sending social mobilisers into villages for weeks or months to gain the trust and cooperation of the population before initiating construction work. This is a variant of the conscientisation strategy mentioned above in the Introduction. One might usefully term it an 'active marketing' strategy, for it involves taking the initiative to persuade villagers to co-operate through establishing new and positive social relations with them. But was this the best solution to the distrust problem?

The 'passive marketing' strategy employed by the 'Fanta Company' that is, set some good examples of reliability and then rely on reputation to interest other villagers and elicit requests for assistance - appears superior. It assumes a high and often justified faith in the capacity of communities to organise themselves once they are confident that they have reliable external partners. This obviates the need for external social mobilisers, and provides a more valid test of community engagement and sense of ownership than do commitments made in response to 'active marketing' strategies employed by influential outsiders.

The employment of social mobilisers raises the possibility of moral hazard problems. One has to assume that social mobilisers generally are biased in favour of obtaining formal commitments from communities to engage on projects. This will enhance their sense of job satisfaction (mission accomplishment) and is likely to advance their careers. The organisations that employ them are vulnerable to similar temptations. What is to stop an effective social mobiliser from persuading villagers to co-operate on schemes that are badly designed or constructed but look good on the papers that go to the aid donors? 
The social mobiliser is anyway leaving the village once the project is complete, and the relative inaccessibility of most of rural Nepal means that few aid projects are ever independently and properly assessed.

Could it be true, as alleged to us, that NGOs sometimes 'saved' vast sums of money and cut short construction times by, for example, hanging polythene water pipes between trees rather than burying them deep in the ground out of harm's way? Perhaps the impressive performances that some of them were reporting really were based on misuse, unintended or conscious, of a position of power that they had established through their marketing techniques? Note that there was a clear affinity between this 'active marketing' strategy and the fact that many NGOs were working on a very small scale, often spreading their resources widely over more than one locality - a village here and a village there. This wide scattering of activities provides little scope for building up local reputations for credibility. The more sceptical view is that it protected NGOs against performance scrutiny and helped maintain their dominance in their relationships with the communities where they were working.

The water projects we have discussed here work better if local people engage in collective action and invest substantial resources in collaboration with external agencies, all the time ensuring that the collaboration takes place on equal terms. If they are to make substantial investments in planning and construction, communities need a concordant relationship - both generalised trust and extensive co-operation in implementation. The credibility of the external agency, and the reputation it thereby acquired, were central to project success. Programme predictability was a secondary factor, of some significance. Communities needed some assurance that their external partner would be around long enough to ensure completion of individual projects. Although the programme that we studied was aid-funded and very likely to come to an end within a few years, it had been operating for six years and worked through the permanent Nepali government agencies. Rights played no significant role. There was no legal recourse for villagers if things went wrong, and very little political recourse: the programme was relatively insulated from Nepali politics, and project mistakes and failures are easily concealed from external evaluators in the mountains of Nepal.

\section{PUBLIC WORKS IN INDIA: PROGRAMME PREDICTABILITY, RIGHTS AND DISCORDANT COLLECTIVE ACTION}

Our second example deals with a different type of anti-poverty intervention; and a relationship between the poor and external agencies that has frequently 
been discordant. The core of the story is the way in which programme stability and, more especially, an ingenious set of rights mechanisms, have provided significant opportunities and incentives for local politicians and social activists to intermediate between organised groups of poor people and the public bureaucracy.

In the mid-1970s, the state of Maharashtra, India, introduced an Employment Guarantee Scheme for its rural population - assured unskilled manual employment on local public works on request. The Employment Guarantee Scheme (EGS) appeared innovative and in its early years received considerable attention from the outside world. Over the 23 years from 1975/6 to $1998 / 9$, it has provided an annual average of 132 million work-days, on 341,661 separate work-sites - soil and water conservation, small-scale irrigation, reforestation, and local roads. Despite many problems, EGS continues to provide relatively cost effective and reliable income support for significant sections of the rural poor of Maharashtra. We have recently conducted field and documentary research on EGS, focusing on the 'guarantee' and the role of client mobilisation in making the scheme work. ${ }^{5}$ The conclusions are encouraging.

EGS is an innovative scheme for providing paid work for the rural poor on a self-selection basis, with (a) a substantial in-built guarantee of work, and (b) a set of procedures for using this labour to construct public infrastructure. The precise procedures and conditions offered under EGS to achieve these goals have changed over the years. It is convenient here to summarise the rules when the scheme was formalised in the mid-1970s. All rural adults over the age of 18 who were willing to do manual unskilled work on a piece-rate basis were offered a guarantee of employment within 15 days of the demand being made, provided that (a) job-seekers registered with the local administration; and (b) there were at least 50 jobseekers in one locality. In principle - although almost never in practice - government was obliged to pay an unemployment benefit (originally Rs 1 per day) if it were unable to provide suitable work for registered jobseekers.

More significant, if the job offered were more than eight kilometres from the residence of the job-seeker, the government was required to provide a specified set of amenities, including temporary housing. Although there is no single comprehensive set of figures, most sources indicate that around half of all EGS employment has gone to women. On the government side, EGS committees identified and designed shelves of projects, so that the scheme could be operationalised at short notice during the dry, lean season and during unusual droughts. Projects were required to create productive assets. At least 60 per cent of expenditures were to be on unskilled labour. Soil and water conservation and drought prevention works were given priority. EGS 
operates through two parallel lines of administration: the Revenue Department (that is, territorial administration) that controls the financing, opening and closing of projects and directs workers to appropriate sites; and various technical departments (Irrigation, Agriculture, Forestry, Highways and so on) that identify and design particular projects and manage the construction process.

What makes EGS distinctive is the fact that it is enshrined in law. The implementation details - wage rates, eligibility conditions, criteria for pro jects and so on - can be, and are, changed by the executive authority of the state government. But the Maharashtra Employment Guarantee Act of 1977 obliges the Government of Maharashtra to operate an Employment Guarantee Scheme for the rural poor. Equally important, the Maharashtra State Tax on Professions, Trades, Callings and Employments Act of 1975 provides a dedicated financing mechanism, that is, a revenue stream devoted only to EGS. There are five specific taxes, of which the most important is the 'professional tax', that is borne mainly by registered professionals and formal sector employees in the urban sector. The state government is obliged to make a contribution to the Employment Guarantee Fund that matches the yield from these dedicated taxes. Once the Secretary to the Government of Maharashtra (EGS) has certified in an appropriate fashion that funds are required to honour the employment guarantee, the state government is legally obliged to release the money.

How did such progressive ideas ever get onto the statute books? One part of the story is the pioneering role played by a group of progressive politicians and social activists, notably the Congress politician V.S. Page, who had been experimenting with similar pilot projects since 1965. A more structural factor was the major drought that affected large areas of Western Maharashtra in 1970-74. The massive public works programme mounted to deal with the consequences of drought provided the basis on which EGS became a state-wide programme. The state government responded effectively to the drought in part because the Communist and left political parties and trades unions rooted in Mumbai (Bombay), the state capital, had established bases in the drought areas. They organised many 'agitations' and sparked a fear of more general unrest. ${ }^{6}$

The more important question for us is why EGS has continued to be implemented relatively effectively, in a country where there often appear to be several public programmes for every conceivable development problem, many of them quickly mired in clientelist politics and/or corruption? The major reason is that EGS job-seekers, via political representatives of various kinds, have continuously been mobilised to demand their rights. That mobilisation is far from predictable. For this is in no sense a variant of a standard 
story about public sector trades unions. Few EGS workers belong to a union. The Scheme is far from the labour organisers' dream. The workforce is casual and fluctuating; and work-sites dispersed and temporary. There is no basis for solidarity around a common, long-term employment relation or permanent work place. There is no scope to use the strike weapon: if eligible job-seekers strike, government simply saves money. Because implementation is shared locally between several government agencies, it is difficult to find one clear target against which to mobilise. Yet there is a great deal of mobilisation. There have been morchas (marches) dharnas (sit-ins) and gheraos (sieges of government offices) at many levels. Activist coordinating committees develop around EGS issues. The Government of Maharashtra has several times been taken to court by trades unions and social activists over EGS issues. This level of mobilisation, and the consequent relative success of EGS as a social insurance scheme for the rural poor, result from the interaction of several factors. They are listed here in ascending order of importance:

(i) Incentives to collective action are built into the Scheme: a minimum number of people need to be in search of employment before work-sites can be opened.

(ii) The funding mechanism for EGS is near-automatic and funds have not generally been scarce at the aggregate level. Consequently, there have been limited incentives for politicians to undermine the Scheme by concentrating allocations on their own supporters, thereby punishing particular localities, caste groups or other population categories.

(iii) While there are recurrent problems with the execution of the Scheme, the public agencies involved enjoy a degree of credibility. EGS is implemented more honestly and effectively than many public anti-poverty programmes. One reason is that there is a balance of power between two distinct sections of the state apparatus: the 'line departments' that directly manage EGS projects (Irrigation, Agriculture, Forestry, Highways); and the Revenue Department (general territorial administration) that controls the finances and constitutes the channel through which demands for work are expressed and, more generally, political concerns and pressures are treated. Neither part of the state apparatus can abuse EGS too far without risking complaints and exposure from the other. It is also important that, in response to past revelations of corruption, the mechanisms for checking and approving EGS expenditures have become relatively demanding and transparent. 
(iv) EGS is characterised by a high degree of programme predictability, in three important respects. The first is longevity: the Scheme has been in place in much the same form for 20 years, is well institutionalised, and operates virtually throughout the state. Knowledge of how to 'work' it has accumulated over time. The second is security: it is worthwhile for politicians and social activists to invest in developing their knowledge of the Scheme because they have a high degree of confidence that EGS will be in place next year and the year after. EGS is legislated. Unlike other government programmes, it cannot easily be abolished and replaced with another anti-poverty programme. The third dimension of predictability is continuity. EGS work is always in process. Projects are always being prepared and implemented. Even during the monsoon period, when labour is needed for agriculture, the Forestry Department is rearing seedlings and planting trees with EGS funds. And a substantial amount of employment is given every year during the driest months of March to May.

Contrast the permanency of EGS with the more typical situation, where large-scale public employment is offered on an ad hoc basis whenever drought strikes. The administrative machinery to provide this employment is disbanded at the end of each drought, and re-created some years later [e.g., Tendler, 1997: Ch.3]. Without programme continuity, public servants have to re-learn how to do the job each time. Politicians and social activists representing the poor also have to re-learn the rules, and put a great deal of effort into stimulating government action on each occasion - for example, securing a declaration of emergency and a commitment of public funds - and in trying to re-write operational rules.

In Maharashtra, with EGS in place, political and organisational energy need not be dissipated on these 'first stage' responses to crisis. It can be focused instead on much more concrete, locally-specific, questions of what will be done, where, by whom. Government agencies are required to be ready to deal with these questions. They have incentives not to be obstructive or resistant because the funding is generally available. There is a separate office within the Revenue Department that does nothing but coordinate EGS work. EGS is not an extra burden to them; and the line agencies that manage projects obtain a significant fraction of their regular funding from EGS. Because implementing EGS does not pose major problems for government agencies, they are responsive to pressures to provide work. That itself is an incentive for politicians and social activists to demand it. From the perspective of providing incentives to activists to invest in pro-poor mobilisation, the permanency and continuity of EGS provide a functional substitute for the absence of 
strong workforce solidarity around the workplace (see above). It is the character of the public programme, rather than workforce and workplace conditions, that makes feasible the mobilisation of EGS jobseekers.

(v) Above all, the legal rights enshrined in EGS create incentives for jobseekers and their (potential) political representative to engage in political mobilisation of various kinds at both local (taluka and district) and state levels. Action at these two levels is mutually reinforcing. EGS legislation in principle guarantees a range of rights in addition to the core entitlement to employment under the conditions set out above. These include: payment if workers use their own tools; plastic spectacles for people employed in stone-breaking; provision of on-site drinking water, first-aid and child-care; compensation payments ('unemployment pay') in the case of failure of government to provide work; and, for work sites more than eight kilometres from employees' homes, camping facilities and access to fair price shops.

Except for drinking water provision, few of these additional formal entitlements have been realised regularly. They have however provided the focus for mobilisation, along with grievances typically found on all public works sites: delays in initiating work; disputes over piecework norms (for example, payment per cubic metre for digging and shifting different types of soil and rock); delays or cheating in paying wages; and corruption of various kinds. These rights and grievances have led to a wide range of local level political activities, including filing cases against the state government in district courts. Some of these issues have also been taken up by organisations campaigning at state level. However, at state level it is general policy issues that have dominated, above all the recurrent question of revising EGS wage rates in line with inflation, and the related issue, now settled, of whether EGS wages should be the same as the minimum agricultural wage rates. Petitions relating to EGS have twice been heard in the High Court in Mumbai.

The significance of the right to EGS employment can be illustrated by comparing it with the Employment Assurance Scheme (EAS), which was introduced in all Indian states in 1994. EAS is a central government scheme. Impressed by the reputation of EGS, and no doubt wishing not to appear less effective or concerned than a state government in dealing with rural unemployment, the Government of India created and directly funded EAS. In one respect EAS appears better targeted than EGS because preference should be given to members of households below the poverty line. 
EAS was often described to us as 'identical to EGS - except for the lack of a guarantee of work'. That is the administrators' perspective. For the 'except for the guarantee' is crucial. There is no mobilisation around EAS, because the lever of rights is lacking. It is the entitlement to employment that limits bureaucratic discretion and ensures that, to a substantial degree, EGS opportunities really are self-targeted on the poor. The implementation of the Scheme does involve a great deal of routine friction between activists and the local state apparatus. Local administrators have used the discretion they enjoy to try to suppress local activism. They have had some success, but are still constrained by the strong rights element built into EGS, the relative autonomy and power of the Indian courts, and the institutionalisation of mobilisation around the right to work.

The EGS is far from perfect. It is unlikely to be directly replicable elsewhere. But it provides a great deal of inspiration, and illustrates clearly how clever political and institutional design can encourage the mobilisation of the poor around public programmes in a non-corporatist fashion while helping to make those programmes more effective.

\section{ENABLING INSTITUTIONAL ENVIRONMENTS AND CONTEMPORARY DEVELOPMENT POLICY}

How relevant are our concerns about enabling institutional environments to the shape of contemporary anti-poverty interventions in poor countries? Although contemporary anti-poverty policies tend formally to be justified in terms concepts like 'participation' and responsiveness to client needs, there appears in practice to be little concern for the issues and relationships we have discussed here. There is a problem of disabling institutional environments. Two widespread development policy trends that give grounds for concern.

First, there has been a big expansion in the use of NGOs as agents for the delivery of public services to the poor. We can look again at Maharashtra to illustrate the consequences. Maharashtra is a relatively developed and politically aware state in the Indian context. It enjoys a history of extensive popular and leftist political activity, and, since the 1980s, has shared in the big expansion of the activities of development NGOs. Some rural activists blamed the slackening of political activity around the Employment Guarantee Scheme and related issues in the late 1980s and early 1990s on the growth of (foreignfunded) NGOs. These NGOs are said to be attractive employers, and to have 'seduced' the rural activists who had previously helped mobilise the poor around issues of a broadly 'class' nature [Joshi, 1998]. 
Whatever the truth of that charge, it is clear that the development activities of NGOs do not elicit the same kind of countervailing popular organisation that the EGS has generated. This is especially true of NGOs that (a) are not strongly rooted in the populations they serve; (b) are oriented mainly to obtaining external financial resources; and (c) are engaged more in service delivery than advocacy. These types of NGOs in particular provide pure 'benefits', not rights in either the moral or legal sense of the term. There is no moral or legal basis on which to organise to ensure that NGOs deliver what they promise. Equally important, NGO activities are invariably small scale and dispersed, and frequently experimental and in practice flexible, temporary and unstable. To the NGO staffers and their funders, flexibility and experimentation are positive values that constitute 'learning experiences'. To potential social activists these same values are disabling, for the central role of NGOs undermines the scope for mobilisation of the poor around programme implementation.

We will not dwell too much on the impact of the induction of grassroots activists into an NGO and programme implementation 'establishment.' This is certainly a widespread phenomenon [e.g., Clarke, 1998: 208]. More important are the points made above that (a) NGO programmes typically are diverse, fragmented and unstable (they lack programme predictability); and (b) they are not even potentially formally enforceable in the way that programmes run directly by government agencies may be. The wider use of NGOs for service delivery is sometimes defended or justified on the grounds that NGOs are better able to mobilise the poor. Some element of mobilisation is often built into the programmes they implement. To that degree, there is a potential counter-argument to the one we have advanced. We are however sceptical of the capacity or willingness of any but the most exceptional organisations to encourage or even tolerate the autonomous and potentially antagonistic mobilisation of their own client groups.

Second, and despite the rhetorical and substantive shift to the NGO sector, over the past decade there has been a massive expansion of one particular type of public anti-poverty programme: the so-called 'Social Funds'? The amounts of money involved are enormous. Social Funds are thick on the ground in Latin America, and fairly common in Africa. They were originally justified mainly in terms of coping with the social costs of economic adjustment. They have become the dominant anti-poverty instrument of the international financial institutions and banks, and are spreading to Asia. The main aid donors committed substantial money to deal with the social costs of the post-1986 implosion of the Indonesian economy only when a Social Fund was put in place in late 1998. It is estimated that, since the late 1980s, the World Bank, the Inter-American Development Bank and the main European 
aid donors spent about US\$4 billion on Social Funds in Latin America and Africa [Tendler, 2000].

Although Social Funds come in many shapes and sizes, a core component, both substantively and ideologically, is the idea of response to 'community demand'. Much Social Fund expenditure is committed by asking poor, territorially-defined 'communities' to decide how they would like to spend an external cash injection for community purposes. Do they want a water supply system or a tool-shed? A road or a new school building? A tractor or latrines? Social Funds are often managed by a special bureaucratic agency, and private firms and NGOs are frequently contracted to undertake preparation, design and construction work. The rhetoric is of decentralisation; moving away from the monolithic state and its 'old-fashioned', unresponsive specialist departments (Water, Irrigation, Health, Agriculture, etc.); tapping the strengths of the private sector and NGOs; and shifting from 'supplydriven' to 'demand-driven' service delivery. From our particular perspective on anti-poverty programmes then, Social Funds are expected to encourage the mobilisation of beneficiaries.

The reality is not only more complex but substantially different. To a large degree, the real choices are made somewhere up the line: by politicians, by bureaucrats, or by the private companies and NGOs who are formally supposed to elicit community desires. There are a number of interacting reasons for this situation. But the dominant factor is that Social Funds programmes are neither designed nor implemented to produce what we have labelled an enabling institutional environment for the mobilisation of the poor. While characterised by tolerance, they are deficient in respect of credibility, programme predictability and rights. Communities are presented with their Social Funds opportunity out of the blue. They face what appears to be a once in a lifetime opportunity, since the programmes are not so well funded or established that they become a regular part of the annual round in any community. Information on the resources actually available is limited. Publicity campaigns are poor - not because governments do not know how to run such campaigns, but because every agency in a position of authority has a strong interest in limiting information, so that they can influence community choice. Politicians do not want accurate and transparent information, since that would (a) reduce their discretion to grant access for political reasons and (b) lead to excess demands for access to Social Funds that would generate political disappointment. Government agencies do not want to generate more demand than they can handle; and generally find some types of community projects easier to handle than others. They want both to limit demands and standardise the types of facilities they supply. And the private companies that design and construct projects also want to 
standardise, because that reduces costs and increases profits. Since these are all 'one-shot games' as far as any individual community is concerned, there is little opportunity to build up knowledge of what is really on offer, and how best to bargain with these better informed external agencies.

The Social Funds case is very similar to that of the NGOs: a new set of institutional arrangements for delivering public services to the poor are justified through the rhetoric of 'community', 'client demand', 'localism' and 'decentralisation', while little real attention is paid to creating an organisational context that will enable to poor actually to organise to help ensure that programmes work in their favour.

\section{CONCLUDING COMMENT}

Gordon White would not have been shocked by this story of Social Funds. The mean-spiritedness of public life over the past two decades has made most of us a little cynical. But Gordon tragically died just before the intellectual anchor of this mean-spiritedness, the doctrine of neo-liberalism, began clearly to lose its holding power. ${ }^{8}$ What chance that we will we be able to say, in ten years time, that he died just before international aid and development agencies began to take seriously their own rhetoric about empowering the poor, and that they approached this as a substantial problem of political and institutional design, rather than a matter for feel-good sloganeering?

\section{NOTES}

1. For a useful discussion of the types of resources needed and used by social movements, see McAdam et al. [1997].

2. It was an acute awareness of this possibility that led Piven and Cloward [1971], for example, to argue that 'poor people's movements' could be effective only if they totally rejected co-operation of any kind with state agencies, and pursued the strategy of making a nuisance of themselves.

3. The general argument that the inferior party in an unequal relationship may be able to benefit from the limited attention paid to the relationship by the superior party is presented in Hirschman [1981].

4. We undertook some research on this programme in 1996. See Moore et al. [1996].

5. There is a large literature on EGS, most of it published in India. The more internationally accessible sources are Acharya [1990], Dev [1996], Echeverri-Gent [1993], Gaiha [1996, 1997], and Herring and Edwards [1983]. For more details on the arguments put forward in this analysis, see Joshi [1998].

6. Another part of the story is found in changes in state boundaries and in the fact that in the late 1960 s power within the ruling Maharashtra Congress Party shifted decisively from Mumbaibased industrial and commercial capitalists, most of them non-Marathi speakers and thus 'outsiders' to the new linguistic-based state of Maharashtra. The people who inherited power 
were mainly big farmers and rural commercial interests of the Maratha caste, many based in the drought affected areas of Western Maharashtra. EGS was essentially funded by a tax on Mumbai. It was in part an expression of the political dominance of this new Marathi-speaking, rural-based class.

7. This section is based heavily on Judith Tendler's recent thorough review of the Social Funds [Tendler, 2000]. More corroborating analyses from the agencies financing Social Funds, see for example, Inter-American Development Bank [1998] and Cornia [1999].

8. See especially the damning and authoritative critiques of the appropriateness of neo-liberal economic policy for developing countries by Stiglitz [1998] and Rodrik [1999].

\section{REFERENCES}

Acharya, S., 1990, 'The Maharashtra Employment Guarantee Scheme: A Study of Labour Market Intervention', ARTEP Working Paper, International Labour Organization/Asian Regional Team for Employment Promotion.

Clarke, G., 1998, The Politics of NGOs in South-East Asia: Participation and Protest in the Philippines, London: Routledge.

Cornia, G.A., 1999, Social Funds in Stabilization and Adjustment Programmes, Research in Action Paper 48, Helsinki: World Institute for Development Economics Research.

Dev, M., 1996, 'Experience of India's (Maharashtra) Employment Guarantee Scheme: Lessons for Development Policy', Development Policy Review, Vol.14, No.3, pp.227-53.

Echeverri-Gent, J., 1993, The State and the Poor: Public Policy and Political Development in India and the United States, Berkeley, CA: University of California Press.

Fox, J., 1994, 'The Difficult Transition from Clientilism to Citizenship: Lessons from Mexico', World Politics, Vol.46, No.2, pp.151-84.

Gaiha, R., 1996, 'How Dependent are the Rural Poor on the Employment Guarantee Scheme in India', The Journal of Development Studies, Vol.32, No.5, pp.669-94.

Gaiha, R., 1997, 'Do Rural Public Works Influence Agricultural Wages? The Case of the Employment Guarantee Scheme in India', Oxford Development Studies, Vol.25, No.3, pp.301-14.

Herring, R. and R.M. Edwards, 1983, 'Guaranteeing Employment to the Rural Poor: Social Functions and Class Interests in the Employment Guarantee Scheme in Western India', World Development, Vol.11, No.7, pp.575-92.

Hirschman, A.O., 1981, 'Beyond Asymmetry: Critical Notes on Myself as a Young Man and on Some Other Old Friends', in A.O. Hirschman, Essays in Trespassing. Economics to Politics and Beyond, Cambridge and New York: Cambridge University Press.

Houtzager, P.P., 1998, 'State and Unions in the Transformation of the Brazilian Countryside, 1964-1979', Latin American Research Review, Vol.33, No.2, pp.103-42.

Inter-American Development Bank, 1998, 'The Use of Social Funds as an Instrument for Combating Poverty’, IDB Sector Strategy, POV-104, Inter-American Development Bank, Washington, DC.

Joshi, A., 1998, 'Mobilizing the Poor? Activism and the Employment Guarantee Scheme, Maharashtra', mimeo, IDS.

McAdam, D., Tarrow, S. and C. Tilly, 1997, 'Toward an Integrated Perspective on Social Movements and Revolution', in M.I. Lichbach and A.S. Zuckerman (eds.), Comparative Politics: Rationality, Culture and Structure, Cambridge: Cambridge University Press pp.142-73.

Moore, M. et. al., 1996, 'Ownership in the Finnish Aid Programme', Evaluation Study, 1996:3, Ministry of Foreign Affairs of Finland, Department for International Development Cooperation.

Pinhanez, M.F., 1997, 'Shattered Power, Reconstructed Coalitions: An Analysis of Rural Labor 
Unions in Maranhao, Brazil', thesis Masters in City Planning, Massachusetts Institute of Technology, Cambridge, MA.

Piven, F.F. and R.A. Cloward, 1971, Regulating the Poor. The Functions of Public Welfare, New York: Vintage Books.

Rodrik, D., 1999, The New Global Economy and Developing Countries: Making Openness Work, Washington, DC: Overseas Development Council.

Stiglitz, J.E., 1998, 'More Instruments and Broader Goals: Moving Beyond the Post-Washington Consensus', Wider Annual Lectures, 2, WIDER, Helsinki.

Tendler, J., 1997, Good Government in the Tropics, Baltimore, MD: Johns Hopkins University Press.

Tendler, J., 2000, 'Why Are Social Funds So Popular?', in S. Yusuf, W. Wu and S. Evenett (eds.), Local Dynamics in the Era of Globalization, Oxford: Oxford University Press for the World Bank, pp.114-29. 


\section{WELFARE}





\title{
State Entrepreneurship and Community Welfare Services in Urban China
}

\author{
GORDON WHITE and \\ XIAOYUAN SHANG
}

\section{STATE ENTREPRENEURSHIP AND WELFARE PROVISION}

The conventional idea of 'entrepreneurship' has been used mainly to describe a particular type of behaviour by a distinctive type of economic actor, usually but not exclusively an individual. The quintessential entrepreneur possesses an amalgam of creativity, acquisitiveness and opportunism through which he or she can combine factors of production - labour, land, capital and technology - to develop new products and processes, improve existing levels of productivity and create wealth both for the individual and for the economic system as a whole. Entrepreneurship is thus a basic factor of production in itself and is characteristically in short supply. In earlier days, the lack of economic dynamism in certain poor societies was attributed to the lack of this quality; conversely, the emergence of entrepreneurs and the establishment of a socio-political environment in which entrepreneurship could flourish was a powerful determinant of dynamic economic growth.

The notion of entrepreneurship is thus rooted in the analysis of economic behaviour, in particular in the context of market competition and the profit motive which are the key driving forces of a capitalist economy. As such entrepreneurship differs from other forms of economic behaviour (such as those based on gift relationships or reciprocity), and the realm of entrepreneurship is different from the public realm of the state and the associational realm of civil society which are conventionally held to operate with different motives and forms of organisation. According to commonly held stereotypes, the realm of state institutions is populated by bureaucratic forms of

\footnotetext{
This contribution is part of the result of the research programme 'Institutional Changes in Social Welfare Provision in China's Transition to the Market'. The late professor Gordon White was director and Xiaoyuan Shang worked as research officer. They started preparing this study in 1997. Xiaoyuan Shang is grateful to Barbara Harriss-White for agreeing to let this contribution be published. It is dedicated to the memory of Professor Gordon White.
} 
organisation motivated by politically defined public objectives and staffed by career administrators motivated by notions of professionalism and public service. The associational realm in turn is populated by civic organisations with social objectives and staffed by 'voluntary' employees motivated by altruism or social commitment.

Research and experience has shown the latter two stereotypes to be partial and misleading representations of real-world institutions and behaviour in both spheres. Our concern here is with the public realm. Work over the past two decades in the tradition of the 'new political economy', 'rational choice' and 'public choice theory' has analysed political and bureaucratic behaviour as analogous to economic behaviour. While this intellectual tradition has usually applied notions of the utilitarian pursuit of interest on the part of politicians and officials, it has also opened up the possibility of 'entrepreneurial' behaviour on their part. There is thus analysis of 'political entrepreneurs' who seek personal advantage by competing to provide collective goods in a political market.' Analysis of 'rent-seeking' by both politicians and bureaucrats has demonstrated how they may compete among each other to acquire rents, both legal and corrupt. ${ }^{2}$

In this economics-derived tradition, competitive behaviour in the context of relationships between the public sector and the economy are usually perceived as unproductive (either neutral or wasteful in their economic effects), although they may be highly profitable to the state actors involved. ${ }^{3}$ Thus the politicians and officials who engage in this activity through various forms of direct intervention are behaving exploitatively and any states that they inhabit pervasively are predatory entities. State entrepreneurship is thus to be seen as an intrinsically unproductive and reprehensible activity which should be controlled through greater internal controls and reduction in the directive power of the state. More recently, however, certain analysts have questioned these assumptions. Khan [1996] has used a political economy perspective to distinguish 'patrimonial' and 'clientelist' forms of corruption in his study of South Asia and argues that the extent to which different forms of corruption are productive or unproductive depends on the 'political settlement' between state and economy in which they are embedded. Wank [1995] and Solinger [1992], working on the emergence of businesses established and maintained through informal 'connections' between officials and business people and Smart [1993], working on the entrepreneurial rent-seeking behaviour of local governments in attracting foreign investment (all in the context of contemporary China), have allowed for the strong possibility that, at least in certain politico-economic circumstances, state behaviour of an entrepreneurial kind, previously thought to be unproductive by definition, could in fact make a net contribution to accumulation. 
It is also in the context of work on the economic transition in China that a more focused analysis of 'state entrepreneurship' has emerged. ${ }^{4}$ This reflects the fact that state entrepreneurship seems to be one form of adaptation by state institutions and officials to the impact of economic liberalisation, particularly in societies where market reforms have been the most sweeping and yet the power of the state remains formidable. Thinking about state entrepreneurship began with path-breaking work by Blecher [1991] on the distinction between 'developmental' and 'entrepreneurial government' at the county level and was followed by work by White [1991] in regard to urban bureaux of economic administration and by Duckett's study [1997] of municipal government in the large city of Tianjin.

State entrepreneurship embodies the techniques of classical economic entrepreneurship - an orientation towards profit-making by exploiting market opportunities through the manipulation of political, bureaucratic and economic resources in order to protect or expand the resources available to an institution.

- State entrepreneurship is a particular form of institutional response to the political and economic pressures and opportunities opened up by market reform, particularly in situations where the scope of reform is relatively profound but the pace is relatively gradual and where state institutions retain considerable authority.

- State entrepreneurship can operate at various levels and in different parts of the governmental and administrative apparatus. In the Chinese case, this includes three institutional levels, each of which has received attention in the literature: (a) level of government: Chinese local governments at all levels have acted in entrepreneurial ways to promote the interests of their own localities, for example, by generating markets for local enterprises, angling for external investment for their local economies, promoting the development of the local economy through political bargaining with superior authorities, targeted investment, labour recruitment and inter-enterprise co-ordination; ${ }^{5}$ (b) state administrative institutions: the process whereby specific state institutions act in entrepreneurial ways to protect and extend their bailiwicks by generating extra revenue to fund their operations and reward their staff. There are now numerous case-studies of such institutional behaviour: for example, Blecher's work [1991] on the Guanghan County Federation of Rural Supply and Marketing Cooperatives in the province of Sichuan; White's study [1991] of the Shanghai Municipal Textile Bureau and Duckett's analysis [1997] of three institutions in the city of Tianjin; (c) public insti- 
tutions such as universities, hospitals and the like who have adapted to financial stringencies by raising money in a wide range of innovative ways, partly through cost-recovery through fees and partly through the establishment of profit-generating enterprises. ${ }^{6}$

- State entrepreneurship is an active and often pro-active response to a changing politico-economic environment rather than a merely conservative reaction based on bureaucratic 'vested interests' as was the general assumption of analysts of similar Eastern European reforms in the 1980s. ${ }^{7}$

- State entrepreneurship involves direct participation by state institutions in markets and direct involvement in productive activities with the purpose of generating new resources and making profits.

The nature of the politico-economic context is a crucial determinant of both the nature and feasibility of state entrepreneurship. The market reforms in China have created several pressures which have produced entrepreneurial responses: a political context in which subordinate units, whether governmental or administrative, have acquired considerable room for institutional manoeuvre; a need to counter political pressures to change (or in extreme cases abolish) the functions of specific institutions; pressure to counter dwindling fiscal revenues through alternative forms of income-generation; and the ability to use political/administrative power as a resource in an economy in which the state is still pervasively entangled.

Most of these studies have focused on the entrepreneurial behaviour of the state in relation to productive and commercial activities. In this contribution, we shall be examining state entrepreneurship in the unlikely realm of social welfare. The notion of 'entrepreneurship' seems far away from conventional ideas of social welfare. When provided by social organisations, welfare reflects motives of charity or social concern; when provided by government, it reflects social priorities defined by the interplay of political forces and political ideologies. Of course, such a stark distinction has never been true and over recent years it has become less and less so as government agencies have contracted out welfare services to private agencies, as the leaders of non-profit organisations have been forced to become more 'entrepreneurial' in their welfare activities and as the welfare role of the private for-profit sector has increased. Pressures on state provision and the move towards 'welfare pluralism' have eroded the previously clear distinction between the realms of entrepreneurship and welfare.

It is our thesis that the Chinese market reforms have generated a series of pressures - political, economic and social - which have prompted the state 
agencies responsible for welfare at various levels to seek to strengthen their institutional capacity and maintain their activities through an entrepreneurial pattern of behaviour which appears very different from the conventional view of how welfare agencies should and do operate. We shall be interested in exploring how and why this came about, how it operates in practice, and whether or not it is sustainable in the longer term or merely an understandable but ultimately doomed phenomenon characteristic of a transitional economy. Our underlying aims are to gain a clearer understanding of the phenomenon of state entrepreneurship in general and of its compatibility with the welfare functions of the state in particular. The analysis focuses on China's urban sector, with an officially estimated population of 369.9 million in 1997 (29.92 per cent of the total population) [SSB, 1998: 105] and is based on field research in China over the 1994-97 period.

\section{ECONOMIC REFORMS AND THE CHINESE WELFARE SYSTEM}

The urban welfare system prior to the onset of economic reforms in 1979 was based on the public sector (state and collective) work-unit and covered most of the urban workforce. ${ }^{8}$ Welfare benefits were provided by individual enterprises or units to their own employees and their range was remarkably wide: insurance benefits including pensions, health, work-injury, maternity and sick leave; services such as crèches, schools, clinics, sports and recreational facilities; subsidies and allowances for a wide variety of purposes, the most important of which was subsidised housing; and many other small categories of assistance to individuals and households. This system of unit-based provision rested on the most fundamental welfare benefit of all - job security - otherwise known as the 'iron rice-bowl' for manual workers and the 'iron armchair' for white-collar staff.

The urban welfare system was dualistic in that the relatively small proportion of the urban population who fell outside the unit-based system only qualified for state social assistance on a means-tested basis and were forced to rely much more heavily on their own and their family resources. Strictly speaking, only this latter 'residual' area of social relief could be referred to as state welfare, since benefits were disbursed directly by state agencies, notably departments of Civil Affairs. As of 1978 at the beginning of the reforms, departments of civil affairs were only responsible for paying 2.8 per cent of total 'social insurance and welfare funds' for public employees and retirees. Moreover, direct state outlays for the social relief of people outside the public sector were similarly minuscule, with the result that official state outlays on social welfare were a very small percentage of total 
expenditures - 1.7 per cent for the last year before the reforms in 1978 . However, since urban enterprises were tied umbilically to government, they were functionally part of a state-sponsored and financed welfare system, the key feature being that welfare funds were generated and managed by the unit not a state agency. Welfare was thus part of a wider system of planned production and, to the extent that state agencies were involved, it was largely through the sectoral and functional agencies of economic administration. ${ }^{9}$

The impact of nearly two decades of economic reform changed the socio-economic context of welfare policy in major ways. The economy became rapidly commercialised through the development of markets for capital, labour and commodities and the diversification of an economy once totally dominated by public enterprises. Public enterprises were becoming increasingly marooned in a sea of new-style enterprises - private, household, foreign-invested and 'new collective' - which had greater autonomy and dynamism. As competitive pressures on public enterprises increased, they found themselves hampered by an increasingly onerous burden of state-guaranteed welfare payments, as the costs of health-care rose rapidly and numbers of pensioners increased. Public enterprises were also saddled with large numbers of redundant workers, variously estimated at between one fifth and one third of the work-force, acting in effect as labour reservoirs to avoid high levels of open unemployment. As the reforms deepened during the 1990s, however, these surplus workers were increasingly being extruded into the urban economy, by a process of 'stepping down from one's job' (xiagang) whereby a worker retained his or her formal employment status with an enterprise but had become de facto unemployed..$^{10}$

These changes in the economy had a growing impact on urban social structure. As the non-state sector developed, the number of employees outside the public-sector welfare system increased, thereby increasing the proportion of the urban population outside the unit-based welfare system." Moreover, the gradual growth in unemployment and the declining ability of public enterprises to meet their welfare obligations to their employees and retirees meant a growth in the numbers of vulnerable or deprived groups among the urban population, notably among unemployed and older people. The problems were compounded by the high inflation rates of the early 1990s and led to the beginnings of officially recognised urban poverty, estimated (conservatively) at about 12 million in 1993, 3.6 per cent of the total urban population then. ${ }^{12}$

The spread of these problems and the resulting pressures on the welfare system were restrained by conscious policies to slow the rate of redundancies in the public sector; moreover, the booming economy throughout the 1990 s meant that most people capable of taking jobs found it relatively easy 
to do so, particularly in the more dynamic coastal and southern regions. However, a basic shift in the nature of the welfare system was under way. Responsibilities were increasingly being shifted away from enterprises and institutions to public agencies of various kinds. While there were efforts to reconstitute the employment based system of social insurance for health and retirement pensions, more and more problems were being shifted into the previously residual sector of social relief as people left the safety and security of their occupational homes in the public sector. ${ }^{13}$ This in turn meant steadily escalating pressures on the public institutions formerly responsible for this sector, departments of Civil Affairs, particularly at the basic-level of urban government.

However, the Ministry of Civil Affairs (MOCA) was ill-equipped to deal with its evolving responsibilities. Traditionally a weak ministry, it faced a series of constraints which made decisive action very difficult. In spite of the fact that pressures for welfare services were increasing, governments at all levels were unable or unwilling to commit more resources to them, specifically by increasing substantially the flow of resources to departments of Civil Affairs. In fact, direct state expenditure on welfare purposes as a proportion of total expenditures had dropped from 1.7 per cent in 1978 to 1.6 per cent in 1996. The government's budget for social welfare (services) and social relief was reduced from 0.58 per cent of GDP in 1979 to 0.19 in 1997 [SSB, 1998: 20, 280].

This fiscal reluctance reflected several important factors. First, the state has faced a generalized fiscal crisis fuelled partly by the drop in the tax 'take' during the reforms and the ability of newer sections of the economy to avoid or evade taxation, and partly by the continuing political need to spend money on unproductive purposes such as subsidising ailing state enterprises. Second, since the MOCA was a weak institution, moreover, it could not prevail against more powerful institutions in the realm of national defence, heavy industry, capital construction, utilities and the like. Third, while employees of public enterprises were able to exert considerable political pressure through formal and informal channels to protect their welfare entitlements, people in the residual sector who had lost the protection of their unit were more atomised and, to the extent they were vulnerable or needy, were not able to exert sufficient political pressure for increased spending.

Changes in the political realm also bore down heavily on most state institutions. Part of the overall logic of market reform in China was that, first, the overall scale and role of government should be comprehensively reduced and, second, that some institutions would lose their functions altogether and go out of existence while others would take on a greater role, notably agencies of economic regulation and welfare provision. However, 
this scenario was impeded by the resistance of theoretically redundant state institutions which made re-allocation of fiscal resources to more relevant institutional sectors more difficult; moreover, the pressures for governmental reform, which involved fiscal and personnel constraints, bore down on all institutions regardless of their role. In turn, this put a squeeze on the incomes and facilities available to state employees which looked increasingly exiguous in contrast with the large sums being made in the private sector.

In this circumstance, institutional survival not to mention expansion depended on the ability of state institutions to 'generate income' (chuang shou) to service their clients and provide for their own personnel. It was this need which generated the phenomenon of state entrepreneurship which can be seen as a kind of intermediate response between the Scylla of personal corruption and the Charybdis of institutional weakening or even extinction. In financial terms, it led to the emergence of a second budget across the nation, composed of 'extra-budgetary revenue' which depended on a multiplicity of 'fees' (fei) rather than 'taxes' (shui) and which could be levied independently by levels of government and by individual state institutions.

But two key politico-economic conditions are necessary for state entrepreneurship to become a reality. First, the government or institution involved must have enough freedom of manoeuvre in relation to superior authorities to be able to engage in unorthodox activities. This condition was provided by the deliberate and unintended 'loosening' of inter-level and inter-institutional ties within the governmental machine as a consequence of the reforms, endowing subordinate governmental and organisational actors with considerable room for manoeuvre. Second, governmental and state institutions must retain a continuing ability to exert substantial influence over economic processes. In the Chinese case, which involved a more gradual process of change than its Soviet and eastern European counterparts and did not seek fundamentally to undermine the basis of state control over society, state institutions were able to retain considerable influence in their spheres of operation. This has been, and still is, a 'mixed economy' in which state and economic actors are still heavily entwined and mutually dependent. Instead of retreating to a merely regulatory role, as the logic of economic reform required, state institutions could still intervene directly in economic processes in a variety of ways.

In effect, 'the state' has become a myriad of loosely linked institutions, each with some (variable) degree of manoeuvre to set their own agendas and reproduce them materially. In a situation of political sauve qui peut, institutions in charge of potentially lucrative areas of activity are better placed to do this whereas agencies in charge of deficit or declining sectors are less so. 
Welfare agencies are differentially placed here. Institutions and localities able to preside over new contributory forms of social insurance (notably for retirement pensions) which generate substantial surpluses in the short and medium terms, may fare relatively well. However, an institution such as the MOCA, whose precise welfare function has taken the form of social relief to vulnerable or needy groups, has of necessity relied on government funding. It would seem, therefore, that such an agency would have been condemned to impotence, trapped between the double constraints of fiscal indigence on the one hand and an impoverished clientele on the other. The rest of this chapter is about how departments of civil affairs have sought to deal with this dilemma in entrepreneurial ways.

\section{THE RISE OF URBAN 'COMMUNITY SERVICES'}

\section{(i) The Emergence of 'Welfare Entrepreneurship'}

The rise of urban 'community services' was part of a wider effort by departments of Civil Affairs to protect and expand their institutional profile in a period of profound socio-economic change. The other major 'front' was the Ministry's attempt to expand into the relatively open terrain of rural social insurance, notably by establishing contributory programmes for personal retirement pensions. This not only had the potential of raising substantial investible funds under the control of Civil Affairs but it also provided an opportunity for institutional expansion in areas relatively unpopulated by other state institutions. The Ministries of Labour and Personnel both had responsibilities for urban employees and the MOCA's only serious competitor in the rural areas was the People's Insurance Company of China (PICC) which, though a state-owned agency, operated along commercial lines by selling personal pensions and other forms of insurance to the local population.

The MOCA competed with the PICC in a process of 'cherry-picking' by seeking to involve relatively well-off rural groups in their pension programs; it competed with the Ministry of Labour (MOL) in seeking to control social insurance arrangements for the growing number of workers in rural 'township and village enterprises' (TVEs). While this competition revolved around provisions for 'welfare', it is clear that all institutional parties saw these opportunities in the rural sector, focusing on relatively advantaged sectors as they were intended to do, as opportunities for financial accumulation and institutional aggrandisement and the programmes adopted had a heavily 'commercial' aspect to them. ${ }^{14}$ Indeed, the MOCA actually refused 
to take over from the Ministry of Agriculture the role of institutional conduit for 'aid the poor funds' which came from a special office under the supreme governmental agency, the State Council. According to an official of the MOCA, this was because 'this is a potentially troublesome area because there would be a contradiction between the funds and the demand for them'. ${ }^{15}$

The development of urban 'community services' (shequ fuwu) was also only one part, but the major part, of a wider range of entrepreneurial efforts by departments of Civil Affairs to generate extra income for welfare institutions and activities. There were also efforts to encourage state welfare homes (for older people, people with disabilities and for orphaned or abandoned children) to make money through advertised appeals for donations, charging for beds and accommodation for better-off sections of the urban population, renting out surplus real estate and setting up their own businesses. Another method was to make use of tax concessions to develop 'welfare enterprises' for the employment of people with disabilities, many of which were in reality profit-making concerns run by private entrepreneurs with some limited financial spin-off for disabled workers, some of whom might be on the books but were not actually working. ${ }^{16}$

'Community services' began in the mid-1980s with the establishment of various 'social welfare service networks' by local departments of Civil Affairs in connection with basic-level urban governmental and quasi-governmental institutions. The term 'community' refers to the bottom two layers of urban administration - the population who are residents in a territorial unit under the aegis of a 'street office' or a 'residents committee', the former with populations of between 30,000 and 120,000 and the latter varying between 2,000 to $5,000 .{ }^{17}$ It is stretching the term 'community' to refer to these entities as such since the 'street office' is formally a bureaucratic extension of the higher-level district government. The 'residents' committee', though formally a 'mass-type, self-governing institution' separate from government proper, is in reality a semi-official agency under the control of the street office.

Thus the principles of local community and state are fused together here since neither the street office nor the residents' committee can be described as components of the state proper; in their different ways they have begun to form organic links with and extensive responsibilities to their local populations which are outside the formal chains of state command. In the welfare field, this implies the process whereby local governments and welfare agencies seek to supplement limited state fiscal appropriations for welfare services and facilities by mobilising new sources of income locally to establish new facilities and services. This is referred to as a process of 'socialisation' (shehuihua) in the sense of transferring financial and managerial 
responsibilities for welfare from state agencies proper to various kinds of semi-state, 'community', social and economic institutions.

The 'social welfare service networks' which emerged in various cities in the early-mid 1980s reflected this gradual transformation of local institutions, with the central city of Wuhan playing a pioneer role. In consonance with the familiar cyclical process of bottom-up/top-down policy process characteristic of the Chinese policy process during the reforms, the local experiences were recognised by the central Ministry in Beijing, which officially ratified the term 'community services' to describe these activities. The Ministry also conducted local experiments in chosen cities, popularised 'model' experiences across the country and held a series of workshops and meetings to identify, assess and spread their results across the country. ${ }^{18}$

In the initial stage, from 1987 to 1992, the expansion of social services attempted to rely on a combination of government appropriations, neighbourhood volunteer labour (for example, by groups of young people or neighbours) and donations. Cost-recovery was also instituted for certain services on a graduated basis, depending on the nature of the service and the identity of the recipient - some services were still free while others were set rates adequate to recover current costs. However, these methods, which were still largely within the collectivist, social service orientation of China's previous urban welfare tradition, were to prove inadequate to the task. Government money is only available in relatively small amounts, mainly to pay for core staff and capital investments. However, by the 1990s, the escalating value of urban real estate made property for offices, service centres or welfare homes increasingly expensive and departments of civil affairs were having to fight to keep their existing facilities. Moreover, the growing commercialisation of urban life meant that it became more and more difficult to maintain the old altruistic forms of collective commitment. Maintaining a wide range of free or subsidised services also proved inadequate to the financial needs of local agencies.

A strategic change in policy at the national level launched by the paramount Chinese Communist Party leader Deng Xiaoping's visit to the commercialised south-east of the country in 1992 precipitated a decisive change in direction in the MOCA's line on urban community services. In essence, Deng's trip to the south heralded a radical acceleration in the process of market reform, giving the green light to all agencies in the country - state or non-state - to behave in ways conducive to a pervasive market economy. One local welfare official in Beijing described the impact of Deng's initiative: 
In 1992, Deng's trip down South caused a change. Government departments studied this and realized that we could develop our work, but not according to the old principle of free or low cost. Our new idea was to move from a complete concentration on welfare services to a combination of welfare and business services ... This meant organizing profit-making activities. ${ }^{19}$

This statement expresses the essence of the entrepreneurial approach to welfare provision - the combination of welfare and commercial activities based on the principle of 'using business services to promote welfare services'. In other words, welfare agencies and their local institutional associates began to expand the principle of cost-recovery and encourage the development of profit-oriented businesses oriented towards ordinary urban residents and use part of the profits generated to provide free or subsidised services to needy groups within that population, notably older people, people with disabilities, orphaned or abandoned children and individuals/households living below basic poverty levels. The range of businesses launched is enormous: for example, home-help agencies, marriage introduction bureaux, leisure centres, job centres, funeral parlours, marriage service agencies, repair shops, hairdressing salons, breakfast bars and small restaurants, small shops, tailors shops and laundries. Local welfare agencies did this in a variety of ways, direct and indirect. Civil Affairs departments might set up their own marriage service agencies, marriage introduction agencies or funeral parlours; residents committees might set up their own small enterprises employing local people.

Alternatively, each of these might sub-contract an enterprise to a private individual and take a share of the profits, or lease out some premises at a specified rent and profit percentage. As for the revenue generated, it goes in three directions: (i) it stays with the people running the business in the form of profit; (ii) it goes to local government or Civil Affairs departments to use for their own institutional purposes (staff salaries and other personnel costs, renting offices, buying and maintaining cars, etc.); and (iii) it is used directly to pay for or subsidise welfare services to needy groups, through services and subsidies to households or subsidies to welfare institutions such as activity centres and welfare homes for older people or welfare workshops for the mentally disabled. The actual distribution between these three purposes is highly discretionary and virtually impossible to estimate.

\section{(ii) Problems and Response}

It is clear that officials in departments of Civil Affairs have seen this new conception of 'community services' as one decisive way out of their financial and institutional dilemma. But the principle of combining commercial 
and welfare principles is fraught with difficulties, both in general and in the Chinese context.

The following problems are evident in both contexts: (i) commercial and welfare activities require different skills and different people and any attempt to combine them is problematic; (ii) if staff working in welfare agencies have to spend a considerable amount of their time on commercial activities, they have less time to spend on welfare. In the relatively prosperous city of Nanjing in the central-south region, for example, we found that nearly all street offices have to keep half of their welfare staff working on incomegenerating activities, leaving an inadequate number of people to deal with welfare issues; (iii) when the principle of cost-recovery is extended to mean that a substantial proportion of residents in welfare facilities, notably oldpeople's homes, are on a pay-bed basis, there is a tendency towards 'crowding out' people in real need because they are a financial burden; (iv) welfare institutions and their staff have their own needs and wants and a substantial amount of the revenue is spent on them, for both defensible and indefensible reasons; and (v) until now there are no clear rules governing the process of financial cross-subsidisation. At present, such budgeting relationships are discretionary, so some of the funds generated may be used for purposes other than providing services to the people who really need them; (vii) the last, and most fundamental point, is that there is an in-built tendency for income generation to displace welfare provision as the goal of the concerned institutions. One Chinese researcher expressed his concerns as follows:

Community services should direct their eyes at the poorer strata. At present, they tend to look at the whole population and the richer parts of the population can afford their services. I think that the original purpose of helping vulnerable groups has got lost. Community services have become a channel for the civil affairs departments to collect money ... The underlying problem is that government departments have to solve problems of their own welfare themselves. We have to be able to pay government employees more money; otherwise we cannot solve this problem. ${ }^{20}$

These are problems intrinsic to the very notion of 'community services'. There are other problems stemming from the political and economic environment in which it is operating. In political terms, welfare agencies face a number of constraints, many of them stemming from the fact that the Chinese state is a complex network of competing organisations, each with their own administrative responsibilities and entrepreneurial agendas. There are three sets of political problems.

First, basic-level welfare agencies face problems from their own bureaucratic system. They often find themselves in a doubly invidious position: on the one hand, higher level departments of civil affairs have converted 
'community services' into a series of administrative targets which they are obliged to fulfil by hook or by crook; on the other hand, to the extent that they do, they run the risk of extra revenue of successful enterprises being appropriated by higher-level agencies for their own benefit.

Second, community services bring departments of civil affairs and community agencies into conflict with the formal administrative responsibilities of other urban agencies, incurring what is perceived as excessive bureaucratic red-tape. For example, one street-office official in the western city of Lanzhou complained that, if a local residents committee wanted to open a new office, it had to be approved by numerous agencies, including the bureaux of city construction, railways and land. Community service businesses can also fall foul of local regulations: in the same location, for example, the street office had established a number of community service businesses but in July 1995 there was a 'campaign for a clean city' and the agency in charge of the campaign instructed the street office to demolish the new businesses. In the words of the official:

The clean-city inspection asked us to demolish the service points because they thought they were not in accordance with the campaign. I argued that we had been told to build them and now we were being told to demolish them. This is actually a waste of money and manpower. In future, the district office will be asking us to build them again. We tried hard to keep them, but did not succeed. ${ }^{21}$

To take another example, the revenue-generation side of community services and other activities by welfare agencies is meant to supplement scarce fiscal resources from local and national governments but not to replace them. However, welfare agencies face a 'success trap' that is, to the extent that they are financially successful, local departments of finance will seek to reduce fiscal appropriations accordingly. A national level financial official in the MOCA alluded to this problem directly and said 'we have to keep quiet about this'. ${ }^{22}$ Moreover, if community service operations are financially successful, they may attract the attention of local taxation bureaux who become reluctant to provide them with the tax concessions 'welfare' enterprises currently enjoy.

Third, the entrepreneurial ambitions of the welfare agencies come into conflict with those of other state institutions. For example, local construction departments caught up in the urban construction boom may put pressure on existing welfare facilities or prevent access to new ones since the opportunity costs of, for example, providing space for offices, business premises or welfare centres are too great. Local departments of industrial and commercial management may be reluctant to license community service industries because they are potentially less lucrative than more 
commercially viable alternatives.

There is also a serious threat to community services posed by the rapid spread of a market economy. Community service business enterprises are engaged in providing services or goods which can be or are being provided by private firms and they are supposed to make a profit in doing so. However, since their personnel are often ill-adapted to business activity and the level of skill and quality of facilities is relatively low, particularly in poorer areas, they often find it very difficult to compete with a growing number of private enterprises. This not only applies to non-welfare enterprises, but also to welfare institutions such as old-people's homes which are trying to generate more revenue by providing pay-beds but face a potential challenge from private homes. Competition with private providers can also create political pressures on local government as members of the increasingly assertive private sector complain, with considerable justification, about unfair competition.

Political and economic problems of this nature led the MOCA to take action to protect and extend community services. By skilful politicking at the national level, the Ministry managed to get the central authorities - in the form of the State Council and 13 of its key administrative agencies - to put their name to an official document promulgated in 1993. This document, and the political process which lay behind it embodied two measures designed to strengthen community services.

First, it officially designated community service enterprises as a distinct sector of the urban economy - 'community service industry' (shequfuwuye). This implied that all government and state institutions were to regard it as such and treat it differently from other economic sectors. Second, the presence of the 13 other administrative agencies was meant to demonstrate that they were in a position to facilitate the development of community services and had publicly stated their willingness to do so. ${ }^{23}$

So, for example, the State Planning Commission called on all local Planning Commissions to regard community services as constituting an official target area when national plans were being drawn up for labour, capital and land. The Construction Ministry was to allow space for community service facilities in both old and new urban areas and they were to be allowed to buy or use these at cost-price. The General Taxation Bureau declared that there should be no taxes on facilities such as nurseries, funeral parlours, or homes or centres for older people and people with disabilities. The People's Bank of China stated that banks should give priority loans to 'good' community service businesses at subsidised rates. This was a victory for the MOCA and it followed it up with pressure on top CCP leaders. One national MOCA official described one element of this process: 
How to spread awareness of community services? Get (President) Jiang Zemin and (Premier) Li Peng to say it is important. In the official State Council statement on the Ninth Five-Year Plan [1996-2000], community service work got one whole sentence, whereas other MOCA activities only got half a sentence. We had to get this written into government agendas at all levels. We also increased our propaganda in the media and through volunteer activities by famous stars. ${ }^{24}$

Within this network of bureaucratic support and protection, the Ministry has had bold plans for the future of community services: to rationalise management of the system by establishing specialised management agencies in each locality and a co-ordinating committee to link together various functional bureaux within a locality; to increase professionalisation of staff through expanded training programmes; to establish a systematic network of welfare institutions with either a multi-functional social service centre at the street-office level or the 'four ones', that is, an old people's home, a centre for people with disabilities, a nursery and a centre for school-age children; and to expand coverage gradually from urban districts into rural counties and towns. Community services explicitly became the main element of civil affairs work in the cities.

But these responses, however rational from the point of view of the MOCA, are much weaker than they seem. First, though the 13 central agencies or key central leaders may be 'on-side' in declaratory terms, it is difficult for them to enforce their priorities on subordinate governments and departments, even if they make a big effort to do so (which does not in general appear to be the case). Local governments have many other things to worry about and individual local agencies have their own institutional wellbeing to consider which brings a certain reluctance to be overly generous to 'community services industry'. ${ }^{25}$ This is also true at the 'community' level of the street office since the office as a whole has its own revenue needs and has established small-scale enterprises - known collectively as 'tertiary industry' - to provide for them. This sector also depends on favoured treatment from local governments and departments and is thus in direct competition with community service enterprises which are operating within its own bailiwick. It is hardly surprising, therefore, that many of the local welfare officials interviewed spoke of the difficulties encountered in wringing money out of local governments or getting favoured treatment from urban agencies. ${ }^{26}$

There is a deeper underlying political/ideological problem with the plan to establish 'community services industry' as a protected economic sector. The spirit of the economic reforms over the longer term is to remove government from direct involvement in economic activity and to encourage a level playing-field for fully-fledged market competition. The logic of 'community service industry' clearly runs contrary to this. Moreover, as the 
non-state economy develops and more and more private, profit-oriented firms emerge to supply the services currently provided by community service businesses, the tension between the two sectors will increase, as will pressures on local governments to do something about it. The future of 'community service industry', it would seem, is likely to be a fraught one.

\section{THE FUTURE OF WELFARE ENTREPREURSHIP IN CHINA}

The Chinese experience of state entrepreneurship in welfare provision shows a clear link between this distinctive form of institutional behaviour and the logic of market transition. State agencies of all kinds come under greater pressure in terms of both funding and functions and it is crucially important for them to find ways not merely to survive but also to do so at levels which maintain their operational impact and sustain the quality of their staff and facilities. This is particularly difficult for agencies whose previous functions under the planned economy are manifestly redundant in a marketising economy. The agencies previously responsible for managing small-scale consumer industries are good examples of these and many of them have lost their former identity, in many cases becoming a kind of floated-off semi-state and semi-private corporation operating along market lines. Welfare agencies like the MOCA, one might think, would be relatively fortunate because their responsibilities are likely to increase as the public sector of the economy declines and the social problems of a market economy become more evident.

However, as we have seen in the Chinese case, there are a number of political reasons why this has not been the case so far and departments of Civil Affairs have been forced to rely heavily on themselves to retain and expand their institutional capacity. In contextual terms, moreover, political changes during the reforms had opened up political room for manoeuvre and the spread of a market economy offered many opportunities to potentially profitable state involvement. In short, the MOCA had reason, opportunity and some capacity. As the theory and practice of 'community services' and other aspects of their welfare activities have shown, they have responded to their dilemma in innovative and entrepreneurial ways.

How are we to interpret this relatively unfamiliar aspect of state behaviour? There is considerable evidence to support the theses of 'new political economy' and 'public choice theory' concerning the self-seeking motives behind the behaviour of officials and institutions and the use of power to extract rents from society and economy. Departments of Civil Affairs provide strong evidence of a wish to protect and extend the power of the institution in both defensive and offensive ways. The urge towards institutional aggrandise- 
ment seems particularly apparent in the bid to dominate rural pension provision, but it is also visible in the efforts in the mid-1990s to create a privileged sector of 'community service industry' to expand its resources and activities. At the same time, they have had to do this within a wider context of pervasive state entrepreneurship in which other state agencies have the same motives in mind. This produces a novel form of politico-economic market which combines bureaucratic politics with commercial competition.

But this is only part of the story. Officials in the Ministry are well aware of their wider functions within the market reform process - they have a crucial role to play in managing the social tensions which are an inevitable aspect of market transition and maintaining social stability within the potentially politically explosive cities. Moreover, it is evident to anybody who talks with officials within the Ministry at all levels and with 'community' officials at the urban basic-level that they are motivated by professional and social concerns which cannot be reduced to mere self-interest. ${ }^{27}$ At the lowest, 'community' levels, moreover, there is a close relationship between welfare agencies and their clientele which creates feelings of responsibility and concern. Given the lack of political voice of many members of urban vulnerable groups, moreover, the Ministry - along with other organisations such as the Old People's Commission and the Disabled Persons Federation acts as an advocate of their interests in a political arena dominated by much louder voices.

State welfare entrepreneurship of this nature would seem to reflect a multitude of motives. It can also be described as 'rational' in three senses: in a systemic sense, in that it reflects the logic of market transition and plays some role in easing its social and economic stresses; in a utilitarian sense in that it meets the immediate needs of weak institutions and their occupants; and in a social sense in that it serves certain wider social objectives in reducing human distress. Currently, these rationalities intersect in ways which, in net terms and for the time being, seem beneficial for the progress of China's economic reforms and for the well-being of China's urban population. However, this intersection could shift and the net impact could become negative - for example, if the MOCA over-reaches itself in a bid for institutional expansion, or if the benefits of 'community services' flow disproportionately towards better off segments of the urban population.

State entrepreneurship in the welfare area is by its very nature ambiguous and contradictory, both within itself and in relation to its politicoeconomic environment. Even if it continues to play its net positive role on the urban scene, it will operate in ambiguous, uneven and contested ways. Over the longer term - say, more than ten years from now - it is likely to be unsustainable for a number of reasons. At present, the viability of commu- 
nity services and other aspects of urban social relief, such as the financing of welfare homes and the expansion of welfare factories for disabled people, depends heavily on the micro-monopolistic power of state welfare agencies to exercise control over their political, social and economic environment on their own terms and in their own interests. Not only is this ideologically incompatible with the logic of reform, but it will also become more and more difficult in real terms as the economic power of the state wanes and the power of the non-state institutions and interests increases. The balance of power in society is gradually shifting against state entrepreneurship in the welfare field.

If it is unfeasible over the longer term, it is also undesirable for several reasons. First, experience so far suggests that the principles of commercial and welfare activity are in fundamental contradiction and it is very difficult to combine them in practice, at least in long-term systemic terms. Second, the continuation of state dominance over a process of putative 'socialisation' of welfare has the effect of excluding or inhibiting private welfare providers, whether of the profit or non-profit variety. Third, by generating 'extrabudgetary revenue' to support welfare, it not only reinforces a financial tendency which is highly discretionary and potentially exploitative but also allows governments at all levels to 'get off the hook' and not confront the need to spend more on escalating welfare needs. Fourth, the concentration on commercial activities impedes the professionalisation of welfare staff, thereby affecting the quality of welfare services. Fifth, decision-making by welfare agencies and managers, however 'responsible' they think they are to urban welfare needs, is neither visible nor accountable to its beneficiaries or to the general public.

It would seem likely, therefore, that state entrepreneurship in the welfare field is a defensible but temporary phenomenon which is a characteristic of the reaction of state institutions to sweeping programmes of market reform. In spite of the negative elements discussed above, however, it can be viewed positively in the sense that it contains within it the seeds of a new system of social assistance appropriate to the long-term needs of Chinese urban society. The notion of 'socialisation' implies a tendency towards the development of a multi-provider welfare system involving nonstate providers. While relations between these sectors are at present very tangled and the idea and reality of an autonomous voluntary sector is still embryonic, welfare reformers are aware of the long-term need to separate different providers institutionally and work out a clearer and more precise division of labour between them. Hong Kong's reversion to China is likely to strengthen the emergence of the voluntary sector because it is the dominant welfare provider in Hong Kong and has proven effective there. 
However, this does not mean that the state - both government and responsible agencies - can rest on its laurels. Welfare reformers are pressing for a fundamental reconsideration of the state's role, not in terms of some simplistic logic of retreat, but of a broader programme of reform involving the need for increases in state financing, a clarification of state responsibilities in the welfare field, re-organisation of state institutions and professionalisation of state welfare personnel.

However, this latter would require much greater concentration on the issue by key leaders at the apex of power in Beijing which is not forthcoming at present. Moreover, particularly in regard to the emergence of the voluntary sector in 'civil society', it would also require basic changes in the parameters of the politically possible which is also not in the offing.

\section{NOTES}

1. For an early use of this concept, see Frohlich et al. [1971]; compare Bennett and Dilorenzo [1984] in their study of the United States.

2. For one example from the literature on corruption, see Schleifer and Vishny [1993] on the impact of competition between state agencies on the level of bribes.

3. This literature is voluminous, but for an early review see Buchanan et al. [1980].

4. There has been some limited attention to the notion in other societies. One highly complimentary interpretation of 'entrepreneurial government' in the United States is the book by Osborne and Gaibler [1992].

5. Jean Oi's work on 'local corporatism' [for example, 1992] has thrown considerable light on these processes; see also the study by Hubbard [1995]. See also Blecher and Shue [2001: 368-93].

6. For example, see Yin and White's study [1994] of the marketisation of higher education in China.

7. For a representative example of this literature, see Kornai [1992].

8. For more detail on the pre-reform system, see White and Shang [1996: 21-3].

9. The urban welfare system was itself a protected and privileged sector, maintained by a strongly enforced administrative distinction between 'urban' and 'rural' sectors. The rural population over three-quarters of the population in the late 1970s - received far less welfare benefits per capita from government and had to rely on their own communities and families in the context of the commune system.

10. Official levels of unemployment have remained low, fluctuating between 2.3 per cent and 2.9 per cent between 1990 and 1995 - for example, it was estimated at only 2.9 per cent in 1995 [SSB, 1996: 114]. As of 1996, only 1.7 per cent of the formally unemployed were receiving unemployment relief [SSB, 1997: 142].

11. The proportion of public-sector employees in the urban work-force gradually declined: from virtually zero in 1978 to 84 per cent in 1992 to 72 per cent in 1996 [SSB, 1997: 93]. The latter figures are an overestimate since they do not account for workers who had left their jobs but were still formally on the public payroll.

12. These trends were being exacerbated by a long-term process of societal ageing. This posed increasing pressures on the state welfare system because the first bastion of support and care for older people - the family - was changing. Partly as a result of long-term demographic change and partly of the 'one-child family' policy which has been strictly enforced in the urban 
areas, the average size of households has been declining (from an average of 3.89 persons per household in 1985 to 3.28 in 1994) [MOL, 1995: 63].

13. For reforms in retirement and unemployment insurance, see White and Shang [1996a] and for health insurance see Min [1996].

14. For example, an official of the rival PICC, interviewed in Beijing on 24 June 1996, complained that the MOCA's 'social insurance' was 'really commercial insurance in spite of the title' and it did not meet the international standards for 'social insurance' set by the ILO.

15. Personal interview, Beijing, 24 June 1996.

16. For a more detailed discussion of these other innovations, see White and Shang [1997].

17. One should note that the term 'community' only attaches to a proportion of people resident in a given area. People who live in accommodation supplied by public enterprises form their own 'communities', have their own equivalent of the 'residents' committees' ('dependants' committees') and, most importantly, are the financial responsibility of the enterprise not the local government.

18. The crucial first occasion was a national meeting convened in Hangzhou in 1989 and this has been followed by similar meetings across the country, including one in December 1994 in Shanghai and another in October 1997 in Wuhan. For a short history of the early evolution of this policy, see Yan Mingfu [1994].

19. Interviewed in the Western City District, 17 Oct. 1995.

20. Interviewed in Beijing, 23 Oct. 1995.

21. The interviewee was the sub-director of a street-office sub-district in Lanzhou and was interviewed on 28 March 1996.

22. Interviewed in Beijing, 24 June 1996.

23. Apart from the MOCA, the agencies were as follows: the Ministries of Finance, Health, Labour, Personnel and Construction; the Commissions of Economic Structural Reform, Education, State Planning, Older People, Sports and Family Planning; the General Taxation Bureau and the People's Bank of China.

24. Interviewed in Beijing, 23 Oct. 1995.

25. This research covered the two cities of Nanjing and Lanzhou and it was clear that the government of the former was much more supportive of community services than the latter, largely reflecting the structure and dynamism of the local economies and the consequent capacities and concerns of the two governments.

26. For a good analysis of this problem in the city of Lanzhou, for example, see Zhang [1997].

27. For confirmation of this phenomenoin, see Blecher and Shue [2001].

\section{REFERENCES}

Bennett, J.T. and T.J. Dilorenzo 1984, 'Political Entrepreneurship and Reform of the Rent-Seeking Society', in D.C. Colander (ed.) Neoclassical Political Economy: The Analysis of Rent-Seeking and DUP Activities, Cambridge, MA, Ballinger, pp.217-27.

Blecher, M., 1991, 'Developmental state, entrepreneurial state: the political economy of socialist reform in Xinji municipality and Guanghan county', in White [1991: 265-91].

Blecher, M. and V. Shue, 2001, 'Into Leather: State-led Development and the Private Sector in Xinji', China Quarterly, 166, June 2001, 368-93.

Buchanan, J.M., Tollison, R.D. and G. Tullock (eds.), 1980, Towards a Theory of the Rent-Seeking Society, College Station, TX: Texas A\&M University Press.

Duckett, J., 1997, 'Market Reform and the Emergence of the Entrepreneurial State in China', unpublished D.Phil dissertation, Department of Political Studies, University of Manchester.

Frohlich, N., Oppenheimer, J.A. and O.R. Young, 1971, Political Leadership and Collective Goods, Princeton, NJ: Princeton University Press. 
Hubbard, M., 1995, 'Bureaucrats and Markets in China: The Rise and Fall of Entrepreneurial Local Government', Governance: An International Journal of Policy and Administration, Vol.8, No.3, July, pp.335-53.

Khan, M.H., 1996, 'A Typology of Corrupt Transactions in Developing Countries', IDS Bulletin, Vol.27, No. 2, April, pp.12-21.

Kornai, J., 1992, The Socialist System: The Political Economy of Communism, Oxford: Clarendon Press.

Min Q., 1996, 'Reform of the "Public Medical Care System" and "Labour Insurance Medical Care System" in China', in White and Shang (eds.) [1996: 121-54].

MOL, 1995, China Labour Statistical Yearbook 1995, Beijing: State Statistical Press.

Oi, J., 1992, 'Fiscal Reform and the Economic Foundations of Local State Corporatism in China', World Politics, Vol.45, No.1, October, pp.99-126.

Osborne, D. and T. Gaibler, 1992, Reinventing Government: How the Entrepreneurial Spirit is Transforming the Public Sector, New York: Penguin Books.

Schleifer, A. and R.W. Vishny, 1993, 'Corruption', Quarterly Journal of Economics, Vol.108, No.3, pp.599-617.

Smart, A. 1993, 'The Political Economy of Rent-Seeking in a Chinese Factory Town', Anthropology of Work Review, Vol.XIV, No.2, Summer/Fall, pp.15-19.

Solinger, D.J. 1992, 'Urban Entrepreneurs and the State: The Merger of State and Society', in A.L. Rosenbaum (ed.), State and Society in China: The Consequences of Reform, Oxford: Westview Press, pp.121-42.

State Statistical Bureau (SSB), China Statistical Yearbook 1996, 1997 and 1998, Beijing: State Statistical Press.

Wank, D.L. 1995, 'Capitalism and Clientelism in Communist China: The Political Consequences of Private Business', in A.G. Walder (ed.), Departures from Central Planning: The Economic Origins of Political Change, Berkeley, CA: University of California Press.

White, G., 1991, 'Basic-Level Government and Economic Reform in Urban China', in White (ed.) [1991: 215-42].

White, G. (ed.), 1991, The Chinese State in the Era of Economic Reform: The Road to Crisis, London: Macmillan.

White, G. and X. Shang, 1996a, 'Social Security Reforms in Urban China: A Preliminary Research Report', in White and Shang (eds.) [1996: 18-58].

White, G. and X. Shang (eds.), 1996, Issues and Answers: Reforming the Chinese Social Security System, Brighton: Institute of Development Studies, University of Sussex.

White, G. and X. Shang, 1997a, 'Reform of the System of Social Relief and Social Services in China', in White and Shang (eds.) [1997: 1-2].

White, G. and X. Shang (eds.), 1997b, Reforms in Chinese Social Assistance and Community Services in Comparative Perspective, Brighton: Institute of development Studies, University of Sussex.

Yan, Mingfu, 1994, 'Forcefully Develop the Business of Community Services: Establish a Complete Network of Urban Social Welfare Services', Renmin Ribao (People's Daily), Beijing (27 Dec.), p.3 (in Chinese).

Yin, Q. and G. White 1994, "The "Marketisation" of Chinese Higher Education: A Critical Assessment', Comparative Education, Vol.30, No.3, pp.217-37.

Zhang, J., 1997, 'Discussion on the Development of Community Services in Lanzhou City', in White and Shang (eds.) [1997b: 45-5]. 


\title{
Creating Wealth and Welfare: Entrepreneurship and the Developmental State in Rural China
}

\author{
SARAH COOK
}

The entrepreneur embodies a scarce and distinctive amalgam of vision, drive, creativity, acquisitiveness and opportunism which enables him or her to ... combine factors of production in innovative ways to create wealth both for him/herself and for society as a whole. As such, the notion [of entrepreneurship] is inextricable from both markets and the profit motive ... It is also part of the private realm of society as opposed to the public realm of the state or the associational realm of 'civil society' which operate with different sets of motives and behavioural codes.

(Gordon White, unpublished ms.)

Conventional notions of entrepreneurship are infrequently applied to government behaviour and, as Gordon White pointed out in the paper cited above, are even further removed from discussions of social welfare provision. The concept of entrepreneurship, rooted as it is in the analysis of economic behaviour in the context of competitive markets, contrasts with behaviour conventionally associated with public sector managers or with those responsible for welfare provision. The Chinese experience may however provide counter examples - of entrepreneurial local governments and of 'welfare entrepreneurship'. In post-Mao China, there is considerable evidence that government officials exhibit the characteristics of entrepreneurs in directly engaging with business as well as indirectly facilitating market development. Furthermore, wealth thus created is in certain circumstances used to fulfil the more traditional roles of government including the provision of public goods and social welfare. This discussion considers the proposition that local offi-

\footnotetext{
The author is at the Institute of Development Studies, University of Sussex (on leave) and Ford Foundation, Beijing. This contribution arises from research initiated jointly with Gordon White who was and remains, through his work, a remarkable source of ideas and inspiration. She is grateful to Robert Benewick and Lu Yuelai for valuable comments on an earlier version.
} 
cials have been entrepreneurial in the cause of welfare provision. In other words, it asks whether social responsibilities influence the behaviour of local government officials in their engagement in, or relationship with, local business and the market.

Sharp dichotomies between public and private sector behaviour have been eroded in the context of shifting ideologies concerning state and market, and within recent debates over welfare provision and the behaviour of public officials. None the less the applicability of the term entrepreneurship to the field of welfare provision has been described as 'unlikely' (White and Shang, this volume). ${ }^{1}$ In the paper cited above, Gordon White was exploring the emergence of 'welfare entrepreneurship' in China, which he defined as the efforts of government agencies to expand into unconventional activities in order to finance and deliver public and social goods. Earlier work by scholars doing research on urban business had recognised entrepreneurship outside the usual market sphere, including efforts by the Communist Party 'to stimulate entrepreneurial behaviour on the part of state managers as well as private businessmen' [Gold, 1988: 20]. The type of entrepreneurial state activity which emerged in China's countryside was not, however, initially promoted by the party or by higher level government; rather, the changing structure of incentives (whether intentional or not) in the reform era led to its rapid spread.

The level of government where the greatest entrepreneurial activity by local officials was observed was the township where rural industrialisation developed rapidly from the mid-1980s, mainly in the guise of collectively owned (township and village) enterprises. The township was therefore the principal focus of attention among researchers interested in the changing role of local government, and the incentives for the local state to generate income through enterprise promotion. In this context, the local Chinese state was theorised as developmental and entrepreneurial [White, 1991; Blecher, 1991] or corporatist [Oi, 1992]. These debates focused on the unique institutional experiments in local economic development that emerged during the 1980s, most notably the rapid growth of township and village enterprises. The observed pattern of development appeared to challenge predictions of established theories of transition - that bureaucrats will resist changes that reduce their own power, that they are motivated by rent-seeking opportunities, and that clearly defined property rights are a prerequisite for successful economic development. $^{2}$

These township and village levels of administration are also primarily responsible for the provision and financing of welfare to the rural population. Relatively little explicit attention, however, has been paid to the welfare implications of changes in the rural economic environment, beyond discus- 
sions of the general impact of growth on income levels and employment, and to some extent a concern with growing intra-regional income inequality.

In this contribution I examine the locus of responsibility for provision and financing of rural welfare, and the ways in which entrepreneurship by local governments has contributed to meeting these responsibilities. The discussion draws on the literature on the local state in China - to which Gordon White's writing on the developmental state made a significant contribution - as well as on fieldwork undertaken as part of a project started with Gordon. ${ }^{3}$ While his work on social security and welfare in China, and his exploration of 'welfare entrepreneurship', had principally focused on the urban sector, his later research interests had extended to include poverty and welfare in China's countryside. The analysis concludes with a discussion of the likely impact on rural welfare provision of new policy initiatives that will affect the incentives and behaviour of local officials, the powers and resources of the local state, and the relationship between farmers and officials. These initiatives include reforms of the fiscal system, local government restructuring, and the promotion of open and transparent government, most notably through direct elections to village committees.

\section{DEVELOPMENT, ENTREPRENEURSHIP AND THE LOCAL STATE}

\section{Local Economic Development}

Two types of entrepreneurship have been the focus of attention in the literature on China's rural economic transformation during the past two decades. First, in response to changing incentives and market opportunities, formerly collectivised peasants moved rapidly into new areas of economic activity as farmers and private business entrepreneurs. Many cadres, uncertain whether local initiatives would obtain the approval of the central authorities, initially opposed private entrepreneurial activity and wealth creation. Such opposition appeared to support arguments, based largely on Eastern European experience, that government bureaucrats or 'redistributors' would lose power to 'producers' - the new entrepreneurs - during the transition to a market economy, and therefore resist change [Kornai, 1992; Nee, 1989, 1991; RonaTas, 1994].

However, entrepreneurs operated in many cases with at least the tacit support of local government leaders, and such activities expanded rapidly once the central government signalled its approval. Indeed, local government officials themselves emerged as an entrepreneurial class, taking advantage of opportunities to capitalise on their networks and access to resources in the 
partially reformed economy [Cook, 1998]. Such officials were instrumental in establishing collective (township and village) enterprises or in supporting private or quasi-private enterprises wearing the 'red hat' collective guise. Incentives to operate in this manner were largely embedded in the decentralised fiscal system, and in the imperative for local governments to raise and retain extra-budgetary funds in the absence of formal tax raising powers. ${ }^{4}$ Major potential sources of such funds were township and village enterprises (TVEs).

The township emerged with a pivotal role in local economic development soon after the abolition of the commune in 1983. As the lowest level of government, the township fulfils a range of government functions with specified responsibilities, limited power, and some mechanisms of accountability. Its responsibilities lie principally in the areas of social service and welfare provision (including education, health and relief). While not a level of government, the village has similar responsibilities in the area of welfare provision. The township has no formal tax-raising powers, so its capacity to raise other (extra-budgetary) revenues in the absence of significant transfers from higher levels determines its ability to fulfil these responsibilities. From the mid-1980s rural enterprises - particularly TVEs - provided the major source of growth in the local economy, and thus in local government revenues. By 1990 they provided over three times the total revenue raised through agricultural taxes, accounting for 37 per cent of all fiscal revenues at and below the county level [Wong et al., 1995: 108].

The unanticipated performance of rural enterprises challenged conventional thinking on the adaptability of public officials during transition and gave rise to debates about the nature of the 'local state' in China. As rapid growth unfolded, existing theory failed to provide adequate explanations for the pattern of development. Rather than resisting reform or losing power in the process of market transition, bureaucrats were playing a direct entrepreneurial role, contradicting the predictions of the literature on the politics of economic liberalisation that rent-seeking officials would resist reform or distort the market. ${ }^{5}$ Alternative explanations for the behaviour of officials and for local economic development were required.

Drawing on his earlier work on the developmental state, Gordon White was at the forefront of this discussion. Models of the developmental and entrepreneurial local state [Blecher ,1991; White , 1991] and the local corporatist state $[O i, 1992]$ suggested ways in which officials adapted and shaped economic reform to the benefit of their localities. Some of these authors (notably Oi) focused particular attention on the incentives provided by the decentralised fiscal system, and the capacity of local governments to retain extra-budgetary revenues, as key factors in explaining the entrepreneurial 
involvement of local officials in collective industry, as well as their relationship with private business. ${ }^{6}$ In this literature, the role of government as market facilitator and entrepreneur could be viewed as (potentially) productive rather than purely rent seeking.

The principal dimensions of these models of the 'local state' concern: the nature of bureaucratic adaptation to market transition; the locus of entrepreneurship - in business or government; the role of the state as facilitator of, or participator in, the market; and its relationship with private business. While the distinctions between models may not be as clear in reality as the initial formulations suggest, the overlaps between them help to highlight the 'developmental' purpose of the local state, which may be entrepreneurial and/or corporatist, and may operate both for the promotion of local economic development and for the enhancement of social welfare.

\section{Developmental and Entrepreneurial Local States}

The notion of entrepreneurship had been largely absent from relevant literatures - both on state socialism, which has 'planners, not entrepreneurs' [Blecher, 1991: 266] and on the developmental state where '... by and large entrepreneurship is conceptualised as an activity undertaken by enterprises which are implicitly or explicitly viewed as distinct from the developmental state administration' [Blecher, 1991: 266-7]. Describing the concept of 'state entrepreneurship', White [1991] highlighted the adaptability of the state, and the active institutional response to opportunities opened up by market reform and the changing politico-economic environment. Both authors examined the distinctive market-facilitating role of the 'entrepreneurial state' - 'the process whereby individual levels of government, state agencies and individual officials become not only stimulants to but also participants in emergent markets' [White, 1996: 171]. Local governments were seen to be 'acting as powerful and effective agencies for local socio-economic development. They are, in effect, mini "developmental states"' [White and Benewick, 1995: 6].

Drawing on examples of development in two counties in the 1980s, Blecher distinguished clearly between developmental and entrepreneurial states by focusing on the locus of entrepreneurship and the relationship of the enterprise to the state: 'a developmental role of the state ... emphasises entrepreneurship by state administrative or bureaucratic agencies as a central activity' in contrast to 'a rather different developmental role for the state in which entrepreneurship is undertaken by enterprises' [1991: 267]. In the entrepreneurial state conceptualisation, government bureaux engage in entrepreneurial activity, not merely to assist the agency in carrying out its assigned task, but in order to earn profits [Blecher: 267-7]. It was this 
behaviour which Gordon White more recently observed in government welfare institutions, and which formed the basis of his discussion of 'welfare entrepreneurship'.

\section{The Local Corporate State}

In her formulation of the local corporate state (LCS), ${ }^{7}$ Jean Oi also investigated the adaptability of cadres to changing incentives in the transitional economy, providing a framework within which the local state may be both entrepreneurial and developmental. ${ }^{8}$ Her work is particularly concerned with the incentives 'embedded in the institutions that shape the actions of officials' including the property rights regime, the nature of central-local relations, and the fiscal system. She suggests that where the risks or costs to individuals were too high, the state - in China's case the local government had to step in and assume the entrepreneurial role to start rural industry.

Oi's use of the term 'corporatism' differs from more conventional usage and has evolved over time. It is 'not concerned with the role of the central state in the vertical integration of interests within society as a whole ... [but] is constituted and co-ordinated by local government - specifically counties, townships and villages' [1999: 11-12]. Initially it referred to the running of village governments as a diversified corporation, redistributing income to their members and giving members a stake [Oi, 1988] raising the paradox that increasing industrialisation could strengthen the corporate nature of the village, albeit with a different character. ${ }^{9}$ The term has evolved to refer to 'the degree to which the LCS has been able to restrain the private sector from becoming an independent economic class. Local governments have used a combination of inducements and constraints to fashion a local corporatist system that melds the entrepreneurial and governmental roles of local governments' [1999: 138].

Oi's 'developmental state' has both a market facilitating and redistributive role. Within a local corporatist context, local officials turn the administrative bureaucracy into a channel for the flow of information and resources to facilitate market production and serve local economic growth [1999: 178]. They can also redistribute income among different sectors and enterprises within the local corporate state. This broader conceptualisation of entrepreneurial activity suggests that it may take place within developmental local governments, in which case state entrepreneurship may serve to promote broader developmental objectives. Thus with sufficient incentives and resources, bureaucracies can assume an entrepreneurial role in promoting economic reform [Oi, 1999: 193].

More recently Whiting [2001] has described the ways in which local 
government officials, starved of revenues but with a range of under-funded responsibilities for government administration and service provision, developed rural industries from which they could then extract revenues. Rather than interpreting this as a 'corporatist' agenda, however, she argues that officials acted above all as politicians, aiming to maximise their revenues (often at the expense of enterprise interests), rather than as entrepreneurs concerned with the maximisation of enterprise profits. ${ }^{10}$

\section{The Redistributive Local State}

How do these models of the local state assist in understanding the allocation or use of resources created by entrepreneurial governments, and what are the implications for the provision and financing of welfare? Just as local economic growth, and hence improved incomes and living standards, depended on the entrepreneurial drive to create a vibrant local economy, so too the capacity to develop local welfare services depends on the ability of the local state to control some of these resources as well as their willingness to finance such provision. In the literatures on the local state and economic growth, references are made to the use of resources for welfare promotion, for example through the provision of employment to villagers and the use of funds to finance welfare programmes or relief. Early work on TVEs, for example, noted the dilemma faced by local officials wanting to be successful businessmen as well as 'good' government officials fulfilling their responsibilities for village welfare provision [Byrd and Lin, 1990].

The result is a continued redistributive role for the state operating through different mechanisms. Under the developmental or corporatist state, Oi suggests that enterprises (whether collectively or privately owned) most likely to receive government assistance are those deemed most capable of contributing to the 'corporate good', the definition of which changes over time but may include social interests such as the provision of employment, as well as profitability and growth $[O i, 1999]$. In those villages where resources are available to the collective, high levels of public services may be provided. In many highly industrialised villages from Guangdong to Shandong, the collective has effectively taken over all responsibilities for welfare provision through enterprise-raised funds. Thus in some circumstances reforms have led 'not to the end of redistributive socialism but to a new form of redistributive corporatism ... the power of the local government has grown along with the provision of collective welfare' [Oi, 1999: 79-80]. Enterprise ownership may be less important in this process than the relationship between government and business (whether collective or private) which determines the capacity of the local state to marshall resources for redistri- 
bution towards developmental purposes." The next section describes the responsibilities of central and local governments, the availability of resources and the mechanisms for financing welfare services.

\section{WELFARE CREATION BY LOCAL STATES}

\section{Responsibilities for Welfare Provision}

The local state, in the form of the village committee and township government, is primarily responsible for welfare provision and financing. Under the pre-reform collective system, rural welfare provision was in principle comprehensive, with public provision of health care and education existing alongside basic guarantees to relief and social assistance for certain categories of people. In practice, however, stark differences existed in levels of provision both between rural and urban populations, and within rural areas where individuals were dependent ultimately on family and community economic resources. Following decollectivisation, the government has redefined its responsibilities towards the rural population, limiting these to minimal forms of relief and assistance to the very poor and destitute, to specific vulnerable or deserving groups, and to those affected by natural disasters. The principal social security programmes for the rural population are summarised in Table 1.

The devolution of responsibilities from the centre to localities may have had little immediate impact in many rural areas given already low levels of transfers for welfare purposes. None the less, it represents a significant change of principle with implications for the ongoing financing and delivery of services. While the main policies for social assistance are defined by the central government, provision has increasingly been transferred to 'society' - including local communities, mass organisations, work units, families and individuals - through a process referred to as welfare 'socialisation' (shehuihua) [Caireng, 1995: 229; Zhu and Pan, 1994; L. Wong, 1998]. The implicit assumption is that, given access to land, the main sources of livelihood protection for the rural population can be self-provided [Leung and Nann, 1995; Wong, 1994].

Rural relief and social assistance are the domain of the Civil Affairs system. Related welfare programmes involve relevant agencies under the Ministries of Health, Education, and Labour and Social Security. Implementation takes place through these agencies at different levels in the administrative hierarchy, involving co-operation with, and financial contri- 
TABLE 1

RURAL SOCIAL WELFARE PROGRAMMES

\begin{tabular}{|c|c|c|}
\hline Category & Programmes & Provider/financer \\
\hline $\begin{array}{l}\text { i. social relief and } \\
\text { assistance }\end{array}$ & $\begin{array}{l}\text { - payments in cash or kind to } \\
\text { poor households } \\
\text { - material assistance to victims } \\
\text { of natural disaster }\end{array}$ & $\begin{array}{l}\text { - collective welfare funds } \\
\text { - Civil Affairs budget, 'society', } \\
\text { donations }\end{array}$ \\
\hline ii. social welfare & $\begin{array}{l}\text { - institutional care for the aged, } \\
\text { disabled and orphans } \\
\text { - welfare factories providing } \\
\text { employment for the disabled }\end{array}$ & $\begin{array}{l}\text { - collective welfare funds } \\
\text { - self-funding activities } \\
\text { - local government subsidies }\end{array}$ \\
\hline iii. social insurance & $\begin{array}{l}\text { - pension schemes } \\
\text { - community health insurance } \\
\text { - insurance against disasters } \\
\text { - insurance for TVE workers } \\
\text { - insurance for public employees }\end{array}$ & $\begin{array}{l}\text { - individual contributions } \\
\text { - collective welfare funds } \\
\text { - employer provision } \\
\text { - government budget }\end{array}$ \\
\hline iv. social preference & $\begin{array}{l}\text { - special payments to veterans, } \\
\text { disabled, demobilised and } \\
\text { - and retired soldiers and } \\
\text { their dependants }\end{array}$ & $\begin{array}{l}\text { - Civil Affairs and collective } \\
\text { welfare funds }\end{array}$ \\
\hline v. medical security & $\begin{array}{l}\text { - curative health services } \\
\text { - preventive services } \\
\text { - Immunisation and } \mathrm{MCH} \\
\text { insurance schemes } \\
\text { - medical fee exemptions }\end{array}$ & $\begin{array}{l}\text { - Ministry of Health/budget } \\
\text { allocations } \\
\text { - user fees } \\
\text { - collective welfare funds }\end{array}$ \\
\hline vi. other & $\begin{array}{l}\text { - mutual savings/credit societies } \\
\text { - minimum living standard } \\
\text { guarantee } \\
\text { - other, e.g. childcare, activities } \\
\text { for elderly. }\end{array}$ & $\begin{array}{l}\text { - individual contributions } \\
\text { - county budget and collective } \\
\text { welfare funds } \\
\text { - collective funds }\end{array}$ \\
\hline
\end{tabular}

butions from, township, community and village-level organisations, households and individuals. At the township level, social welfare activities are coordinated by a local committee on social security and civil affairs led by the director of the township government [Leung and Nann, 1995: 103, 112]. The responsibilities of these committees include the provision of regular relief to particular categories of people, ${ }^{12}$ often in homes for the elderly, ad hoc assistance to poor households, and in some cases the administration of insurance, pension or co-operative medical schemes. The local civil affairs bureau is also responsible for providing 'social preference' benefits to veterans, soldiers and their families, which often account for a large proportion of local civil affairs budgets, particularly in poor or 'old revolutionary base' areas. 
The role of the central government in direct provision or financing of rural welfare has declined since 1978. Sub-national governments are responsible for around 99 per cent of total (rural and urban) expenditures on social relief and welfare, a figure that has remained stable during this period. The Ministry of Civil Affairs budget has remained around 1.5 per cent of state expenditure, declining marginally from 1.65 per cent per year under the 6th Five year plan (1981-85) to 1.5 per cent under the 8th Five-year plan (1991-95) [Wong, 1998: 149]. However, the 1980s saw a decrease in overall funding for rural relief of 50 per cent in real terms, with expenditures in poor areas experiencing the greatest reduction. When compared with the increase in labour insurance and welfare funds for the urban population, the imbalance is even more stark: in 1995 state spending on civil affairs was only 4.4 per cent of such expenditure [C. Wong, 1998: 151].

A widely recognised problem is the inadequacy of revenues to cover even basic administrative costs, particularly at the township level. Budget allocations from higher levels are generally used first to pay cadre wages and are often insufficient even for this purpose. This payroll budgeting (chifan caizheng) is particularly apparent in poorer areas, where local finances barely cover basic salaries of cadres, with little if anything remaining for developmental or welfare activities. Many of the officials interviewed reported not having been paid, or only partially paid, for several months. ${ }^{13}$ At the same time, pressure to employ new graduates or demobilised soldiers has led to the continuing expansion of the payroll. In one site, officials described the problem they faced of the budget having been fixed for five years while the township has had to absorb about thirty new college graduates or retired army personnel during this period. Poorer areas with greatest need, and facing relatively heavier burdens in meeting nationally determined wage standards, tend to receive proportionately lower levels of fiscal transfers, but to have the weakest capacity to raise funds locally.

\section{Local Sources of Welfare Finance}

The key problem is the gap between local expenditure responsibilities for welfare provision and the availability of funding. The breakdown between central and collective revenues and expenditures is seen from official data in Table 2, with actual provision dependent on local resources. The result has been a proliferation of multiple channels of funding as the local state seeks ways to meet its obligations, for example through the imposition of fees and levies on farmers and businesses, entrepreneurial activities by the state, welfare lotteries and 'welfare enterprises'.

Since decollectivisation, the individual or household has become 
TABLE 2

SOCIAL WELFARE RELIEF FUNDS

$(10,000$ Yuan $)$

\begin{tabular}{lrrrr}
\hline Item & 1985 & 1990 & 1995 & 1997 \\
\hline National Total & 218,349 & 426,772 & 797,289 & 107,7496 \\
$\quad$ Government Funds & 71,097 & 202,456 & 375,313 & 461,710 \\
$\quad$ Collective Funds & 147,252 & 224,316 & 421,976 & 615,786 \\
Funds for Family Members of & 106,983 & 242,732 & 435,359 & 615,411 \\
Martyrs and Disabled Veterans & & & & \\
$\quad$ Government Funds & 35,328 & 141,163 & 240,980 & 293,670 \\
Collective Funds & 71,655 & 101,569 & 194,379 & 321,741 \\
Funds for Poor Households & 28,688 & 38,744 & 56,210 & 75,088 \\
$\quad$ Government Funds & 11,826 & 18,650 & 26,867 & 36,127 \\
Collective Funds & 16,863 & 20,094 & 29,343 & 38,961 \\
Five Guarantee Funds (wubao) & 55,196 & 85,052 & 160,121 & 196,951 \\
$\quad$ Government Funds & 6,693 & 11,851 & 22,277 & 26,545 \\
Collective Funds & 48,503 & 73,201 & 137,844 & 170,406 \\
Funds for Urban and Rural & 27,483 & 60,245 & 145,599 & 190,046 \\
Welfare Homes of All Types & & & & \\
$\quad$ Homes for Disabled Veterans & 3,040 & 6,213 & 11,737 & 17,095 \\
$\quad$ Government Funds & 2,911 & 5,920 & 10,920 & 15,966 \\
$\quad$ Collective Funds & 129 & 293 & 817 & 1,129 \\
$\quad$ Social Welfare Homes & 24,443 & 54,032 & 133,862 & 172,951 \\
$\quad$ Government Funds & 14,340 & 24,873 & 74,269 & 89,402 \\
$\quad$ Collective Funds & 10,103 & 29,159 & 59,593 & 83,549 \\
\hline
\end{tabular}

Source: China Statistical Yearbook 1997: 737; 1998: 793.

increasingly responsible for self-provision. Rural health and education are now predominantly privately financed through user fees, while households make a major contribution to welfare funds (gongyijin) which are collected and allocated at the village or township level. The primary source of such funds are the fees and levies (tiliu and tongchou) collected from farmers and rural residents, usually on a per capita basis. Due to the rapid proliferation of extra-statutory charges on farmers to meet local financing requirements, the central government has set a limit on the amount that can be raised of five per cent of average per capita village income. ${ }^{14}$ Most relief and 'social preference' expenditures are financed from such locally raised funds. Welfare homes are funded partly from Civil Affairs budgets, township extrabudgetary funds (including remittances and public welfare funds of township enterprises), and in richer villages from the collective funds derived from village enterprises.

As noted above, in the most heavily industrialised and economically developed rural areas, such as parts of Zhejiang, Jiangsu and Guangdong, high levels of social security and insurance are collectively provided using enterprise-raised funds. In addition, many institutions responsible for the 
care of the elderly or disabled have started 'welfare enterprises' or operate other income-generating activities which enjoy tax reductions or receive various forms of support from the township such as allocation of land or subsidised essential services. In some areas welfare lotteries provide an additional source of finance, although these funds are usually used for capital investments, such as old age homes, rather than current expenditures.

Social insurance is increasingly seen as an alternative source of funding for relief and assistance, as well as a mechanism for expanding the rural social security system. Two major initiatives are in areas of community health insurance and rural pensions (or old age insurance), although other schemes include crop, housing and various forms of personal insurance as well as insurance for government and TVE employees. Contributions to government-run insurance or pension schemes may either be collected from individuals on a voluntary basis, as part of regular compulsory levies, or paid from collective funds raised from other sources, including enterprises. ${ }^{15}$ In some cases, however, these contributions become another form of disguised fee or levy. For example, insurance for children may be included in education fees, and therefore becomes compulsory where it should be voluntary.

Funds raised by the collectives are part of off-budget funds that have received increasing attention in recent years. The decentralisation of the fiscal system gave rise to two forms of off-budget finance - extra-budgetary funds (yusuanwai zijin) under the control of local governments and administrative agencies, and self-raised funds (zichou zijin) at the county and township levels. The ability to retain these revenues was a key incentive to the promotion of enterprises by localities and administrative agencies. While accurate data are hard to obtain, it is clear that their scale is considerable. According to official aggregate statistics, in 1993 off-budget funds accounted for about 36 per cent of total revenues. Local studies point to considerably higher proportions, particularly at the township level [Wong, 1997: 59; Fan, 1998].

Comparing the division of expenditure responsibilities among administrative levels, Wong also notes that lower levels are remitting more than they retain (see Table 3). These levels bear the main burden of local government financing responsibilities, including wage increases that have exceeded the average rate of price inflation and have pushed up the costs of administration and service provision [Wong 1997: 58]. Thus even as local states are being entrepreneurial, pressures are increasing on local budgets, and the share of resources available for welfare is likely to be squeezed as localities try to meet administrative and wage costs. In a climate of growing competition between enterprises, and a slowdown in overall growth, a major source of finance available to at least some local states for redistributive or welfare purposes is clearly under pressure. 
TABLE 3

EXTRA-BUDGETARY REVENUE AND EXPENDITURES OF CENTRAL AND LOCAL GOVERNMENTS

(100 million yuan)

\begin{tabular}{|c|c|c|c|c|c|c|}
\hline Year & $\begin{array}{r}\text { Total } \\
\text { Extra } \\
\text { Budgetary } \\
\text { Revenue }\end{array}$ & $\begin{array}{r}\text { Central } \\
\text { Govern- } \\
\text { ment }\end{array}$ & $\begin{array}{r}\text { Local } \\
\text { Govern- } \\
\text { ment }\end{array}$ & $\begin{array}{r}\text { Total } \\
\text { Extra- } \\
\text { Budgetary } \\
\text { Expenditure }\end{array}$ & $\begin{array}{r}\text { Central } \\
\text { Govern- } \\
\text { ment }\end{array}$ & $\begin{array}{r}\text { Local } \\
\text { Govern- } \\
\text { ment }\end{array}$ \\
\hline 1985 & 1530.03 & 636.10 & 893.93 & 1375.03 & 562.05 & 812.98 \\
\hline 1986 & 1737.31 & 716.63 & 1020.68 & 1578.37 & 640.94 & 937.43 \\
\hline 1987 & 2028.80 & 828.03 & 1200.77 & 1840.75 & 741.61 & 1099.14 \\
\hline 1988 & 2360.77 & 907.15 & 1453.62 & 2145.27 & 842.86 & 1302.41 \\
\hline 1989 & 2658.83 & 1072.28 & 1586.55 & 2503.10 & 975.87 & 1527.23 \\
\hline 1990 & 2708.64 & 1073.28 & 1635.36 & 2707.06 & 1037.69 & 1669.37 \\
\hline 1991 & 3243.30 & 1381.10 & 1862.20 & 3092.26 & 1263.27 & 1828.99 \\
\hline 1992 & 3854.92 & 1707.73 & 2147.19 & 3649.90 & 1592.81 & 2057.09 \\
\hline 1993* & 1432.54 & 245.90 & 1186.64 & 1314.30 & 198.87 & 1115.43 \\
\hline 1994 & 1862.53 & 283.32 & 1579.21 & 1710.39 & 225.02 & 1485.37 \\
\hline 1995 & 2406.50 & 317.57 & 2088.93 & 2331.26 & 351.38 & 1979.88 \\
\hline 1996 & 3893.34 & 947.66 & 2945.68 & 3838.32 & 1034.92 & 2803.40 \\
\hline
\end{tabular}

Note: *The coverage of extra-budgetary revenue and expenditures was adjusted in 1993 and the subsequent data are not comparable with those from previous years.

Source: China Statistical Yearbook, various years.

\section{WELFARE, FINANCE AND FARMER-CADRE RELATIONS}

Responsibility for the livelihoods and welfare of the rural population, and the need to create resources with which to fulfil this role, place potentially contradictory demands on local officials. In the absence of adequate tax revenues or transfers, they can either raise funds through directly entrepreneurial activities or from private enterprise; alternatively, they must raise funds from the very constituency for whose welfare they are responsible. These options may either strengthen their position - if they are able to create resources and use them for developmental or welfare purposes; or weaken it - if they create resources but fail to use them to benefit the community, or if they fail to create such resources except by additional impositions on villagers. In all cases there are implications for relations between farmers and officials, and for the nature of the local state in an era of more intense market competition and tighter budget constraints.

The major source of tension between farmers and cadres in recent years has been the burden of collective fees. Conflicts arise not only from the absolute level of fees but also from perceptions of what the money is being used for, the commitment of officials to local development, and widespread 
corruption in local government. Rising rural unrest, an increasing frequency of protests by farmers against local government, and violent incidents of resistance and repression have generated renewed efforts by the central government to find ways to reduce burdens on farmers. Discussions around the 2002 National People's Congress have elevated rural problems, including raising farmers' incomes and agricultural productivity and reducing the tax burden, to a priority area of work for the government.

These tensions are not new. The five per cent limit on levies was adopted in response to earlier protests against rising extra-statutory charges. More recently a number of other institutional changes have been introduced to reduce tensions. Probably the most important are fiscal reforms to rein in some of the off-budget funds, and convert the proliferating arbitrary fees to a uniform tax. Introduced experimentally in Anhui province, initial assessments pointed to positive impacts in reducing the burden on farmers and thus increasing incomes. However, the wider problems to which it gave rise, including making explicit the revenue crisis at the township level, and the inability of local governments to fulfil under-funded mandates such as the provision of basic education, led to a temporary halt to its expansion. Currently the reform is being introduced more widely and will pose serious challenges for many local governments in fulfilling their responsibilities for welfare and basic service provision.

Other reform initiatives involve scaling back the size of township government, particularly through a reduction in personnel, in some cases involving the merging of townships. These reforms aim at reducing the administrative costs involved in financing this level of government. In addition, a range of programmes aims at increasing the openness, transparency and accountability of local governments, including systems of open financial accounting, monitoring of revenues and expenditures, and direct elections to village committees.

How might these reforms affect the revenue raising capacities of local governments, and what are the likely implications for farmer-cadre relations? Not surprisingly, in townships with sources of collective finance, whether relatively wealthy or poor, relations between villagers and leaders were generally found to be better than in those without. The latter (regardless of income level) can be broadly categorised into two types. First are those which (based on comparisons with neighbouring areas) potentially could have promoted greater local development but where the government appears to have few developmental or entrepreneurial aspirations or the capacities to achieve their objectives. In these areas, township and village leaders resort to imposing additional levies on farmers to meet any new obligation (such as pension or insurance schemes) mandated from above, gener- 
ating increasingly high levels of tension between farmers and the state. Second are those townships with few entrepreneurial opportunities, and thus limited resources, which tend to be located in the poorer areas.

The strongest conflicts were over the imposition of fees that led to no direct or visible gain for the community, or where villagers' preferences over the use of funds were ignored. In one case, fees were withheld by villagers in protest at the relocation of the local school to a neighbouring village. ${ }^{16} \mathrm{In}$ other villages, the points of tension were between the village and township or higher levels - one example where the village leader refused to co-operate with township and county authorities concerned the overestimation of village incomes in order to levy higher taxes. ${ }^{17}$ Another source of frustration at both village and township levels was the use of funds for urban development. Farmers complained of their fees being used for the development of nearby cities while officials in one township complained that its development was benefiting the nearby county seat. Furthermore, rising incomes of farmers engaged in providing services for the urban area were impossible to tax. Thus although some individuals were becoming wealthier, the township government was impoverished. ${ }^{18}$ Even townships with collective resources, however, face problems in meeting their administrative and wage costs, quite apart from funding their other responsibilities. An urban and relatively affluent township near Qingdao continued to face problems of payroll budgeting and pressures to absorb new personnel. ${ }^{19}$

Exacerbating the tensions between farmers and cadres, and between levels of government, are inter-agency or -departmental tensions over the control and allocation of resources. Each agency vies for resources to fulfil its own mandate. In one township in Hubei province, the director of the poverty alleviation office commented on problems created by the civil affairs' system in its efforts to raise resources:

The civil affairs' sector used to be the government sector to help farmers, but now it seems that it only collects money from farmers - e.g. for pension insurance, social pooling, preference funds, etc. The most unfortunate thing for farmers is that these collections do not benefit them, for example, the township is required to subscribe to various kinds of newspapers and magazines at national, provincial and county levels, and the only way to cover the cost is to collect money from farmers.

Likewise, townships officials pointed out how 'compulsory education' (yiwu jiaoyu) has been distorted from its intention to provide universal access to nine years education, to a mechanism to raise funds to cover the expenses of teachers, including their wages, welfare and health costs, as well as school equipment - costs which vastly exceed the amount allocated through the budget. At the same time further reforms in the welfare field are creating new 
obligations and partially or un-funded mandates for local governments. The minimum livelihood security (zuidibaozhang) programme which is being expanded from urban areas to small towns and some wealthier rural areas was seen in many areas as yet another burden. Although many local officials regard it as an important direction for rural social security, funding remains the main constraint. The requirement that the township government pay 30 per cent of the costs creates yet another burden on farmers. As we discuss further in the concluding section, the range of responsibilities devolved to local governments, their lack of resources for meeting them, and the sources of tensions between officials and farmers, suggest significant challenges for the current rural reform agenda.

\section{CONCLUSION}

The initial discussion of the nature of the local state described the ways in which local governments have created wealth through their engagement with collective and private business. Their lack of fiscal revenues, combined with their responsibilities for local economic development and the provision of public goods, created an imperative to generate income. The nature of fiscal decentralisation provided incentives for this to occur through revenue extraction from local industries. In the absence of such opportunities, governments can only resort to collecting fees from farmers. Thus we saw the emergence of seemingly entrepreneurial local governments, in some cases acting as mini-developmental states. The resources generated have been used to a varying degree to fulfil the welfare obligations of local governments. In all but the wealthiest areas, however, they remain insufficient.

The rural reform policies referred to above are likely to have mixed outcomes for the local state and its capacity to pursue these closely related entrepreneurial and welfare objectives. There is no doubt that such reforms are needed: revenue raising activities by local states are frequently excessive and illegal, and may not be used to benefit the local population. They may also involve collusion between local officials and business to evade taxes to higher levels of government [Whiting, 2001]. As a result of these kinds of activities, the township government is widely perceived as the most corrupt level of government. The proposed reforms begin to address some of these problems and may relieve some sources of tensions in local state-society relations. Experiments in tax reforms have led to a reduction in farmers' burdens. Village elections and the introduction of methods of open government and accountability provide villagers with stronger mechanisms for holding officials accountable. 
At the same time, it is also possible that these reforms will work in contradictory directions. While accountability mechanisms are strengthened, the capacity of officials to control income sources with which they can meet the demands of villagers and provide collective and welfare goods is further compromised. Tax reform has led to a decline in revenues available to the township. These developments occur at a time when rural industries in many areas are under pressure. Thus in more developed, industrialised townships, where services are largely provided by enterprise-raised funds, officials are expressing concern about how residents might react if fees had again to be introduced for services in the event of declining enterprise revenues. For those collectives with limited opportunities to raise resources there is little indication that more transfers will be available.

While fiscal reform and rationalisation is clearly necessary to reduce corruption and illegal revenue raising, it imposes costs on entrepreneurial governments. As resources are squeezed, a major casualty will be rural welfare provision. Already the problems facing basic education, and the lack of commitment to transfers from the centre, points to future problems. Far from a more redistributive agenda, the devolution of responsibility from central to local state and society involves a strong emphasis by central government agencies on the local determination of affordable levels of welfare provision. Thus local officials already face greater pressures to respond to the demands of the local population - through new accountability and electoral mechanisms - but control fewer resources with which to meet their obligations. Successful institutionalisation of fiscal reforms, more accountable village and township government, and the resolution of serious tensions and conflicts between farmers and the government, will only be achieved if accompanied by a greater commitment to redistributive welfare from the centre.

NOTES

1. The wider use of 'entrepreneur' is becoming more common. For example, Tony Blair has described as 'social entrepreneurs' 'those people who bring to social problems the same enterprise and imagination that business entrepreneurs bring to wealth creation'.

2. There is a considerable literature on property rights in China, particularly in TVEs. This issue is not addressed here.

3. The research was funded by a grant from ESCOR, Department for International Development, UK.

4. Township governments are unable to borrow or to run deficits.

5. See also Duckett [1998] for a development of this argument with reference to entrepreneurship among municipal government agencies in Tianjin.

6. More recently Whiting [2001] has examined the financial and fiscal incentives for local governments to raise money through extraction from collective enterprises. 
7. These ideas evolved from early discussions, for example, Oi $[1988,1992]$ to the most fully developed presentation in Oi [1999].

8. Duckett [1998] also suggests that there may be a mixed model of developmental and entrepreneurial states.

9. See also Walder [1998] for a related argument at the county level.

10. See review of Whiting by Marc Blecher (Pacific Affairs, forthcoming 2002).

11. Of course, local states can also be 'predatory' with local officials raising revenues for nondevelopmental purposes or for private gain.

12. Referred to as 'Five Guarantee' households (wubao hu), those with no labour, no family or other means of support are in theory guaranteed food, clothing, housing, education (for orphans) and burial (for the elderly).

13. Fieldwork was undertaken in Guizhou, Hubei and Shandong between February and May 1998 by the author and researchers from the Ministry of Civil Affairs, Beijing. The following sections draw on this research.

14. The five per cent limit refers to all levies, not just those for welfare purposes. There are frequent reports of levies exceeding this amount, while the limit leads to incentives for the government to inflate reports of average income in order to increase the amount that can be collected.

15. Interviews: Hubei, 1998.

16. Interview: Hubei, Enshi, 1998 (HEC-06).

17. Interview: Hubei, Enshi, 1998 (HEC-03).

18. Interview: Hubei, Enshi, 1998 (HEZ-06).

19. Interview: Shandong, Jiaozhou, 1998 (QJZ-11).

\section{REFERENCES}

Blecher, M., 1991, 'Developmental State, Entrepreneurial State: The Political Economy of Socialist Reform in Xinji Municipality and Guanghan County', in G. White (ed.), The Chinese State in The Era of Economic Reform: The Road to Crisis, London: Macmillan.

Brean, D. (ed.), 1998, Taxation in Modern China, New York and London: Routledge.

Byrd, W. and Q. Lin (eds.), 1990, China's Rural Industry: Structure, Development and Reform, Oxford: Oxford University Press for the World Bank.

Caireng, D., 1995, Xin Shiqi Zhongguo Shehui Baozhang Tizhi Gaige De Lilun Yu Shijian (Theory And Practice of Recent Social Security System Reform in China), Beijing: Central Party School Publishers.

Cook, S., 1998, 'Work, Wealth, and Power in Agriculture: Do Political Connections Affect the Returns to Household Labour?', in Walder (ed.) [1998].

Duckett, J., 1998, The Entrepreneurial State in China: Real Estate and Commerce Departments in Reform Era Tianjin, London and New York: Routledge.

Fan, G., 1998, 'Market-Oriented Economic Reform and the Growth of Off-Budget Local Public Finance', in Brean [1998].

Gold, T., 1988, 'The Social Implications of Private Business', mimeo.

Jilin, M.C.A., 1993, 'Wanshan tepinkunhu baozhang zhidu' (Perfect the Social Security System for Extremely Poor Households), Zhongguo Minzheng, Vol.12, pp.19-20.

Kornai, 1992, The Socialist System: The Political Economy of Communism, Oxford: Clarendon Press.

Leung, J. and R. Nann, 1995, Authority and Benevolence: Social Welfare in China, Hong Kong: Chinese University Press.

Nee, V., 1989, 'A Theory of Market Transition: From Redistribution to Markets in State Socialism', American Sociological Review, Vol.54, pp.663-81.

Nee, V., 1991, 'Social Inequalities in Reforming State Socialism: Between Redistribution and 
Markets in China', American Sociological Review, Vol.56, pp.267-82.

Oi, J., 1988, 'The Chinese Village, Inc.', in B. Reynolds (ed.), Chinese Economic Policy: Economic Reform at Midstream, New York: Paragon House.

Oi, J., 1992, 'Fiscal Reform and the Economic Foundations of Local State Corporatism', World Politics, Vol.45, No1.

Oi, J., 1999, Rural China Takes Off: Institutional Foundations of Economic Reform, Berkeley, CA: University of California Press.

Rona-Tas, A., 1994, 'The First Shall be Last? Entrepreneurship and Communist Cadres in the Transition from Socialism', American Journal of Sociology, Vol.100, No.1, pp.40-69.

State Statistical Bureau (various years), China Statistical Yearbook, Beijing: China Statistical Publishing House.

Walder, A., 1998, 'The County Government as an Industrial Corporation', in Walder (ed.) [1998].

Walder, A. (ed.), 1998, Zouping in Transition: The Process of Reform in Rural South China, Cambridge, MA: Harvard University Press.

White, G., 1991, 'Basic-Level Local Government and Economic Reform in Urban China', in G. White (ed.), The Chinese State in the era of Economic Reform: The Road to Crisis, London: Macmillan.

White, G., 1996, 'The Chinese Development Model: A Virtuous Paradigm?', Oxford Development Studies, Vol.24, No.2, pp.169-80.

White, G., n.d., 'Welfare Entrepreneurship' (unfinished ms.).

White, G. and R. Benewick, 1995, 'Central-Local Relations and Local Government Reform in China: Rural County-Level Government', China Research Report, Brighton: Institute of Development Studies.

Whiting, S., 2001, Power and Wealth in Rural China: The Political Economy of Institutional Change, Cambridge: Cambridge University Press.

Wong, C., 1998, 'Fiscal Dualism in China: Gradualist Reform and Growth of Off-Budget Finance', in Brean (ed.) [1998].

Wong, C. (ed.), 1997, Financing Local Government in the People's Republic of China, Asian Development Bank, Hong Kong: Oxford University Press.

Wong, C., Heady, C. et al., 1995, Fiscal Management and Economic Reform in The People's Republic Of China, Oxford University Press: Asian Development Bank.

Wong, L., 1994, 'Privatization of Social Welfare in Post-Mao China', Asian Survey, Vol.34, No 4, pp.307-25.

Wong, L., 1998, Marginalization and Social Welfare in China, London: Routledge.

Zhu, Y. and Y. Pan, 1994, Shehui Fuli De Bianzou: Zhongguo Shehui Baozhang Wenti (Social Security Problems in China), Beijing: Central Party School Publishers. 


\section{Can Welfare Systems be Evaluated Outside Their Cultural and Historical Context? A Case Study of Children's Homes in Contemporary Japan}

\section{ROGER GOODMAN}

\section{THE EM-ETIC CONUNDRUM}

In his paper on 'Social Security Reforms in China: Towards an East Asian Model?', Gordon White [1998: 174] asks the apparently simple question: 'To what extent can emergent patterns of social provision (in China) be described as distinctively Chinese ... ?'

The tension implicit in this question turns on a problem for any social scientist trained to think in terms of general theories of society who becomes deeply immersed in the study - and fluent in the language - of one particular country. At its core is the search for what is universal about the society one studies and what is unique about it; in anthropology, this dilemma has classically been reduced to a distinction between an emic (inside) and an etic (outside) analysis of any particular society.

As Gordon White and I [White and Goodman, 1998] discuss in our introduction to The East Asian Welfare Model, the distinction between emic and etic perspectives is crucial for understanding how welfare regimes are constructed, perceived and legitimated. One of the themes of the book is that notions of both a general East Asian Welfare Model and more nationallybounded models such as the so-called 'Japanese-style welfare society' (Nihongata shakai fukushi shakai) are the constructions of elites within East Asian and Japanese society, drawing on discourses of 'tradition' and cultural determinism to justify low welfare expenditures and the maintenance of the expectation that individual welfare needs should be met primarily by the company, community or family, but not, if it can be avoided, the state. If there is anything distinctive about the role of the state in East Asian welfare regimes, we concluded, it is that it is expected to play the role more as a regulator than a provider of welfare.

When I review my own position in the discussions that Gordon White, 
Huck-ju Kwon and I had while putting together The East Asian Welfare Model, I now realise that I instinctively took the position that the state should not limit itself to a regulatory role in welfare provision and that the level of 'social inclusiveness' or 'citizenship' (to use the current jargon) in a society could be measured in terms of the extent to which the state itself actually supplied the welfare. In general, I now realise, Gordon was more openminded than I about the potential for non-state agencies in welfare provision, as long as the state, on behalf of its citizens, took a proper regulatory role: for him what mattered was the quality of care, not how it was provided. Certainly a passage in our joint introduction which I remember him inserting would suggest this was his viewpoint [1998: 18]:1

What does 'welfare' mean in different societies? For example, the options available to a person with disabilities in Britain or the United States, where a substantial network of state support exists, may be greater than in a welfare system where the only or main provider is the family and the state plays a residual role. The latter welfare systems may be cheaper, but are they producing less 'welfare', in terms of both quality and quantity?

This chapter is an exploration, therefore, of how assumptions about how welfare should be provided can affect the conclusions one draws from studying the welfare system of another society, and how immersion in a welfare system of another country can lead to different conclusions about how welfare might best be provided in one's own society; or how an etic view of welfare systems needs to be balanced by an emic one. It is based on my own experience of, and changing perspectives while, undertaking research on Japanese child welfare during the 1990s which finally resulted in the publication of my monograph Children of the Japanese State [2000].

\section{CHILDREN'S HOMES IN JAPAN}

The particular institutions on which I wish to concentrate in this exploration are jidô yôgoshisetsu (generally called just yôgoshisetsu in Japanese and children's homes in English) which are the longest-established welfare facilities in the society and hence, since historical depth is so important in Japanese society, those with the highest status. Of the current 540 yogoshisetsu, over ten per cent can date their founding to the Meiji period (1868-1912) and a further 15 per cent to the pre-war period; very few have been founded in the past 20 years. $^{2}$

Throughout the post-war period, the yogoshisetsu have catered for around 30,000 children (the figure has changed little until recent years) 
whose parents cannot look after them. Some of the reasons behind their coming into care represent a social history of post-war Japan: war orphans in the late 1940s; the children of poor labourers in the 1950s and 1960s forced to move around the country looking for work (dekasegi); the offspring of those who borrowed too much in the 1970s and became indebted to loan sharks (sarakin); the result of growing rates of drug and alcohol abuse in the $1980 \mathrm{~s}$; the victims of the recession in the 1990s as increasingly large numbers of individuals declared themselves bankrupt (jiko hassan) and placed their children in the care of the state. Significantly, though, it has until very recently always been maintained that children come into care not through any fault of their own, but because of their parents' problems. Only in the last couple of years have more than a handful of children been placed in children's homes by the courts in Japan because of abuse they have suffered at home.

Through the post-war period, yogoshisetsu themselves have changed remarkably little and have retained a number of distinctive features which make them very different from similar institutions in North Europe ${ }^{3}$ or North America.

- Except for a brief period immediately after the war, yôgoshisetsu have consistently cared for over $90 \%$ of the children who come into care of the state. Systems of fostering and adoption for such children - which have become the norm in many other capitalist societies - are still very undeveloped and indeed have been in decline, to the point of almost disappearing in some areas, in recent years [Goodman, 1998].

- Yôgoshisetsu tend to be large, dormitory-style institutions. Even today the average capacity of a home is over 60 and many homes have capacities of over 100 , though only the best homes are full to capacity.

- In the immediate post-war period, around 20 per cent of homes were staterun and indeed these homes were often better funded than private homes. In the past 30 years, however, the majority of state homes have been shut down and today over 90 per cent of homes are privately owned and run, though state funded. Of these 90 per cent, around 70 per cent are run by family concerns who pass the running of the institution down from one generation to the next, ideally through patrilineal primogeniture, though, as always in the Japanese inheritance system, this rule will be bypassed if a better candidate is available. This system is known as the dôzoku keiei (same-family management) system and has had important implications for the development of the whole welfare system in post-war Japan. Since yôgoshisetsu 
have the longest history of welfare institutions in Japan, those families which have run yogoshisetsu have often been allowed to establish other welfare institutions, such as old people's homes; today most yogoshisetsu are part of, often the flagship institution in, large welfare corporations (shakai fukushi hôjin) which may have as many as 20 welfare institutions, many of which will be run by members of the same family.

- Staffing levels in Japanese yôgoshisetsu have remained virtually unchanged since 1976 at six children over the age of six per each member of staff. Since staff work eight-hour shifts this means, on average, around 14-16 children at any one time under the care of each member of staff. Staff in homes tend to be non-unionised, young and often short-term, except for those who are members of the families who own the homes who tend to remain in the institutions throughout their working lives.

- These families, over the years, have generally built up long-term relationships with the local community in which they operate, which are often crucial for the running of the homes. One means through which homes have been able to provide some level of extra care has been through the use of local volunteers; in the case of one yogoshisetsu with less than 70 children where I undertook research, it was estimated that around 500 members of the local community gave up at least one day a year in the form of volunteer activity at the home each year.

\section{ANALYSING JAPANESE CHILD WELFARE: \\ TOWARDS AN ETIC CRITIQUE}

My early attempts at analysing yôgoshisetsu [Goodman, 1993, 1996] were generally very negative of the way in which they were run and were highly influenced, I now realise, by the 'welfarists' in Japan who believe (a) that the state should be responsible for welfare provision and (b) that the agents of the state in Japan are generally primarily interested in saving money and social control rather than providing quality control. I was critical of the child welfare system in general and of yogoshisetsu in particular on a number of points: the over-reliance of institutionalisation; the lack of concern about normalisation; the virtual absence of professionalisation; the dearth of investment; and the non-existence of debates about children's rights.

The system was run more in the interests of the homes themselves and the bureaucrats who placed children in those homes, than it was for the children who came into the care of the state. All placements were made by untrained (in social work terms) local government officers (jidofukushishi) 
who were transferred often to short-term positions in the local government child guidance centres (jidôsôdanjo) where they took advice from locallyappointed, high-status, often elderly (average age over 60) volunteers (jidôiin-minseiiin) in the community, and placed children in decrepit and almost-Dickensian welfare institutions from which they often could not leave until they were 16 or even 18 and then were forced to make their own way in the outside world - unprepared and unsupported. Small wonder, therefore, that many of those who came into care were the children of parents who had themselves been in care and even less wonder that no one was prepared to find out exactly how many such children there were in care and what happened to others as they left the care system. ${ }^{4}$

Although my view of the child welfare system in Japan was extremely negative, I was far from alone in holding to it. After 40 years of virtual silence about the whole system in Japanese society, the 1990s saw a sudden explosion of debate. The driving force behind this was the UN Convention on the Rights of the Child which was signed by Japan in September 1990, ratified by the government in May 1994 and reviewed by the UN Committee for the Rights of the Child in July 1998. While the Japanese government argued that ratifying the Convention necessitated only minor changes to Japanese practice and law (the Child Welfare Law was revised for the first time for forty years in 1998), critics within Japan argued that it meant radically overhauling the whole child welfare system. ${ }^{5}$ Chief among these critics was the national association of lawyers in Japan (Nichibenren) which argued very much along the lines I had myself taken in my work ${ }^{6}$ and submitted a counter-report to that of the Government to the UN Committee in the summer of 1998 [Nichibenren, 1997].

The UN Committee in its final report dabbed faint praise on those reforms the Japanese government had made and largely followed and repeated the criticisms of the Nichibenren report; indeed, it castigated the government representatives for working in opposition instead of together with Nichibenren, when it was clear that the latter only had the best interests of children (the key to the Convention) at heart, implying that the interests of the government representatives perhaps lay elsewhere. Even more interesting, however, was the response to the government line that there was no widespread desire among the Japanese public to see the child welfare system changed: the UN committee retorted that it was the duty of the government to educate and lead rather than to follow public opinion.

As one stands back from these often rather heated debates, however, it is clear that the position of the UN, Nichibenren and indeed my own position are based on a number of common assumptions which need to be made more explicit: 
(1) As we have just seen, the idea that government welfare bureaucrats' main concern is to save money (and have an easy life) rather than the welfare of children in the care of the state;

(2) Those who have professional qualifications will necessarily provide higher quality care;

(3) Fostering and/or adoption are better ways to care for children than in large institutions;

(4) The experience of children who are in institutions should be made as similar to that of those in 'normal' families as possible (Bowlby's classic notion of 'normalisation');

(5) Children who come into the care of the state through no fault of their own are entitled (as 'citizens' of a society) to a decent standard of life and should not be dependent on the arbitrary nature of charitable giving and voluntary help;

(6) Also mentioned earlier, that the state should lead the development of better welfare provision rather than be pushed into it.

The Japanese child welfare system measured up very poorly against these criteria; hence it deserved to be criticised.

\section{TOWARDS AN EMIC UNDERSTANDING}

While the account that the above assumptions generate is logically consistent and coherent and, also, judging from the reaction of the UN Committee, compelling, it is problematic for an anthropologist in that it is hypothesis-led rather than empirically-deprived. It is possibly also ethnocentric. As David Tolfree $[1995 a: 12 ; 1995 b: 61]$ powerfully points out in the only large-scale comparative project of children's homes (or as he more accurately calls the system 'residential care for separated children'): 'It is important to view residential institutions in their local context and to avoid imposing Western assumptions and expectations.' Equally seriously, for an anthropologist, it cannot account for all the ethnographic evidence which is available; not all yogoshisetsu today can be understood within the above model, since they are far from homogeneous in the way they operate. It is necessary therefore to take these assumptions above in turn and see how they can be modified in the light of the evidence from the particular context of contemporary Japan. 
TABLE 1

AGGREGATE SOCIAL WELFARE EXPENDITURES IN SOME OECD COUNTRIES ${ }^{a}$ (\% GDP, 1993)

\begin{tabular}{lcccccc}
\hline & Japan $^{\mathrm{b}}$ & France & Germany & Sweden & UK & US \\
\hline Education & 3.70 & 5.60 & $4.70 \mathrm{c}$ & 6.70 & 5.20 & 5.20 \\
Health care & 5.27 & 7.28 & 6.43 & 6.22 & 5.75 & 5.85 \\
Old age, & & & & & & \\
$\quad$ surv. pensions & 5.70 & 11.69 & 11.24 & 10.30 & $7.15^{\mathrm{d}}$ & 6.19 \\
Unemploymente & 0.36 & 3.33 & 4.34 & 5.84 & 1.78 & 0.79 \\
Family benefits & 0.20 & 2.12 & 1.37 & 2.78 & 1.81 & 0.35 \\
Other social security & 0.57 & 2.05 & 3.03 & 4.44 & 2.34 & 1.60 \\
Personal social & & & & & & \\
$\quad$ services & 0.42 & 1.11 & 1.01 & 6.39 & 1.05 & 0.35 \\
Housing benefits & - & 0.92 & 0.24 & 1.17 & 1.84 & - \\
Others & 0.12 & 0.22 & 0.59 & 0.91 & 1.70 & 0.55 \\
& & & & & & $\mathbf{2 0 . 6 2}$ \\
Total & $\mathbf{1 6 . 1 4}$ & $\mathbf{3 4 . 3 3}$ & $\mathbf{3 2 . 9 7}$ & $\mathbf{4 4 . 7 3}$ & $\mathbf{2 8 . 6 2}$ \\
\hline
\end{tabular}

Notes: ${ }^{a}$ Consolidated, general government expenditures, current plus capital accounts

b 1992 (except education: 1993)

c 1994

d This figure significantly overstates national data

e Includes benefits plus active labour market policies

f Includes disability, occupational illness and injury and sickness

Source: Jacobs [1998: 47].

(1) There is no doubt that politicians and bureaucrats in Japan are under heavy pressure to control welfare expenditure. As Table 1 suggests, welfare expenditure in Japan may be still low in comparison with North European societies, but this will be increasingly hard to contain as Japan's population continues to age faster than that of any other largescale society; by 2015, one in four Japanese will be over the age of 64; by 2050, one in three (Nikkei Weekly, 27 Jan. 1997). While Japan's personal tax burden $[K a, 1999: 120]$ is also low in comparison with North European and North American competitors, raising taxes has always been highly problematic in post-war Japan;? as Japan struggles to climb out of its 1990 s recession, raising taxes has become a virtually taboo subject. Tokyo and Osaka in particular are currently running enormous budget deficits and are committed to major welfare expenditure on the elderly through their participation in the Gold Plan of 1990 and the New Gold Plan of 1994.

As well as supporting a growing elderly population, there have also been demands on local government for a variety of child welfare measures under the so-called Angel Plan of 1995 and the New Angel Plan of 1999 which aims to support childrearing and stem the rapidly declining fertility rate in Japan (currently around 1.38 against a replacement rate 
of 2.1). The Angel Plan calls for a massive increase over the next ten years of extended day-care centres and after-school clubs so that women can combine careers with bringing up families [Roberts, 2002].

All this suggests, therefore, that even if welfare officials in Japan are interested in providing better care for children in care, the political agenda has forced them to focus on better provision for the elderly and working mothers; on those who have votes and who are productive members of society rather than those who are too young to vote and are unproductive. As the economy actually contracts, their room for manoeuvre is increasingly limited.

(2) The debate about professionalisation is a long one, though perhaps in the case of social workers best known through Ivan Illich's book on The Disabling Professions [1977]. If Illich pushes the argument to extreme lengths - that social workers, and other caring professions, ultimately serve their own interests rather than those of their clients - more moderate versions can be found in Ezra Vogel's Japan as Number One [1980]. The workers in the child guidance centres may not be qualified, but they are drawn from the top educational echelons in Japan; ${ }^{8}$ similarly, few workers in residential institutions have formal social work credentials, but almost all of them have been through university. As elsewhere in Japanese recruitment practices, there is a preference for generalists over specialists and for training to be on-the-job as much as possible. As some writers on the social work system in Japan have suggested [e.g., Matsubara, 1996], it may be the overall level of educational background rather than the specific qualifications in social work which ultimately effect the quality of care provided to children in homes.

(3) There are a number of different aspects of the debate about fostering versus institutional care which need examination. First, as Figure 1 shows, even within Western Europe, there is a clear distinction between north European countries which favour fostering and south European societies which still support high rates of institutionalisation. This division maps, of course, quite neatly on to Esping-Andersen-type distinctions between Mediterranean, Anglo-Saxon, Continental Europe and Scandinavian welfare regimes in terms of state mechanisms of welfare provision. While it goes unrecognised in the UN or Nichibenren reports, Japan is not as out-of-line in its reliance on institutional care as most critics have suggested. Perhaps more significant though is the concern in many north European societies that an ideological commitment to 
FIGURE 1

APPROXIMATE RELATIVE PROPORTIONS OF CHILDREN AND YOUNG PEOPLE IN RESIDENTIAL AND FOSTER CARE IN 16 EUROPEAN COUNTRIES, 1992

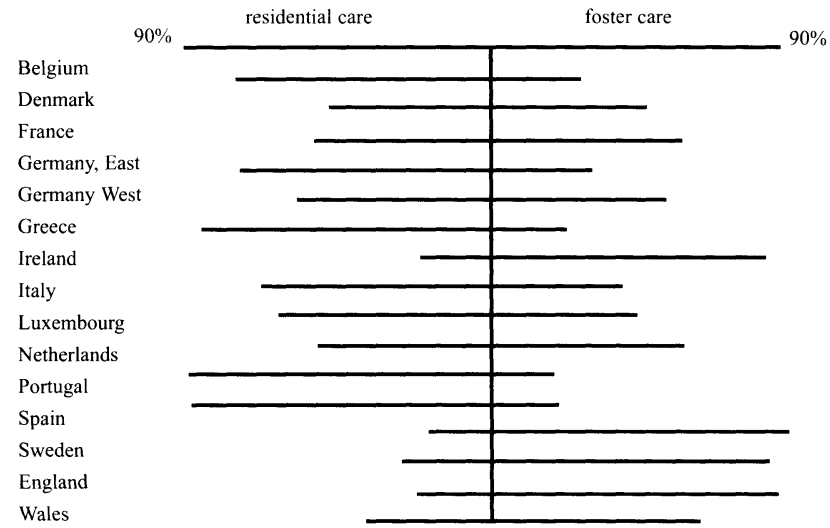

Source: Adapted from Madge [1994].

fostering over institutional care has not always been in the best interests of some children as placements have continually broken down and children have needed to be moved from home to home [Berridge and Cleaver, 1987]. The average stay in yogoshisetsu, which at almost five years has been criticised as being too long, might be argued to offer a level of continuity and stability for some children not available in other forms; certainly this idea is gradually being accepted in the UK in recent years as more child welfare institutions are being opened for certain categories of children in care [Berridge and Brodie, 1998].

(4) Such child welfare institutions in the UK, however, are established on the basis of being as small and as invisible as possible. Ideally, no-one should know they are there and ideally children should pass through them and back into society without being stigmatised by the experience.

Yogoshisetsu in general, as we have seen, take a very different line: the homes are clearly signposted, the children drive around in buses with its name emblazoned on the side and wear sweat shirts with it on their chests. They are told that they should not be ashamed to be members of the home - it is not their fault that they are in care - and not to do anything that will bring shame on its name. Indeed, the home 
should provide them with a sense of group identity - without which no one can operate in Japan - and a point of reference in an otherwise uncertain future. Homes build up long-term relations with their local communities: they develop a relationship with the teachers in the local schools who understand the particular needs of children who often come from very troubled backgrounds; they build up relationships with local employers who in the past often took children on as apprentices and provided them lodging when they left school and the home. Moreover, since the families who run the homes are committed to them for life, its senior members will still be there for former residents to talk to when they return in later life and indeed many do just that: the heads of homes regularly act as in loco parentis at the weddings of former residents and quite a few former residents come and work in homes as staff later in life, sometimes alongside the children of their former head's family with whom they grew up.

(5) If the idea of children's rights has not been fully incorporated into Japanese society, then it may be that there is a different sense of both the child and of rights in the society. In the UK, debates about children's rights and children in care have led to a determination that such children should be 'given space' and that their voices should be listened to as they are helped to reintegrate into mainstream society; in Japan, the emphasis is on teaching children how to work together in groups and to fit into hierarchies so that they are prepared for the realities of life after institutional care. Sadly, in the UK at least, there has been a vicious backlash against the freedom given to children in care as newspapers run stories about 'delinquents' being taken on safaris and summer holidays as a 'reward' for their bad behaviour; in Japan, where there has been debate on such issues, it has normally been accepted that children in care need discipline as much as love, perhaps more so since they will be very much on their own when they go into the outside world. As is often pointed out, children are Japan's only natural resource and hence it is the duty of the state to prepare them to be useful members of society as much as to educate them about their own rights.

(6) Perhaps most importantly though, yoggoshisetsu can and do evolve; indeed, in the 1990s, homes changed more than in any of the previous five decades for a number of interconnecting reasons: debates about the UN Convention and growing public awareness of the idea of children's rights; the dramatic decline in the fertility rate and the possibility that 
within a few years far fewer yôgoshisetsu would be needed; the 'discovery' of child abuse in Japanese society and the awareness that many of the children in care were not simply in need of protection but also help. ${ }^{9}$

As a result of these pressures, there was a number of interesting developments during the 1990s among yôgoshisetsu. In particular, there was bifurcation between progressive homes which tried to set up innovative programmes (including for the first time therapeutic care for abused children and various services to support children in their own homes and to look for foster placements for those who come into long-term care) and conservative homes (which continued to argue that the style of large, dormitory-type of care that relied to a large degree on peer socialisation was appropriate in a Japanese context and did not need changing). As the last century came to an end, it seemed increasingly likely that only the progressive homes would be able to survive long into the next, as only those homes considered the 'best' by the jidôsodanjo would be sent children. ${ }^{10}$ In 2000 and 2001, however, there was a dramatic reverse in the decline in the number of children coming into care as the courts began to intervene for the first time in cases of child abuse and place children in institutions. This has meant a reprieve for some of the 'conservative' homes and an enormous boost (in terms of both finance and prestige) to the most progressive homes many of which have found themselves expanded into family support centres at the forefront of fighting what is seen to be a rapidly growing problem of child abuse [Goodman, $2002]$.

While the changes that have taken place may be particular to the last decade, the way in which they have occurred are consistent with virtually all changes in social welfare institutions in Japan over the past 50 years; they have been led by private institutions needing to be entrepreneurial in order to ensure their survival, in many cases so that the institution can be passed on to the next generation of the same family as a viable operation. There is no doubt that those who run the yôgoshisetsu have vested interests in maintaining them as going concerns. There is no doubt also that this may not always be in the best interests of the children in care since unregulated market forces can lead to some unfortunate results: children being kept in care for longer periods, children who do not need to be in care being taken into care, new programmes being set up to take new categories of children into care without there being the proper support systems or staffing for them once they are there." There is evidence for all of these during the 1990s [Goodman, 1993, 1996; Tsuzaki, 1993, 1997]. Where such abuses are regulated, however, there is evidence that when the child welfare market is as 
competitive as it is in Japan in the late 1990s, then this can lead to positive change as institutions are forced to become increasingly entrepreneurial in their bid to survive.

\section{CLEARING UP THE EM-ETIC MESS}

Which brings me back to where we started. How should we understand welfare systems? Do we develop universal criteria about the 'correct' role for the state in welfare provision and measure societies against those criteria; or do we examine each society purely in its own historical and cultural context and thereby render comparative analysis very difficult indeed? The UN Committee on the Rights of the Child (and some progressive yogoshisetsu) clearly feels the former; the Japanese government (and some conservative yogoshisetsu) the latter.

Perhaps our first task as academics, who have access to both the emic and etic versions of social welfare development, is simply to lay these out to allow others to see the range of possibilities that lie along the regulatoryprovider continuum and the outcomes that these different models produce. In doing so, as we argue in The East Asian Welfare Model, it is possible to begin to separate images and discourses about welfare from the actual management and provision of welfare. When the economies of East Asian societies were booming, idealised versions of cheap and efficient East Asian welfare systems were drawn upon by western politicians in order to legitimate their own welfare reforms; as East Asian economies went into recession, the fallout or downside of such systems become only too obvious. For the first time in 50 years, one can see in Japan queues of unemployed day-labourers lining up in open-air soup kitchens and sleeping in charity-provided tents; in the Airin area of Osaka alone, the number of such homeless in early 2000 passed 10,000 . Extolling the virtues of East Asian welfare systems has all but disappeared from the western political agenda. The systems themselves, of course, have not changed over the past ten years, as much as the evaluations of them in the light of the region's changing economic circumstances.

Perhaps most importantly, however, academics should be in a position to draw on emic discourses to confront the most extreme etic ones, and vice versa. Should we accept Boyden's [1990] argument that the UN Convention is the last vestige of western colonialism, any more that the UN's own line that there is a universal way to protect the best interests of all children? As Gordon, Huck-ju and I discovered in the course of our discussions, the answer was always, 'yes, but ...'; East Asian welfare systems are both similar (from an etic perspective) and yet very different (from an emic one) 
from each other; they have both developed along their own lines and have been susceptible to the same sorts of political and economic pressures as any other welfare system. Ultimately, though, as Gordon White reminded us, it is the quality of welfare provided which matters and not how it is produced; and if, as academics, we are able to show both how a variety of welfare systems have ideologically developed and how they work in practice, and thereby allow policy makers to examine their own systems in the light of this full knowledge, then we may have done something worthwhile.

\section{NOTES}

1. I remember that Gordon based this passage on thinking through how he himself would be treated differently in the UK and Chinese welfare systems. This was just a few days after he had appeared on a TV documentary discussing the changing position of those with physical handicap in Chinese society.

2. There is an interestingly constructed 'official history' of child welfare institutions as a whole in Japan which seeks to trace their origins back to Prince Shôtoku Taishi in the sixth century and even to the activities of various emperors a couple of centuries earlier before written records were available [Tsuji, 1934; Tatara, 1975; Nomoto, 1998]. These 'histories', which appear for example in all official accounts of child welfare institutions in Japan, have played an important role in securing continuing imperial patronage and 'demonstrating' their long 'roots' though their historical accuracy is extremely dubious [Hastings, 1995].

3. There are major differences in the child welfare systems between North and South Europe [Aarre, 1998; Madge, 1994]. Indeed, in many ways, the system in Southern European societies such as Spain, Portugal, Italy and Greece, which also rely mainly on residential over foster care, resembles the Japanese system; Esping-Andersen [1990] points out the structural similarities between South Europe and Japanese welfare systems in his magisterial, if flawed, work, The Three Worlds of Welfare Capitalism.

4. There has been virtually no work undertaken on what happens to care leavers, an even bigger gap in Japan where meticulous statistics are generally kept on all issues to do with those who come into contact with the state than it would be in many other societies.

5. The intensity of the argument was exacerbated by the fact that Japanese is not a UN language and hence much of the meaning of the Convention was open to interpretation. Even in translating the title of the Convention, the government insisted on using the bureaucratic term for child, 'jidô', while organisations like Nichibenren (see below) used the more child-focused term, 'kodomo'.

6. I was indeed in contact with some members of this organisation from early in my research and I have little doubt that I was influenced by their approach which tended to be implicitly comparative between best practice in certain western societies (particularly the UK and Scandinavia) and what they took as worst practice in Japan [Nichibenren, 1993, 1995].

7. The taboo about raising taxes in current Japan is largely related to a lack of confidence in how the government spends public taxes; there is no public budget system in Japan and hence people have little sense of knowing what happens to their tax payments.

8. In recent years, large number of social work courses and universities have opened up in Japan in recognition of the need for more social welfare workers to deal with the ageing society. As Ito [1995] points out, however, these tend not to be at the top level universities and hence their graduates seldom pass the competitive exams to become local or central government bureaucrats. Ironically, therefore, few of those who are qualified in social work can get jobs in local 
government social work offices; and few of those who work in such offices are qualified.

9. The idea that child abuse is possible is a very recent one in Japan and the figures for abused children remain very low. Official statistics on abused children only begun to be collected in 1991 ( 1,101 cases) but immediately began to show the type of exponential growth $(18,000$ cases in 2000) which characterised the 'discovery' of child abuse in the US in the 1970s and the UK in the 1990s. Jido gyakutai (child abuse), though, still remains associated essentially with physical abuse, normally related to over-zealous discipling; there is little recognition of the idea that adults might indulge in abusive behaviour for sadistic pleasure nor that they might abuse children sexually, both of which have become the common understandings of child abuse in most western societies (for more on the 'discovery' of child abuse in Japan, see Goodman [2002].

10. While the number of children in homes declined (if only slightly) throughout the 1990 s, very few private homes were actually forced to close, in part because the budget they received from central and prefectural governments was based on their capacities and not the actual number of children in their care.

11. Tolfree [1995b: 47-8] suggests that Japan is far from alone in having children's homes which may not be run in the interests of the children in them.

\section{REFERENCES}

Aarre, Karen, 1998, 'The Child Welfare Debate in Portugal: A Case Study of a Children's Home', in Iain R Edgar and Andrew Russell (eds.), The Anthropology of Welfare, London: Routledge, pp.57-72.

Berridge, David and Isabelle Brodie, 1998, Children's Homes Revisited, London: Jessica Kingsley Publishers.

Berridge, D. and Cleaver, H., 1987, Foster Home Breakdown, Oxford: Basil Blackwell.

Boyden, Jo, 1990, 'Childhood and the Policy Makers: A Comparative Perspective on the Globalization of Childhood', in Allison James and Alan Prout (eds.), Constructing and Reconstructing Childhood: Contemporary Issues in the Sociological Study of Childhood, London, New York and Philadelphia: The Falmer Press, pp.183-215.

Esping-Andersen, Gosta, 1990, The Three Worlds of Welfare Capitalism, Cambridge: Polity Press. Goodman, Roger, 1993, 'Children's Homes and Children's Rights in Contemporary Japan', Research Papers in East Asian Studies, University of Sheffield, School of East Asian Studies, No.1, pp.31-65.

Goodman, Roger, 1996, 'On Introducing the UN Convention on the Rights of the Child into Japan', in Roger Goodman and lan Neary (eds.), Case Studies on Human Rights in Japan, Kent: Japan Library (Curzon Press), pp.109-40.

Goodman, Roger, 1998, 'A Child in Time: Changing Adoption and Fostering in Japan', in Joy Hendry (ed.), Interpreting Japanese Society (2nd edition), London: Routledge, pp.145-63.

Goodman, Roger, 2000, Children of the Japanese State: The Changing Role of Child Protection Institutions in Contemporary Japan, Oxford: Oxford University Press.

Goodman, Roger, 2002, 'Child Abuse in Japan: "Discovery" and the Development of Policy', in Goodman (ed.) [2002].

Goodman, Roger (ed.), 2002, Family and Social Policy in Japan: Anthropological Approaches, Cambridge: Cambridge University Press.

Goodman, Roger, White, Gordon and Huck-ju Kwon (eds.), 1998, The East Asian Welfare Model: Welfare Orientalism and the State, London and New York: Routledge.

Hastings, Sally Ann, 1995, Neighbourhood and Nation in Tokyo, 1905-1937, Pittsburgh, PA and London: University of Pittsburgh Press.

Illich, Ivan, 1977, Disabling Professions, London and Salem, NH: Marion Boyars. 
Ito Yoshiko, 1995, 'Social Work Development in Japan', Social Policy and Administration, Vol.29, No.5, pp.258-68.

Iwasaki Mieko, 1992, Zadankai (General Discussion) in Atarashii Kazoku (New Family), No.21, Yôshi to Satooya o Kangaeru Kai.

Jacobs, Didier, 1998, Social Welfare Systems in East Asia: A Comparative Analysis including Private Welfare, CASE paper 10, London: Centre for Analysis of Social Exclusion, London School of Economics.

Ka, Lin, 1999, Confucian Welfare Cluster: A Cultural Interpretation of Social Welfare, Acta Universitatis Temperensis 645.

Kikuchi Midori, 1998, 'Tokubetsu Yôshi Seido to Koseki' (Koseki and the Special Adoption System), in Sakakibara Fujiko (ed.), Koseki Seido to Kodomotachi (The Koseki System and Children), Tokyo: Akashi Shoten, pp.79-116.

Kôseitôkeikyôkai (ed.), 1992, Kokumin no Fukushi no Dôkô (Trends in Public Welfare), Vol.39, No. 12.

Madge, Nicola, 1994, Children and Residential Care in Europe, London: European Children's Centre and National Children's Bureau.

Matsubara, Yasuo, 1996, 'Social Work in Japan: Responding to Demographic Dilemmas', in M.C. Hokenstad, S.K. Khinduka and James Midgley (eds.), Profiles in International Social Work, Washington, DC: National Association of Social Workers Press, pp.85-97.

Ministry of Foreign Affairs, Japan, 1996, The First Report to the UN Committee on the Rights of the Child, Tokyo: Gaimusho (Japanese language version).

Nichibenren (Japan Federation of Bar Associations), 1997, 'Report on the Implementation in Japan of the Convention on the Rights of the Child', mimeo, June.

Nichibenren (ed.), 1993, Kodomo no Kenri Jôyaku to Kazoku, Fukushi, Kyôiku, Shônenhô (Convention on the Rights of the Child and the Family, Welfare, Education and the Juvenile Justice System), Tokyo: Kouchi Shobô.

Nichibenren (ed.), 1995, Kodomo no Kenri Manual (The Children's Rights Manual), Tokyo: Nichibenren.

Nihon Sôgô Aiiku Kenkyûjo (ed.), 1988. Nihon Kodomo Shiryô Nenkan (Annual Statistical Review of Children in Japan), 1988/89, Nagoya: Chûô Shuppan.

Nomoto Sankichi, 1998, Shakai Fukushi Jigyô no Rekishi (The History of Social Welfare Work), Tokyo: Akashi Shoten.

Roberts, Glenda, 2002, 'Pinning Hopes on Angels: Reflections from an Aging Japan's Urban Landscape', in Goodman (ed.) [2002].

Tatara Toshio, 1975, ' 1400 Years of Japanese Social Work from Its Origins Through the Allied Occupation, 552-1952', Ph.D. thesis, Bryn Mawr College.

Tolfree, David, 1995a, Residential Care for Children and Alternative Approaches to Care in Developing Countries, Save the Children (London), Working Paper No.11.

Tolfree, David, 1995b, Roofs and Roots: The Care of Separated Children in the Developing World, Aldershot, Hants: Arena.

Tsuji Zennosuke, 1934, Social Welfare Work by the Imperial Household of Japan (trans. by Masao Nagasawa), Tokyo: The Japanese Red Cross Society.

Tsuzaki Tetsuo, 1993, 'Eikoku no "Kodomo no Koe” Undô to Waga Kuni ni okeru Genjô' (The Children's Voice Movement in England and the Situation in our Country), in Kodomo no Koe (ed.), Jidô Fukushi Shisetsu ni okeru Jidô no Kenri Hoshô no Jittai ni kansuru Chôsa Kenkŷ̂ (Survey Report on the Situation of the Protection of Children's Rights in Child Welfare Institutions), Tokyo, pp.102-25.

Tsuzaki Tetsuo, 1997, 'Socio-Cultural Causes of Institutional Abuse in Japan: The Issues of Leadership, Authority and Power Relation', Early Child Development and Care, Vol.133, pp.87-99.

Vogel, Ezra F., 1980, Japan as Number One: Lessons for America, Tokyo: Tuttle. 
White, Gordon, 1998, 'Social Security Reforms in China: Towards an East Asian Model?' in Goodman, White and Kwon (eds.) [1998: 175-97].

White, Gordon and Goodman, Roger, 1998, 'Welfare Orientalism and the Search for an East Asian Welfare Model', in Goodman, White and Kwon (eds.) [1998: 3-24].

Zenkoku Yôgoshisetsu Kyôgikai (ed.), 1998, Zenkoku Jidô Yôgoshisetsu Ichiran, Heisei 1996-7 (Register of all Yôgoshisetsu, 1996-7), March. 


\title{
The East Asian Welfare States in Transition: Challenges and Opportunities
}

\author{
HUCK-JU KWON
}

Over the last 15 years there has been a growing interest in East Asian societies among the communities of policy-makers and scholars. By and large this interest has stemmed from the extraordinary economic success of East Asian countries. This interest has also led a number of scholars and policymakers to study the welfare systems in East Asia [e.g., Jones, 1993; Kwon, 1997; Goodman, White and Kwon, 1998]. In particular, British Prime Minister Tony Blair and former Governor of Hong Kong Chris Patten expressed a keen interest in the magic combination of economic growth and a low level of welfare expenditure. ${ }^{1}$

After the spectacular economic crisis at the end of 1997, the appeal of the magic combination became a thing of the past. Instead, academics and politicians alike are eager to find the causes of the crisis in the East Asian economies. For example, in Japan and South Korea, bureaucrats in the Ministry of Finance, once regarded as the spearhead of economic growth, are blamed for their incompetence in governing financial markets. Overstretched Zaibatsu and Chaebols are also said to be responsible for the shoddy economic structure. Although Taiwan has managed to escape from the falling dominos of economic crisis, the Taiwanese government has been in a state of alert, which signals that it is not so confident about its economic prospects. $^{2}$

\footnotetext{
This study was initially commissioned by the Centre for Development and Enterprise, South Africa, with financial support from the Faculty Research Fund 1998, Sung Kyun Kwan University enabling the author to conduct his research. Thanks are due to Marc Blecher and Sarah Cook for comments on an earlier version. The author's deepest thanks go to the late Gordon White, who gave him many insights while working on East Asian welfare states at the IDS 1995-96.
} 
Amid such economic turmoil, there was also strong pressure for reform of social welfare systems in East Asia. It seemed clear that social welfare reform was a prerequisite for successful economic restructuring. For example, the welfare system in South Korea was unable to deal with social problems arising from the massive unemployment, which was inevitable, at least for some time during the economic reform. In Japan, then Prime Minister Hashimoto strongly argued that the present Japanese system of government should be reformed, embracing new policy ideas for the millennium. He went on to advocate setting up a powerful committee for administrative reform, which would oversee government policy, including policy on social welfare. Does this all mean that East Asian welfare systems are now obsolete and not worth the interest of academics and policy-makers?

In this contribution we will seek, first, to identify what the strengths and drawbacks of the East Asian welfare states are in a development context. Despite the economic crisis, the East Asian welfare states must have had some strong points which worked in the era of economic development, and the future welfare reform must be grounded in their strengths rather than abandoning all things indiscriminately. Secondly, this analysis will attempt to point out the pressures for change, especially in the light of the economic crisis and subsequent restructuring. Finally, the discussion will seek to answer the question of whether the low-spending regimes of the East Asian welfare states will be maintained after the welfare reforms which have been under way in East Asia. This discussion will cover Japan, South Korea and Taiwan, and pay special attention to the social policies and institutions important in each country's context. ${ }^{3}$

\section{EAST ASIAN WELFARE MODEL: STRENGTHS AND WEAKNESSES}

In her pioneering study, Jones argues that societies in East Asia, particularly Japan, South Korea, Taiwan, Hong Kong and Singapore, together make up their own brand of welfare state [Jones, 1993: 199]. She goes on to say that Confucian values are at the heart of their welfare states: hierarchy, duty, compliance, consensus, order, harmony, stability and staying in power [Jones, 1993: 202]. In contrast to Jones' contention, Esping-Andersen does not believe that there is a distinct 'Pacific' model of social welfare. In his analysis of the Japanese welfare system, he maintains that the Japanese welfare system is a fusion of key elements of catholic-conservative welfare states (occupational segmentation and familialism) with a liberal, Americanstyle dominance of private welfare plans. He calls it a hybrid system 
[Esping-Andersen, 1997]. Although his paper was a critique of the contention that there was a 'unique' Japanese welfare system, which was put forward by scholars like Vogel [1980], the notion of a hybrid system does not carry our understanding of the Japanese welfare system much further. His analysis of the Japanese welfare state, moreover, cannot justify his dismissal of the case for the East Asian welfare model, since his analysis did not include other East Asian countries such as South Korea and Taiwan.

In a comparative study of the Japanese and South Korean welfare systems, Kwon agrees with Esping-Andersen in the sense that the Japanese and South Korean welfare systems are not as unique as Vogel maintained [Kwon, 1997]. Kwon suggests that the Japanese and South Korean welfare systems are closer to the model of conservative welfare regimes than other models of Esping-Andersen's typology. He indicates three characteristics of East Asian welfare systems to illustrate his point. First, the structure of social policy is organised mainly according to the principle of compulsory insurance, supplemented by public assistance for the poor. This insurance principle does not automatically guarantee welfare rights to every citizen. It requires contributions prior to entitlements to benefits. Second, the family is expected to play a central role in guaranteeing minimum welfare provision. Third, the underlying politics of social welfare places emphasis on maintaining rather than transforming the prevailing order [Kwon, 1997: 477].

Given these similarities, Kwon is cautious about simply identifying the welfare systems in Japan and South Korea with the conservative welfare regime [Kwon, 1997: 478]. First, there is a subtle but important difference in the emphasis on the role of the family between Germany, for example, on the one hand, and Japan and South Korea on the other. In Japan and South Korea, childcare and the care of aged parents are regarded as basic responsibilities of the family and women in particular. There has been little outside support for the family in these areas of social welfare, while in Germany the state fosters the family's ability to make necessary welfare provision for their members in need.

Second, the level of welfare provision in Japan and South Korea in particular is considerably lower than in Germany and Austria, typical conservative welfare states. This substantial gap in welfare provision would also prevent us from simply including the welfare systems of Japan and South Korea in the cluster of conservative welfare regimes.

Third, there is a difference in the nature of class politics underlying the development of the welfare state. It is true that most social policy initiatives in Japan and South Korea came from the top rather than from below as in 'Bismarckian' Germany. The major introduction of social welfare programmes in South Korea followed the military coup d'état in 1961 as an 
effort to consolidate the political situation. The Tanaka welfare initiative of 1973 in Japan was also a political response to the declining popularity of the Liberal Democratic Party. Despite such a Bismarckian strategy behind the welfare initiatives, the class politics in these two countries does not quite fit into what Esping-Andersen formulates in his typology of conservative welfare regimes. Class has limited applicability in explaining the politics of Japan and South Korea in general and the development of their welfare systems in particular [Goodman and Peng, 1996].

Since Kwon's study [1997] dealt mainly with Japan and South Korea, he did not go further on to say whether a distinctive East Asian welfare model existed. Other studies were also not in a position to substantiate a more concrete case for the East Asian welfare model or explain it through more theoretically informed perspectives. This was mainly due to the fact that those studies on social policy in the region were in the format of case studies, which did not enable the authors to determine whether East Asian societies shared common characteristics in their social welfare systems. For instance, Shinkawa and Pempel [1996] did not articulate a comparative perspective on the East Asian welfare model, when they explained how the conservative government's political strategy to hold on to power and big business interests to control labour resulted in a minimalist welfare state. Ku [1996] and Kwon [1998a] explained the development of the Taiwanese and Korean welfare systems in terms of legitimisation of authoritarian governments and the necessity of economic development, but they did not elaborate further a comparative perspective on East Asian welfare systems. Apparently there seemed to be similarities as well as differences among welfare systems in the region, but these authors did not say much about the welfare systems in other societies.

The East Asian Welfare Model [Goodman, White and Kwon, 1998] attempted to break through this limitation by undertaking empirical research as well as developing comparative perspectives on East Asian welfare systems. Based on field research in Japan, South Korea, Taiwan, Hong Kong and Singapore, Kwon [1998b] argues that the welfare systems in East Asia share many important characteristics, which, in turn, support the case for an East Asian welfare model. He points out, inter alia, four attributes of the East Asian welfare model.

First, with the exception of Hong Kong where the minimalist welfare system is financed by the state, the role of the state in the financing of the welfare systems is largely that of regulator. ${ }^{4}$ Instead of state agencies, quasigovernmental bodies manage the various funds to which social welfare contributions are made. Within this arrangement of social welfare, the actual delivery of social welfare may be private, although not voluntary, and the 
cost of services is met by public insurance agencies. These agencies are not normally parts of the governments. Public health insurance systems in Japan, South Korea and Taiwan and the Central Provident Fund in Singapore operate in this way.

Second, the method of financing social welfare has resulted in a fragmented welfare system in which the pooling of risk is narrower than in an integrated system. Public pension systems in Japan, South Korea and Taiwan, for instance, have several sub-funds, each covering different groups of people: public employees, private school teachers, employees in big businesses and farmers have their own pension funds. Public health care programmes are also fragmented in Japan and South Korea, while Taiwan's new National Health Insurance has integrated all the existing programmes.

Third, the welfare system in East Asia is less redistributive than their counterparts in the West, such as in Britain. Singapore's Central Provident Fund has no mechanism of redistribution: whether intra- or inter-generational. In Japan, South Korea and Taiwan, redistribution between incomegroups takes place but the better-off get the lion's share of social policy benefits.

Last, the political battles behind the welfare system in East Asia have been largely dominated by conservative political forces. In all five East Asian countries, labour unions and social democratic parties failed to exert any significant influence on social policy. However, the political mould in Japan, South Korea and Taiwan has undergone important changes, which has already begun to influence public policy.

Given such similarities, East Asian welfare systems have strong developmental propensities, which might appear attractive to some policy-makers in developing countries [Goodman and White, 1998: 17].

- They promote an ideology and practice which subordinate welfare, particularly in the form of progressive redistribution and a universal and generous benefits system, to the overriding priorities of economic efficiency and growth.

- They are relatively cheap in financial and personnel terms, allowing the diversion of financial resources directly to productive purposes.

- They create a welfare environment (in which publicly provided safety nets are weak or non-existent) which fosters both positive and negative incentives for hard work and discipline.

- They discourage dependence on the state and make full use of available social resources, including community, firm, group and family. 
- Funded social insurance schemes provide substantial financial resources, which can be used for developmental purposes under state direction, notably through investment in social and physical infrastructure.

On the other hand, Goodman and White [1998: 17-18] point out the downside of the East Asian welfare systems.

- The heavy reliance on the welfare role of the family has serious implication for gender relations and the position of women. The model rests implicitly on a context in which women are the main carers within the family and therefore potentially imposes an extra load on top of their 'double burden' of housework and paid employment.

- These welfare systems tend to reinforce socio-economic inequalities. If you are weak, vulnerable or poor, you may not only be in trouble but even be stigmatised for being so.

- The lack of institutional integration until recently in the fragmented social insurance systems in North-east Asia poses high efficiency costs in terms of management and co-ordination.

- Welfare policy has reflected the political logic of conservative dominance and/or authoritarian institutions and has been established and maintained on this basis.

\section{WELFARE REFORM: CHALLENGES AND OPPORTUNITIES}

We have discussed the strength and weakness of the East Asian welfare model in a developmental context. Those strengths and weaknesses may be useful guidelines for policy-makers in some other countries, which are exploring the way in which social welfare could be constituted or reformed. However, each welfare state has been through its own history of development, and those policy-makers who are pondering the relevance of the East Asian welfare model to their countries need to consider their own countries' distinctive political, social and economic conditions.

Besides the relevance of East Asian welfare experience to other countries, we need to answer another question: How will the East Asian welfare systems cope with the social challenges, especially in the wake of the economic crisis of 1997-98? First of all, the crisis which East Asian countries have experienced has put a great deal of strain on their welfare systems. 
Economic downturn certainly reduces the ability of the state, business, and households to pay for public welfare. This forces governments to think again about what they might have planned in an era of economic growth. At the same time, however, economic restructuring following the crisis inevitably creates mass unemployment or forces workers to retire earlier than intended. For the last three decades, Japan, South Korea and Taiwan have enjoyed economic growth, and unemployment rates in the region were very low. This certainly helped them to keep welfare spending relatively low, but the sharp increase in unemployment and early retirement now put a great deal of pressure on the welfare state. In particular, welfare programmes dealing with unemployment are relatively underdeveloped so that it is necessary to reinforce existing programmes and introduce new ones.

Secondly, the welfare state will be influenced by the political changes that the three East Asian countries have experienced. In particular, South Korea witnessed for the first time a power shift to the opposition party within the framework of the democratic constitution. The government of President Kim Dae-jung, a long-time politician in opposition, took a different stance towards social policy, namely the 'productive welfare' initiatives. In Taiwan, the Democratic Progressive Party (DPP) has fought successive elections on a platform of democratisation, Taiwanisation and social welfare. The DPP's electoral performance has been very strong in local elections, where their commitment to social welfare appealed to voters. In the local elections of December 1998, the then governing Kumomintang (KMT), however, made a comeback in Taipei, where the DPP had been in power for the past five years. At the 2000 presidential election, the issue of social welfare was at the centre of political debate since the DPP had realised that the issue of Taiwanisation would not appeal to voters due to military intimidation from Beijing. It is true, however, that the DPP after taking power became cautious about social policy.

Compared to the volatile politics in South Korea and Taiwan, Japanese politics seems to be unable to move forwards over the last five years following the unexpected fall of Hashimoto. Prime minister Koizumi who used to be an outsider within the LDP establishment has not been able to carry out reform and revitalise the economy. Nevertheless, he has continued his effort to break the old mould of Japanese politics against the diehard LDP elders who established it and want to keep it in tact.

Thirdly, changes in demographic structure will also put a great deal of pressure on social welfare systems in East Asia. Compared to other OECD countries, the population is still young in East Asia, but demographic changes are taking place fast. In 1995, the proportion of elderly people (that is, 65 years old or over) was 11.9 per cent in Japan, 5.9 per cent in South 
Korea and 7.6 per cent in Taiwan, which was still smaller than in other OECD countries, such as the USA (12.6 per cent) and Sweden (17.4 per cent) $[U N, 1998]$. In the year 2020, however, 25.2 per cent of the population of Japan will be elderly, one of the highest proportions of elderly population in the world. With respect to South Korea, the figure was 7.1 per cent in 2000 and 13.2 per cent in 2020 [NSO, 1997]. Taiwan's elderly population will be 14.1 per cent of the whole population in 2021 [DGBAS, 1997]. Despite the varying degrees of ageing, these three societies are all facing the social challenges of an ageing society.

Lastly, there are endogenous pressures to reform the welfare systems. As in other countries, bureaucrats and officials in East Asia are not running welfare systems as efficiently as they had hoped. As the East Asian countries become more democratic, pressure groups and the media put pressure on the bureaucracy to be more efficient. On top of the efficiency issue, the fragmented structures of welfare systems are in need of reform. The fragmented systems often have overlapping functions, which would be otherwise unnecessary in an integrated system.

Policy-makers in East Asia seem to be aware of these political, economic and demographic pressures on the welfare systems as well as of the problems within the welfare systems. The policy-makers in South Korea have already pushed through reform policies while their counterparts in Japan and Taiwan are still considering what steps they should take. Within this context, which we have outlined, the following sections will be concerned with welfare reform in Japan, South Korea and Taiwan respectively. Through this examination we will seek to answer whether the low spending regime of East Asian welfare states will be maintained after those reforms.

\section{Japan}

The Japanese welfare system has evolved through several stages into its present form, which is both fragmented and complex. Three different concepts of social welfare played an important role in shaping the recent history of its development. In 1973, the then Prime Minister Tanaka promised that his government would make rigorous efforts to catch up with the welfare states of Western societies. He declared the year 1973 as the first year of significant progress towards the welfare state, an ambition that was short-lived, mainly because of the oil crisis and the economic recession that followed. In 1979, in contrast to Tanaka's initiative, Prime Minister Ohira launched the idea of the 'Japanese-style of welfare society' in his speech to the Diet [Tabata, 1990: 2]. The Liberal Democratic Party (LDP) argued that Japan should not follow the Western style of social welfare, which only 
caused 'welfare diseases', which referred to disincentives to work and single parenthood [Hashimoto, 1979]. Instead, Japan needed a welfare system in which the family would play a key part.

In the late 1980s Japan came up with yet another idea for social welfare. The Economic Planning Agency and the Ministry of Health and Welfare promoted the idea of 'participatory welfare' to 'prepare for an ageing society'. In this period, the Japanese government began to emphasise the role of volunteers and non-governmental organisations as well as the family as important welfare providers [Fujimura, 2000: 7]. This was the recognition that changes in the family structure could not be prevented in order to provide welfare in a traditional manner, as previously thought by the government and many LDP politicians. As a part of the new policy drive, the Ministry of Health and Welfare established an advisory council, the Council on Welfare Vision for an Old-aged Society. It published a report entitled $A$ Welfare Vision for the 21st Century. This report initiated reforms, which resulted eventually in a policy called the 'New Gold Plan'. This 'New Gold Plan' is to be implemented step by step to the year 2010 [Ministry of Health and Welfare, 1997a].

As we mentioned, by 2020 Japan will have the highest proportion of elderly population. Nevertheless, Japan is still a young society compared to other OECD countries in terms of its population structure. Why, then, is there so much ado about ageing? Such social and political attention to ageing is strongly related to the Japanese experience of social welfare. A close examination of the 'New Gold Plan' also revealed the Japanese government's efforts to control the cost of social protection and a shift in Japanese welfare policy towards more state involvement.

It was Tanaka's welfare initiative of 1973, which brought the issue of ageing and elderly care into the sphere of national politics. In the early 1970s, the LDP's share of the vote continually declined, although it managed to keep a majority in the parliament, due to the electoral system, which was strongly in favour of the LDP. The Tanaka welfare initiative was a political response to the LDP's declining popularity. It introduced, inter alia, Medical Care Aid for the Elderly (MCAE), which would provide free medical care for people over 70 . This free medical care programme caused two immediate setbacks.

First, the MCAE put a great deal of the financial burden on National Health Insurance, which was already in a difficult situation [Campbell, 1992], due to the fragmented system of health care. Secondly, the MCAE turned out to be extremely expensive. A considerable number of the aged went to geriatric hospitals and occupied medical facilities and the time of medical personnel. This was mainly due to the lack of a social care system 
for the aged. It was also related to changes in the Japanese family structure. Since the 1950s the Japanese family structure had undergone a fundamental transformation, but the government did not recognise that the family could not provide the same degree of welfare to its members, particularly the elderly, as it had done in a traditional setting [Sumitaka, 1998: 191]. The Japanese government simply assumed that the family would continue to play the caring role for the elderly as it tried to reinforce the family [Council on Family Life Problems, 1967]. The phenomenon of 'hospital-becomingnursing-home' was a spectacular manifestation of the discrepancy between social policy and social reality. This phenomenon also engraved a strong image of 'welfare problems' in Japanese people's minds.

These problems provoked a welfare backlash and paved the way for the idea of a Japanese-style of welfare society. It was to promote the idea of selfhelp and the role of families and firms providing necessary welfare for their members. Under the banner of a Japanese-style welfare society, Japan carried out a series of welfare reforms to take control of welfare costs during the 1980s. The 1983 health care reform replaced Medical Care Aid for the Elderly with the Health Service for the Aged. This reform required central and local governments and all providers of public health care insurance to bear a greater share of the health care cost, which used to be paid mainly by the National Health Insurance scheme. ${ }^{5}$ The elderly also had to share the medical costs when they visited health care institutions (ten per cent of the medical service): it was hoped that this would deter elderly people from visiting hospitals [Watanabe, 1993].

The 1985 pension reform dealt with the public pension system. It aimed at curtailing pension costs in the forthcoming ageing society by introducing a system which would gradually increase the eligibility age for pensions to 65. It also instituted basic pensions, which are guaranteed to all pensioners as basic income. These basic pensions would be financed by a National Fund, to which different public pension schemes would contribute. The Japanese government's long-term aim was to integrate all public pension programmes into one national programme, which would, in turn, reduce the cost of pensions and the risk of financial difficulties for pension funds [Ministry of Health and Welfare, 1997a].

These social welfare reforms, mostly carried out under the Nakasone government, aimed at reducing the government budget deficit without any further increase of taxes. Such an extraordinarily difficult task was partly due to the fact that the successive LDP government had failed to introduce a consumption tax, which eventually came into force in 1989. On the eve of its introduction, the Ministry of Finance and the Ministry of Health and Welfare agreed that there should be social welfare programmes for elderly people, 
which would be financed by this consumption tax [Sato, 1997].

Following this agreement, the Ministry of Health and Welfare announced the 'Gold Plan' in 1990. In a nutshell, the 'Gold Plan' was a programme to increase the number of social service workers and facilities for elderly people to certain target numbers by the year 2000. In particular, the 'Gold Plan' aimed at providing social services to elderly people in their homes. Home-helpers, short-stay centres, day-service centres and a home-help service were focal points of the 'Gold Plan'. The underlying strategy of the 'Gold Plan' was to reduce the cost of social protection by establishing cheaper social service institutions for the elderly. Such social service institutions and personnel will replace to a large extent more expensive hospital care for the elderly. In 1995, the Murayama government replaced the 'Gold Plan' with the 'New Gold Plan'. The basic idea of the 'New Gold Plan' was almost identical but more money was promised to the 'New Gold Plan' [Sato, 1997]. To pay for the 'New Gold Plan', the Japanese Diet passed the Chronic Care Insurance in 1997. A similar strategy was also applied in the area of childcare. The new childcare policy, the Angel Plan, will also increase the number of childcare institutions [Peng, 1998].

TABLE 1

TARGETS OF THE NEW GOLD PLAN

\begin{tabular}{lrrr}
\hline & 1990 & 2000 & 2010 (target) \\
\hline Home-helpers & 35,905 & 247,518 & 402,554 \\
Short-stay Centers & 7,674 & 89,373 & 148,119 \\
Day-service Centers & 1,780 & 27,727 & 49,181 \\
In-home Care Centers & 300 & 8,500 & 15,500 \\
Special Nursing Homes & 172,019 & 347,491 & 462,473 \\
Help-service Facilities & 47,811 & 422,000 & 706,000 \\
Care Houses & 1,700 & 169,300 & 307,900 \\
Residential Centres for the Elderly & 40 & 560 & 880 \\
\hline
\end{tabular}

Source: Ministry of Health and Welfare [1997b, 2000].

The Japanese welfare reform in the 1990s marked a significant change in policy direction. While the policy orientation in the 1980s was welfare retrenchment, the focus in the 1990s was on taking control over the cost of social protection. In other words, the Japanese government is trying to control the overall cost by investing in cheaper options. For this goal, the Japanese government wanted volunteers and non-governmental organisations to get involved in welfare provisions. Despite this strategy, the cost of social protection will inevitably rise, though potentially it is cheaper than other alternatives. There have also been feminist criticisms about the 'participatory' strategy since the emphasis on volunteers is aimed 
at women, mainly middle-class women, whose husbands work in salaried employment.

\section{South Korea}

Among the three East Asian countries under review, South Korea suffered most from the economic crisis. Since then, South Korea has managed to stabilise the situation through paying back some short-term debts and rescheduling the terms of others. A year after the crisis, South Korea became the first casualty of Asia's financial crisis to cross back into the investment grade category of credit rating. ${ }^{6}$ In August 2000 South Korea was able to repay all loans to the IMF. During this time, however, Korean society experienced a social crisis due to the rise of unemployment, and poverty resulting from economic restructuring. Amid the economic crisis of 1997-98 a tripartite committee, which included delegates from the government, the Korean Federation of Business, the Korean Federation of Trade Unions and the Democratic Congress of Trade Unions, signed a social pact, which allowed employers to lay off their employees under certain conditions set by the new legislation. Since then the number of the unemployed has increased sharply from two per cent of near full-employment and reached a record high 8.7 per cent in 1999. This, in turn, puts a great deal of strain on the welfare system of the country. How did the Korean welfare system respond to such pressure? Before trying to answer the question, we need to divide problems of the welfare system into two categories: those related to factors within the welfare system (endogenous) and those that are due to factors outside the welfare system (exogenous).

First, two main programmes of the Korean welfare system, the National Health Insurance and the National Pension Programme, are in need of reform due to endogenous problems. The National Health Insurance schemes originated from a pilot programme for health insurance, which was tried for ten years from 1965 [Choe, 1991: 121], and became a compulsory programme in 1977. It started first with large-scale companies, then public employees and private school teachers. By 1987 when the first democratic presidential election was held for 20 years, the gradual expansion of coverage was complete and the entire population now had access to National Health Insurance. During the period of gradual expansion of National Health Insurance, separate health care funds were established rather than establishing one integrated national fund. Under the name of National Health Insurance, more than 400 health care funds were operating.

The fragmented system of health care had, inter alia, two shortcomings. First, the pooling of risk was too narrow to smooth risk across the different 
risk categories. Second, the cost of administration in the fragmented system is higher than in an integrated one, since there is inevitable overlap in terms of personnel and organisations. The Kim Dae-jung government, which demanded the integration of National Health Insurance schemes when it was in opposition, decided to change the system in 1998. As a first step towards integration, health funds for public sector employees and private school teachers were merged with those for farmers and the self-employed. As a consequence, low-income earners, mostly farmers and urban informal workers, within this integrated health fund will pay less than before, while high-income earners will pay more contributions for their health insurance. The final integration of all National Health Insurance funds in terms of finance as well as administration was blocked by the opposition Grand National Party in 2001. The opposition party argued that financial integration would produce unfair cross-subsidy from wage earners to the self-employed whose reported income level is very often lower than actual income. The political parties agreed that they would revisit the issue in 2003.

Another endogenous problem of the Korean welfare system is the potential financial crisis of the National Pension Programme. Like National Health Insurance, this started with industrial workers in 1988. It has gradually increased its coverage over the years. It included the self-employed in urban areas in 1999, completing its expansion. Since it is a funded pension system and requires a 20 -year contribution for full pensions, there are no pensioners who receive full pensions, although there are recipients of survivor pensions, invalidity pensions and lump-sum benefits.

According to Korean government's projection, the fund for the National Pension Programme would run out by the year 2033 without reform [Committee for Social Security, 1997: 33]. The National Pension Programme would have financial difficulties, since it promised too a high internal rate of return. At the end of 1998, the Korean government changed the parameters of the National Pension Programme, lowering the level of pensions and increasing the level of contributions. Despite the reform in 1998, its financial sustainability is still in question as some provisional estimations suggest [Kim, 2001].

Now let us examine the exogenous problems for the welfare system. The toughest challenge to the Korean welfare system at present is unemployment. The Employment Insurance Programme was introduced in 1995. This Programme requires contributions prior to entitlement to unemployment benefits. It is only mandatory for workplaces with more than five employees. This Programme also places a strong emphasis on training. At the time of the economic crisis, those eligible for unemployment benefits were small due to its narrow coverage. The Korean government extended the Employment 
Insurance Programme to all workplaces, but the proportion of workers covered by the programme remains low. This is mainly because informal sector workers are still outside the programme although they are more prone to unemployment.

Rapid population ageing is another social challenge to the Korean welfare system, although it has not attracted public concern as in Japan. In 1995 , the proportion of the elderly population (65 years old and over) was 5.9 per cent in South Korea, which implies that the population structure is still young compared to other OECD countries. Nevertheless, its ageing process is fast, and the figure will be 13.2 per cent in 2020. The public pension system in Korea comprises the National Pension Programme for ordinary citizens, the Public Employees' Pension for government employees and the Private School Teachers' Pension for private school teachers. Since the Public Employees' Pension and the Private School Teachers' Pension are for specific groups of people, the number of pensioners within these programmes is small and stable. Of these public pension programmes, the National Pension Programme is the main pension programme for most Korean people. It has expanded its coverage over the years to cover the entire working population by April 1999 [Kwon, 1999a]. ${ }^{7}$ It requires a 20-year contribution to be eligible for full pensions and 15 years for partial pensions. Partly because of this requirement and partly because of the ineffective implementation, it will take a substantial time before the National Pension Programme can provide pensions universally to the elderly.

Table 2 shows that only 13.7 per cent of elderly people received pensions from various programmes in 1995. These figures will remain stable until the year 2002 when the first group of people who joined the National Pension Programme in 1988 will be eligible for partial pensions. Even then, the number of people who are entitled to receive pensions will be small. Since in 1995 the whole public pension system covered only 41.9 per cent of the working population, less than half of the elderly will be entitled to public pensions in 2015.

What is more serious in relation to the ageing population is that the present elderly population is far more prone to poverty. According to Kwon [1999b], more than half the single elderly households and a third of coupleonly elderly households live in poverty. Among the households, which include at least one elderly person, 23 per cent live in poverty, while the general poverty rate in relative terms is 10 per cent. To alleviate this poverty, it is necessary to increase the level of old age allowances, which is a third of the poverty line at present. An increase in old age allowance will require a good amount of public money. It remains to be seen whether Korean society is able and willing to pay for that. To sum up, the Korean welfare system, 
TABLE 2

NUMBER OF PENSIONERS FROM PUBLIC PENSION PROGRAMMES (1995)

\begin{tabular}{llllll}
\hline & $\begin{array}{l}\text { Old Age } \\
\text { Pension }\end{array}$ & $\begin{array}{l}\text { National } \\
\text { Pension } \\
\text { Programme* }\end{array}$ & $\begin{array}{l}\text { Public } \\
\text { Employees' } \\
\text { Pension }\end{array}$ & $\begin{array}{l}\text { Private School } \\
\text { Teachers' } \\
\text { Pension }\end{array}$ & Total \\
\hline $\begin{array}{l}\text { Number } \\
\text { (persons) }\end{array}$ & 266,000 & 38,162 & 56,343 & 3,950 & 364,455 \\
$\begin{array}{l}\text { Proportion } \\
\text { of people age } \\
65 \text { and over }\end{array}$ & $10 \%$ & $1.45 \%$ & $2.1 \%$ & $0.15 \%$ & $13.7 \%$ \\
\hline
\end{tabular}

*Number of special old age pensioners

Source: MoHW [1997], Yearbook of Health and Welfare Statistics.

which was developed in the era of economic development, underwent reforms in the era of restructuring. Despite the efforts of the Korean government, the reform has only been partially implemented and still poses a tough challenge for some time ahead.

\section{Taiwan}

The history of the Taiwanese welfare system can be traced back to 1950, when the Labour Insurance programme was introduced as the first social insurance scheme. This was already a part of the manifesto of the KMT government before it was forced to cross the Taiwanese straits. In 1945, in an effort to out-manoeuvre the Communists, the KMT had already launched a social policy manifesto in the wake of the establishment of the Ministry of Social Affairs. After the introduction of the Labour Insurance programme, the Government Employees' Insurance and Retired Government Employees' Insurance programmes were introduced in 1958 and 1965. In the 1980s, health insurance programmes for private school teachers, their dependents and local councillors were introduced.

In a nutshell, the Taiwanese welfare system until the late 1980s was complex and fragmented and provided social protection only to a small section of the population. Given such an orientation, the introduction of the Farmers' Health Insurance programmes in 1989 and subsequently the National Health Insurance programme in 1995 were the major developments in social welfare. After the introduction of National Health Insurance, the health care related programmes were integrated and the Taiwanese welfare system became simpler. The DPP played a significant role in the introduction of National Health Insurance in 1995, which was initially scheduled to 
be implemented in the year 2000, as it placed strong emphasis on social welfare in every election $[\operatorname{Lin}, 1995] .{ }^{8}$ It is worth noting that international organisations such as the World Health Organization (WHO) put pressure on the Taiwanese government to introduce social welfare programmes, and Taiwan was very sensitive to such demands due to its international isolation [Kwon, 1998b].

Since the introduction of National Health Insurance, Taiwan has been engaged in a political debate on what form of National Pension Programme should be introduced. The debates were intensified before the presidential election in the year $2000[\mathrm{Ku}, 1998]$. According to the Council for Economic Planning Board's planning report [CEPB, 1995], the National Pension Programme in Taiwan should be a funded scheme, requiring a 40-year contribution for a full level of pension. Persons who pay contributions for between 10 to 40 years can claim a reduced pension only, minus 2.5 per cent of the full pension per year. Unlike the case of National Health Insurance, the National Pension Programme would not integrate the existing pension programmes. The principle set up by the Taiwanese government was that Labour Insurance, Government Employees' Insurance and the National Pension Programme would be separately managed, but with the same level of contribution and payment $[L i, 1998]$. After the presidential election victory in 2000, however, the DPP became more cautious about the National Pension Programme, in contrast to its previous stance. In consequence, progress has not been made towards the introduction of the National Pension Programme.

Although Taiwan has not yet introduced a national pension programme for ordinary citizens, Labour Insurance, Government Employees' Insurance and Insurance for Private School Teachers and Staff cover 54 per cent of the working population. Within these schemes people can choose a lump-sum retirement benefit or pensions. Labour Insurance is now fully matured and is paying lump-sum retirement benefits, and there are also Farmers' Old Age Allowances, which will be phased out once the National Pension Programme is introduced. The number of persons receiving pensions or allowances from these schemes is 27.5 per cent of the elderly population aged 65 or over. Some city and county governments, including Taipei, Ilan, Hsinchu, Tainan, Chiayi, Kaoshiiung and Penghu, provide old-age allowances ranging from NT $\$ 3,500$ (£54.3) to 7,000 (£108.6) per month. ${ }^{9}$

Compared to other countries in East Asia, the Taiwanese economy is relatively strong despite the Asian economic crisis, and more social welfare programmes are becoming available for its citizens. Public support for the welfare system has been growing (Figure 1), and political parties cannot ignore such popularity of social welfare, as democracy has made progress. 
FIGURE

TREND OF PUBLIC SUPPORT FOR NATIONAL HEALTH INSURANCE

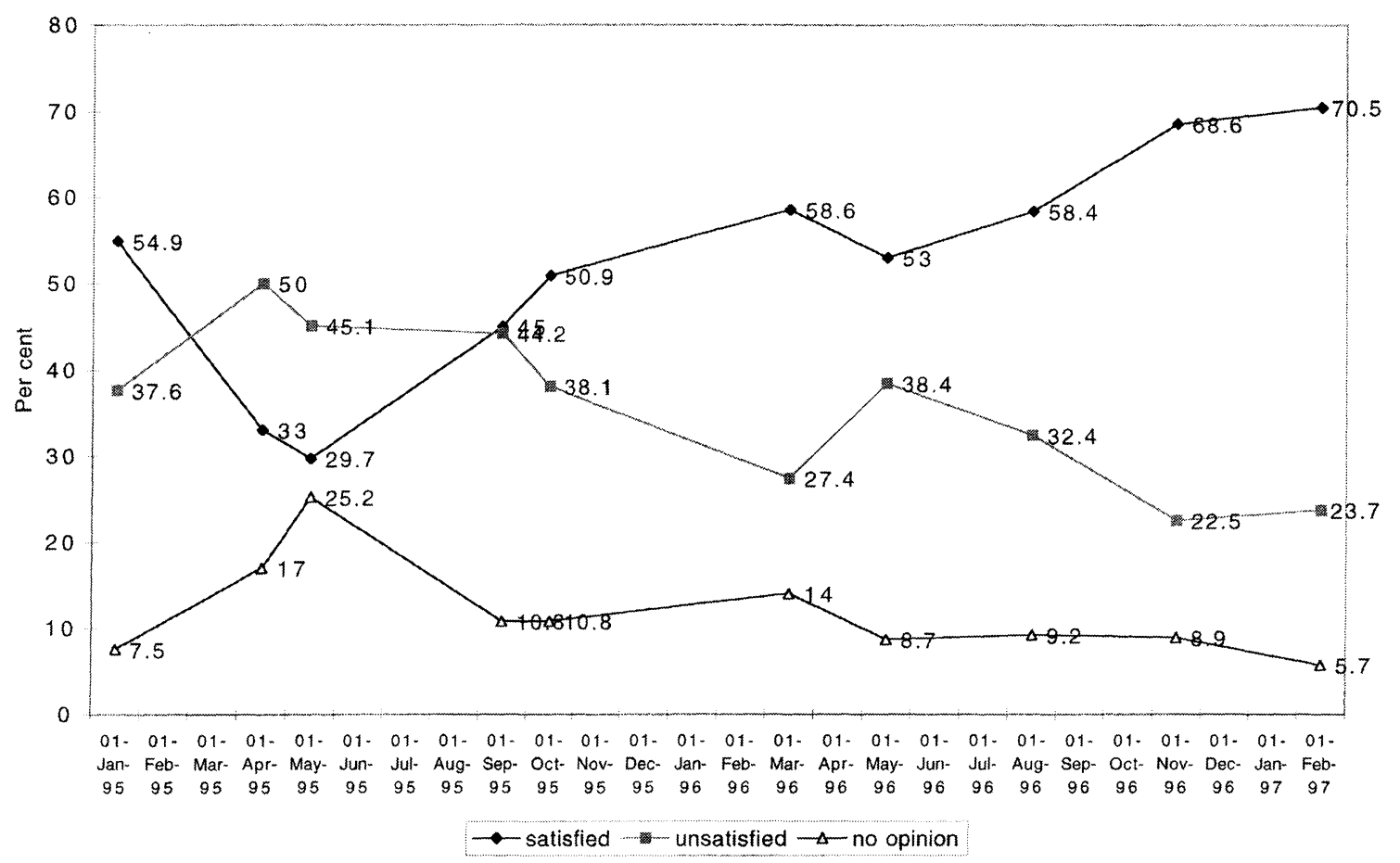

Source: Yeh and Jeng [1998]. 
The question, however, is the extent to which the Taiwanese people can afford and are willing to pay for the new social welfare institutions and programmes.

\section{CONCLUDING REMARKS}

We have identified some strengths and weaknesses of East Asian welfare systems. To recapitulate the strong points of the East Asian welfare model in a development context: it promotes an ideology and practice, which gives overriding priorities of economic efficiency and growth to social welfare, particularly in the form of progressive redistribution and a universal and generous benefits system. The East Asian welfare systems are also relatively cheap in financial and personnel terms, allowing the diversion of financial resources directly to productive purposes. They discourage dependence on the state and makes full use of available social resources, including families, communities, firms, and voluntary groups.

There is also a downside of the East Asian welfare systems. Their heavy reliance on the welfare role of the family has serious implications for gender relations and the position of women. The models rests implicitly on a context in which women are the main care providers within the family and therefore potentially imposes an extra load on top of their 'double burden' of housework and paid employment. These welfare systems tend to reinforce socioeconomic inequalities.

However, the East Asian welfare systems are rapidly changing in nature, as we have seen in this analysis. In Japan, the ageing of the population has been one of the main challenges to the welfare system, since the Japanese government introduced welfare reforms in the 1980s. In South Korea, the pressure on the welfare system is high, due to the economic crisis on top of the problems within the welfare system. The Kim Dae-jung government has pushed through some measures to deal with such problems, but a whole range of difficult tasks lie ahead. The restructuring of the National Health Insurance and National Pension Programme are, inter alia, main items on the current agenda of the Korean government. The Employment Insurance Programme and the Old Age Allowances also need a considerable amount of public money. In Taiwan, society has been debating what the National Pension Programme should look like, after the introduction of the National Health Insurance programme, while Taiwan has witnessed a sharp rise in the cost of social protection since 1993.

The issues and challenges are different in the three countries we have examined, and therefore reform measures should be different. Despite such 
FIGURE 2

TREND OF THE COST OF SOCIAL PROTECTION

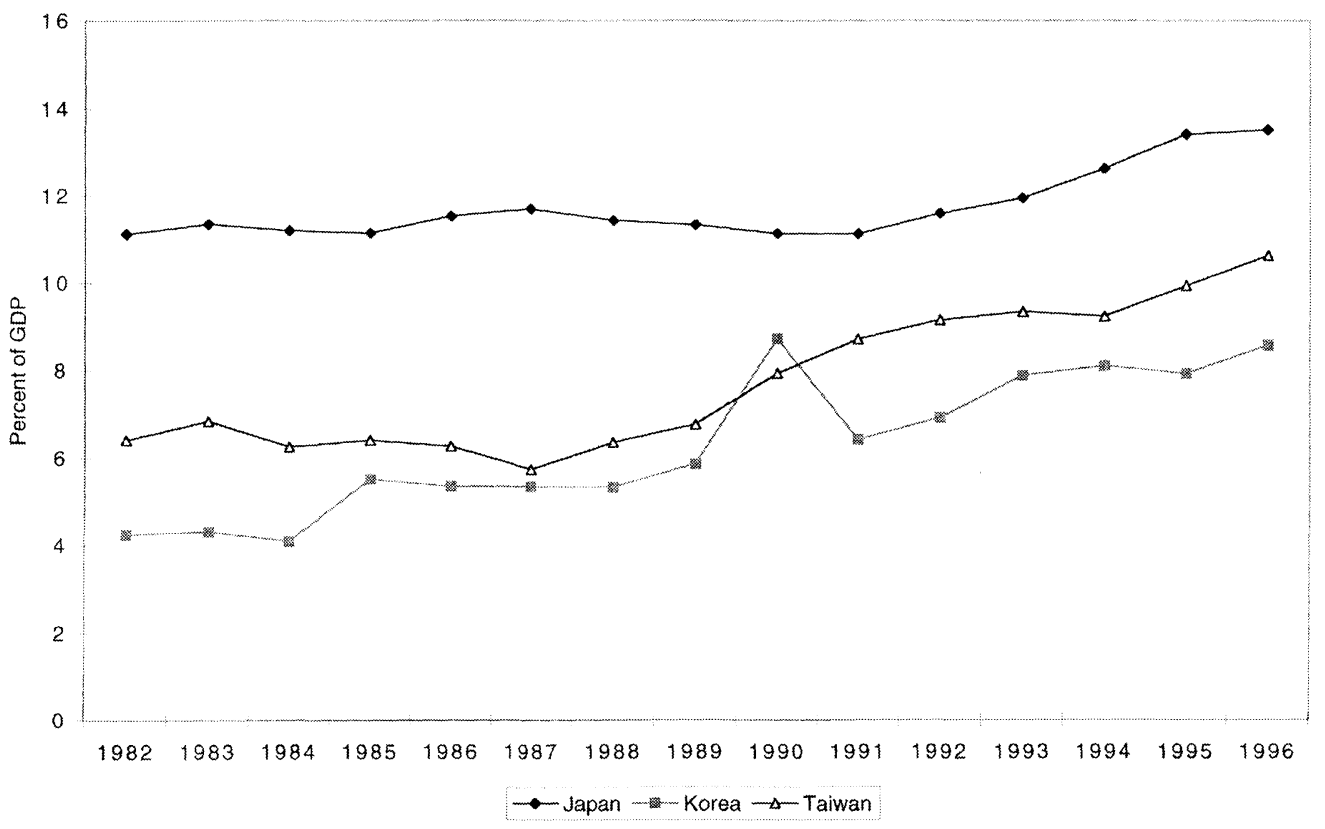

Note: The figures do not include expenditure on housing, and Taiwan figures do not include employers' and employees' contributions to various programmes. Source: Ministry of Health and Welfare (Japan), Annual Report on Health and Welfare 1995-1996; National Office of Statistics (South Korean), Korea Statistical Yearbooks 1995-1996; Ministry of Health and Welfare (South Korea), Yearbooks of Health and Welfare Statistics 1995-1998; Board of Insurance (South Korea), Yearbook of Insurance; Director General of Budget, Accounting and Statistics (Taiwan), Social Indicators: The Republic of Chia 1997. 
differences, what is common among the East Asian welfare systems under review is that the low spending regime of social welfare cannot be maintained. They will still be the low spenders in the cross-national league table of social expenditures among developed nations, but the East Asian welfare systems will be much more expensive than they used to be. These societies must decide where the line of balance between social cost and social protection should be drawn.

\section{NOTES}

1. See the article by Tony Blair in Sunday Times, 29th Oct.1995.

2. For a further discussion, see Kwon [2001].

3. Of course, these three countries alone cannot represent the whole region of East Asia, and economies in the region such as Hong Kong and Singapore deserve our attention. Nevertheless, these three countries share institutional characteristics of social policies to the extent that they form a cluster of the 'East Asian Welfare Model', while Hong Kong and Singapore stand further away from it [Goodman, White and Kwon, 1998].

4. The terms of regulator and provider denote the role of the state in the financing of the welfare system. The state can be referred to as a provider, in the case where the state itself delivers social policies such as health care, which are then paid for through government expenditure. The National Health Service in Britain is a classic example.

5. All insurers of health insurance programmes such as the government-managed Health Insurance, Mutual Aid Association and other insurance funds bore 70 per cent of medical costs, the central government 20 per cent, and prefecture and municipal government paid five per cent each.

6. Fitch ICBA, the rating agency, upgraded South Korea's credit rating to investment grade in January 1999 and Standard \& Poor's and Moody's Investors Service also followed the Fitch ICBA move (Financial Times, 20 Jan. 1999).

7. This does not include people within other programmes, that is, the Public Employees' Pension and the Private School Teachers' Pension

8. Of course, the DPP's main political agenda is the independence of Taiwan. Nevertheless, it has made no progress due to the intimidation of the Chinese government in Beijing.

9. http://www.gio.tw/info/yb97/ch19_5.htm

\section{REFERENCES}

Campbell, John, 1992, How Polices Change: The Japanese and the Ageing Society, Princeton NJ: Princeton University Press.

Chang, Ha-joon, 1998, 'South Korea: The Misunderstood Crisis', in K.S. Jomo (ed.), Tigers in Trouble: Financial Governance, Liberalization and Crisis in East Asia, Hong Kong: Hong Kong University Press.

Choe, Ch'onsong, 1991, The History of Korean Social Policy Research (in Korean), Seoul: Korean Institute of Social Security.

Committee for Social Security, 1997, 'Institutional Reform of the National Pension Programme', mimeo, Seoul: Office of Prime Minister.

Council for Economic Planning and Development, 1998, The Fourteenth Meeting Record of the Working Team on the NPI (in Chinese), Taipei. 
Council for Econmic Planning Board (CEPB), 1995, A Planning Report on the Integrated System of National Pension Insurance (in Chinese), Taipei.

Council of Family Life Problems, 1967, For Family Life Tomorrow, Ministry of Health and Welfare: Tokyo (in Japanese).

Director General of Budget, Accounting and Statistics, 1997, Statistical Yearbook of the Republic of China 1996, DGBAS: Taipei.

Esping-Andersen, G., 1997, 'Hybrid or Unique? The Japanese Welfare State Between Europe and America', Journal of European Social Policy, Vol.7, No.3, pp.179-89.

Fujimura, Masayuki, 2000, 'The Welfare State, the Middle Class and the Welfare Society', Review of Population and Social Policy, No.9, pp.1-23.

Goodman R. and Ito Peng, 1996, 'The East Asian Welfare States: Peripatetic Learning,Adaptive Change, and Nation-Building', in G. Esping-Andersen (ed.), Welfare States in Transition: National Adaptation in Global Economies, London: Sage.

Goodman, Roger and Gordon White, 1998, 'Welfare Orientalism and the Search for an East Asian Welfare Model', in Goodman, White and Kwon [1998].

Goodman, R., White, Gordon and Huck-ju Kwon (eds.), 1998, The East Asian Welfare Model: Welfare Orientalism and the State, London: Routledge.

Hashimoto, Tomisaburo 1979, The Constitution of Welfare Society, Tokyo: The Policy Affairs Research Council of the LDP.

Jones, Catherine, 1993, 'The Pacific Challenge-Confucian Welfare State', in Catherine Jones (ed.), New Perspectives on the Welfare States in Europe, London, Routledge.

Kim, Won-sik, 2001, 'The Institutional Changes in the National Pension Programme', paper presented at the Korean Social Security Association conference, June.

$\mathrm{Ku}$, Yeun-wen, 1996, Welfare Capitalism in Taiwan: The State, Economy and Social Policy 1895-1990, London: Macmillan.

$\mathrm{Ku}$, Yeun-wen, 1998, 'Who Will Benefit? The Planning of National Pension Insurance in Taiwan', Public Administration and Policy, Vol.7, pp.33-45.

Kwon, Huck-ju, 1997, 'Beyond European Welfare Regimes: Comparative Perspectives on the East Asian Welfare Systems', Journal of Social Policy, Vol.26, No.4, pp.467-84.

Kwon, Huck-ju, 1998a, The Welfare State in Korea: The Politics of Legitimation, London: Macmillan.

Kwon, Huck-ju, 1998b, 'Democracy and the Politics of Social Welfare: A Comparative Analysis of Welfare Systems in East Asia', in Goodman, White and Kwon [1998].

Kwon, Huck-ju, 1999a, 'Inadequate Policy or Operational Failure? An Analysis of the Potential Crisis of the Korean National Pension Programme', Social Policy and Administration, Vol.33, No.1, pp.20-38.

Kwon, Huck-ju, 1999b, 'Income Transfers to the Elderly in East Asia: Testing Asian Values', CASE working paper, Centre for the Analysis of Social Exclusion, London School of Economics.

Kwon, Huck-ju (2001), 'Globalisation, Unemployment and Policy Responses in Korea: Repositioning the State?', Global Social Policy, Vol.1, No.2, pp.213-34.

Li, Shu Jung, 1998, 'Living Standards of the Elderly and Income Maintenance Policy in Taiwan', paper presented at the conference 'New Prospect for Social Welfare Systems in East Asia', National Chinan University, Taiwan (in Chinese).

Lin, Wan-I, 1995, The Welfare State, Vanguard: Taipei (in Chinese).

Ministry of Finance, 1986, White Paper on Japanese Economy 1985, Tokyo: Ministry of Finance, Japan.

Ministry of Health and Welfare, 1997a, Annual Report on Health and Welfare 1995-1996, Tokyo: Ministry of Health and Welfare, Japan.

Ministry of Health and Welfare, 1997b, Health and Welfare Statistics in Japan, Tokyo: Health and Welfare Statistics Association.

Ministry of Health and Welfare, 2000, Annual Report on Health and Welfare 1998-1999, Tokyo: Ministry of Health and Welfare, Japan. 
National Pension Corporation, 1995, National Pension Statistical Yearbook 1995, Seoul: NPC.

National Statistical Office, 1997, Statistical Yearbook of Korea, Seoul: National Statistical Office.

Peng, Ito, 1998, 'Japanese Welfare State: Perspectives and Patterns of Change', paper presented at the conference on 'New Prospects for the Social Welfare Systems in East Asia', National Chinan University, Taiwan.

Sato, Jin, 1997, 'Old Gold Plan and New Gold Plan: Social Welfare in the End of 20th Century', Nihon Hukushi Yonkam 95-96, Tokyo: Japan (in Japanese).

Shinkawa, Toshimitsu and T. J. Pempel, 1996, 'Occupational Welfare and the Japanese Experience', Michael Shalev, The Privatization of Social Policy? Occupational Welfare and the Welfare State in America, Scandinavia and Japan, London: Macmillan.

Sumitaka, Harada, 1998, 'Ageing Society, Family and Social Policy', in Junji Banno, The Political Economy of Japanese Society, Vol.2, Oxford: Oxford University Press.

Tabata, Hirokuni, 1990, 'The Japanese Welfare State: Its Structure and Transformation', Annals of Institute of Social Science, Vol.32, pp.1-29.

United Nations, 1998, World Population Prospects: The 1996 Revision, New York: United Nations.

Vogel, Erza, F., 1980, Japan as Number One: Lessons for America, Tokyo: Tuttle.

Watanabe, Yoshiki, 1993, 'Japan's Health-Care System and Its Reform', Review of Social Policy, No.2, pp.57-87.

Yeh, Shiow-jen and Jeng Wen-huei, 1998, 'An Analysis of Determinants on Public Perception towards National Health Insurance', paper presented at the conference 'New Prospect for Social Welfare Systems in East Asia', National Chinan University, Taiwan (in Chinese). 

GLOBALISATION 



\title{
Is Globalisation All It is Cracked Up to Be?
}

\author{
RAPHAEL KAPLINSKY
}

Despite unevenness in the process, it is incontrovertible that the pace of global integration has increased remarkably over the past two decades. Many of the world's population, particularly those with influence over the political process, have gained as openness has grown. However, there is compelling evidence that the benefits of globalisation have not been evenly spread, and that openness has been associated with growing unequalisation and, in many cases, also in the incidence of poverty. These adverse developments express themselves both within and between countries.

The correlation between growing openness and increasing inequality and poverty does not in itself mean that these phenomena are causally related. However, I will argue in this contribution that there are indeed reasons why the increasing globalisation of factor, product and financial markets leads to growing inequality and poverty, both in developing and industrialised countries. The entry of China into world markets in the 1980s exacerbated trends which were already in evidence during the process of post-war trade liberalisation. As China increases its participation in the global economy, and as India and other low wage developing economies follow the same path, it is likely that there will be a further squeeze on the incomes of many, not just of the unskilled, but also increasingly of semi-skilled and skilled labour.

Globalisation is a multi-faceted process and can be characterised as a systematic decline in the barriers to the cross-national flow of products,

\footnotetext{
Earlier versions were presented as a paper to the Gordon White Memorial Conference in 1999 and subsequently published in the IDS Bulletin and The Review of Political Economy. The author is indebted to Sarah Cook who greatly aided his understanding of the Chinese labour market, and was largely responsible for the section on the level and growth of unemployment and underemployment in China and made helpful comments on an earlier draft. Kenneth Fung, Glenis Morrison and Howard White assisted him with data and Gwen Sullivan provided him with the incentive to go the further mile.
} 
factors (capital and people), technology ideas and values. In this analysis I will primarily focus on one particular element of globalisation, that is, the trade in goods and services. Although this might appear to be a narrow agenda, as we shall see, the sustainability of open product markets is influenced by, and has implications for the global movement of people and ideas. (For a wider discussion of globalisation, and a measurement of different types of flows, see Baldwin and Martin [1999], and Bairoch and KozulWright [1996].

I discussed many of the issues covered in this analysis with Gordon (usually in that hotbed of intellectual exchange, the Bristol pub). Gordon was acutely concerned with the association between advancing globalisation and the rapid advance of inequality, and its harmful impact on working people. The title of this piece is one which I can visualise him tossing off - I believe, too, that the discussion which follows accurately reflects what emerged between our trade in gossip (in which Gordon was clearly a 'net exporter').

\section{FOR WHOM IS GLOBALISATION NOT ALL IT IS CRACKED UP TO BE?}

A primary measure of the globalisation of product markets is the ratio of trade to GDP. Here, as Table 1 shows, with the exception of Sub-Saharan Africa (SSA) and Latin America and the Caribbean during the 1980s, globalisation has grown at an astonishing rate since 1980. Remarkably, this rate of growth has been more rapid for poorer countries, as well as for the two most populated economies, China and India.

Has the increasing integration of the global economy been associated with higher rates of economic growth? If we assume that the post-1960 period has seen a largely monotonic trend towards growing globalisation, the answer is clear. As can be seen from Table 2, there was a steady decline in growth rates for most of these 57 countries in the three decades after 1960, particularly for the OECD. Econometric studies also show no robust relationship between growth and openness [Rodriguez and Rodrik, 1999]. The only exception to this trend was East and South-east Asia, where the balance between growth-increasing and growth-decreasing economies was generally even. However, the crash in the region in the late 1990s suggests that even here, the growth record of globalisation was not as impressive as is generally assumed.

What has happened to living standards during this period of globalisation? (Here we will focus on earnings, rather than non-financial indicators of poverty and living standards.) There are two main approaches to the 
TABLE 1

TRADE AS A PROPORTION OF GDP

\begin{tabular}{lrrrrrr}
\hline $\begin{array}{l}\text { Imports + Exports } \\
\text { as a \% of GDP }\end{array}$ & 1960 & 1970 & 1980 & 1985 & 1990 & 1995 \\
\hline High income & 23.7 & 27.1 & 38.3 & 37.3 & 36.4 & 39.8 \\
Middle income & & & 48.7 & & 47.2 & 55.9 \\
Upper middle income & 34.3 & 36.4 & 48.2 & 41.8 & 42.0 & 51.4 \\
Lower middle income & & & & & 50.2 & 58.7 \\
Low income & 17.1 & 13.9 & 23.5 & 26.2 & 31.9 & 42.9 \\
Low income, excl. China \& India & & 34.6 & 48.7 & 41.8 & 51.2 & 60.5 \\
East Asia \& Pacific & 20.1 & 18.6 & 31.9 & 35.7 & 44.4 & 58.3 \\
Latin America \& Caribbean & 25.8 & 23.4 & 32.5 & 30.8 & 31.1 & 35.6 \\
Sub-Saharan Africa & 47.4 & 44.3 & 59.5 & 51.0 & 53.2 & 56.1 \\
China & 9.3 & 5.2 & 12.9 & 24.0 & 26.9 & 40.4 \\
India & 12.5 & 8.2 & 16.6 & 15.0 & 18.3 & 27.7 \\
World & 24.5 & 27.1 & 38.7 & 37.1 & 37.9 & 42.5 \\
\hline
\end{tabular}

Source: World Development Indicators, 1998.

TABLE 2

GROWTH RATE OF PER CAPITA GDP COMPARED WITH 1960-71 AVERAGE

\begin{tabular}{lcc}
\hline & $1972-81$ & $1982-91$ \\
\hline All countries (57) & 18 & 10 \\
Decade ratio higher & 39 & 47 \\
Decade ratio lower & & 7 \\
All non-oil exporting countries (48) & 11 & 41 \\
Decade ratio higher & 37 & 2 \\
Decade ratio lower & & 18 \\
& & \\
OECD countries (20) & 1 & 1 \\
Decade ratio higher & 19 & 9 \\
Decade ratio lower & & \\
Latin America (10) & 4 & 3 \\
Decade ratio higher & 6 & 4 \\
Decade ratio lower & & \\
East and South-East Asia (7) & & 5 \\
Decade ratio higher & 2 & \\
Decade ratio lower & & \\
\hline
\end{tabular}

Source: Streeten [1998].

measurement of poverty - that which focuses on absolute living standards and that which considers relative living standards.

With respect to absolute standards of living, between 1987 and 1998 (a period of growing global integration), the number of people living below the poverty line (defined in terms of the domestic purchasing power of $\$ 1$ per 
day in 1985 prices) was effectively unchanged at around 1.2 billion [World Bank, 1996; World Bank, 2000]. In some regions - notably South Asia, SubSaharan Africa and Europe and Central Asia, the number of poor people has increased significantly. This decline in income levels is matched by declines in the social wage. The proportion of social expenditure in total government expenditure declined from 35 to 29 per cent between 1972 and 1986 in the developing world (World Bank data cited by Streeten[1998]). This is hardly a compelling case for the positive impact of globalisation on absolute global living standards. This prevalence of falling real incomes is not confined to developing countries. Real wages in the Netherlands fell between 1979 and 1997 [Hartog, 1999]. In the USA, real wages were lower in the mid 1990s than they were in the late 1960s, and family incomes only held up as a consequence of longer working hours and more working members of the family [United States, 1997: Table B-45].

But what of the relationship of globalisation to relative living standards? Considered at the level of countries, the pattern of inter-country income distribution has become complex, with the development of a 'twin-peak' distributional pattern. Two groups of countries have emerged between 1960 and 1988 - those clustered at a level of five per cent of US GDP/worker, and those where earnings are between one- and two-thirds of US levels [Jones, 1997].

But does this growing complexity of inter-country income distribution correspond to a worsening of inter-country income distribution? On the one hand, it is argued that the rapid growth of China and India in recent years has led to a narrowing of inter-country income differentials, that is, to an improvement in inter-country income distribution [Wolf, 2000]. This is because these two countries which have seen a significant rise in average per capita incomes, account for a very large share of global population. Therefore, comparing income differentials between countries on the basis of population-weighted average incomes produces an equalising trend. But, global income inequality can also be measured in relation to individual incomes, rather than to inter-country average incomes. Even if the estimations used by Wolf with regard to the inter-country distribution of income are correct (they are indeed disputed: Lundberg and Milanovic [2000]) the flaw in Wolf's argument is that it does not take account of worsening inequality within China (see below).' If this is factored into the analysis, then the share of global income going to individuals has indeed become more unequal during the past two decades.

With respect to relative intra-national income distribution, at least in Latin America there is evidence of significant increases in inequality as countries opened-up over the last two decades [Streeten, 1998; Bhalla, 
1998]. Notably this includes Chile, often thought to be the paradigmatic gainer from globalisation, where the gini-coefficient increased from 0.46 in 1971 to 0.58 in 1989 [Rodrik, 1999]. In the context of a very rapid pace of economic growth and integration into the global economy - the export/GDP ratio rose from 10.5 per cent in 1985 to 21.3 per cent in 1995 - China experienced a sharp rise in inequality. This was between urban and rural areas, coastal and interior provinces, and within urban and rural areas [Khan, 1999]. In the industrially advanced countries (IACs), since the 1970s there has been a significant tendency towards greater inequality in the OECD economies, particularly in the Anglo-Saxon economies [Dunford, 1994]. In developing countries, income distribution too has tended to become more unequal [Streeten, 1998]. Inequality between skilled and unskilled wage earners has also tended to increase, in the IACs [Wood, 1994; 1998] and in Latin America over the past decade [Wood, 1997].

\section{WHY DID GLOBALISATION NOT DELIVER THE GOODS?}

The outcomes which were described in the previous section are not supposed to happen. Adam Smith essentially saw international specialisation as a progressive force: 'If a foreign country can supply us with a commodity cheaper than we ourselves can make it, better buy it of them with some part of the produce of our own industry, employed in a way in which we have some advantage' [Smith, 1776: 457]. He cautioned against the too-rapid removal of these protective measures: '[w]ere those high duties and prohibitions taken away all at once, cheaper foreign goods of the same kind might be poured so fast into the home market, as to deprive all at once many thousands of people of their ordinary employment and means of subsistence' [ibid.: 469].

However, among the classical economists, it was Ricardo who is most clearly recognised as arguing the benefits of global specialisation, and hence openness. Elaborating the principle of comparative advantage, Ricardo showed that specialisation in comparative advantage would work to the benefit of all. There were however provisos which were required for these benefits to the reaped. First, capital must not be internationally mobile; second, the trade between countries should be balanced; third, mechanisms should be in place to ensure a process of income transfer from those who gained to those who lost; and, finally and most importantly, all countries should experience full employment.

As we shall see below, it is the last two of these Ricardian assumptions which are most problematic. Before we explore these limiting assumptions 
more deeply, it is helpful first to briefly digress into the contribution made by Schumpeter in our understanding of the barriers to entry which underwrite the growth of sustainable incomes in a globalising world. Elaborating Schumpeter's ideas, it is helpful to distinguish the related concepts of commodities and rent [Kaplinsky, 1998]. A commodity can be defined as a product - and even a factor input - where barriers to entry are low. Consequently, when competition is intense the returns to the producers of these products, or to those factors which operate in markets characterised by low barriers to entry, fall. By contrast, where barriers to entry are high, the incomes of producers of the products or factors which are not subject to intense competition, will be protected. One of Schumpeter's main contributions was to put a dynamic perspective into this distinction between commodities and rents. His idea of 'gales of creative destruction' was designed to capture a process whereby, over time, the barriers to entry in particular product and factor markets are eroded and incomes are not sustainable. At the same time, new products and factors, not subject to intense competition, are created in the quest by entrepreneurs to appropriate rents. Schumpeter believed that these rents were primarily defined by new technologies, but there is no intrinsic reason why this should be the case.

The central contention of this analysis is that two events have conspired to reduce the barriers to entry in many sectors. First, during the recent decades of increasing globalisation, an increasing number of global producers began to command the capability to physically transform inputs into outputs for products destined for global markets. And, secondly, at the same time the barriers to international exchange have fallen. Consequently, we have witnessed an increasing supply of many commodities (using my terminology) - not just primary products, but also increasingly manufactures and services such as tourism. This has been complemented by a systematic search for and fostering of low-cost sources of supply by global buyers (whether these be retail chains or TNCs coordinating production in global value chains). The result has been a tendency towards systemic 'over production' (or its counterpart, underconsumption) [Brenner, 1998]. These dual processes have meant that the incomes of non-scarce factors have, and will continue to diminish. The key abundant factor whose income has been under threat has been labour.

Let us return to those two Ricardian assumptions, namely that for comparative advantage to be welfare-enhancing, it is necessary that compensation mechanisms be developed and that there be full employment. Focusing on the second of these assumptions for the moment (we will return to the politics of globalisation below), my central contention will be that labour is in excess supply globally and it is this which largely explains the 
fall in living standards (both relative and absolute) of much of the world's population documented in the section above. Operating in a world of unemployment and excess labour, the consequence has been, and will increasingly be growing unequalisation and the erosion of the standard of living in many countries. This is a process which I refer to as immiserising growth - that is, an expansion of economic activity which coincides with a decline in real incomes.

This process was foreseen in different ways by both Malthus and Marx. Malthus believed that real living standards would fall as a consequence of rising population. This could be reversed by either (what he strangely called the 'positive' check of) raised mortality, or as a consequence of the 'preventative' check of reduced fertility as couples married at a later age. In the absence of the 'preventative' check, standards of living would fall, mortality would rise and incomes would only be restored when the population balance had been restored. Marx observed a similar tendency. But for him the outcome of falling living standards was not so much a consequence of an autonomous rise in the population, but as a result of growing capital-intensification in production which would lead to the expansion of 'the reserve army of labour'.

Writing after the industrial revolution (which Malthus had failed to predict), Marx was acutely aware of the impact which technological progress had on the demand for labour. The rising capital-intensification of these technologies (which he referred to as a rising organic composition of labour) led to the increasing displacement of labour. This meant that the existence of the unemployed was not a reflection of the cyclical nature of growth, but rather an intrinsic element of the capitalist mode of production: 'The superficiality of Political Economy shows itself in the fact that it looks upon the expansion and contraction of credit, which is a mere symptom of the periodic changes of the industrial cycle, as their cause' [Marx, 1687: 633]. In fact, he argues, ' $[t]$ he whole form of the movement of modern history depends ... upon the constant transformation of a part of the labouring population into unemployed or half-employed hands' (passim). This swelling number of the unemployed 'forms a disposable industrial reserve army' [ibid.: 632], and consequently 'the general movement of wages are exclusively regulated by the expansion and contraction of the industrial reserve army ... They are ... not determined by the variations of the absolute number of the working population, but by the varying proportions in which the working class is divided into active and reserve army' [ibid.: 637]. Further, Marx adds another analytical element which is relevant to our discussion. In addition to the swelling reserve labour force caused by the capital intensification of production, and the intensification of work as a response to rising competi- 
tive pressures, 'the capitalist ... progressively replaces skilled labourers by less skilled, mature labour-power by immature, male by female, that of adults by that of young persons and children' [ibid.: 635].

There is a clear overlap between Marx's reserve army of labour and the theory of the labour surplus economy in post-1950s development economics. Ranis, building on W. Arthur Lewis's formulation of the labour surplus economy, sets out the circumstances in which economic growth may mop up surplus labour:

The heart of the development problem in the labour surplus economy may thus be seen as the ability of the two sectors, the agricultural or non-commercialized [read LDCs] and the non-agricultural or commercialized [read IACs], to move together in a sufficiently balanced and rapid fashion to eliminate the dualistic characteristic of the economy, i.e. to eliminate the labour surplus condition ... [W] hat results is a balance between increases in productivity in agriculture and non-agriculture approaching the notion of 'balanced growth'. Such 'balance' has two dimensions: one, the volume of agricultural [LDC] workers freed up through productivity increase in the agricultural sector must not be too far out of line with the new employment opportunities created in the non-agricultural sector [the IACs]; and two, the markets for the goods of the agricultural and non- agricultural sectors must clear without a major change in the inter-sectoral terms of trade [Ranis, 1998: 106].

It is my contention that the growing gap between global labour demand and supply undermines Ranis's sanguine perspective on the reserve army of labour. The liberalisation of product markets in the global economy after the 1950s has been associated with a growing incidence of unemployment in the industrialised economies, especially in those (non Anglo-Saxon) economies where wages have not fallen (Table 3). ${ }^{2}$ Rates of unemployment in the late 1990 s are in many cases not dissimilar to those of the 1930s.

A similar process of labour displacement is to be seen in developing countries. In Latin America and the Caribbean labour displacement has led to growing urban unemployment, especially in the three largest economies, Argentina, Brazil and Mexico (Table 4); this was before the crisis which hit Brazil (and then Mercosur) in 1997 and Argentina in 2001.

In the second place, both the overall population and the active labour force in the developing world are a very large proportion of the global totals (Table 5). The reservoir of unemployed labour in developing countries thus has the proportionate capacity to easily drown the employed labour force in the industrially advanced economies.

It might be argued, that even if this reserve army of surplus labour in the developing world leads to the fall of wages in these labour surplus developing economies, this will have little impact on wage incomes in the industrialised economies. This is because this reserve army does not have the skills to compete with rich country workers. It is here that the global 
TABLE 3

RATES OF UNEMPLOYMENT IN THE IACS, 1970 AND 1997 (\%)

\begin{tabular}{lrr}
\hline & 1970 & 1997 \\
\hline Australia & 1.4 & 8.6 \\
Canada & 5.9 & 9.2 \\
Finland & 2.0 & 14.3 \\
France & 1.7 & 12.5 \\
Germany & 0.6 & 9.4 \\
Ireland & 6.9 & 10.2 \\
Italy & 3.2 & 12.3 \\
Japan & 1.1 & 3.4 \\
Netherlands & 1.3 & 5.5 \\
Spain & 2.0 & 20.8 \\
Sweden & 1.5 & 8.0 \\
United Kingdom & 11.8 & 7.1 \\
United States & 5.0 & 4.9 \\
\hline
\end{tabular}

Source: ILO, World Employment Report, 1998-99.

TABLE 4

URBAN UNEMPLOYMENT IN LATIN AMERICA AND THE CARIBBEAN (\%)

\begin{tabular}{lllllrrr}
\hline & 1990 & 1991 & 1992 & 1993 & 1994 & 1995 & 1996 \\
\hline Argentina & 7.5 & 6.5 & 7.0 & 9.6 & 11.5 & 17.5 & 17.2 \\
Brazil & 4.3 & 4.8 & 5.8 & 5.4 & 5.1 & 4.6 & 5.7 \\
Mexico & 2.7 & 2.7 & 2.8 & 3.4 & 3.7 & 6.3 & 5.7 \\
Latin America and & 5.8 & 5.8 & 6.3 & 6.3 & 6.4 & 7.3 & 7.7 \\
$\quad$ Caribbean region & & & & & & & \\
\hline
\end{tabular}

Source: Bhalla [1998].

TABLE 5

SHARE OF COUNTRY INCOME GROUPS (AND CHINA AND INDIA) IN GLOBAL POPULATION AND GLOBAL LABOR FORCE (\%)

\begin{tabular}{|c|c|c|c|c|c|}
\hline & \multicolumn{3}{|c|}{ Population } & \multicolumn{2}{|c|}{ Labour force } \\
\hline & 1980 & 1995 & $\begin{array}{l}2010 \\
\text { (est) }\end{array}$ & 1980 & 1995 \\
\hline Low income & 53.7 & 56.1 & 58.0 & 52.2 & 54.9 \\
\hline $\begin{array}{l}\text { Low income } \\
\text { (excl. China and India) }\end{array}$ & 16.0 & 18.5 & 21.6 & 14.3 & 16.0 \\
\hline Middle income & 27.9 & 28.0 & 28.0 & 27.7 & 27.9 \\
\hline Lower middle income & 20.4 & 20.3 & 20.1 & 20.3 & 20.2 \\
\hline Upper middle income & 7.5 & 7.7 & 7.9 & 7.4 & 7.6 \\
\hline High income & 18.4 & 15.9 & 14.1 & 20.2 & 17.2 \\
\hline China & 22.1 & 21.2 & 19.7 & 22.6 & 23.0 \\
\hline India & 13.1 & 14.3 & & 20.8 & 20.2 \\
\hline
\end{tabular}

Source: Calculated from World Bank, World Development Indicators, 1997. 
economy emerging in the early twenty-first century appears to be entering a decisive new phase. This is because, increasingly, workers in the developing world possess both the skills and the industrial experience to compete with rich country labour forces even in the industrial sector which was formerly the specialised preserve of the rich economies in global trade. Partly as a consequence of this development, the barriers to entry in the production of goods for the global market have fallen, reflected in significant increases in over-capacity in many sectors [Brenner, 1998], and a decline in the relative prices of globally traded goods. This has a direct bearing on the second caveat made by Ranis (see quote above).

Ranis's sanguine view, as we have seen, is that the products produced in the labour surplus (developing) economies must not experience sustained falls in their terms of trade: 'the markets for the goods of the agricultural and non-agricultural sectors must clear without a major change in the intersectoral terms of trade'. However, the consequence of growing industrial capacity in the developing world has indeed led to just such a fall in the terms of trade. But this time, unlike earlier periods when declining terms of trade affected primary products [Singer, 1950; Prebisch, 1950], it is being experienced in manufactured goods. The terms of trade of developing manufactured exports fell by 20 per cent between 1985 (when China first entered global markets) and 1995 [Wood, 1997]. ${ }^{3}$

\section{WHY IS CHINA (AND INDIA) AN IMPORTANT PART \\ OF THE STORY?}

The issue which we will now explore is the non-marginal nature of China's recent entry into the global market. Consider, first, the size of China's contribution to global exports in a growing number of product markets, particularly in the manufactured products sector. As can be seen from Table 6, since China's entry into these global markets in the first half of the 1980s, it has come to account for a growing share of imports into each of the triad economies. In each of these markets, China is no longer a marginal supplier, but plays a major role in determining overall product availability, and hence the prices realised for these products; its presence therefore also affects the terms of trade of all economies trading in these product categories. China's low production costs arise from and are coupled with growing industrial competence. The recent experience of the Mexican maquiladora economy is instructive; wages ( $\$ 1.50$ an hour) are six times those in China; and during 2001170,000 jobs were lost, mostly due to the relocation of production by US TNCs from Mexico to China [Greider, 2001]. 
TABLE 6

SHARE OF MERCHANDISE IMPORTS FROM CHINA

\begin{tabular}{|c|c|c|c|c|c|c|c|c|c|}
\hline \multirow[t]{2}{*}{ Sector } & \multicolumn{3}{|c|}{ USA } & \multicolumn{2}{|c|}{ Japan } & \multicolumn{2}{|c|}{$\mathrm{EU}$} & \multicolumn{2}{|c|}{ Global } \\
\hline & 1980 & 1990 & 1994 & 1990 & 1994 & 1989 & 1997 & 1990 & 1995 \\
\hline Textiles & 5.9 & 10.3 & 11.5 & 19.7 & 32.5 & 3.9 & 5.1 & 7.2 & 9.4 \\
\hline Clothing & 4.0 & 13.7 & 17.3 & 27.5 & 53.9 & 7.6 & 15.2 & 8.9 & $18.0^{*}$ \\
\hline $\begin{array}{l}\text { Other consumer } \\
\text { products }\end{array}$ & 0.8 & 11.0 & 24.0 & 4.5 & 17.0 & & & & \\
\hline Footwear & 0.7 & 15.7 & 45.2 & 12.5 & 43.5 & 7.2 & 18.2 & 7.4 & 10.8 \\
\hline Toys and games & 0.1 & 25.0 & 48.7 & 7.7 & 25.0 & 37.8 & 51.2 & 4.2 & 6.0 \\
\hline Photo apparatus & & & & & & & & 7.3 & 14.6 \\
\hline TV & & & & & & & & 0.7 & 4.6 \\
\hline Sound apparatus & & & & & & & & & \\
\hline $\begin{array}{l}\text { Total merchandise } \\
\text { exports* }\end{array}$ & 0.5 & 3.1 & 6.0 & 5.1 & 10.1 & & & & \\
\hline $\begin{array}{l}\text { Total manufactured } \\
\text { exports }\end{array}$ & & & & & & 2.7 & 7.6 & 0.8 & $4.0^{*}$ \\
\hline
\end{tabular}

* 1997

Source: World Trade Organization 1995; Eurostat: Intra- and Extra-EU Trade, 1998; Ken-ichi Takayasu, Atsuko Toyama and Minako Mori, 1998.

Next, consider the size of China's population and labour force (Table 5). Here, too, China (and India) has a non-marginal presence. In 1995, China alone accounted for just over one-fifth of global population, and almost one quarter of the global labour force. Together with India these proportions rise respectively to over two-thirds of the global total. Therefore, developments in these labour forces, when these economies are integrated into the global labour force, have the capacity to significantly affect global wage levels.

It is not just the wages of unskilled labour in the global economy which are being, and will increasingly be undermined by the size of the labour reservoir in China (and India). One of the most striking features of the Chinese labour market is its growing level of education and skilling (Table 7). By 1996, almost all primary school age children were enrolled in education; 93 per cent of primary school graduates entered secondary school (an increase from 68 per cent in 1985); almost half of junior secondary school graduates entered senior secondary school. By 1996, over 400 million people had completed primary education and, at the opposite end of the spectrum, there were more than six million university graduates. More than three million students entered technical schools, and a growing number have begun studying abroad. At the same time there has been a large growth in the number of teachers, especially in secondary and higher education. This has meant that pupil-teacher ratios -23.7 in primary schools - are remarkably low. All of these investments in education and training are reflected in the 
TABLE 7

LEVELS OF EDUCATION, 1985-96

\begin{tabular}{|c|c|c|c|c|}
\hline & 1985 & 1990 & 1995 & 1996 \\
\hline$\%$ of school age in education & 96.0 & 97.8 & 98.5 & 98.8 \\
\hline $\begin{array}{l}\% \text { of primary school graduates } \\
\text { entering junior secondary school }\end{array}$ & 68.4 & 74.6 & 90.8 & 92.6 \\
\hline $\begin{array}{l}\% \text { of junior secondary school } \\
\text { graduates entering senior } \\
\text { secondary school }\end{array}$ & 41.7 & 40.6 & 48.3 & 48.8 \\
\hline Numbers in Technical schools & 761,000 & $1,567,000$ & $2,874,000$ & $3,348,000$ \\
\hline $\begin{array}{l}\text { Number of students studying } \\
\text { abroad }\end{array}$ & 2,124 & 2,950 & 20,381 & 20,905 \\
\hline \multicolumn{5}{|l|}{ Numbers with: } \\
\hline University education & & & & $6,140,000$ \\
\hline Three years of college educatio & & & & $9,620,000$ \\
\hline Completing specialised seconda & ary school & & & $17,280,000$ \\
\hline Completing senior secondary sc & chool & & & $72,600,000$ \\
\hline Completing junior secondary $\mathrm{sc}$ & chool & & & $263,000,000$ \\
\hline Completing primary school & & & & $420,000,000$ \\
\hline \multicolumn{5}{|l|}{ Number of full time teachers } \\
\hline Higher education & 247,000 & 395,000 & 401,000 & 403,000 \\
\hline Secondary schools & $3,171,000$ & $3,492,000$ & $3,883,000$ & $4,040,000$ \\
\hline Primary schools & $5,499,000$ & $5,582,000$ & $5,664,000$ & $5,736,000$ \\
\hline \multicolumn{5}{|l|}{ Pupil teacher ratio } \\
\hline Colleges and universities & 5.0 & 5.2 & 7.2 & 7.5 \\
\hline Secondary schools & 17.2 & 14.6 & 15.9 & 16.4 \\
\hline Primary schools & 24.9 & 21.9 & 23.3 & 23.7 \\
\hline Number of books published & 21,621 & 80,224 & 101,381 & 112,813 \\
\hline
\end{tabular}

Source: China Statistical Abstract, 1997.

growth of published material, for example, in the more than fivefold increase in books published between 1985 and 1996.

In itself, none of this need lead to a decline in global wages if there is full employment in China (and India). ${ }^{4}$ However, even after a period of significant growth, reaching 14.2 per cent in 1992 and exceeding eight per cent through much of the 1990s, China faces rapidly rising open unemployment. Three major sources are fuelling this growing unemployment problem. First, starting in the mid-1980s large numbers of rural workers have been migrating to urban areas in search of employment; with estimates that four million migrants per year will need to be absorbed annually in urban areas. Second, each year approximately 12 million school or college leavers join the urban labour force. Finally, contributing to the current upsurge and raising fears of social unrest are the large numbers of workers being laid-off by bankrupt or restructuring state enterprises. Redundant labour, previously disguised within the urban 'iron rice bowl' system of guaranteed employment, is now being pushed into the open, a process which has been speeded up by the launching in 1997 of a three year programme of state enterprise 
restructuring which both generates higher levels of urban unemployment, and puts pressure on urban areas to control the in-flow of rural migrant labour [Cook and Maurer-Fazio, 1999].

Official urban unemployment statistics include only those formally registered and thus provide a partial picture of the numbers involved. In 1997 the official rate was 3.1 per cent or 5.7 million people, up from 2.5 per cent or 3.83 million in 1990 [State Statistical Bureau, 1998]. These figures exclude workers who are 'laid-off' (xiagang) but still retain an attachment to their original 'work unit'. Estimates of laid-off workers in 1998 range from eight to 11 million workers (Ministry of Labour, interviews), with projections that during the next few years approximately 3.5 to 4 million state sector workers, and five million collective enterprise workers will be laid off each year. However, other estimates for xiagang workers at the end of 1997 are as high as 14.4 million, bringing the total number of urban unemployed to approximately 20 million out a total of 147 million formal urban employees [State Statistical Bureau, 1998]. Significantly, the average education level of the officially registered unemployed is above the average level for the workforce as a whole. Fifty-two per cent of urban unemployed have junior middle school education, 34 per cent senior middle school and 4.1 per cent college education, compared with the average for all employees of 35 per cent primary school, 38 per cent junior middle school, 12.1 per cent senior middle school and 3.5 per cent college leavers [State Statistical Bureau, 1998].

This growth in the incidence of skilled unemployed took place during periods of rapid economic and export growth. But not only has the global economy moved into recession, but China's accession to the WTO is likely to be associated with a reduction in tariffs and other import barriers, exposing much of its inefficient industry to international competition, and therefore forcing the further displacement of labour. The size of its reserve army of labour can therefore be expected to grow significantly in the future.

\section{CONCLUSIONS}

What conclusions can be drawn from this? On the one hand, there are undoubted efficiency gains arising from international specialisation. In a competitive world, these efficiency gains will be reflected in a reduction in product costs and an improvement in product availability and quality. Those consuming these internationally produced products will reap these efficiency gains.

There are two primary routes to consumption power. The first is employment. But, in the absence of full employment, a second source of income 
arises from the redistribution of consumption power from those who are able to maintain employment to those whose jobs are displaced in this process of international specialisation. Assuming that these two conditions are met, increasing openness has much to offer. (These are two of the important assumptions which underlay Ricardo's model of comparative advantage see above.) Let us think of this as the 'blue globalisation scenario' reflecting a win-win world of globalisation. ${ }^{5}$

Counterposed to this is a negative sum outcome to globalisation - the 'red globalisation scenario'. This can arise if in a world of non-full employment. I have argued that it is my belief that the spectre of global unemployment is likely to grow rather than to diminish - Malthusian (population growth) Marxian (capital intensification) and Hobbsian (overproduction/ underconsumption) explanations underlie this systemic trend towards surplus labour. Moreover, political processes do not allow for effective or widespread redistribution of consumption power. These conditions may apply within individual countries: do the rich in the US redistribute income to allow the unemployed and the poor to buy products sourced from developing countries at progressively falling prices? They also apply across countries - do rich countries provide aid resources to compensate poor countries for falling per capita incomes?

Globalisation has made this redistributive outcome more difficult to sustain. In part, this is because it has led to wars of incentives by governments anxious to attract an increasing share of globally mobile investment. These incentives have increasingly eroded tax bases. In addition, the desire to promote openness has led to the removal or reduction of tariffs on trade. Together these two developments have weakened the fiscal capacity of states to move resources from the gainers to the losers. But, this is not just a fiscal issue since the political capacity and will of governments to fund social expenditures and other forms of income transfer has been undermined by the conscious and systematic spread of 'Thatcherite' ideologies by the International Financial Institutions and global carriers of ideology such as the Murdoch empire.

If all of this is correct, the sustainability of globalisation depends on the ability of those who gain from globalisation to maintain their political ascendancy over those who lose. Is this political balance likely to endure? Here the key battles are likely to be fought in three parts of the global economy.

The first is in the USA where there has been a growing coalition against globalisation, as reflected in opposition to the Seattle Round trade talks in late 1999. Although focusing on labour and environmental standards, the net effect of these protests (and some would say their hidden agenda) was to generate increasing pressures for protection. 
But, perhaps more serious is the possibility of falling real asset prices if the US stock markets (which by 2000 had higher price-earnings ratios than before the great crash of 1929) crash. Rapid growth in the US during the 1990s - in employment, in GDP and the stock market - had fostered the revival of economic activity in parts of East Asia. If stock prices fall and hence when personal consumption falls (as personal savings, now negative, rise in response to falling asset values) and unemployment begins to rise, the balance may easily sway in favour of more protection. If so, the implications for full employment in the global economy are deleterious.

In Europe, high rates of unemployment (Table 4) and the rise of protofascist and racist parties provide fertile ground for new forms of protectionism. And in China and other parts of the developing world which offer potential markets to global production, the social and political tensions which are surfacing are leading many to question the ability of the Chinese military and political establishment to maintain its current outward-oriented growth trajectory.

The red globalisation outcome thus has two components. On the one hand, if growing openness is sustained, then increasing unequalisation and falling standards of living are likely to be experienced on a global scale. On the other hand, rising unemployment and/or falling incomes may result in the growth of protectionism in major markets, and the dynamic of globalisation is interrupted. This latter component of the red globalisation scenario is usually greeted with a 'don't cry wolf' response, or by those who argue that the benefits of globalisation are so great that nothing will be able to undermine it. But the same may have been said in the late nineteenth century. ${ }^{6}$ Then, too globalisation seemed to be associated with a closing of the gap in inter-country living standards. Yet, as Williamson shows, the consequent rising intra-national income inequality led to a less-open world:

immigration policy in labour-scarce parts of the global economy became increasingly less generous and more restrictive prior to 1914, and much of this retreat from open immigration policies was driven by a defence of the deteriorating relative economic position of the working poor. In addition, ... liberal attitudes towards trade were brief, and ... protection rose sharply almost everywhere on the European Continent from the 1870s onwards [Williamson, 1998: 69].

At that time, the arena of disputation with regard to globalisation was the trade in unskilled labour (through migration); in this generation it is likely to include, in addition, the global flows of goods, services and, perhaps, even finance. 


\section{NOTES}

1. '... until about 1985, China achieved a remarkable reduction in the incidence of poverty. [But] [a]fter the mid 1980s the rate of reduction in poverty drastically slowed down and arguably was halted or even reversed' [Khan, 1999: 2].

2. There is a heated debate in the literature on whether unemployment in the IACs is the direct consequence of globalisation or not [Cline, 1997; Wood, 1998]. Some observers argue that these growing levels of unemployment are due to autonomous technical change, rather than to the displacement of labour by imports of labour intensive manufactures from LDCs. The counterargument is that technological change is to a considerable extent a response to the threat of imports from low wage countries. For the purposes of my argument at this stage, it does not really matter which of these viewpoints is correct; rather, it is the existence of high levels of unemployment which is important.

3. Wood's calculation of falling terms of trade in manufactured exports is corroborated by a recent study of the barter terms of trade in manufactures between developing countries and the European Union, which estimates an annual rate of depreciation of 2.2 per cent between 1979 and 1994 [Maizels et. al., 1998]. In a further study focusing on the terms of trade in manufactures between the US and developing countries for the period 1981-97, Maizels et al. [1999] conclude that ' $[0]$ ver the whole period, the relative terms of trade trend of developing countries, compared with that of developed countries, has significantly worsened [Maizels et al., 1998: 23]. It is significant that neither of these recent studies by Maizels et al. reflect the fall in developing country manufactured export prices which followed the East Asian crisis of 1997-98.

4. This and the following two paragraphs were contributed by Sarah Cook.

5. The choice of colours reflects the broad political coalitions which are likely to group around these pro- and anti-globalisation options.

6. In many respects, the degree of global integration before the First World War exceeded that of the late 1990s [Bairoch and Kozul-Wright, 1996].

\section{REFERENCES}

Bairoch P. and R. Kozul-Wright, 1996, 'Globalization Myths: Some Historical Reflections on Integration, Industrialization and Growth in the World Economy', UNCTAD Discussion Papers No.13, March, Geneva.

Baldwin, R.E. and P. Martin, 1999, 'Two Waves of Globalization: Superficial Similarities, Fundamental Differences', in H. Siebert (ed.), Globalization and Labour, Tubingen: Mohr Siebeck.

Bhalla, A.S. (ed.), 1998, Globalization, Growth and Marginalization, New York: Macmillan and IDRC.

Brenner, R., 1998, 'Uneven Development and the Long Downturn: The Advanced Capitalist Economies from Boom to Stagnation, 1950-1998', New Left Review, 229.

Cline, W., 1997, Trade and Income Distribution, Washington, DC: Institute for International Economics.

Cook, S. and Margaret Maurer-Fazio (eds.), 1999, 'Introduction', in The Workers' State Meets the Market: Labour in China's Transition, London and Portland, OR: Frank Cass (also as a special issue of The Journal of Development Studies, Vol.35, No.3).

Dunford, M., 1994, 'Winners and Losers: The New Map of Economic Inequality in the European Union', European Urban and Regional Studies, Vol.1, No.2, pp.95-114.

Eurostat: Intra- and Extra-EU Trade, 1998.

Greider, W., 2001, 'A New Giant Sucking Sound', The Nation, 31 Dec. 
Hartog, J., 1999, 'Country Employment Policy Reviews: The Netherlands', Social Dialogue and Employment Success, ILO Symposium 2-3 March, Geneva: ILO.

ILO, 1999, World Employment Report 1998-99, Geneva: ILO.

Jones, C., 1997, 'On the Evolution of World Income Distribution', Journal of Economic Perspectives, Vol.11, No.3, pp.3-19.

Kaplinsky, R. (1998), 'Globalisation, Industrialisation and the Pursuit of the Nth Rent', IDS Discussion Paper No.365, Brighton: Institute of Development Studies.

Ken-ichi Takayasu, Toyama, Atsuko and Minako Mori, 1998, 'ASEAN's Industrial Structures: Currency Turmoil Spawned by Import-inducing Structures', Pacific Business and Industries, Vol.1, No.39.

Khan, A.R., 1999, 'Poverty in China in the Period of Globalization: New Evidence on Trend and Pattern', Issues in Development Discussion Paper 22, Geneva: ILO.

Lewis, W.A., 1954, 'Economic Development with Unlimited Supplies of Labour', Manchester School of Economics and Social Studies 22, pp.139-91.

Lundberg, M. and B. Milanovic, 2000, 'The Truth About Global Inequality', Financial Times, 25 Feb.

Maizels, A., Berge, K., Crowe, T. and T.B. Palaskas, 1998, 'Trends in the Manufactures Terms of Trade of Developing Countries', mimeo, Oxford: Finance and Trade Policy Centre, Queen Elizabeth House.

Maizels, A., Berge, K., Crowe, T. and T.B. Palaskas, 1999, 'The Manufactures Terms of Trade of Developing Countries with the United States, 1981-97', mimeo, Oxford: Finance and Trade Policy Centre, Queen Elizabeth House.

Malthus, T.R., 1798 [1926], An Essay on the Principles of Population, London: Macmillan.

Marx, K., 1876 [1970], Capital: A Critique of Political Economy, Vol.1, London: Lawrence \& Wishart.

Prebisch, R., 1950, The Economic Development of Latin America and its Principal Problems, New York: ECLA, UN Department of Economic Affairs.

Ranis, G., 1987, 'Labour Surplus Economies', in J. Eatwell, M. Milgate and P. Newman (eds.), The New Palgrave: A Dictionary of Economics, London: Macmillan.

Rodriguez, F. and D. Rodrik, 1999, 'Trade Policy and Economic Growth: The Sceptic's Guide to Cross-National Evidence', NBER Working Paper No.7081, Cambridge, MA: NBAER.

Rodrik, D., 1999, 'The New Global Economy and Developing Countries: Making Openness Work', Policy Essay No.24, Washington, DC: Overseas Development Council.

Schumpeter, J., 1961, The Theory of Economic Development, Oxford: Oxford University Press.

Singer, H., 1950, 'The Distribution of Gains Between Borrowing and Investing Countries', American Economic Review, Vol.40, pp.473-85.

Smith, A., 1776, An Enquiry into the Nature and Cause of The Wealth of Nations, Oxford: Oxford University Press.

State Statistical Bureau (SSB), 1997, China Statistical Abstract 1997, Beijing: China Statistical Publishing House.

State Statistical Bureau, 1998, China Labour Statistical Yearbook, Beijing: China Statistical Publishing House.

Streeten, P, 1998, 'Globalization: Threat or Salvation', in A.S. Bhalla (ed.), Globalization, Growth and Marginalization, New York: Macmillan and IDRC.

United States, 1997, Economic Report of the President, Transmitted to the Congress February 1997 Together with the Annual Report of the Council of Economic Advisers, Washington, DC: United States Government Printing Office.

Williamson, J.G., 1998, 'Globalization, Labour Markets and Policy Backlash in the Past', Journal of Economic Perspectives, Vol.12, No.4, Fall, pp.51-72.

Wood, A., 1994, North-South Trade, Employment and Inequality: Changing Fortunes in a SkillDriven World, Oxford: Clarendon Press. 
Wood, A., 1997, 'Openness and Wage Inequality in Developing Countries: The Latin American Challenge to East Asian Conventional Wisdom', World Bank Economic Review, Vol.11, No.1, pp.33-57.

Wood, A., 1998, 'Globalisation and the Rise in Labour Market Inequalities', Economic Journal, Vol.108, No.450, pp.1463-82.

Wolf, M., 2000, 'The Big Lie of Global Inequality', Financial Times, 9 Feb.

World Bank, 1996, Poverty Reduction and the World Bank, Washington, DC: World Bank.

World Bank, 1997, World Development Indicators, 1997, Washington, DC: World Bank.

World Bank, 2000, Global Economic Prospects and the Developing Countries 2000, Washington, DC: World Bank.

World Trade Organization, 1995, International Trade: Trends and Statistics, Geneva. 


\section{Globalisation, Privatisation and China's Industrial Labour Systems}

\section{PAUL BOWLES and XIAO-YUAN DONG}

Analysing the interactions between agents, institutions and politicaleconomic forces occupied a central place in much of Gordon White's work. This analysis is a contribution to that tradition. We analyse the interactions between two of the most important factors shaping China's dual transition and China's evolving industrial labour systems. To briefly expand upon this, consider first China's dual transition - from a developing to an industrial economy and from a centrally-planned to a market economy. Both of these transitions imply major structural changes and have significant implications for labour. In the contemporary period, the two dominant factors shaping this dual transition are globalisation and privatisation. That is, first, the development process in China and other developing countries must be seen as operating within the context of a new phase of global capitalism. Secondly, privatisation, while a major component of the transition in the countries of the former Soviet bloc but initially eschewed by China's leadership, has recently risen to a prominent position on China's policy agenda. So far, privatisation has been selectively applied in the state-owned enterprise sector but has been implemented with great speed in the rural industrial sector since the mid-1990s.

In this contribution, we analyse the interactions of globalisation and privatisation with China's industrial labour systems. A labour system can be defined as a specific set of social relations whose functions are to allocate, organize and reproduce labour, functions which are patterned by institutions (such as organisations, legislation and formal and informal social rules) and which determine economic, social and political outcomes for labour.' The concept of a labour system therefore provides rich terrain on which to analyse the forces of globalisation and the program of privatisation. It is important to note that by setting out our objective as analysing the interactions between globalisation and privatisation on the one hand, and 
industrial labour systems on the other, we are specifically adopting the position that globalisation and privatisation should not be viewed deterministically but must be seen as operating within a specific societal context which produces a dynamic, two-way, interactive process. It is precisely the nature of these interactions that we wish to highlight in this discussion.

As such, this analysis contributes to the literature on the role of 'national systems' and the extent to which they are 'converging' as economies - and societies - become increasingly integrated. ${ }^{2}$ That is, we wish to examine the extent to which globalisation and privatisation are moving China's industrial labour systems to resemble a universal capitalist model and, conversely, the extent to which globalisation and privatisation are modified and adapted to China's own distinctive national characteristics.

In the following section, we provide a more detailed overview of China's industrial labour systems before proceeding, in further sections, to analyse their interactions with globalisation and privatisation.

\section{INDUSTRIAL LABOUR SYSTEMS: A BRIEF OVERVIEW}

To proceed, it is necessary to provide a more concrete analysis of the labour system. Here, it is clear that even within the industrial sector, China has a number of labour sub-systems defined mainly in terms of ownership and differences between enterprises in four different ownership categories can be summarised by the following 'stylised facts'. State-owned enterprises (SOEs) tend to be more capital-intensive, are still largely under the control and regulation of the state administrative agencies, and operate partly according to the previous system of central planning and increasingly under market criteria. They are penetrated by political institutions such as the Communist Party and the official trade union (the All China Federation of Trade Unions (ACFTU)) and are subject to various systems of administrative labour regulation in terms of wage levels, welfare provision and job allocation. SOEs are still largely populated by workers who are recruited from the immediate urban environment and are the beneficiaries of the employment demarcation established for urban and rural residents during the Maoist period, although the reforms have seen an increasing penumbra of casual or contract workers recruited form further afield. SOEs contain a relatively high proportion of middle-aged and older workers, have limited new recruitment, and mobility between enterprises is low. These workers used to enjoy a high degree of job security but the incidence of state sector lay-offs (xiagang) has become significant since the mid-1990s. To a certain degree, urban collectives resemble SOEs in all these respects. 
The township and village enterprise (TVE) sector is more diverse and contains various forms of collective, shareholding, partnership and private enterprises although they are all typically classified in the collective sector in official statistics. TVEs were directly linked to township and village governments which influenced the hiring levels and practices of the enterprise, often pursuing local employment maximisation objectives. TVEs are staffed predominantly by local residents from rural areas although here too, especially in the south-eastern coastal provinces, migrant workers from outside of the locality have also been employed in significant numbers. TVEs, even while linked to local governments, were typically subject to harder budget constraints than SOEs and were more market oriented. Larger enterprises in this sector have often set up branches of the ACFTU but labour organisation in this sector, especially for migrant workers, is much less formalised than in the SOE sector. It is this sector which has been the subject of an intensive privatisation programme since the mid-1990s.

The joint venture (JV) sector is found across the country but is concentrated in the special economic zones and open areas in coastal provinces. JVs have tended to have greater flexibility in their ability to hire and fire labour and employ contract labour from both urban and rural sectors. However, joint ventures may also share some of the same labour market characteristics as the Chinese partner firm whether it be an SOE, an urban collective or a TVE. Wholly foreign invested firms (FIFs) are similar to joint ventures in their geographical concentration and in their reliance on contract labour drawn from both urban and rural sectors, especially young and low-skilled (particularly female) labour. While workers in this sector are sometimes relatively highly paid in monetary terms, they often lack the welfare benefits and organisational protection afforded to their counterparts in the state sector and are often subject to primitive forms of capitalist work organisation and discipline. FIFs typically operate a much looser regulatory regime and exercise more enterprise autonomy than other enterprises.

As can be seen from this brief review of 'stylised facts', China's industrial labour systems are complex and have been affected by the post-1978 reform process in a variety of ways. ${ }^{3}$ We now turn our analysis to focus on globalisation and privatisation. We analyse in broad brush strokes the impacts of globalisation on the range of labour sub-systems while our analysis of privatisation will focus specifically on the TVE labour subsystem. In analysing both processes our aim is to highlight their inactions with domestic Chinese institutions. It is by examining these interactions, we argue, that the evolving nature of China's industrial labour systems can be best understood. 


\section{GLOBALISATION}

The aspects of globalisation considered here are those represented by the quantitative expansion of international economic flows. In the Chinese context, the policy of 'opening up to the outside world' has, since 1978, had a dramatic effect on trade and foreign investment in China. In the immediate pre-reform period, China's trade to GDP ratio was around ten per cent, one of the lowest in the world. Since then, the 'open door' policy has led to a rapid rise with China now having a level of trade openness - a 36 per cent ratio of trade to GDP in the mid-1990s - which is comparable to other large developing countries [World Bank, 1997: 6]. Much of this increase in foreign trade was the result of China becoming a site for the processing of raw materials and semi-finished goods following the changes to import duties announced in 1984. China's exports have been dominated by labour-intensive manufactured goods such as textiles, apparel, footwear and toys, which rely on these imported raw materials. By the early 1990s, 45 per cent of all exports were made up of these processed exports, a high figure even by East Asian standards [World Bank, 1997: 7]. The imported content of these processed goods averaged over 90 per cent of their export value. Recent figures also suggest that imports account for a large share of the value of exported goods and Zhang and Zheng [1998: 4] report that in FIFs, exports are 127 per cent of the value of their imports.

Much of this trade was undertaken directly by foreign firms and joint ventures. However, Chinese foreign trade corporations and state-owned enterprises were also significantly involved and the links with the domestic economy were therefore substantial although trade is highly concentrated in the 12 coastal provinces which accounted for 90 per cent of all trade flows (exports plus imports) in 1997 with Guangdong alone accounting for 41 per cent $[E A E P, 1999: 21]$. The result has been a shift in the production from inland to coastal provinces with the share of the 12 coastal provinces in GDP rising from 52 per cent in 1980 to 57 per cent in 1995 which has led to increasing per capita differences between the inland and coastal provinces.

With respect to foreign direct investment (FDI), flows to China were minimal prior to 1978 , increased steadily during the 1980 s and exploded in the 1990s. By the mid-1990s China had become the leading recipient of FDI among developing countries (accounting for about 40 per cent of total flows to developing countries). The total value of FDI actually used (as opposed to total contact value) was a staggering US\$219 billion between 1979-97 with the trend sharply upwards over this period [Zhang and Zheng, 1998: 4]. Two features of this FDI flow are worth noting. One is again its geographical concentration with 12 coastal provinces and municipalities accounting for 
over 90 per cent of all FDI inflows. The second is the concentration by home country with the majority coming from overseas Chinese investors, and 60 per cent from Hong Kong alone [World Bank, 1997: 22].

China's opening up has therefore been a steady process leading to cumulative changes that have been dramatic and which have affected, albeit unequally, a wide spectrum of sectors and regions of the Chinese economy. These changes, and the form that globalisation has taken in China, have led to discernible pressures arising from the dynamics of global production. ${ }^{4}$ Two such pressures concern the location of labour and the nature of cost minimisation. First, the location of employment has changed with the coastal provinces requiring large inflows of labour to satisfy the expansion of global market oriented production in general and the needs of foreign invested firms in particular. Thus, globalisation has led to the need for increased geographical labour mobility. Secondly, a distinctive feature of Chinese exports is the high share of processed exports, suggesting that there are strong pressures for the containment of labour costs; in short, labour costs are one of the few that can be squeezed to maintain profit margins given that import costs are likely to be subject to less flexibility. This provides important insights into how China has been incorporated into the global economy, insights which can be understood with reference to the concept of the 'global commodity chain' [Gereffi, 1995].

Buyer-driven commodity chains are those where brand name retailers play the pivotal role and typically do not engage in production themselves but operate on the basis of sub-contracting to firms in low cost countries. This pattern is more typical in labour-intensive industries such as garments, footwear, toys, and consumer electronics which are, as we have seen, major exports. In China, the organisation of the production of these goods is often a 'triangular' one in which the link between the developed country retailer and the Chinese workers is mediated by overseas investors who supply the capital and organisational skills through foreign-invested firms.

The pressures on firms are therefore to contain labour costs in industries where the scope for raising labour productivity through higher education levels or increased use of sophisticated technology is limited. The increases in productivity must come mainly from increasing the pace and quality of the work itself. These pressures also operate indirectly on governments in that a policy of attracting foreign investment requires policies which are attractive to international capital in terms of limiting labour demands both pecuniary and non-pecuniary.

Thus, globalisation has resulted in an increase in labour mobility, and the annual flow of around 100 million migrant workers, and the operation of firms which typically operate at the bottom of global commodity chains 
positioned as suppliers of low cost labour. As might be expected, these implications of globalisation have had important interactions with industrial labour systems. To analyse the nature of these interactions more concretely, we consider two aspects, namely, industrial relations and the phenomenon of wage arrears. ${ }^{5}$

Consider first industrial relations. With respect to the operation of foreign firms in China, it is often here that some of the worst forms of labour abuse are found with long work hours, enforced overtime, authoritarian management-worker relations, physical punishment of workers and, in the very worst cases, even death. Asian foreign-invested firms are often identified as being among the worst offenders of labour rights. Previous work in this area has tended to stress either the cultural origins of the foreign investor or to argue that the home country conditions are important in determining how firms operate abroad so that firms from social democratic Europe or rights-based US tend to treat workers better than enterprises from countries with strictly controlled unions such as Taiwan, Hong Kong and Singapore [Chan, 1998b].

We agree with the home country conditions explanation but add to it the importance of the enterprise's position in the global commodity chain and the characteristics of that chain. Thus, foreign investors at the lower levels of buyer-driven commodity chains have great incentives to lower labour costs. The attraction of China is precisely its low paid labour force and China's incorporation into the global economy depends crucially on this feature. The result is continuous pressures to increase output and reduce unit labour costs by increasing hours of work and under-paying workers. The increase in the employment of young unmarried (usually migrant) women workers in the export-processing factories of southern China parallels that found in other developing countries in Asia and elsewhere. ${ }^{6}$ The increase in pay and economic independence which may accompany such employment needs to be heavily balanced against the new forms of control and subordination which are also typical accompaniments.

However, foreign firms in China do not operate in an institutional vacuum. For these practices to occur requires compliance by Chinese governments at all levels. The central government has been instrumental in setting the policy of attracting foreign investment and this has been a pillar of policy to modernise the economy, and provincial and local governments have seen FDI as a tool for increasing economic growth and have often acted more as chaperones than regulators of foreign firms. However, examples of worker mistreatment and the open discussion of 'exploitation' in the Chinese media have forced the central government to act. The Labour Law of 1994 was a response to this and has been accompanied by an aim to have trade 
unions in all of China's foreign enterprises and joint ventures. It has been claimed that this has been achieved in about 70-80 per cent of cases with the trade union being designed to eliminate the worst cases of abuse but still controlled by the state to implement pro-reform policies. The intention has been to extend the traditional role of the ACFTU as a 'conveyor belt' for central policy in the state sector into the foreign sector. Such a trade union is, of course, compromised by this role in protecting workers' rights and serving as a vehicle for workers' mobilisation. ${ }^{7}$ Implementation of the labour law has also been, to say the least, patchy and has been a low priority for governments at all levels.

The position of migrant workers is perhaps worst of all. As Chan [1998a: $3]$ notes, 'the household registration system provides fertile conditions for the creation of a system of forced and bonded labour'. In Chan's work on the footwear industry she has shown that migrant workers, especially in foreign, joint venture and private firms, are much more likely to be charged a 'deposit' than other workers, and this ties them to the enterprise even in the face of poor working conditions. However, it is not always the case that it is only foreign firms which are engaged in the violation of labour rights. Chan [1998a: 6] also reports that 'even in the state sector, the low-skill footwear industry has begun to employ migrant workers, and [there appears to be] a transfer of the harsh labour regime of the foreign Asian managers to the mainland state and collective sectors' ${ }^{8}$

The competitive pressures of production for the global economy seem therefore to have forced many firms in the footwear industry to adopt more authoritarian forms of work practices, a clear example of the race to the bottom in labour standards that critics of globalisation predict. Furthermore, ACFTU data indicate that this result is applicable much more widely than simply the footwear industry and evidence of violations of the labour law provisions on the length of the working week, payment for over-time, and violations of other labour rights are widespread [ACFTU, 1995-96: 357, $358,390,391]$. In this respect, there is strong evidence of convergence in all of the labour systems to a form of primitive capitalism, a form which has strong parallels with conditions found in many developing countries.

While this may be the case for firms operating in highly competitive labour-intensive, export oriented, manufacturing industries, what is happening elsewhere? Producer driven commodity chains are typically more capital intensive and give firms more market power and there is thus a greater scope for rent sharing with workers, a factor enhanced by the fact that more capital intensive firms typically have longer investment horizons than labour intensive firms. Data presented by Zhang and Zheng [1998] shows that multinational corporations (MNCs) operating in China have higher 
profit rates than the average of all foreign funded firms, have higher capital per employee, pay higher wages, have lower export to sales ratios and operate in more concentrated markets.

It is not surprising to find, therefore, that US, European and Japanese MNCs operating in China typically display different labour-management practices than those outlined above. Again, they have to deal with Chinese institutional settings and there is evidence that in joint ventures, MNCs often adopt the practices of SOEs. For example, research by Goodall and Warner [1997: 592] on joint ventures in Beijing and Shanghai between Chinese firms and partners from the US, Netherlands, Switzerland, Germany, Japan and Hong Kong finds that "the "iron rice bowl" is, as we have taken pains to show in some detail, still in evidence and may be found in foreign-invested joint ventures as well as many SOEs'. Thus, there is also evidence of foreign firms adapting to Chinese institutional frameworks in ways which might, in some but not all respects, benefit workers.?

One other sector to analyse in terms of assessing the impact of globalisation on labour is China's attempt to build its own global conglomerates. ${ }^{10}$ Enterprise reform in the state-owned sector has, since the early 1990s and most explicitly since the 15th Party Congress in September 1997, focused on building large conglomerates to compete internationally. The aristocracy of labour in state-owned enterprise which included a large proportion of the urban workforce in the Maoist period is slowly shrinking to the core workers employed in China's new, large, globally focused conglomerates. It is here that the parallels which some scholars have seen with Japanese employment practices may be evident.

As Chan [1997: 202] argues "'Socialism with Chinese characteristics" (and even core-sector "capitalism with Chinese characteristics") may well end up meaning an organisation-oriented system akin in many ways to that of core Japanese industry.' Whether such an outcome will occur is an open question. This is an area where more research is needed but it is important to note that the result of developing countries 'going global' is not necessarily the adoption of developed country labour relations systems. To take the example of perhaps the most global manufacturing industry, that of the automobile, wide variations in labour-management relations exist.

Thus, Rodgers [1996] in his examination of the globally successful South Korean automobile industry, argues that, given institutional pathdependence, there is little prospect of a transition to newer - and more worker friendly - production methods. He argues that 'as might be expected in a society where the traditional mass production model is predominant, government and business elites do not seem to consider the benefits of cooperative labour-management relations to be worth the cost in terms of 
higher wages or reduced managerial prerogatives' [1996: 110]. Similarly, Deyo's account of the Thai auto industry also concludes that workers in developing countries are unlikely to enjoy the benefits of changing production methods that are sometimes identified for their advanced country counterparts. Instead, 'autocratic low-trust flexibility may provide an adequate basis for competitive success in the second-tier technology-dependent automotive industries of developing countries' [1996: 152].

In China, the desire to build global conglomerates - and to create a modern enterprise system more generally in the state sector - has paid little attention to what type of industrial relations system might be required for a 'modern' or 'global' firm. The institutional legacy of state socialism is one where the social bargain was based on employment stability in return for state/managerial control of the work-place; in much of the SOE sector employment stability has been seriously eroded but state/managerial control continues. Even in those enterprises which succeed in 'going global', workers might expect to enjoy greater employment stability and higher wages than their counterparts elsewhere in Chinese industry but 'going global' is unlikely, in itself, to change the nature of industrial relations; institutional path-dependence in the SOE sector makes moving to forms of more democratic workplace management an unlikely outcome.

As a further illustration of the importance of institutional path dependence, consider, secondly, the phenomenon of wage arrears. This requires special analysis because, as Earke and Sabirianova [1999: 3] note, 'wage arrears are peculiar in that, unlike [enterprise and tax] arrears, they are virtually unheard of in market economies'. And yet, data published by the ACFTU [1995-56: 348-9] indicate that wage arrears in Chinese industry are widespread. It shows that approximately one in six workers was owed wages. Wage arrears are inversely related to the enterprise's financial situation although even firms in good and excellent financial situations had wage arrears owing to eight to nine per cent of their workers. It appears that, contrary to the Russian evidence presented by Earle and Sabirianova [1999], in China private firms are the worst offenders with SOEs having one of the lowest incidences of wage arrears; joint ventures and foreign-invested firms fell in between although much nearer the SOE end. Similar to the Russian evidence, workers with less employment security seem to experience higher incidences of wage arrears.

How can we explain the phenomenon of widespread wage arrears? With respect to financial assets, Bowles and White [1993: 139] argued that

the struggle for resources through bond issue can by no means be described as a real 'bond market', meaning the free and voluntary sale and purchase of bonds. The 
politico-economic relationships involved are more complex, with at least three main aspects: ... coercion ... collusion ... [and] market. Such a diversity of relationships falls short of anything that can be called a 'market' and can be understood as reflecting the dynamics of a partly reformed and structurally ambiguous economy.

The phenomenon of wage arrears would appear to be a new and particularly virulent form of this politico-economic struggle for resources. This type of explanation suggests that transitional economies are, as Earle and Sabiriavano argue, distinctive types of economies which operate in ways quite different from market economies. Thus, the interaction of globalisation and China's institutional structure has, in this instance, resulted in foreign firms quickly adapting their behaviour to take advantage of the opportunities offered by the 'transitional economy'.

\section{PRIVATISATION}

To continue our analysis, we now turn to the interactions of privatisation and Chinese institutions on the industrial labour system of TVEs. The TVE sector represents a unique characteristic of the Chinese economy, a feature which indicated that China had followed, in Xu's [1995] words, 'a different transition path'. However, by the mid-1990s, with TVE employment growth slowing and profits falling, the privatisation of TVES was officially sanctioned. The impetus given to the private sector following Den Xiaoping's southern tour in 1992 was also instrumental in this decision as local governments worried about asset-stripping by TVE managers now more able to divert resources to the private sector. In some cases, TVEs had been collective in name only but in others local government ownership had real content and consequences for the operation of TVEs. The privatisation of TVEs led to real changes in enterprise organisation as millions of TVEs were privatised in the late 1990s. In this section, we analyse the implications of this for TVE labour systems based on in depth interviews with local cadres and enterprise managers in 39 large privatised TVEs in Jiangsu and Shandong."

The privatisation process, determined in outline at the national level, was left to local governments to implement. ${ }^{12}$ Our interviews revealed that a major concern amongst local government officials was the desire to establish clear managerial responsibility for assets. This led to the design of the privatisation programme which sought to concentrate the ownership of TVEs in the hands of enterprise managers. In the case of most small enterprises, local governments sold them directly and exclusively to the enterprise managers, typically at a 30 per cent discount. For larger enterprises, this 
approach was not possible primarily due to the large sums that were required for enterprise purchase and shares were therefore also sold to other employees. In these cases, the objective of local governments was to ensure that managers were the dominant shareholders, an objective which was largely met in our sample of 39 large enterprises as the average post-privatisation distribution of share ownership below indicates:

TABLE 1

POST-PRIVATISATION SHARE OWNERSHIP IN 39 ENTERPRISES

\begin{tabular}{lr}
\hline Managers & 52.6 per cent \\
Other Board Members & 24.9 per cent \\
Employees & 17.9 per cent \\
Local government & 2.9 per cent \\
Others & 1.7 per cent \\
\hline
\end{tabular}

In 33 of the 39 enterprises the manager held at least 50 per cent of the shares and only in six enterprises were the non-managerial employees the dominant shareholders. This outcome was more the result of the way in which the privatisation process was carried out, with managers being given the right of first refusal, rather than any reluctance on the part of workers to purchase shares. Indeed, our survey of over 1,000 workers in these enterprises showed that 64 per cent of those who did not hold any shares gave as the reason for this the fact that they were not given the opportunity to purchase shares. Workers were therefore excluded to a significant degree from the privatisation process. It is perhaps not surprising to find, therefore, that many were not initially favourable to the idea of privatisation. This potential opposition was solved however in a way redolent of the traditional methods employed for decades by the Party. As the manager of one enterprise told us, 'workers, as well as part of the management staff, found it very hard to accept private ownership. They gradually came to a unified understanding of the reform only after two month's persuasive work and repeated meetings.'

The privatisation of TVEs, and the concentration of ownership in the hands of managers, transferred to managers considerable decision-making authority and autonomy. The result of this was a change in many of the functions of the TVE labour system towards those more commonly associated with the private sector. For example, in China as elsewhere, privatisation seems to have been accompanied by an increase in the power of managers to fire workers and has therefore resulted in reductions in the size of the workforce as well as a strengthening of labour discipline. This is borne out by our interviews. One manager told us that before privatisation, it was common for 
'two people to do one job' whereas after privatisation it was common for 'one person to do two jobs' in the enterprise.

Thus, privatisation was accompanied by the elimination of many jobs and an increase in the intensity of work for those who remained employed. Lay-offs were often substantial and our interviews showed that reductions of employment in the region of 40 per cent of the workforce were not uncommon. Two types of worker seem to have been commonly singled out in this respect. First, elimination of administrative jobs seems to have been high as managers used their new found powers to shed those who had typically been given such jobs at the behest of local officials keen to find jobs for their relatives and friends. Secondly, the manager who relayed that 'all those who were too old, too weak, too sick, or disabled were dismissed' was not expressing a unique view. The social objectives of TVE employment were replaced with profit criteria.

In terms of labour discipline, we were informed that stricter enforcement of work starting and stopping times had been introduced together with deductions for poor performance. But there was also evidence of more primitive forms of labour discipline being introduced. For example, one local cadre told us approvingly of how productivity had been increased in one enterprise. Here, the mowei toatai $z i$ method of labour discipline had been introduced. This involved ranking all employees' performance each year and dismissing the bottom five per cent. The ranking was made on the basis of employees' votes of each others' performance, the assessment of the supervisor, and a set of measures on absenteeism and product quality.

In terms of how the outcome of the new labour system were realised in terms of rewards, the increased work intensity and productivity which accompanied privatisation resulted in significantly higher wage levels for remaining workers. However, there is also evidence that wage inequality and gender wage discrimination increased..$^{13}$

Where privatisation included share ownership by employees, the distribution of shares reflected the inequalities found in wider Chinese society. Specifically, in our sample, the between-group ratio of share values was 3.3 to 1 between men and women, 8.0 to 1 between local and migrant workers, and 3.3 to 1 between managerial staff and production workers. Moreover, ranked by family income, the value of shares owned by the employees who were among the top 20 per cent of the sample ranked by family income was 6.4 times that of the mean value of employees who were ranked among the lowest 40 per cent of family income.

The privatisation process has also given rise to new forms of differentiation and stratification among the workforce and attitudes to the enterprise vary significantly between shareholding and non-shareholding employees. 
For example, differences are evident between these two groups of workers when asked about intentions to look for another job, whether privatisation had affected them positively and on their degree of participation in enterprise decision-making. Along all of these dimensions, employee shareholders viewed their enterprise and privatisation more positively than non-shareholders.

Table 2 below illustrates this point with respect to exit intentions for shareholder and non-shareholder employees in our sample enterprises. For comparison, we also provide information on the same question drawn from employees in six non-privatised TVEs. As can be seen turnover intention is lowest among workers in non-privatised firms and highest among the nonshareholder workers in the privatised firms. Analysis which takes account of differences between workers in terms of personal characteristics such as age, sex, seniority and education still indicates that these ownership effects are significant in explaining turnover intentions. ${ }^{14}$

TABLE 2

SUMMARY STATISTICS OF TURNOVER INTENTION

\begin{tabular}{|c|c|c|c|}
\hline & $\begin{array}{c}\text { Privatised TVEs } \\
\text { Shareholders } \\
\text { (1) }\end{array}$ & $\begin{array}{c}\text { Non-shareholders } \\
\text { (2) }\end{array}$ & $\begin{array}{c}\text { Non-privatised TVEs } \\
\text { (3) }\end{array}$ \\
\hline \multicolumn{4}{|c|}{$\begin{array}{l}\text { How likely is it that you will actively look for a new job in the next year? } \\
1=\text { not likely } 2=\text { likely } 3=\text { very likely }\end{array}$} \\
\hline & $\begin{array}{l}1.25 \\
(0.48)\end{array}$ & $\begin{array}{l}1.35 \\
(0.52)\end{array}$ & $\begin{array}{l}1.16 \\
(0.36)\end{array}$ \\
\hline \multicolumn{4}{|c|}{$\mathrm{t}$-test for difference in mean score between groups: } \\
\hline & $(1)-(2)$ & $(1)-(3)$ & $(2)-(3)$ \\
\hline & $-2.59^{*}$ & $2.40^{* *}$ & $5.19^{*}$ \\
\hline Observations: & 291 & 590 & 151 \\
\hline
\end{tabular}

Note: The table presents the mean scores of a worker's response with standard deviations reported in parentheses. ${ }^{*}, * * * *$ indicate significance at 1,5 and 10 per cent, respectively.

The newly privatised enterprises have therefore already showed significant signs of adapting the TVE labour system to reflect the new reality of private ownership. Changing to private ownership, in China as elsewhere, has led to predictable changes for labour with lay-offs, increasing work intensity but higher wages, new forms of labour discipline and differences between shareholders and non-shareholders all in evidence. The character of the labour system in the newly privatised TVEs also illustrates the continued importance of institutions. For example, the manner in which TVEs were privatised - with managers holding the dominant proportion shares and 
workers excluded - was possible because of the unorganised nature of the rural industrial labour force and the power of local cadres and managers.

Furthermore, continuing influence of the previous system can also be found. For example, in Jiangsu, many localities had encouraged large TVEs to set up trade unions in the enterprise to assist in the management of labour relations. With the prospect of increased conflict between managers and workers after privatisation, governments are keen to keep a lid on this through the work of the official union. In one newly privatised enterprise of 300 workers, we were told that there were 14 party members, a youth league and a women's employee representative committee. The continued importance of party members to managers was illustrated to us by the example that 'when products need to be produced in a very short period of time, party members would lead other workers to work overtime and not argue for more compensation'. Furthermore, the practice of wage arrears has carried over into the management of privatised TVEs. This is not simply a practice instituted to address enterprise losses but a policy to discipline labour. As we were informed in one enterprise, wage payments were delayed by three months and if any labour discipline problems arose in this period, then a portion of the wage arrears could be deducted. Important elements of the previous system therefore remain and are critical to understanding how 'private' firms operate in China.

\section{CONCLUSION}

In this contribution we have analysed two of the most important factors shaping the changing world of industrial workers in China, namely, globalisation and privatisation. We have analysed the interactions of both of these factors with China's industrial labour systems and explored the nature of these interactions. We have argued that both globalisation and privatisation have had significant effects on the ways in which labour is allocated, organised and rewarded. In many ways, these effects are predictable and bring China in line with practices frequently found in other developing and transitional economies; significant elements of convergence can be seen as Chinese industrial workers face the same harsh realities as their counterparts in many other countries. And yet, at the same time, we have also argued that the forces of globalisation and the policy of privatisation cannot be viewed deterministically but must be analysed within the specific context that they take place.

The embeddedness of enterprises in local political structures, the state socialist legacy of labour-management relations, the absence of independent 
trade unions, the household registration system, and the power of local cadres and managers, have all influenced the ways in which globalisation and privatisation affected Chinese industrial workers. There is no doubt that China's long transition to capitalism is having clearly recognisable and generalisable effects on the industrial labour system; but it is equally clear that an analysis of Chinese institutions and institutional path dependence is also necessary to an understanding of the process. In one of his last works, Gordon White [1998] argued that 'democracy' was capable of displaying considerable variation around the world and its analysis required taking account of specific institutional contexts and sets of interests; in this analysis, we have argued the same applies to 'capitalism'. In this respect, Gordon's work remains of enduring relevance for it was precisely his ability to effectively tease out the local from the global, the specific from the universal, that made him such a respected social scientist.

\section{NOTES}

1. The concept of a labour system is explained in more detail in Bowles and White [1998].

2. For discussion of 'national systems' in an era of globalisation see, for example, Boyer [1996], and Radice [2000].

3. The discussion in this section has drawn upon Bowles and White [1998]. The continued empirical relevance of the distinctions made between the recruitment and hiring practices of workers in the labour sub-systems is confirmed in Dong and Bowles [2002].

4. Pressures which come from the global financial system and from the inter-state system (such as the WTO) lie beyond the scope of this analysis.

5. For a more comprehensive analysis which also discusses employment, wage and income inequality trends see Bowles and Dong [1999].

6. For details of women's employment in export processing zones see, for example, AMRC, [1998].

7. In some firms, the union representatives are managers of management appointees. This has led to protests. See 'Workers Protest "Imposed" Union Leaders', Agence France-Presse, 28 Oct. 1998, in FBIS-CHI-98-295.

8. See also Zhao and Nichols [1998] for details of labour practices in the SOE sector.

9. See also Corrina-Francis [1996] who argues that joint ventures and firms operating in high-tech zones reproduce the institutional framework of 'old style' SOEs.

10. See Nolan, this volume.

11. This section reports on some of the findings by a project team consisting of the authors and Samuel P.S. Ho and Fiona MacPhail. We are grateful to them for use of the material here. The project was part of UBC's Centre for Chinese Research's programme on 'Rural Change in the People's Republic of China' and was carried out with the aid of a grant from the IDRC, Ottawa, Canada.

12. For discussion of the process of privatisation, see Ho et al. [2003].

13. These results are discussed further in Ho et al. [2002].

14. See Dong et al. [2002] for details of multivariate analysis. 


\section{REFERENCES}

All China Federation of Trade Unions (ACFTU), 1995-96, Zhonggou Gonghui Tongji Nianjin (Chinese Trade Unions Statistical Yearbook), Beijing: Zhonggou Tongji Chubanshe.

Asia Monitor Resource Centre, 1998, We In the Zone, Hong Kong: AMRC.

Bowles, P. and G. White, 1993, The Political Economy of China's Financial Reforms: Finance in Late Development, Boulder, CO: Westview Press.

Bowles, P. and G. White, 1998, 'Labour Systems in Transitional Economies: An Analysis of China's Township and Village Enterprises', International Review of Comparative Public Policy, Vol.10, pp.243-70.

Bowles, P. and X-Y. Dong, 1999, 'Globalisation, "Chinese Walls" and Industrial Labour', IDS Bulletin, Vol.30, No.4, Oct., pp.94-105.

Boyer, R., 1996, 'State and Market: A New Engagement for the Twenty-first Century?' in R. Boyer and D. Drache (eds.), States Against Markets: The Limits of Globalisation, London: Routledge.

Chan, A., 1997, 'Chinese Danwei Reforms: Convergence with the Japanese Model?', in X. Lu and E. Perry (eds), Danwei: The Changing Chinese Workplace in Historical and Comparative Perspective, Armonk: M.E. Sharpe, pp.91-113.

Chan, A., 1998a, 'Globalisation, China's "Free" (Read Bonded) Labour Market, and the Chinese Trade Unions', Asia Pacific Business Review, Vol.6, No.3, pp.260-81.

Chan, A., 1998b, 'Labour Relations in Foreign-funded Ventures, Chinese Trade Unions and the Prospects for Collective Bargaining', in O'Leary [1998: 122-49].

Corinna-Francis, B., 1996, 'A Reproduction of Danwei Institutional Features in the Context of China's Market Economy: The Case of Haidian District's High-Tech Sector', The China Quarterly, Vol.147, pp.839-59.

Deyo, F., 1996, 'Competition, Flexibility and Industrial Ascent: The Thai Auto Industry', in F. Deyo (ed.), Social Reconstructions of the World Automobile Industry, Macmillan, pp.136-56.

Deyo, F. (ed.), 1996, Social Reconstructions of the World Automobile Industry, London: Macmillan.

Dong, X-Y. and P. Bowles, 2002, 'Segmentation and Discrimination in China's Emerging Urban Labour Market: Some Survey Evidence', Chinese Economic Review, Vol.13, No.2-3, pp.170-96.

Dong, X-Y., Bowles, P. and S. Ho, 2002, 'Share Ownership and Employee Attitudes: Some Evidence from China's Post-Privatization Rural Industry', forthcoming in Journal of Comparative Economics, Vol.30, Dec.

EAEP, 1999, 'Recent Trends and Prospects for Major Asian Economies', East Asian Economic Perspectives, Vol.10, Feb. (Special Issue).

Earle, J. and K. Sabirianova, 1999, 'Understanding Wage Arrears in Russia', Stockholm Institute of Transitional Economies, Working Paper No.139, Jan. (Note that this is a preliminary paper.)

Gereffi, G., 1995, 'Global Commodity Chains and Third World Development', paper No.3 prepared for the International Institute for Labour Studies Forum on 'Labour in a Changing World Economy', Bangkok, 23-26 Jan.

Goodall, K. and M. Warner, 1997, 'Human Resources in Sino-Foreign Joint Ventures: Selected Case Studies in Shanghai, Compared with Beijing', International Journal of Human Resource Management, Vol.8, No.5, pp.569-94.

Ho., S., Bowles, P. and X-Y. Dong, 2003, 'Letting Go of the Small: An Analysis of The Privatisation of Rural Enterprises in Jiangsu and Shandong', forthcoming in The Journal of Development Studies, Vol.39, No.4, April.

Ho, S., Dong, X-Y., Bowles, P. and F. MacPhail, 2001b, 'Privatisation and Enterprise Wage Structures During Transition: Evidence from Rural Industry in Jiangsu and Shandong', forthcoming in Economics of Transition, Vol.10, No.3, Nov.

Nolan. P. and W. Xiaoqiang, 1999, 'Beyond Privatisation: Institutional Innovation and Growth in China's Large State-Owned Enterprises', World Development, Vol.27, No.1, Jan., pp.169-200. 
O'Leary, G. (ed.), 1998, Adjusting to Capitalism: Chinese Workers and the State, Armonk, NY: M.E. Sharpe.

Radice, H., 2000, 'Globalisation and National Capitalisms: Theorizing Convergence and Differentiation', Review of International Political Economy, Vol.7, No.4, pp.719-42.

Rodgers, R., 1996, 'Industrial Relations in the Korean Auto Industry: The Implications of Industrial Sector Requirements and Societal Effects for International Competitiveness', in Deyo (ed.) [1996: 87-135].

White, G., 1998, 'Building a Democratic Developmental State: Social Democracy in the Developing World', Democratization, Vol.5, No.3, pp.1-32.

World Bank, 1997, China Engaged, Washington, DC: The World Bank.

Xu, C., 1995, A Different Transition Path: Ownership, Performance and Influence of Chinese Rural Industrial Enterprises, New York: Garland Publishing.

Zhang, F. and J. Zheng, 1998, 'The Impact of Multinational Enterprises on Economic Structure and Efficiency in China', mimeograph.

Zhao, Minghua and Theo Nichols, 1998, 'Management Control of Labour in State-Owned Enterprises: Cases from the Textile Industry', in O'Leary [1998: 75-100]. 


\section{Bibliography of Gordon White's Works}

BOOKS

Blecher, Marc J. and Gordon White, 1979, Micropolitics in Contemporary China: A Technical Unit During and After the Cultural Revolution, White Plains, NY: M.E. Sharpe; and International Journal of Politics, Vol.IX, No.2 (Summer 1979).

Bowles, Paul and Gordon White, 1993, The Political Economy of China's Financial Reforms: Finance in Late Development, Boulder, CO: Westview Press.

White, Gordon, Howell, Jude and Shang Xiaoyuan, 1996, In Search of Civil Society: Market Reform and Social Change in Contemporary China, Oxford: Clarendon Press; New York: Oxford University Press.

White, Gordon, 1993, Riding the Tiger: The Politics of Economic Reform in Post-Mao China. Stanford, CA: Stanford University Press; London: Macmillan.

White, Gordon, 1981, Party and Professionals: The Political Role of Teachers in Contemporary China, Armonk, NY: M.E. Sharpe.

\section{ARTICLES AND PUBLISHED PAPERS}

White, Gordon and Sarah Cook, 2001, 'Alternative Approaches to Welfare Policy Analysis: New Institutional Economics, Politics, and Political Economy', in Germano Mwabu, Cecilia Ugaz and Gordon White (eds.), Social Provision in Low Income Countries, New Patterns and Emerging Trends, New York: Oxford University Press.

White, Gordon, Mwabu, Germano, Hjerppe, Reino and Cecilia Ugaz, 2001, 'Introduction: Context and Scope', in Germano Mwabu, Cecilia Ugaz and Gordon White (eds.), Social Provision in Low Income Countries: 
New Patterns and Emerging Trends, Oxford: Oxford University Press for UNU/Wider Studies in Development Economics.

White, Gordon and Mark Robinson, 2001, 'The Role of Civil Organisations in the Provision of Social Services: Towards Synergy', in Germano Mwabu, Cecilia Ugaz and Gordon White (eds.), Social Provision in Low Income Countries, New Patterns and Emerging Trends, New York: Oxford University Press.

White, Gordon and Sarah Cook, 1998, 'Changing Patterns of Poverty in China: Issues for Research and Policy', IDS Working Papers 67, Brighton: Institute of Development Studies.

White, Gordon, 1996, 'The Chinese Development Model: A Virtuous Paradigm?' Oxford Development Studies, Vol.24, No.2, June.

White, Gordon, 1996, 'Chinese Trade Unions in the Transition from Socialism: Towards Corporatism or Civil Society?' British Journal of Industrial Relations, Vol.34, No.3, Sept.

White, Gordon, 1996, 'Corruption and Market Reform in China, IDS Bulletin, Vol.27, No.2, April.

White, Gordon, 1996, 'Corruption and the Transition from Socialism in China', Journal of Law and Society, Vol.23, No.1, March.

White, Gordon, 1996, "Entrepreneurs" and Business Associations in Contemporary China', Asia Pacific Business Review, Vol.2, No.2, Winter.

White, Gordon, 1996, 'Liberalisation and the New Corruption', IDS Bulletin, Vol.26, No.2, April.

White, Gordon and Paul Bowles, 1996, 'The Political Economy of Late Development in East Asia: China's Financial Reforms in Comparative Perspective', in Barrett L. McCormick and Jonathan Unger (eds.), China After Socialism: In the Footsteps of Eastern Europe or East Asia? New York: M.E. Sharpe.

White, Gordon, 1996, 'Public Sector Pay Bargaining: Comparability, Decentralization and Control', Public Administration, Vol.74, No.1, Sept.

White, Gordon and Bob Benewick, 1995, 'Central-Local Relations and Local Government Reform in China: Rural County-level Government', IDS China Research Report, Feb.

White, Gordon. 'Chinese Trade Unions in the Transition from Socialism: The Emergence of Civil Society or the Road to Corporatism?' IDS Working Paper 18, Brighton: Institute of Development Studies, May.

White, Gordon, 1995, 'Civil Society, Democratization and Development (II):

Two Country Cases', Democratization, Vol.2, No.2, Summer.

White, Gordon, 1995, 1999, 'The Decline of Ideocracy', in Robert Benewick 
and Paul Wingrove (eds.), China in the 1990s, Basingstoke and London: Macmillan; Vancouver: University of British Columbia Press.

White, Gordon, 1995, 'Development and Democratization in Adrian

Leftwich (ed.), China', in Democracy and Develoment: Theory and Practice, Cambridge: Polity Press.

White, Gordon, 1994, 'Chinese Socialism and the Transition to Capitalism', in Antonio Callari et al. (eds.), Marxism in the Postmodern Age: Confronting the New World Order, New York: Guilford Press.

White, Gordon, 1994, 'Civil Society, Democratization and Development (I): Clearing the Analytical Ground', Democratization, Vol.1, No.3.

White, Gordon and Yin Qiping, 1994, 'The "Marketisation" of Chinese Higher Education: A Critical Assessment', Comparative Education, Vol.30, No.3.

White, Gordon and Jude Howell., 1994, 'Market Reform and Civil Society: A Chinese Case Study', UNRISD Discussion Paper 51, Geneva, April. White, Gordon, 1994, 'Market Reforms and the Emergence of Civil Society in Post-Mao China', Brighton: Institute of Development Studies, Sept.

White, Gordon and Paul Bowles, 1994, 'The Political Economy of Financial Reform in China', The Journal of Communist Studies and Transition Politics, Vol.10, No.1, March.

White, Gordon, 1994, 'Prospects for Civil Society in China: A Case-Study of Xiaoshan City', in David S.G. Goodman and Beverley Hooper (eds.), China's Quiet Revolution: New Interactions Between State and Society, Melbourne: Longman Cheshire.

White, Gordon, 1993, 'Chinese Socialism and its Transition', Chinese Social Sciences Quarterly, Autumn.

White, Gordon and Robert Benewick, 1993, 'Economic Reform and Central-Local Relations in Chinese Government: The Provincial Level, Report on a Field Trip, March-April 1992', Brighton: Institute of Development Studies.

White, Gordon, 1993, 'Industrial Planning and Administration in Contemporary China, Transcript of a Research Trip June-July 1983', Brighton: Institute of Development Studies.

White, Gordon, 1993, 'The Political Analysis of Markets', IDS Bulletin, Vol.24, No.3, July.

White, Gordon, 1993, 'Prospects for Civil Society in China: A Case-study of Xiaoshan City', The Australian Journal of Chinese Affairs, 29, Jan.

White, Gordon, 1993, 'Towards a Political Analysis of Markets', IDS Bulletin, Vol.24, No.3, July.

White, Gordon and Robert Benewick, 1993, 'Urban Government Reform in China: The Case of Wuhan, Report on Field Trip: March 16 to April 11, 
1993', Brighton: Institute of Development Studies.

White, Gordon and Bob Benewick, 1992/1993, 'Breeding Dragons in China', China Now, 143, Winter.

White, Gordon, 1992, 'Changing Patterns of Public Action in Socialist Development: The Chinese Decollectivization', in Marc Wuyts, Maureen Mackintosh and Tom Hewitt (eds.), Development Policy and Public Action, Oxford: Oxford Universtiy Press for an Open University Course Team.

Gordon White and Paul Bowles, 1992, 'The Dilemmas of Market Socialism: Capital Market Reform in China - Part I, Bonds', The Journal of Development Studies, Vol.28, No.3, April.

White, Gordon, 1992, 'The Dilemmas of Market Socialism: Capital Market Reform in China - Part II, Shares', The Journal of Development Studies, Vol.28, No.4, July.

White, Gordon, de Kadt, E. and Z. Mars, 1992, 'State and Development in the 1990s: The Issues for Researchers', in Claude Auroi (ed.), The Role of the State in Develoment Processes, London: Frank Cass for European Association of Development Research and Training Institutes (EADI Book Series 15).

White, Gordon, 1991, 'Basic Level Local Government and Economic Reform in Urban China', in G. White (ed.), The Chinese State in the Era of Economic Reform: The Road to Crisis, Armonk, NY: M.E. Sharpe.

White, Gordon, 1991, 'Democracy and Economic Reform in China', in S. Gomulka and Cyril Lin (eds.), Limits to Reform and Transition in SovietType Systems, IDS Discussion Paper 286. Brighton: Institute of Development Studies.

White, Gordon, 1991, 'Urban Government and Market Reforms in China', in Public Administration and Development, Vol.11, No.2.

White, Gordon. 'Chinese Economic Reform and the Rise of Civil Society,' UNRISD, Geneva, 1990.

White, Gordon, 1991, 'The Road to Crisis', in G. White (ed.), The Chinese State in the Era of Economic Reform: The Road to Crisis, Armonk, NY: M.E. Sharpe.

White, Gordon and Paul Bowles, 1989, 'Contradictions in China's Financial Reforms: The Relationships Between Banks and Enterprises', Cambridge Journal of Economics, Vol.13, No.4.

White, Gordon. 'Crisis, Reform and Participation in Socialist Contexts,' UNRISD, Geneva, Oct. 1989.

White, Gordon, 1988, 'Administrative Reforms in Post-Mao China', IDS Bulletin, Vol.19, No.4, Oct.

White, Gordon and Paul Bowles, 1988, 'China's Banking Reforms: Aims, 
Methods and Problems', National Westminster Bank Quarterly Review, Nov.

White, Gordon and Robert Wade, 1988, 'Developmental States and Markets in East Asia: An Introduction', in G. White (ed.), Developmental States in East Asia, New York: St Martin's Press.

White, Gordon, 1988, 'Evolving Relations Between State and Markets in the Reform of China's Urban-Industrial Economy', in Stephen Feuchtwang, Athar Hussain and Thierry Pairault (eds.), Transforming China's Economy in the Eighties - Volume II: Management, Industry and the Urban Economy, Boulder, CO: Westview Press.

White, Gordon, 1988, 'The New Economic Paradigm: Towards Market Socialism?', in R. Benewick and P. Wingrove (eds.), China in Transition: Reforming the Revolution, New York: Macmillan; Chicago, IL: The Dorsey Press.

White, Gordon, 1988, 'State and Market in China's Labour Reforms', Journal of Development Studies, Vol.24, No.4, July.

White, Gordon, 1988, 'The State and Socialist Industrialization in the Third World: The Chinese Case', in Economic Papers 1987, Warsaw: Research Institute for Developing Countries, Central School of Planning and Statistics.

White, Gordon, 1987, 'The Changing Role of the Chinese State in Labour Allocation: Towards the Market?' Journal of Communist Studies, Vol.3, No.2, June.

White, Gordon, 1987, 'Cuban Planning in the Mid-1980's: Centralization, Decentralization, and Participation', World Development, Vol.15, No.1 (also in Andrew Zimbalist (ed.), Cuba's Socialist Economy Toward the 1990s, Boulder, CO: Lynne Rienner).

White, Gordon, 1987, 'The Impact of Economic Reforms in the Chinese Countryside: Towards the Politics of Social Capitalism?' Modern China, Vol.13, No.4, Oct.

White, Gordon, 1987, 'Labour Market Reform in Chinese Industry', in Malcolm Warner (ed.), Management Reforms in China, New York: Frances Pinter.

White, Gordon, 1987, 'The Leninist State Under Threat? The Politics of Economic Reform in China', IDS Bulletin, Vol.18, No.4, Oct.

White, Gordon, 1987, 'Political Aspects of Rural Economic Reform in China', IDS Bulletin, Vol.18, No.3, July.

White, Gordon, 1987, 'The Politics of Economic Reform in Chinese Industry: The Introduction of the Labour Contract System', China Quarterly, No.111, Sept.

White, Gordon, 1987, 'Riding the Tiger: Grassroots Rural Politics in the 
Wake of the Chinese Economic Reforms', in Ashwani Saith (ed.), The Re-emergence of the Chinese Peasantry, London: Croom Helm.

White, Gordon, 1987, 'The Third Great Revolution: The Experience of Revolutionary Socialism in China', in R. Bush, G. Johnston and D. Coates (eds.), The World Order: Socialist Perspectives, Cambridge: Polity Press.

White, Gordon, 1986, 'Labour Allocation and Employment Policy in Contemporary China: Transcript of A Research Trip', Brighton: IDS China Research Report No.2.

White, Gordon and Bob Benewick, 1986, 'Local Government and BasicLevel Democracy in China: Towards Reform?' Brighton: IDS China Research Report No.3.

White, Gordon, 1985, 'Cuban Planning in the Mid-1980s: Centralization, Decentralization and Participation', IDS Discussion Paper 209, Dec.

White, Gordon, 1985, 'Developmental States and African Agriculture: An Editorial Preface', IDS Bulletin, Vol.17, No.1, Jan.

White, Gordon and Kate Young, 1985, 'Nicaragua After the Revolution: Problems and Prospects', IDS Discussion Paper 200, Dec.

White, Gordon, 1985, 'The Role of the State in China's Socialist Industrialization', in Gordon White and Robert Wade (eds.), Developmental States in East Asia: A Research Report to the Gatsby Charitable Foundation (IDS Report No.16), Brighton: IDS Publications. White, Gordon, 1984, 'Changing Relations Between State and Enterprise in Contemporary China: Expanding Enterprise Autonomy', in N. Maxwell and B. McFarlane (eds.), China's Changed Road to Development, Oxford: Pergamon Press.

White, Gordon and Robert Wade, 1984, 'Developmental States in East Asia: Editorial Introduction' and 'State and Market in Socialist Development: The Case of Chinese Industrial Planning', IDS Bulletin, Vol.15, No.2, April.

White, Gordon, 1984, 'Developmental States and Socialist Industrialization in the Third World', The Journal of Development Studies, Vol.21, No.1 (Special Issue) (also in R. Kaplinsky (ed.), Third World Industrialization in the 1980s, London: Frank Cass).

White, Gordon, 1984, 'Distributive Politics and Educational Development: Teachers as a Political Interest Group', in D.S.G. Goodman (ed.), Groups and Politics in the People's Republic of China, Cardiff: University College Cardiff Press.

White, Gordon, 1984, 'Entwicklungsstaaten und sozialistische Entwicklung in der Dritten Welt', Östtereichische Zeitschrift für Soziologie 9, Jg. 4. 
White, Gordon, 1984, 'Mao Zedong yihou Zhongguode chengzhen zhije zhengce ji laodong fenpei zhengce' (China's Urban Employment and Labor Allocation Polices After Mao Zedong), Papers of the Chinese Academy of Social Sciences, Beijing.

White, Gordon and Peter Nolan, 1984, 'Urban Bias, Rural Bias or State Bias? Urban-Rural Relations in Post-Revolutionary China', The Journal of Development Studies, Vol.20, No.3, April.

White, Gordon, 1983, 'Chinese Development Strategy After Mao', in Gordon White, Robin Murray and Christine White (eds.), Revolutionary Socialist Development in the Third World, Brighton: Harvester Press; Lexington, KY: University Press of Kentucky.

White, Gordon and Peter Nolan., 1983, 'Economic Distribution and Rural Development in China: The Legacy of the Maoist Era', in Frances Stewart (ed.), Work, Income and Inequality: Payment Systems in the Third World, London: Macmillan.

White, Gordon, 1983, 'The Post-Revolutionary Chinese State', in Victor Nee and David Mozingo (eds.), State and Society in Contemporary China, New York: Cornell University Press.

White, Gordon, 1983, 'Socialist Planning and Industrial Management: Chinese Economic Reforms in the Post-Mao Era', Development and Change, Vol.14.

White, Gordon, 1983, 'Revolutionary Socialist Development in the Third World: An Overview,' in Gordon White, Robin Murray and Christine White (eds.), Revolutionary Socialist Development in the Third World, Brighton: Wheatsheaf Books; Lexington, KY: University Press of Kentucky.

White, Gordon and Peter Nolan, 1982, 'The Distributive Implications of China's New Agricultural Policies', in Jack Gray and Gordon White (eds.), China's New Development Strategy, London and New York: Academic Press.

White, Gordon, 1982, 'Introduction: The New Course in Chinese Development Strategy: Context, Problems and Prospects', in Jack Gray and Gordon White (eds.), China's New Development Strategy, London and New York: Academic Press.

White, Gordon, 1982, 'North Korean Juche: The Political Economy of SelfReliance', in Manfred Bienefeld and Martin Godfrey (eds.), The Struggle for Development, Chicester: John Wiley.

White, Gordon, 1982, 'Urban Employment and Labour Allocation Policies', in Stephen Feuchtwang and Athar Hussain (eds.), The Chinese Economic Reforms, London: Croom Helm. 
White, Gordon, 1982, 'Urban Employment and Labour Allocation Policies in Post-Mao China', World Development, Vol.10, No.8.

White, Gordon, 1982, 'Why Did China Fail to Follow the Japanese Road?' in Manfred Bienefeld and Martin Godfrey (eds.), The Struggle for Development, Chicester: John Wiley.

White, Gordon and Peter Nolan, 1979, 'Socialist Development and Rural Inequality: The Chinese Countryside in the 1970's', The Journal of Peasant Studies, Vol.7, No.1, Oct.

White, Gordon, 1978, 'Politics and Social Status in China', Pacific Affairs, Vol.51, No.4, Winter.

White, Gordon, 1976, The Politics of Class and Class Origin: The Case of the Cultural Revolution (Contemporary China Paper), Australian National University.

White, Gordon, 1975, 'The Democratic People's Republic of Korea Through the Eyes of a Visiting Sinologist', China Quarterly, Sept.

White, Gordon, 1974, 'The Politics of Hsia-Hsiang Youth', China Quarterly, Vol.59, July-Sept.

White, Gordon and Christine White, 1972, 'The Politics of Vietnamization', Bulletin of Concerned Asian Scholars, Vol.4, No.2, Summer.

\section{EDITED WORKS}

White, Gordon, Mwabu, Germano and Cecilia Ugaz (eds.), Social Provision in Low Income Countries: New Patterns and Emerging Trends, Oxford: Oxford University Press for UNU/Wider Studies in Development Economics.

White, Gordon, Goodman, Roger and Huck-ju Kwon (eds.), 1998, The East Asian Welfare Model: Welfare Orientalism and the State, London and New York: Routledge.

White, Gordon and Barbara Harriss-White (eds.), 1996, 'Corruption, Liberalization and Democracy', IDS Bulletin, Vol.27, No.2, April.

White, Gordon and Robin Luckham (eds.), 1996, Democratization in the South: The Jagged Wave. Manchester: Manchester University Press; New York: St Martin's Press.

White, Gordon (ed.), 1991, The Chinese State in the Era of Economic Reform: The Road to Crisis, Armonk, NY: M.E. Sharpe; London: Macmillan.

White, Gordon (ed.), 1988, Developmental States in East Asia, New York: St Martin's Press. 
White, Gordon and Kate Young (eds.), 1988, 'Nicaragua: Development Under Fire', IDS Bulletin, Vol.19, No.3, July.

White, Gordon and John Dearlove (eds.), 1987, 'Retreat of the State?', IDS Bulletin, Vol.18, No.3, July.

White, Gordon and Theo Mars (eds.), 1986, Developmental States and African Agriculture, Brighton: IDS Publications.

White, Gordon and Robert Wade (eds.), 1985, Developmental States in East Asia: A Research Report to the Gatsby Charitable Foundation (IDS Research Reports 16), Brighton: IDS Publications.

White, Gordon and Elisabeth Croll (eds.), 1985, 'Special Issue on Agriculture and Socialist Development', World Development, Vol.13, No.1, Jan.

White, Gordon (ed.), 1984, 'Developmental States in East Asia: Capitalist and Socialist', IDS Bulletin, Vol.15, No.2, April.

White, Gordon, Murray, Robin and Christine White (eds.), 1983, Revolutionary Socialist Development in the Third World, Brighton, England: Wheatsheaf Books; Lexington, KY: University Press of Kentucky.

White, Gordon and Christine Pelzer White (eds.), c.1982, Agriculture, the Peasantry and Socialist Development, Brighton: IDS Publications.

White, Gordon and Jack Gray (eds.), 1982, China's New Development Strategy, London: New York: Academic Press.

White, Gordon (ed.), 1979, 'Teachers and Politics in Contemporary China', Chinese Education, Vol.7, No.4, Sept.

White, Gordon and J. Craiger (eds.), 1974, Teaching About China in the Secondary School, Australia: Australian Capital Territory Schools Authority, Sept.

ON A LIGHTER NOTE

Gordon, White, n.d., IDS in the Eighties: Collected Pantomime Scripts, Brighton: Institute of Development Studies. 


\section{Notes on Contributors}

Elisabetta Basile is Professor of Rural Development at the Faculty of Economics, University of Roma La Sapienza (Italy). She has published extensively on the role of the rural economy in development, both in Italy and in developing countries. She is currently working on economic and social change in rural India after the green revolution.

Robert Benewick is Research Professor at the University of Sussex and co-author with Stephanie Donald of The State of China Atlas. He is currently working with Akio Takahara on a research project on urban grassroots political reform in China.

Marc Blecher is Professor of Politics and East Asian Studies at Oberlin College, Oberlin, Ohio, USA. He collaborated with Gordon White on Micropolitics in Contemporary China (White Plains, NY: M.E. Sharpe, 1979), and worked closely with him over the subsequent years, particularly as a Visiting Fellow at the Institute of Development Studies in 1982-83. He is also the author of China: Politics, Economics and Society - Iconoclasm and Innovation in a Revolutionary Socialist Country (London: Frances Pinter Publishers, 1986), Tethered Deer: Government and Economy in a Chinese County (Stanford, CA: Stanford University Press, 1996, with Vivienne Shue), and China Against the Tides: Restructuring Through Revolution, Radicalism, and Reform (London: Pinter/Cassell, 1997), which has been translated into Chinese and Korean. He is currently at work on a book tentatively entitled A World to Lose: Workers' Politics and the Chinese State.

Paul Bowles is Professor of Economics at the University of Northern British Columbia. $\mathrm{He}$ is the coauthor, with Gordon White, of The Political Economy of China's Financial Reforms: Finance in Late Development (Boulder, CO: Westview Press, 1993). He is currently researching various aspects of 'globalisation'.

Sarah Cook is a Fellow at the Institute of Development Studies, working on issues of employment, poverty and welfare in China, and is presently working at the Ford Foundation in Beijing. She is currently doing research on China's rural social welfare system in a project initiated jointly with Gordon White, and on poverty and social security in the context of China's state-owned enterprise restructuring. She is editor of The Workers' State Meets the Market: Labour in China's Transition (London and Portland, OR: Frank Cass Publishers, 1999) and co-editor (with Shujie Yao and 
Juzhong Zhuang) of China's Economy Under Transition (New York: St Martin's, 2000).

Stephanie Hemelryk Donald is Senior Lecturer in Media and Communications at the University of Melbourne. Books include: Media in China: Consumption, Content and Crisis (2002), The Global Media Atlas (2001), Public Secrets, Public Spaces: Cinema and Civility in China (2000), The State of China Atlas (1999) and Picturing Power in the People's Republic of China (1999). She is currently working on a history of film culture for children in the PRC and on Nations Online, a collaborative project with other scholars in the Asia pacific region.

Xiao-Yuan Dong is Associate Professor of Economics at the University of Winnipeg. Her recent research has included analyses of China's agricultural and industrial reforms.

Anne Marie Goetz is a Fellow of the Institute of Development Studies, University of Sussex. She conducts research on accountability and poverty, and on gender in politics and policy-making in developing countries. Her published work includes Women Development Workers: Implementing Rural Credit Programmes in Bangladesh (Delhi: Sage, 2001), and Contesting Global Governance: Multilateral Economic Institutions and Global Social Movements (Cambridge: Cambridge University Press, 2000), and the edited volumes Getting Institutions Right for Women in Development (Zed, 1997), and No Shortcuts to Power: African Women in Politics and PolicyMaking (London: Zed, forthcoming).

Roger Goodman is University Lecturer in the Social Anthropology of Japan and a Fellow of St Antony's College, University of Oxford. He is author of Japan's 'International Youth': The Emergence of a New Class of Schoolchildren (Oxford: Oxford University Press, 1990) and Children of the Japanese State: The Changing Role of Child Protection Institutions in Contemporary Japan (Oxford: Oxford University Press, 2000), editor of Family and Social Policy in Japan: Anthropological Approaches (Cambridge: Cambridge University Press, 2002), and co-editor of: (with Kirsten Refsing) Ideology and Practice in Modern Japan (Routledge, 1992); (with Ian Neary) Case Studies on Human Rights in Japan (London: Curzon Press, 1996); and (with Gordon White and Huck-ju Kwon) The East Asian Welfare Model: Welfare Orientalism and the State (London: Routledge, 1998).

Barbara Harriss-White is Professor of Development Studies at Queen Elizabeth House, Oxford University and a fellow of Wolfson College. She has been studying the development of Arni town in South India through business histories every decade since 1972. Her most recent books are: Globalisation and Insecurity (2002), Outcaste from Social Welfare: Adult Disability and Incapacity in Rural India (2002), India Working: Essays on Economy and Society (2002) and Rural India Facing the 21st Century (2003). She worked collaboratively with Gordon White on three interconnected projects: the politics of markets, liberalisation and corruption, and civil society and economic regulation - the last forming the basis of the chapter in this volume.

Jude Howell is a Fellow at the Institute of Development Studies, University of Sussex. She has published widely on civil society, labour issues, gender relations, political reform, and institutional change in China. Her most recent book, co-authored with Jenny Pearce, is Civil Society and Development: A Critical Exploration (Boulder, CO: Lynne Rienner, 2001) and her next forthcoming book is Governance and China 
(Rowman \& Littlefield, 2003). Her other books include China Opens its Doors: The Politics of Economic Transition (Boulder, CO: Lynne Rienner, 1993) and In Search of Civil Society. Market Reform and Social Change in Contemporary China (Oxford: Oxford University Press, co-authored with Gordon White and Shang Xiaoyuan, 1996).

Rob Jenkins is the author of Democratic Politics and Economic Reform in India (Cambridge: Cambridge University Press, 1999), Reassessing the Commonwealth (London: Royal Institute of International Affairs, 1997), and is the editor of Regional Reflections: Comparing Politics Across India's States (forthcoming). His research has been mainly in the politics of development, with a particular emphasis on India, where Jenkins has been conducting field research since 1986 on political economy, regional nationalism, electoral politics, and social movements. He is currently directing a three-year research project on 'Domestic Politics and the WTO: The Cases of India and South Africa', which is funded by the UK Department for International Development. Advisory work and commissioned studies have been undertaken for a number of European governments' aid ministries, as well as the United Nations Development Programme, the African Development Bank, the Ford Foundation, the United States Department of State, and the Economist Intelligence Unit.

Anuradha Joshi has worked on the politics and organisation of anti-poverty programmes as a part of the Institute of Development Studies Poverty Programme. Her research interests include institutional aspects of development, public sector management, natural resource policy, and poverty in developing countries.

Raphael Kaplinsky is a Professorial Fellow at the Institute of Development Studies. A development economist specialising in industry, trade and globalisation, he has worked in Africa, Asia, the Caribbean and many industrialised economies. He is currently the manager of a large programme of research on globalisation at the IDS.

Huck-ju Kwon is Assistant Professor at Sung Kyun Kwan University, Seoul, Korea, and Research Coordinator at the United Nations Research Institute for Social Development, Geneva. He worked with Gordon White and Roger Goodman at the IDS in 1995-96, with whom he co-edited The East Asian Welfare Model: Welfare Orientalism and the State.

Mick Moore is Professorial Fellow at the Institute of Development Studies, Sussex, UK, and Director of the Centre for the Future State. He works on the political economy and institutional aspects of international development, and has a special interest in public policy, public institutions and poverty.

Mark Robinson is a Fellow at the Institute of Development Studies. He recently worked as a Programme Officer on Governance and Civil Society for the Ford Foundation in New Delhi.

Tony Saich is Daewoo Professor of International Affairs and Faculty Chair of Asia Programs at the John F. Kennedy School of Government, Harvard University. From 1994 to 1999 he was the Chief Representative for the Ford Foundation China. He is the author of The Governance and Politics of China (Basingstoke: Palgrave 2001). 
Xiaoyuan Shang is Associate Professor in the Institute of Social Development and Public Policy at Beijing Normal University. She has conducted a series of projects for international agencies relating to China's social security reform, focusing on issues associated with the alleviation of poverty and social services for vulnerable groups. Her previous work includes The Self-Restrained Chinese People: An Anatomy of the Psychology of the Chinese Urban People in the Market Economy (Kunming: Yunnan People's Press, 1989), In Search of Civil Society (with Gordon White and Jude Howell; Oxford University Press 1996), and articles in The Journal of Social Policy, Social Service Review, Social Policy and Administration, and The Chinese Journal of Social Science.

Akio Takahara is Professor of Chinese Politics at the Faculty of Law and Politics, Rikkyo University, Tokyo. He read for M.Phil. and D.Phil. at the IDS in the 1980s and studied politics in China's development under Gordon White's supervision. 


\section{Index}

\section{N.B. numbers in bold type indicate a table or figure.}

Abers, Rebecca 139-40

Anhui province, uniform tax 208

absolute standards of living (1987 and 1998) 257

accountability failures, anti-poor 'bias' variant 131; capture and bias 136, 146; deprivation for poor people 130; institutional 'capture' and $124,130,132,146$

accountability gap, identity politics and 141-4 accountability institutions, access to credit and 132; capture and 134, 146; corruption and 'capture' 130, 132; no remit for punishing officials 131

accountability mechanisms 131, 211

accumulation, social matrix 109-10

ACFTU 94-5, 100, 274-5, 279, 281

activism, moral hazard and 155

ACWF 86, 94-5, 100

administrative reform, problems of adjustment 35

Africa 25, 166-7

aid and development agencies, hypocrisy and $150-51$

All-China Federation of Trade Unions see ACFTU

All-China Women's Federation see ACWF

Althusserian terminology 10

Andhra Pradesh, tribal people and access to land records 143

anti-corruption campaigns, civil servants and 128; forest dwellers and 138-9; local-level auditing and 147; MKSS and 126; requirements for 136

anti-imperialism 16

anti-poverty programmes, definition 16, 151

Argentina 262, 263

Arni, capital-labour relations 117-18; capitalist class 121; caste associations 115-16; electoral politics, caste competition and caste blocs 120; gender in 118-19; Gramscian concept of civil society 120-21; locality of 119; location and businesses 113-14; Muslim businessmen in 116; politics of accumulation 115-17, 120; the State and 119-20; tax evasion 115, 117

ASEAN countries 57

Asia 25, 166

Asian financial crisis (1997) 6, 36, 230; CCP's role since 51; China's attitude to 58-60; reinforcement of party organisation 57-60; welfare systems after 235-6

Asian foreign-invested firms, labour rights and 278

auditing, Bangladesh Bank and 132; failure of 134; financial performance of government and 126; Kerala and public expenditure 145; participatory literature on 140-41; public expenditure at local level 136

Australia 263

Austria 232

Backward Castes (BCs), owners and 114

'backward' status, granted to privileged caste 142

Bank of Agriculture 58

Bank of China 58

Bank of Construction 58

Bank of Industry and Commerce 57

Barmé, J.R. 67, 70-71

Basile, E. 5, 109

Beijing 192, 280

Beijing Number 26 Middle School Red Guards 74

Beijing Review 80

Belgium 222

Benewick, Robert 5, 70, 78-9, 199

Bhalla, A.S. 258, 263

bias and capture go hand in hand 134 
black finance capital, non-productive accumulation and 114

Blair, Tony 230

Blecher, M. 69-70, 175, 196, 198-9

blue globalisation scenario, win-win globalisation 268, 270n5.

Bolivia, 'Law of Popular Participation' 141

Bowles, Paul 57, 281

Brazil 85, 141, 145, 153-4, 262, 263

Brenner, R. 260, 264

bribes $132-3,138$

buyer-driven commodity chains, definition 277-8

\section{Canada 263}

capability-enhancing services, education and health-care 130

capital intensification, 'the reserve army of labour' 261-2, 268

capital intensive firms, labour intensive firms 279

capitalism, China's long transition to 287 ; concept too simplistic 11; gendered nature of economic participation 85 ; market economy 54; variation in 287

capitalist accumulation, organisation of civil society and 110

capitalist economy, entrepreneurship and 173

'capitalist roaders', Little Red Book and 71

Capitalist systems, social institutions and 110

Caribbean (1980s) 156, 257

caste, associations for culture and religion 115; corporatism and 110-13; employment of various 114-15; key pillar of ideology in Arni 116; marriage alliances and top 116; occupational associations 117-18; politics of adapting to accumulation 5

$\mathrm{CCP}$, governance challenge in industrial sector 37; reformist leadership and transition 13 ; reforms in countryside and organisation of 79; role and organisational and personnel systems 50 ; socialist market economy by (2010) 50; SOEs and healthcare 45; strengthening of political and economic role 52

CCP and marketisation 5, 35, 50-51, 60; central-local relations and 61; first half of (1990s) 52; FWC and 57; progress after 1992 55-7; setback in late 1980s-early 1990s 52-4

Central Asia 258

Central Committee for Organisation and Staff (1993) 54

Central Enterprise Discipline and Inspection Committee 61

Central Financial Work Committee see FWC

Central Large Enterprise Work Committee 61 central leadership, vertical leadership system 62
Central Leading Small Group on Finance and Economics (1996) 57

Chan, A. 279-80

Chengdu, People's Vocational Introduction Centre in Qing Yang District, advertisements 89; Qing Yang district labour market 101; re-training retrenched women as community service workers 91

child guidance centres (jidôsôdanjo), volunteers (jidôiin-minseiiin) 218

Children of the Japanese State 215

Chile 259

China 4, 13, 258, 269; (1949), state with capacity over and autonomy from society 7; Asset Management Companies (AMCs) 40; bottom-up/top-down policy 183 ; bureaucratism 53-4; Centre's share of budgetary revenues 45 ; changing role of the state 46 ; civil society in $15,22,126$; colour red 68 ; Commercial Bank Law (July 1995) 56; Document 63, 88; East Asian developmental states and 17; economic reforms and welfare system 177-81; education and skill 265, 266; entrepreneurial rent-seeking of local government 174; FDI 276-8; fiscal capacity, not enough 43-6; FWC and marketisation 57-9, 62; global conglomerates 280-81; globalisation $6,256,257,264,273,276-82$, 286; governance of SOEs and 40; Great Leap Forward (1958-61) 85; health system in distress in rural areas 43, 46; household registration system 279,287 ; import-substitution 14; industrial competence 264 ; labour sub-systems 274; Leninist party-state 79; localities and privatisation 38 ; mainstream of comparative social science 18 ; mixed economy 33-4, 180; pension reform and 35 ; 'picking winners' and 37 ; politically engaged society 7-14; population and labour force 263, 265; poverty 259, 270n; pressures created by market reforms $176-7$; price reforms frozen (1988) 54; privatisation 273-5, 282-6; relationship between state and society businesslike and normal 7, 18n; rise of urban 'community services' 181-9; rural healthcare delivery, too little 41-3; service sector and 34; state entrepreneurship 175-6; state expansion into new areas 34 ; tax reform (1994) 57, 211; teachers 7, 9, 11-12, 14-15; too much industrial policy $36-40$; unemployment 266-7; women in the labour force 83, 278; world markets (1980s) and 255; WTO and China 34, 37, 40, 80, see also CCP; CCP and marketisation; community services; Cultural Revolution; MOCA; SOEs; TVEs; wage arrears China Central Bank Law (February 1995) 56 
China News Analysis 73

China Pictorial 71

China Quarterly 3

China's financial system, specific problems 57

China's State Development and Planning

Commission 40

Chinese 'Brezhnevism' 12

Chinese Communist Party see CCP

Chinese Communist Party Central Documents Institute (1982) 51

civil affairs work in cities, community services and 188

civil service system, establishing 52-3; social relief and assistance 202

civil society $5,21-3,25$; accountability for less privileged citizens 123; accountable governance and 125; associations and democratising role 26,109 ; caste and corporatism 110-13; corrupted nature of 136; democratising potential of 26 ; discussion of advent in China 50; emergence and state action 13; limits of 128-9; organs of are 'compromised' 136, 146; shortcomings of 124 ; White's definition 22

'class', practical policy issues 8

class struggle, against feudalism and imperialism 79

co-optation, relationship with external agency 153

commercialisation, collective commitment and 183

commune, abolition (1983) 198

'community', definition 182

community services, (1980s) 182; administrative targets 185; bureaucratic red tape 186;

financial and institutional dilemma and 184; plans for future 188; threat of market economy 187

community services industry (shequfuwuye)

187; political/ideological problem 188-9; privileged sector (1990s) 190

comparative advantage 259-60, 268

compromised allies 136-9

compulsory education (yiwu jiaoyu), expenses of teachers 209-10

conservative welfare regimes 231-3

Construction Ministry, community service facilities and 187

consumption power, employment and 267-8

contemptuous treatment by service providers, the poor and 133

contentious politics, societal transformation and 150

continuity, EGS and 163

control rights, property rights and 36

Cook, Sarah 5, 198, 267

corporatism, bad reputation 153; definition 112 ,
117; Oi's use of term 200

corporatist arrangements, problems with 154 corporatist associations, independent from the state 112

corporatist rural workers unions (Brazil 1960s) 153-4

corruption 119, 123-5, 128; Bolivia and 141; capture and 130, 132; Chinese township government 210; elite bias in public-service design 133; fiscal reform to reduce 211 ; funding and delivery services 134; government agencies in Nepal 157; government credit programmes 132; India's inability to fight 146; local Chinese government 208; market gains and 129; obstacles to civil society activism 136; 'patrimonial' and 'clientelist' 174; state-fostered forms of civil society 141; trade unions in India and 137-8 cost-recovery $183-4$

credibility $155,157-9,162,167$

Cuba 16

cultural materiality of history, removing trauma from 75

Cultural Revolution 7, 65; campaign to 'cleanse' the past 79; cult of Mao Zedong and 66; dates political and arbitrary 78; defining characteristics? 78; depoliticisation and depth of 78; experience of workers over 40 95-6; laid-off workers and 'lack of skills' 97; Mao and revolutionary political culture 68; 'Newest Directives' 72; political compromise arising from 8; politics of class in 12, 14; Red Guards in 70-71; state workers as revolutionary heroes 89 ; welfare programmes as 'political strategy of accommodation with key groups' 15 ; women and $85,87,91,96$

Cultural Studies, revolutionary culture $67-8$ 'culture of snitching' 78

Dai, J. 75, 77

Dai, Xianglong (governor of People's Bank) 58

Daily China News 55

Dazhai Model production Brigade, study session 71

decentralisation 167, 198, 206

decollectivisation 202, 204-5

definition of class, lives and 8

democracy assistance, indirect interventions and 29

democratic developmental states, construction of 28

Democratic Progressive Party (Taiwan) see DPP

democratisation 26, 112

Deng Xiaoping 9, 15, 53-5, 60; visit to southeast (1992) 52, 183-4, 282 
Dengist period 9, 12-13; depoliticisation and depersonalisation of power 78; Draconian restrictions and 15; far reaching changes 79; market-orientated economy and 68

Denmark 222

departmental system (tiaotiao) 53

Departments of Civil Affairs 189

depoliticisation, politics of 75-80

developing countries, changing production methods and 281; China apart from 22; direct provision of services by government 43; form of primitive capitalism 279; globalisation and poverty 255,258 ; industrial skills to compete 264 ; labour displacement 262 ; labour relations systems 280 ; tax collection and 45; unequal income distribution 259; WHO levels of health spending 41 ; women workers 278

development, entrepreneurship and the local state, developmental and entrepreneurial local states 199-200; local corporate state 200-201; local economic development 197-9; redistributive local state 201-2

development outcomes, politics as key determinate 4

development zones, foreign capital and 55

developmental challenges, poor societies and 25

difference, $\mathrm{BCs}$ and 116

diminished human development, physical insecurity and 134

Director of the Central Commission for Discipline and Inspection 56-7

Disabled Persons Federation (China) 190

disabling institutional environments, problem of 165

discrimination in service provision, the poor and $133-4$

Donald, Stephanie 4, 69-70, 75

Donglan County, Guangxi Autonomous Region, healthcare 42

dôzoku keiei (same family management) 216 DPP 236

Earle, J. 281-2

East Asia, Confucian values 231; culture and welfare systems 6; demographic changes 236-7; globalisation and 256, 257; pressures to reform and efficiency 237; social welfare systems 14,231 ; societies 230 ; welfare systems 6, 249

East Asian Welfare Model, strengths and weaknesses 231-5, 247

East Asian welfare systems, downside of 235, 247; strong developmental propensities 234-5

Eastern Europe, collapse of one-party rule 50,
54; reforms (1980s) 176, 180, 197

economic development, role of the state in 14 economic liberalisation, social disruption and 23

economic resources, societies' negotiations with state 11-12

Editing Committee 59

EGS 160-66

Eighth Five-year plan (1991-95) 204

Electoral systems, interests of the poor and 131

Eleventh Central Committee (Sixth Plenum June 1981) 80

Eleventh Party Central Committee (1978) 51, 80

emic (inside), etic(outside) analysis of society 214

Employment Guarantee Fund 161

Employment Guarantee Scheme see EGS

'empowerment' 150-51

'Enabling Institutional Environments' 151, 155-6; contemporary development policy $165-8$

engendered labour markets, resisting 94-100 engendering the economy 84-7

England 222

enterprise management, instructions and 53 enterprise ownership, relationship between government and business 201-2

entrepreneurship, definitions 173, 195

Esping-Andersen, G., distinction between welfare regimes 221, 232-3; 'Pacific' model of social welfare 231-2

EU, imports from China $\mathbf{2 6 5}$

Europe 222, 258, 269, 278

European aid donors, Social Funds 166-7

Evans, P. 24, 139-41

'external agencies', collective empowerment of poor 151 ; incentives to collective action 155 ; relationship with poor and discord 159-60

'extra budgetary revenue' in China (yusuanwai zijin) 180, 198, 207

extra-budgetary funds (EBF) 44-5, 198

extra-statutory charges, five per cent limit on levies 208

'Fanta Company' 156-8

FDI 276-8

fee-for-service system, financial pressures and 41; preventive care facilities and 42

feel-good sloganeering 168

'fees' (fei), conflicts over 207-9; health and education 205; and levies 204; rather then 'taxes' (shui) 180

fees and levies (tiliu and tongchou) 205

female graduates, SOEs and government offices 86

feminists, transforming gender relations 85 
Fifteenth Party Congress, Fourth Plenum (September 1999) 60-61; national Financial Work conference (November 1997) 57; (September 1997) 280

financial centralism, entrepreneurial localism and 61

financial crimes, lack of supervision and personnel management 58

financial decentralisation, healthcare funding 42; new inequalities 41

financial and institutional dilemma, community services and 184

Financial System Party Committees 58

Finland 263

FINNIDA (Finnish aid agency) 156

First National People's Congress (First Session), People's Republic of China) 70

fiscal reforms (1993-94), local level social welfare 45 ; necessary to reduce corruption 211

fiscal system, decentralisation, off-budget finance 206

'Foolish Old Man who Removed the Mountains' 72

foreign aid, influence on institutional design 28

foreign direct investment (FDI) 276-8

foreign invested firms (FIFs) 275-7

Fortune 500 list 39

Forward Caste control over business 114

fostering, institutional care debate 221

'four olds' (old ideas, culture, customs and habits) 71, 78

'four ones' 188

Fourteenth Party Congress, socialist market economy 55

France 220, 222, 263

fraud $117,119,125$

friends of the poor, anti-poverty programmes and 151-2; conscientisation 152, 155, 158; corporatist sponsorship and 154; creating an enabling institutional environment 151 , 155-6; organisational preference 153-4, 155; provocation and 152

Fulan Gong, semi-mystical movement 79

Fuller, C. 111-12

funded social insurance, financial resources 235

funding mechanism, EGS and 162

funds, urban development and 209

FWC 57-9, 62

Gang of Four 96

gender equity, step backwards for 101

gendered economic activity, China and 83

General Taxation Bureau, no taxes on certain facilities 187

Germany 220, 232, 263, 280
Germany, East 222

Germany, West 222

Girni Kamgar Sangharsh Samiti (GKSS), combating corruption and 137-8

globalisation 6; associated with unequalisation 255; China's industrial labour and 273-5, 277; definition 255-6; not all cracked up to be? 256-9; redistributive outcome difficult 268 ; relative living standards 258 ; why did it not deliver? 259-64

Goa Right to Information Act (GRIA) 142-3

Goa State Commission for Backward Classes 142

Goa state government, right-to-information law 141-2

Goa Union of Journalists, protest campaign 142

Goetz, Anne Marie 5, 144

Gomantak Bahujan Samiti (GBS) 142-4

Goodman, Roger 5-6, 109, 214, 216-17, 224, 230, 234-5

Gordon White Memorial Conference 3

governance 150 ; civil society in representing the poor 123

government, market facilitator productive rather then rent-seeking 199

government health spending, biased toward urban areas 42-3

Gramsci, Antonio 10, 110-11, 121

Gramscian concept of civil society 111,120

grassroots organisations, external agencies and 153

Gray, J. 66, 69, 71

Great Proletarian Cultural Revolution 65

Greece 222

guangchang (consumption of political icons in era of depoliticisation) 77

Guangdong 55, 276; enterprise-raised funds 201, 205

Guanghan County Federation of Rural Supply and marketing Cooperatives (Sichuan) 175

Harriss-White, B. 5, 109, 115-16, 119, 120

Hashimoto, T. (Japanese PM) 231, 236-7

healthcare, Donglan County, Guangxi

Autonomous Region 42

healthcare funding, financial decentralisation and 42

hierarchy, SCs and MBCs 116

'Highest Directives', prior to Cultural Revolution 72

Hindu religion, caste and 111

Hong Kong 231, 233; FDI to China 277; joint ventures in China 280; reversion to China and voluntary sector 191; strictly controlled unions 278

Howell, Jude 4-5, 12, 50, 79

Hubei province, problems created by Civil 
affairs' system 209

human agency, institutional design 21

human capital, key services education and health care 133

human development deprivations, recognising capture and bias 30

iconisation of power, traditional symbols employed 78

identity politics, accountability gap and 141-4; accountability on social justice 125

illegal encroachers, government forest land and 138

illegal financial institutions 58

Illich, Ivan, Disabling Professions, The 221

illness, correlation with poverty 42

IMF 133, 241

immigration policy, labour-scarce parts of global economy 269

impunity, offences against 'undesirables' 135

incentives, EGS and 162

Incident (4 June 1989) 52-5

India 258; Board for Industrial and Financial Reconstruction 138; corruption 123, 135-7, 146; EGS 160-66; electoral rules for women or 'backward castes' 145-6; electoral system seats for dalit and tribal communities 144; Employment Assurance Scheme (EAS 1994) 164; girls and fear of sexual assault 135; globalisation 255-6, 257; health care for poor women 134; neo-corporatist argument 112; neo-corporatist argument and 112; population and labour force $\mathbf{2 6 3}, 265$; public works 159-65; right-to-information movement 128; states fostering new forms of civil society $140-41$; tax evasion 135 , see also caste; MKSS

Indian town, local networks of caste power and 5,109

indirect planning 17

Indonesian economy, Social Fund (1998) 166

industrial labour systems 274-5; globalisation and 278,287

industrial relations, wage arrears and 278

industrialised countries, globalisation and 255; unemployment in 262

industrially advanced countries (IACs), inequality 259; unemployment in (1970 and 1997) 263

inequality, EBFs in China and 46; state budgets 6

inflation 56

inland and coastal provinces, per capita differences 276

Institute of Development Studies 3, 6

'institution building and aid' 150

institutional accountability failure, corruption and 130

institutional 'bias', accountability failure and 124,146

institutional design 24, 28-9

institutional path-dependence $280-81$

institutionalisation of bias 134

intellectual roots of social science concepts, academic viability 22

Inter-American Development Bank 166

'interest group politics', teachers and 11

International Financial Institutions,

'Thatcherite' ideologies 268

international specialisation, efficiency gains 267-8

International Women's Day (8 March), awards for community services 100

Ireland 222, 263

'iron armchair', white-collar staff 177

iron rice bowl system, manual workers 95, 177, 266,280

Italy 222,263

Japan 231, 233; Angel Plan (1995) 220-21, 240; budget deficits in Tokyo and Osaka 220; child welfare, etic critique 217-19; Child Welfare Law (1998) 218; children's homes (yôgoshisetsu) 215-17; Chronic Care Insurance (1997) 240; consumption tax (1989) 239-40; cost of social protection 248; 'discovery' of child abuse 224; effect of subsidies 38 ; elderly population $220,237-9$, 247; emic understanding in child welfare 219-25; financial crisis (1997) 230; Gold Plan 240; Health Service for the Aged 239; idea of children's rights 223; imports from China 265; joint ventures in China 280; LDP 237-8; low tax burden 220; national association of lawyers (Nichibenren) 218; New Gold Plan 238, 240; 'participatory welfare' 238; pension reform deal (1985) 239; 'picking winners' 36; PM Koizumi and reform 236; problems of keiretsu 39; professionalisation 217,221 ; public health insurance 234; role of family 232; Tanaka welfare initiative (1973) 233, 237-8; unemployed day-labourers 225, 263; welfare expenditure 220; welfare homes 6; welfare system 231-3, 237-41; women in the labour force 83, see also yôgoshisetsu

'Japanese-style welfare society' (Nihongata shakai fukushi shakai) 214

Jenkins, Rob 5, 144

Jiang, Zemin (General Secretary of the Communist Party) 54-5, 58, 61; declaration (July 2001) 61; political culture and 77 Jiangsu, enterprise-raised funds 205; TVEs 282,286 
Jiangsu Provincial Women's Federation, redeployment of laid-off women 89

Jidô yôgoshisetsu see yôgoshisetsu

joint ventures $87,275-6,280$; migrant workers and 279

judicial proceedings, protection for the poor and 131

Kerala, right-to-information provisions 143

Kerala Pulayam Maha Sabha (KPMS), democratic benefits 145; funds for dalits and 143

Kim Dae-jung government 242, 247

Kim, Won-sik 242-3

Korean Federation of Business 241

Korean Federation of Trade Unions 241

Korean policy, 'picking winners' 36

$\mathrm{Ku}$, Yeun-wen 233, 245

Kwon, Huck-ju 5-6, 215, 230, 232-3, 243, 245

labour, excess supply globally 260-61

labour discipline, privatised TVEs and 284

Labour Law (1994), women and exploitative practices 88, 278-9

laid-off women workers, suitable jobs for $92-3$, 99

'laid-off worker' (xiagang gongren) 87, 98, 101,267

land reform legislation, collusion between sellers and buyers 132

large welfare corporations (shakai fukushi hôjin) 217

Latin America, elitist democracies 29; evidence of synergy 140; globalisation 256, 257; increase in inequality 258-9; labour displacement 262; optimistic view of statefostered civil society $126,145,147$; Social Funds 166-7

lay-offs (xiagang) 274

legal reforms, civil society and 12

Leninist conception, dictatorship of proletariat 68

Leung, J. 202-3

Li, Guixian (Governor of People's Bank) 56

Li, Peng (Premier) 54, 56

Liberal Democratic Party (Japan) see LDP

Liberation Army press, Red Sun (Hong Ri) and 73

Liberation of China (1949), CCP and women in economy 85

'lieux de mémoire, les' 76

Lin, Biao 66-7, 69, 72

Little Red Book 65-6, 69, 72; entries drawn from Mao's speeches 71-2; foreign collectors and 81 ; memorisation by recitation of Confucius' Sayings 72; portability of 71; series of ten stamps (1968) 70; as visual narrative 69-75 local corporate state, adaptability of cadres 200 local expenditure, funding and 204

local government officers (jidôfukushishi) 217

local government officials, entrepreneurial class $197-8$

local governments, EBF and self-raised funds 45; extra-budgetary revenues 198 ; mini 'developmental states' 199, 210; pensions and 35 ; wealth and collective and private business 210; welfare development 5

local leadership, reckless development 55

local officials, entrepreneurial in welfare provision 195-6; tax evasion and 210

local system (kuaikuai) 53

local volunteers, yôgoshisetsu and 217

localities, control of People's Bank strengthened 56; non-bank financial institutions 55

longevity, EGS and 163

lower agrarian castes, accumulation (1990s) 115

Luckham, Robin 29, 109

Luxembourg 222

McCartney, M. 109, 120

Maharashtra, EGS 160, 163, 165

Maharashtra Employment Guarantee Act (1977) 161

Maharashtra State Tax on Professions, Trades, Callings and Employments Act (1975) 161

Malthus, T.R., population growth 261, 268

Mancini, O. 112, 117

Mao Zedong 4, 65; badges 70-72; cult of 66, 77-8; lieu de mémoire in contemporary China 76; Mausoleum and Remembrance Hall 76; meaning of 76-7; metonym for revolutionary China 67; personalisation of power and 66; personality 74,79 ; postcards 70 ; writings legitimated as MarxismLeninism 69

Mao Zedong thought, embedded with Marxism-Leninism 80; knowledge of crucial 73; legitimated elite 79; political culture and 74; revolutionary political culture $65,69-70$; struggle between Maoists and party-state 69

Maoist period 9; developmental phases and teachers 12; Draconian restrictions 15; economy guided by central plan 33 ; employment demarcation established in 274; far reaching changes 79 ; hostility to markets and skills 11 ; image of women $85-6$; real political bargaining and 13; SOEs shrinking since 280; use of revenues from SOEs 43

Maoist radical socialism, market Stalinism 4

'Maoist School' 74

Mao's Report on an Investigation of the Peasant Movement in Hunan 72 market, inegalitarian effects of 14 
market economy, rules and regulations and 34, 46

market reforms, $\mathrm{CCP}$ and female emancipation 86 ; scale of government reduced 179; 'social stability' 79-80

'market socialism' 11

Marx, Karl 261-2

Marxist-Englesian view, women's liberation and 85

Marxist-Leninism 70, 79

'mass line', application of Little Red Book 71

material memory 79-80

Mazdoor Kisan Shakti Sangathan (Workers and Framers Power organisation) see MKSS

Medical Care Aid for the Elderly (MCAE) 238-9

Mexico 262, 263-4; PRI and Food Councils 154

migrant workers (baomu) 100, 275, 277-9

mills, 'satanic', casualisation of labour force 114

minimum livelihood security (zuidibaozhang) programme 210

minimum living expenses (zuidi shenghuo fei) 88

Ministry in Beijing, ratified 'community services' term 183

Ministry of Civil Affairs see MOCA

Ministry of Health, Council on Welfare for an Old-Aged Society 238

Ministry of health and Welfare 239; 'Gold Plan' 240

Ministry of Labour, re-employment project (1993) 87

Ministry of Labour and Social Security 101; (1998) 35; 'community services' and 91-2

Ministry of Labour(MOL)

MKSS, anti-corruption and 125-6; contextualising the 127-9; experience and 136; fostering and 145; India's decentralised political arenas 146; 'jan sunwais'(public hearings) $125,127-8,136,138,146$; NGOs and 137; 'non-party political formation' 127 ; right-to-information approach 147 ; transformative potential of 144

mobilisation 151, 160-62, 164-5; NGOs and 166; Social Funds and 167

MOCA, action to protect community services 187; effect of institutional expansion 190; Ministry of Agriculture and 181-2; pressure on top CCP leaders 187-8; responsibilities likely to increase 189 ; social relief to needy groups 181; subordinate governments and 188; 'success trap' and 186; urban community services and 183, 189; weak institution 179

modernisation, China 62,80 ; has reworked caste 111-12; institutional fabric of Arni and 114; speed both welcome and horrific 75

Most Backward Castes (MBCs), casual labour force 115-16

mowei toatai zi method, labour discipline 284

Mozambique 16

multinational corporations (MNCs) in China 279-80

Mumbai (Bombay) 137-8, 161; petitions on

EGS in High Court 164

Murayama government, 'New Gold Plan' (1995) 240

Murdoch empire, global carrier of ideology 268

Nakasone government, social welfare reforms 239

Nann, R. 202-3

National Conference on Health (December 1996) 43

National Financial Work conference (November 1997) 57

National Fund 239

National Health Insurance 238-9

National People's Congress (2002), rural problems 208

nature of power, notion of tacit approval 66 neo-liberalism 150,168

Netherlands 222, 258, 263, 280

New Angel Plan (1999) 220

new currency issue, Mao's image and 80

'new political economy' 174, 189

New York Times 73

Newly Industrialising Economies 57

NGOs 27-8; agents for public services to the poor 165; backlash from the state and auditing 137; benefits not rights 166; connection to state 145 ; conscientisation and 152; development activities and 151; dubious business practices and 136; MKSS distinguishes itself from 127; in Nepal 157-9; Social Funds and 168; state funds and 139; as welfare providers in Japan 238, 240

Nichibenren report 218

Nikkei Weekly 220

'nine bad elements' 65, 74

non-financial institution, finance and 58

non-governmental organisations see NGOs

non-performing loans 57-8

non-profit organisations, entrepreneurial in welfare activities 176

North Korea 16

occupational-health inspectors, illicit income and 137

OECD countries 236-8, 256, 257, 259

Ohira (Japanese PM), 'Japanese-style welfare 
society' 237

Oi, J. 196, 198, 200-201

Old People's Commission (China) 190

'On Practice' 72

over production, underconsumption 260, 268

oversight or regulatory agencies that fail to take action 131, 134

ownership structure of village networks, healthcare delivery and 42

Page, V.S. (Congress politician) 161

Panchayati Raj (local government) 128

Panini, M.N. 111-12

Paris Commune 68

parliamentary government, presidential government 25

'participation' 15, 150-51

participation in civil and political society, corruption and

party, role of in marketisation 51

Party Central Organisation Department, 1988 document 53-4, 58-9

Party Committee for Discipline and Inspection, legal and administration regulations 52

party groups, cadres of lower-level units and 59

party and state, separation of 53-4

party-state, defensive approach to gender inequality 98 ; system for re-employment and re-training 88

patriarchal values, resurging wave of 98

patriarchy, intersection with capitalism 84 ; urban civil society in Arni and 118, 121

Patten, Chris 230

peaceful political transition, how best accomplished 27

Pekingologists and journalists, machinations of elite politics and 11

pension reform, debate among institutional actors and social groups 9-10

'People of China cannot be Humiliated: We must win!' 74

People's Bank of China, lending quota 58; loans to good community service businesses 187; private sector and GDP $33,56,58$; provincial branches abolished 58-9

People's Daily 51, 56-8, 62

People's Insurance Company of China (PICC)

People's Liberation Army (PLA) 69, 71

People's Republic of China, fiftieth anniversary 73; normal politics in abnormal times 14; the state and democracy 15

'performance' of external agencies, four dimensions of interest 155

physical insecurity, form of diminished human development 134

physical security, freedom from abuse and neglect by police 130 pluralisation of interests, marketisation and 50

police, agents dispensing violence and terror

135

policy, strong state and 16

policy problems, difficult 16

policy significance, practical applications and 28-9

policy-makers, party system and discipline among the localities 51 ; simplistic solutions 28

Politburo Standing Committee 54

political consciousness, middle class and 50

political cultures, organisation of society and 78

'Political power grows out of the barrel of a gun' 72

politically engaged society, ability to work 16 ; basic-level government 9; White's analysis of 18

politicisation 74,78

politics in development 4, 6; two meanings 5-6

politics of marketisation, first half of (1990s)

52; progress after 1992 55-7; setback in late 1980s-early 1990s 52-4

politics and the State $4-5$

politicisation of Chinese society, Selected Works and 69

poor people's movements, misguided state interventions 139

poor societies, developmental challenges and 25

Poor, the 123, 125, 131, 133-4, 151, 165

Porto Alegre (Brazil) 139-40, 145

Portugal 222

post-communist Russia, state apparatus and 34

post-Maoist era, 50 aphorisms by Communist

Party 72; government officials as entrepreneurs 195

post-Soviet society, problems of 15

posters $66,68-70,74$

poverty $255-8$

poverty alleviation, collective and mobilising dimensions 151

predictability $155,159,163,166-7$

presidential government, parliamentary government and 25

preventive care, public good with large externalities 41

private medical provision, fee-for-service 42

privatisation $35,38,87$; China and 273-5; share ownership and 284

property rights, transition process and 35

property rights regime 200

Protection of Women Staff Members and Workers (1988) 86

protection of women's rights (1992) 86-7

'public choice theory' 174,189 
public ownership, abandon the principle 60-61 public-private partnerships, provision of goods and services 46

public-sector spending, scrutiny of 123

'Putnam paradox' 23

Qingdao, payroll budgeting and 209

quasi-governmental bodies, social welfare contributions and 233

Quotations of Chairman Mao Zedong, The, see Little Red Book

Quotations (Mao Zhuxi yulu) 67

Rajasthan, MKSS in 125, 127, 136, 146

Ranis, G. 262, 264

Rashtriya Mill Mazdoor Sangh (RMMS), criminal gangs and $137-8$

'rational choice' 174

red, colour of revolution and internationalism 70

red globalisation scenario, negative sum globalisation 268-9

'red hat' collective guise 198

Red Sun (Hong Ri), debate about 74, 76; Film of the Masses journal 73

redness, each image is suffused with 74

redness 'survives' Communism 68

reform, role of the state 34

regulation in lieu of planning 17

'rely on yourself' (kao ziji) 94

rent-seeking, officials 174, 196, 198

reporting systems within bureaucratic hierarchies 131

Reservations policy of Indian Government, 'dual culture' 111

'residents' committee, semi-official agency under street office 182

'Resolution of Certain Questions in the History of Our Party since Founding of PRC' 80

retraining in China 95, 100

retrenchment, resistance to 97-9, 101; workers blamed for unemployment 97

'revolution is not a dinner party' 72

revolutionary, relationship with traditional always flexible 78

revolutionary political culture, two related campaigns 74

revolutionary successors (hongse houdai) 70

Ricardo, David 259, 268

right to information, effective auditing of public spending and 126; law (2000) 128, 146; MKSS and 125-7; urban middle-class users 144

rights $155,159,164-5,167$

Robinson, Mark 4, 23-5, 27, 109

Rodrik, D. 35, 256, 259

Rueschemeyer, D.S. 139-40 'rule by person', 'rule by law' 57

rural migrants, attitude to work 97

rural pensions (or old age insurance) 206

rural welfare, programmes 203 ; responsibility for 197

rural/urban divisions, laid-off workers and 97

Russia, warning from 35

Sabirianova, K. 281-2

Saich, Tony 4, 67

'Sanskritisation', caste associations and 111, 116

saturation, post-Maoist political culture 75, 77

Scheduled Castes (SCs), casual labour force 115-16

Schumpeter, J. 260

Seattle Round trade talks (1999) 268

secularisation of caste in India 111-12

security EGS and 163

Selected Readings of Mao Zedong 70

Selected Works (Mao Zedong Xuanji) 67, 69-70

self-conscious collective memory, loss in national psyche $75-6$

self-determination 16

self-raised funds (zichou zijin) 44-5, 206

Shandong 201, 282

Shang, Xiaoyuan 12, 50, 196

Shanghai 280; Municipal Textile Bureau 175

shareholding companies 87

Shenzhen, Special Economic Zone 55

Sichuan Provincial Trade Union, retrenched female workers 89, 91-2

Sichuan Provincial Women's Federation 95

Singapore 231, 233-4, 278

Sixth Five year plan (1981-85) 204

Smith, Adam 259

'social audit' 128

social capital 24, 26-8

'social capitalism' 11

social classes and groups, politics to advance their interests 12

'social democratisation' 13

social engagement in politics, distinctly human 18

Social Funds 166-8

'social inclusiveness' or 'citizenship' 215

social insurance, relief and assistance 206

'social mobilisers', conscientisation and 152; moral hazard and 158-9

'Social Security Reforms in China: Towards an East Asian Model?' 214-15, 225

'social stability', market reforms and 79-80 social status, meanings attached to work 99 social structures of accumulation see SSA social transition, China's policy-makers and 41 social welfare system, government and 39 
'socialisation' (shehuihua) 85, 182, 191, 202 socialism, planned economy 54

'Socialism with Chinese characteristics' 280 socialism and market economy, contradiction between 62

socialist market economy 50,60

society's political engagement, profound political change and 12

socio-economic distribution, the state and 14

SOEs, bankruptcies and 39,87 ; bureaucracies and reforms 37; capital-intensive 274; employment and 38-9; employment stability eroded 281; financial system and 46; foreign trade corporations and 276; 'iron rice bowl' 280; low incidence of wage arrears 281 ; management responsibility contracts 87 ; pension reform and 35 ; preferential policies and 34 ; problems of 37-8; profits and loss in 40; reforms 39, 83, 280; soft-budget constraint 58 ; women and $85-6$

Song, Ping (Director of Central Organisation Department) 54

South Asia 174, 258

South China Morning Post 57

South Korea 18, 231, 233; automobile industry 280-81; chaebol sector 13; cost of social protection 248; economic restructuring and unemployment 241 ; elderly in population 237,247 ; elderly who receive pensions 243 , 244; elites of ancien régime and 13; Employment Insurance Programme(1995) 242-3, 247; endogenous problems of welfare system 241-2, 247; exogenous problems of welfare system $242-3,247$; financial crisis (1997) 230, 241; National Health Insurance 241-2, 247; National Pension Programme 241-3, 247; opposition Grand National Party 242; population ageing and welfare system 243; President Kim Dae-jung on social policy 236; Private School Teachers' Pension 243, 245; problems of chaebols 39, 230; Public Employees' Pension 243; public health insurance 234; role of family 232; social welfare programmes (1961) 232-3; unemployment 231, 242

South-East Asia, globalisation 256, 257

Soviet Union 13, 53, 180

Spain 222, 263

Special Economic Zones 55; opportunities for women 85

speculation in stock market 58

Spence, Jonathan 74-5

SSA 109-10, 112

state, 'interest intermediation' 112

state entrepreneurship, ambiguous and contradictory 190-91; definition 175 ; politicoeconomic conditions 180 ; seen as unproductive 174; social welfare and 176-7; undesirable for several reasons 191; various levels 175-6; welfare provision 173-7

state institutions, ability to 'generate income' (chaung shou) 180; bureaucratic forms of organisation 173-4

State Planning Commission, community services a target area 187

state, the 14-16; in Arni 119; civil society to help the poor 123; as a 'given' 12,14 ; integrity of civil society associations 124; modalities for civil society 12 ; myriad of loosely linked institutions 180; pro-poor forms of civil society 125 ; role in civilsociety organisations 139; welfare reformers in China and 192

state-fostered forms of civil society 125-6 state-fostered civil society, auditing performance of government 145, 147; implications for theories 139-41; 'sectors' redefine themselves 142; 'trickle-down politics' and 144; unintended outcomes 141-4, 147

state-fostering, 'compromised' civil-society organisations 124

state-owned enterprises see SOEs

state-society relations, contemporary China and 22

state-society synergies 140-41

'stepping down from one's job' (xia gang) 178

Stiglitz, J.E. 35-6

stocks of social capital, vary among communities 23

Streeten, P. 258-9

structural adjustment, gender equality and 86 studies, Chinese scholars in Japan and 50 study, productive labour and 74-5

Sub-Saharan Africa (SSA) 256, 257-8

subcontracted service enterprises 87

sustainable livelihoods 130-33

Sweden 220, 222, 237, 263

Switzerland 280

synergy $21,24-5,27,140-41$

Taiwan 19, 230, 233-4; cost of social protection 248; DPP and social policy 236; elderly population 237; Farmers' Health Insurance (1989) 244; Government Employees' Insurance (1958) 244-5; Labour Insurance programme(1950) 244-5; National Health Insurance programme 244-5, 247; National Pension Programme 245, 247; old-age allowances 245; public support for welfare system 245-6; Retired Government Employees' Insurance programmes 244; strictly controlled unions 278 ; welfare system 244

Takahara, Akio 4, 56 
'Talks at the Yan'an Forum on Literature and Art' 72

Tanzania 17

Tendler, J. 163, 167

Thai auto industry 281

Thai Baht crisis (July 1997) 57

theory of 'three representatives' 61

Third World socialist countries 16-17

Thirteenth Party Congress (1987) 52-3

Tiananmen and Mao 70, 76

Tianjin city, Duckett's analysis 175

tolerance 144,167

top caste, marriage alliances and 116

township, no formal tax-raising powers 198

township and village enterprises see TVEs

trade unions 287; anti-corruption movement and 137; employed workers and 96; granted exclusionary powers 139 ; privatised TVEs and 286

training programmes 100

transitional economies 34, 177, 282, 286

transparency 123

transparency and accountability 40 ; identitybased associations and 143; local government and 208; MKSS and 125

Transparency International Bangladesh study 132

TVEs 181, 196; bureaucrats in entrepreneurial role 198; diversity of 275 ; growth in local economy 198 ; local welfare services and 201, 206; ownership of privatised 282-3; privatisation 282 ; profit criteria 284 ; turnover intention $\mathbf{2 8 5}$

\section{UK 220, 263}

UN Convention on the Rights of the Child, Japan and 218, 225

unemployed workers (shiye renyuan) 87

unemployment, China 266; excess labour and 261 ; global likely to grow 268 ; industrialised countries 262; rising 269

urban Chinese communities, welfare entrepreneurship 5

urban 'community services' (shequ fuwu) 182

Uruguay 141

USA 84, 220, 237, 258, 263; coalition against globalisation 268; imports from China 265; joint ventures in China 280; stock market growth and East Asia 269; TNCs relocated to China 264

Vietnam 16, 18

virtuous state action, democratic developmental state 25

Vogel, Ezra 232; Japan as Number One 221

voluntary activity, effect of excessive regulation 24 volunteers 238,240

wage arrears $278,281-2,286$

waged domestic work, rural female migrants 99

Wales 222

Wasserstrom, J.N. 68, 78

'Water in Nepal' 152, 156-9

welfare 5-6; agencies and clientele 190; constraints on agencies 185-6; finance and farmer-cadre relations 207-10; meaning in different societies 215

welfare creation by local state, local sources of welfare finance 204-7; responsibilities for $202-4$

welfare enterprises, tax concessions 182,186 , 204-6

welfare entrepreneurship in China, emergence of 181-4; future of 189-92; problems and response $184-9$

welfare funds (gongyijin) 205

welfare principles, difficulty of combining with commercial 184-5

welfare provision, rural and urban China 41; state entrepreneurship and 173-7

welfare reform, challenges and opportunities 235-7; Japan 237-41; South Korea 241-4; Taiwan 244-7

Welfare Vision for the 21st Century, A 238

Wen, Jiabao (secretary of FWC) 62

West, civil society associated with capitalist transformation 22

Western Maharashtra (drought 1970-74), EGS and 161

White, Gordon 3, 4, 5, 22-3, 55, 69, 273; adaptability of the state 199; 'capitalism' and 'socialism' 17; China and approach to research 20, 29; civic organisations and 110; civil society and $21-3,50,109,110,126$, 144; concept of social capital and 23-4; democracy and 25-6, 109, 287; democratic socialist 14; development studies 20, 29-30, 126, 197-8; East Asian welfare systems 234-5; entrepreneurship in China 195-6, 200; globalisation and 6,256; intellectual legacy 4,16 ; joint projects 21 ; monograph on teaching profession 9; NGOs 27-8; parametric strategy 155 ; policy significance of work, latent and implicit 26 ; political science of (1960s) 150; politically engaged society and 13; problems of market failure 27; public-civic collaboration and 24; quality of care 215, 226; rejected post-structuralist culturalism 10; respect for China 8 ; role of the state 25; Social Funds and 168; the state and 12; state entrepreneurship 175; state and societal corporatism 112; wage arrears in China 281-2; welfare 5-6; welfare systems 
in East Asia 230, 234-5; Writings: In Search of Civil Society 10, 13; Micropolitics in Contemporary China: A Technical Unit During and After the Cultural Revolution 8; Revolutionary Socialist Development in the Third World 16-17; Riding the Tiger 9, 12, 15

Whiting, S. 200-201, 210

women, ACWF retraining and re-employment programmes 95; age barriers to employment 89,92 ; in Chinese labour force 83 ; community service work and 90-92, 101-2; East Asian welfare systems and 235, 247; effects of SOE reform 87-94; EGS employment in India 160; employment in heavy industry in China 85; export-processing factories of China 278; foreign invested factories and 85; household labour unwaged 84-5; older retrenched from SOEs or collectives 88, 100; 'quality' and lack of adaptability 93; retirement and 89-90; roles in Arni 118-19; SOEs and 85-6; Special Economic Zones and 85; state budgets 6 ; as volunteers in Japan 240-41

Women's Federation, training courses validating skills 99

Wong, Christine 44, 198, 204, 206

Wood, A. 259, 264

World Bank 166, 258, 276-7; future development in China 46; health and education in China 41-2; SOEs and 38
World health organisation (WHO) 41, 245

written procedures, access barriers and 135

Wuhan, social welfare service networks and 183

Yan'an period, Mao and 'exegetical bonding' 67

Yang, Rae 70-71

Yao, Yilin (Vice-Premier) 54

Yemen 16

yôgoshisetsu, average stay in 222; children in 215 ; entrepreneurial to survive 225 ; evolution of 223-4; institutionalisation in 217; operate differently 219 ; reasons for children in 216; sense of group identity 222-3; type of institutions 216-17

youth, increased social and economic value 89

Zambia 13

Zhang, F. 276, 279

Zhao, Ziyang 52-4

Zhejiang, enterprise-raised funds in 205

Zheng, J. 276, 279

Zhongdiangong (retrenched women workers) 99

Zhu, Rongji 52, 56, 58

Zhuhai, Special Economic Zone 55 